\title{
Review of the Swedish species of Ophion (Hymenoptera: Ichneumonidae: Ophioninae), with the description of 18 new species and an illustrated key to Swedish species
}

\author{
Niklas JOHANSSON ${ }^{1, *} \&$ Björn CEDERBERG ${ }^{2}$ \\ ${ }^{1}$ Fredriksberg/Baskarp 56692 Habo, Sweden. \\ ${ }^{2}$ Uppsala-Näs, Asplunda 51, 77591 Uppsala, Sweden. \\ *Corresponding author: chrysis32@yahoo.se \\ ${ }^{2}$ Email: bjornceder@gmail.com \\ ${ }^{1}$ urn:Isid:zoobank.org:author:4BB5F059-B4EE-41F9-8313-B529164B1FA6 \\ ${ }^{2}$ urn:1sid:zoobank.org:author:011C3E1F-EB9E-4BDA-B368-1CC50BB525D7
}

\begin{abstract}
The Swedish species of Ophion Fabricius, 1798 are revised. More than 4800 specimens and relevant type material were studied; 234 sampled specimens produced COI sequences. The study recognises 41 species, 18 of which are described as new to science, mainly from Fennoscandian material: Ophion angularis Johansson \& Cederberg sp. nov., Ophion arenarius Johansson sp. nov., Ophion autumnalis Johansson sp. nov., Ophion borealis Johansson sp. nov., Ophion broadi Johansson sp. nov., Ophion brocki Johansson sp. nov., Ophion confusus Johansson sp. nov., Ophion ellenae Johansson sp. nov., Ophion inclinans Johansson sp. nov., Ophion kallanderi Johansson sp. nov., Ophion matti Johansson sp. nov., Ophion norei Johansson sp. nov., Ophion paraparvulus Johansson sp. nov., Ophion paukkuneni Johansson sp. nov., Ophion splendens Johansson sp. nov., Ophion sylvestris Johansson sp. nov., Ophion tenuicornis Johansson sp. nov. and Ophion vardali Johansson sp. nov. Barcoding analysis also indicated the possible presence of at least three additional, partly cryptic species, but these cannot be separated morphologically with certainty at this point. Ophion costatus Ratzeburg, 1848 and Ophion artemisiae Boie, 1855 are interpreted and defined. Ophion slaviceki Kriechbaumer, 1892 is excluded from synonymy with Ophion luteus Linnaeus, 1758 stat. rev. Ophion polyguttator (Thunberg, 1824) stat. rev. and Ophion variegatus Rudow, 1883 stat. rev. are excluded from synonymy with $O$. obscuratus Fabricius, 1798. Ophion variegatus is redescribed and a neotype is designated. Ophion albistylus Szépligeti, 1905 (syn. nov.) is synonymized with Ophion pteridis Kriechbaumer, 1879 and Ophion frontalis Strobl, 1904 (syn. nov.) is synonymized with Ophion areolaris Brauns, 1889 syn. nov. Eleven species are reported from Sweden for the first time: Ophion artemisiae, Ophion crassicornis Brock, 1982, Ophion costatus, Ophion dispar Brauns, 1895, Ophion forticornis Morley, 1915, Ophion kevoensis Jussila, 1965, Ophion ocellaris Ulbricht, 1926, Ophion perkinsi Brock, 1982, Ophion subarcticus Hellén, 1926, Ophion variegatus Rudow, 1883 and Ophion wuestneii Kriechbaumer, 1892. The study shows that a number of species that previously have been treated as highly variable taxa, actually consist of several valid species that are separable using morphological characters. An illustrated key for the determination of the Swedish Ophion species is provided.
\end{abstract}

Keywords. Ophion, barcoding, new species, review, Sweden, taxonomy. 
Johansson N. \& Cederberg B. 2019. Review of the Swedish species of Ophion (Hymenoptera: Ichneumonidae: Ophioninae), with the description of 18 new species and an illustrated key to Swedish species. European Journal of Taxonomy 550: 1-136. https://doi.org/10.5852/ejt.2019.550

\section{Table of contents}

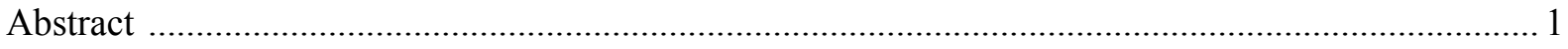

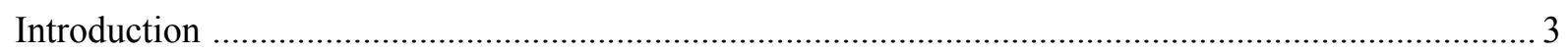

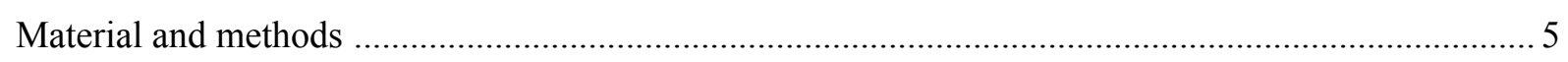

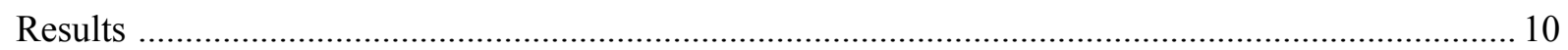

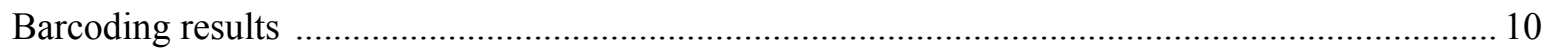

Assessment of morphological characters used in species delimitation .......................................... 10

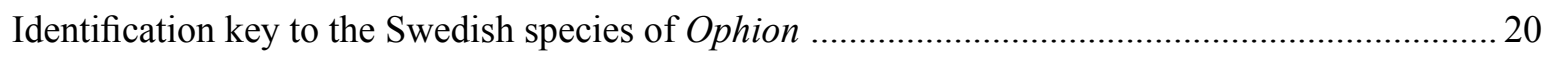

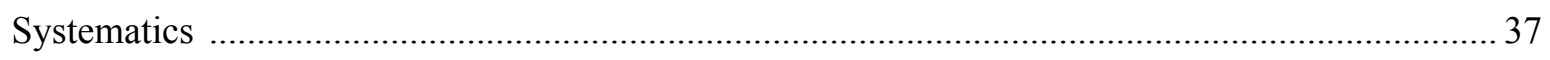

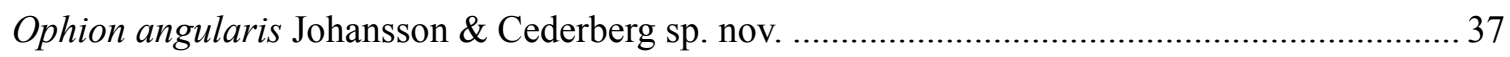

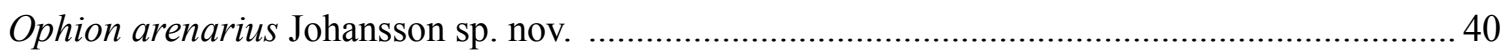

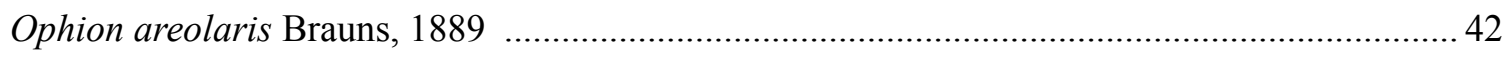

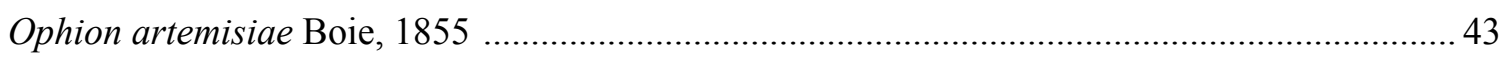

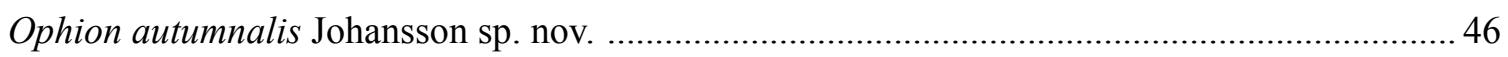

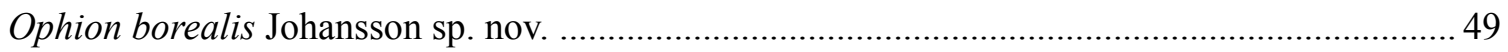

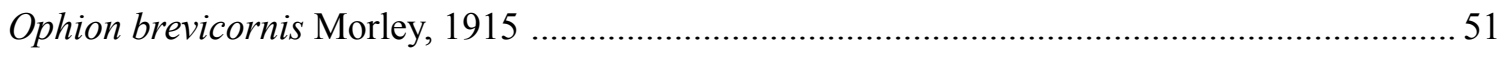

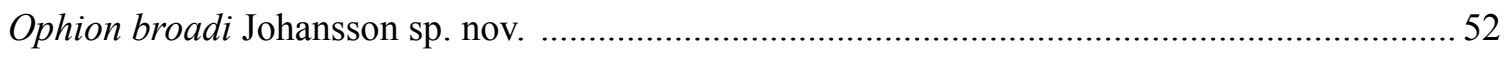

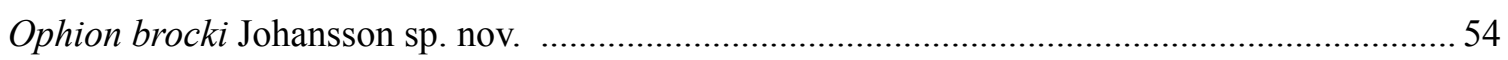

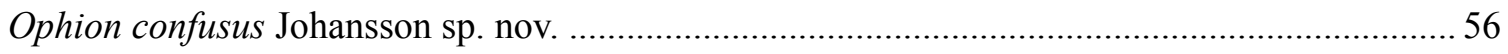

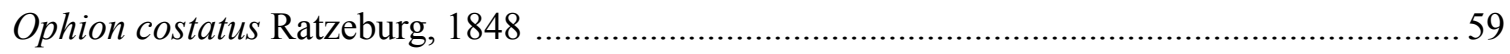

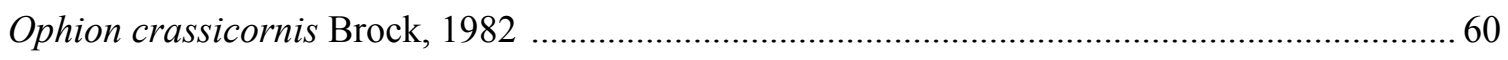

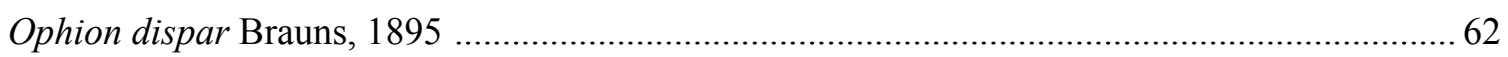

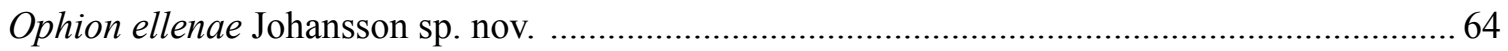

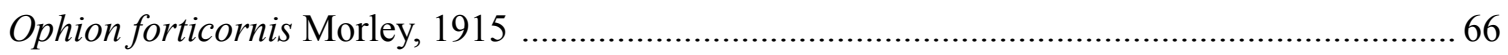

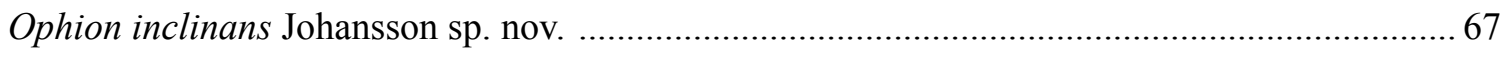

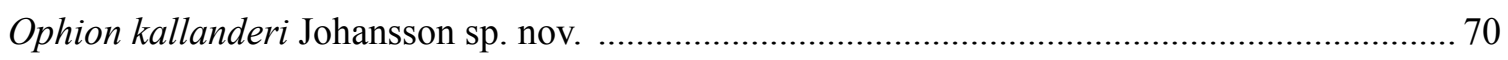

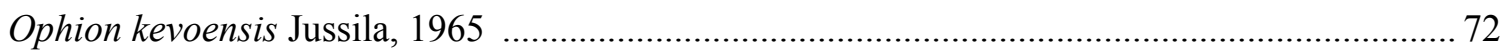

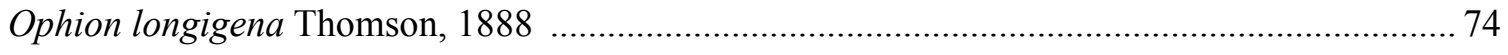

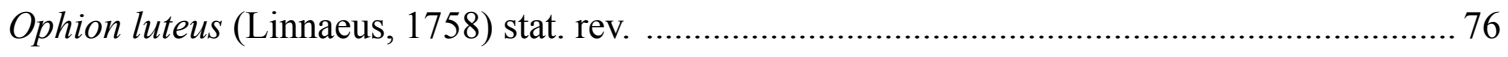

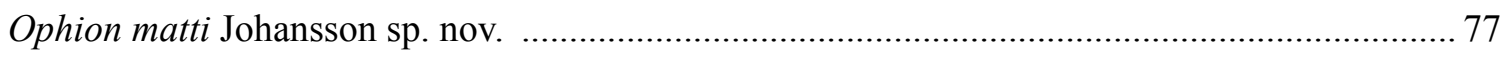

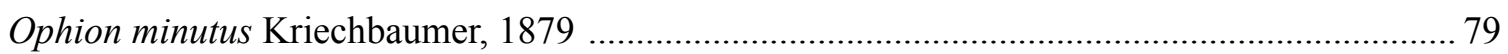

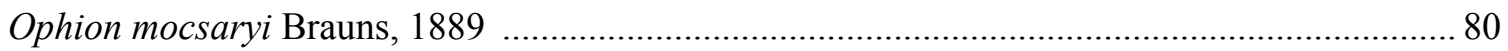

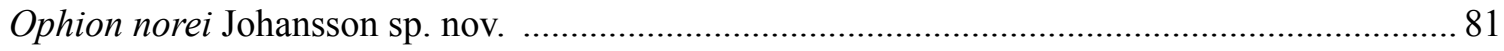




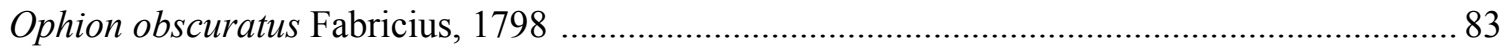

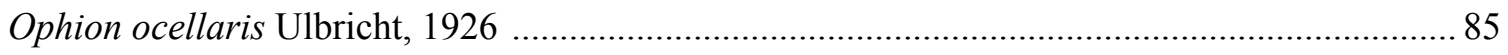

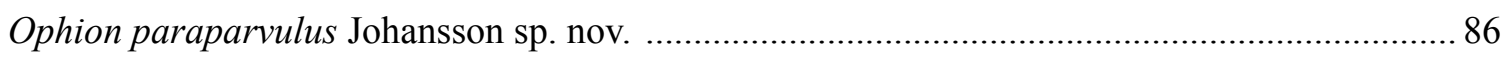

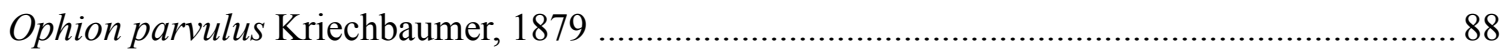

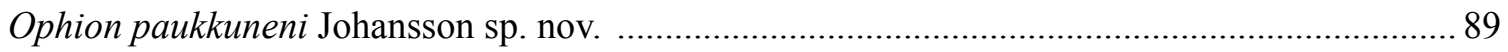

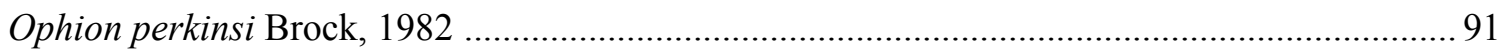

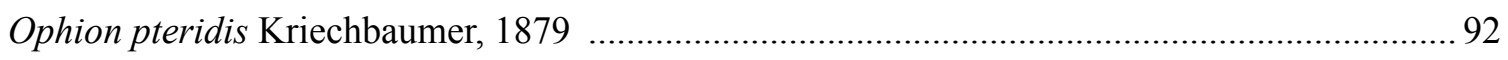

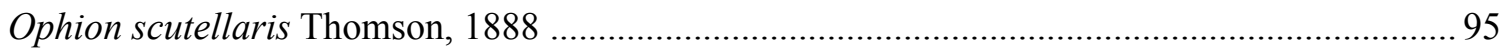

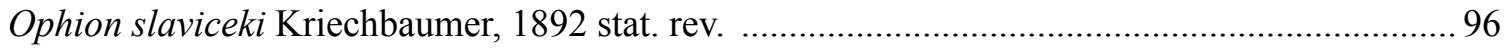

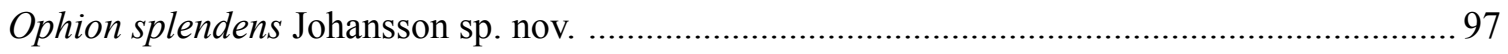

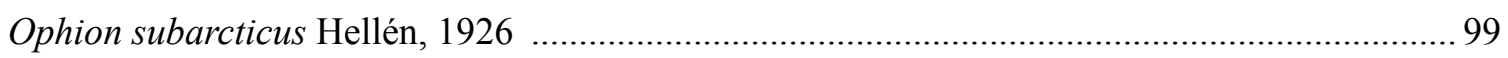

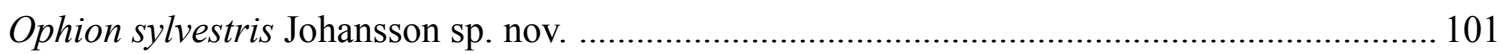

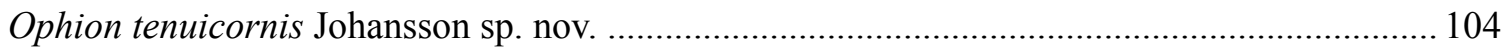

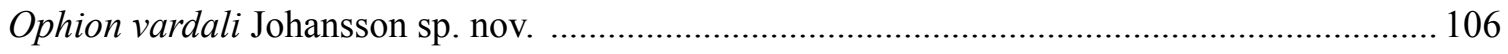

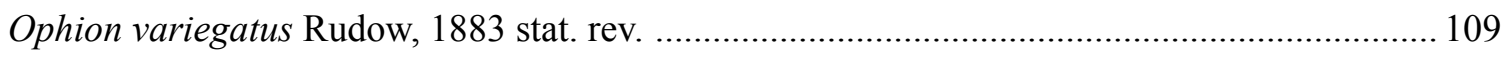

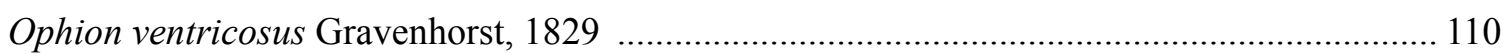

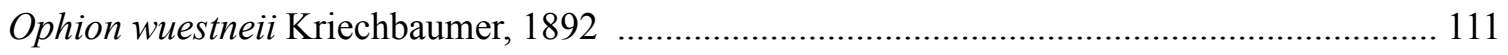

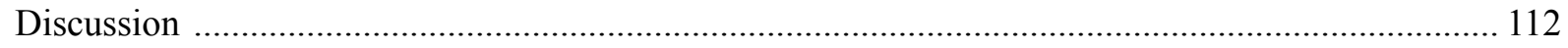

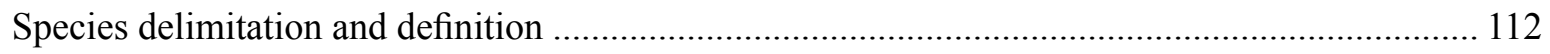

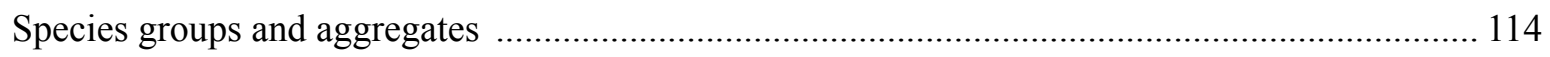

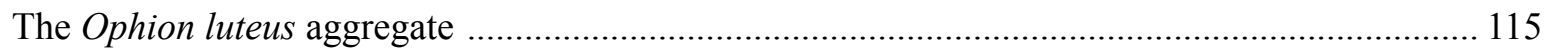

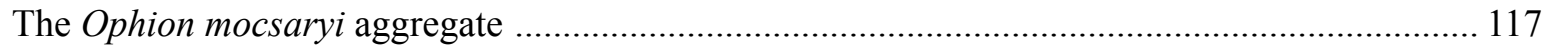

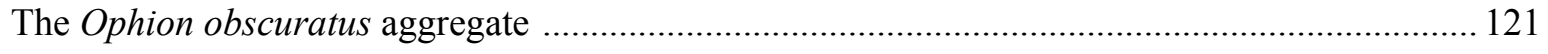

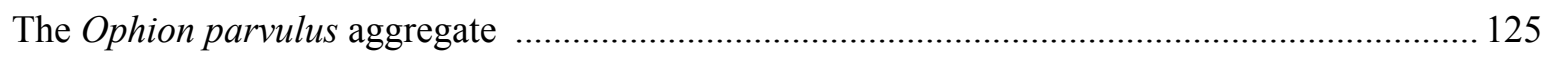

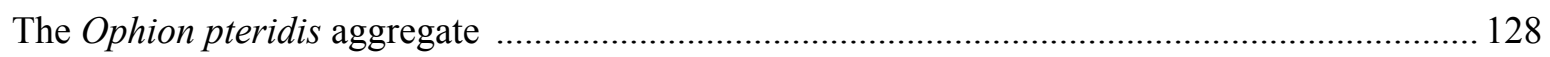

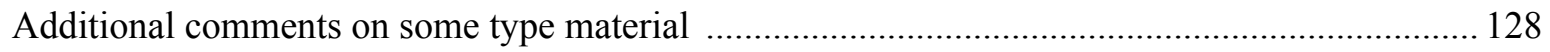

The estimated total number of species in Sweden and Europe ..................................................... 130

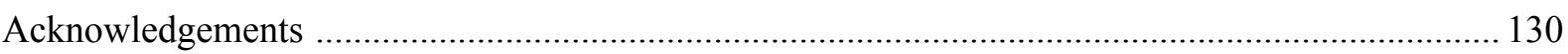

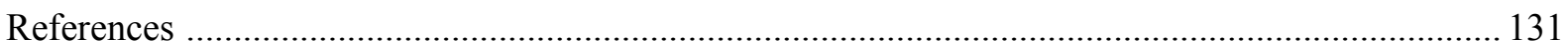

\section{Introduction}

Sweden is situated on the Scandinavian Peninsula in Northern Europe. The country covers $447435 \mathrm{~km}^{2}$ and is more than $1500 \mathrm{~km}$ long, making it one of the largest countries in Europe. Due to its size and length, Sweden harbours several biogeographical zones occurring in Northern and Central Europe, including alpine areas and adjacent subalpine birch (Betula spp.) forests, boreal western taiga and hemiboreal mixed forests to nemoral deciduous forests dominated by beech (Fagus sylvatica L.) and oak (Quercus spp.). On the Baltic islands Öland and Gotland there are vast areas with steppe vegetation on calcareous bedrock ('alvar'), which house many southern faunistic elements. In parts 
of Skåne, the southernmost province, there are also relatively intact ecosystems connected to sparsely vegetated open sandy areas.

This shows, that even if Sweden is biogeographically mainly situated in the boreal zone, it also has several more southern, temperate habitats, especially the in southeastern part of the country. This region is characterized by its dry and hot climate, creating a rich flora and fauna. Noteworthy are also the remnants of old, small-scale agricultural landscapes in the woodlands of Southern and Central Sweden.

The genus Ophion Fabricius, 1798 consists of testaceous slender species of considerable size which are often encountered when attracted to light or light traps. Most Ophion species are predominately nocturnal, but especially males of some species fly during the daytime. They are koinobiont endoparasitoids of lepidopterous larvae, mainly Noctuidae, but to some extent also Geometridae and Drepanidae, which are attacked mainly (or solely) during their final instar. Ophion is a genus predominantly occuring in the temperate zone and there are relatively few species in the tropics and those seem to be restricted to higher elevations and cooler areas (Gauld \& Mitchell 1981; Gauld 1988; Schwarzfeld et al. 2016).

The genus has always been considered to be of certain taxonomic difficulty and all of the previous revisions have confirmed that it is a group where not only are the species quite similar in appearance, but also seem to display a considerable amount of intraspecific variation. Many of the early descriptions by Ratzeburg (1848), Thomson (1888), Kriechbaumer (1879a, 1879b, 1879c, 1892a, $1892 \mathrm{~b}$ ) and Brauns (1889), that followed the rather limited number of taxa described by Linnaeus (1758), Fabricius (1798) and Gravenhorst (1829), were founded on specimens with deviant colour patterns or size. During the first half of the $20^{\text {th }}$ century Kokujev (1906a, 1906b), Szépligeti (1905), Meyer $(1935,1937)$ and Ceballos (1940) described several new Ophion species from Eastern and Southern Europe. Except for Oosterbroek (1978), treating the fauna of the Netherlands, and some Finnish studies by Hellén (1926) and Jussila (1965), accompanied by the more compilatory works of Schmiedeknecht $(1906,1908)$, much of the revisionary work on European Ophion during the last century has been conducted in Britain. Morley (1915), followed by Gauld (1973, 1976, 1978), who mostly based his work on the unpublished manuscripts of J.F. Perkins, started to sort out the genus. Brock (1982) was the first author to treat the genus from a more detailed perspective, thereby making an important systematic contribution in defining species and their variation in relation to accessible type material. In more recent years two studies have also dealt with the presumably diverse Ophion fauna of Southern Europe (Izquierdo 1984; Çoruh \& Kolarov 2012).

The still largely unknown Ophion fauna of the Nearctic has recently been treated in recent years, primarily by combining molecular and morphological methods. Schwarzfeld \& Sperling (2014) treated and defined the Ophion scutellaris group in detail and Schwarzfeld et al. (2016) showed the presumed diversity of species within the genus by sequencing a large number of specimens from the Nearctic and Western Palaearctic.

Today, 79 species are known from the Palaearctic with an additional 17 from the Nearctic (Yu et al. 2012; Schwarzfeld et al. 2016). Gauld (1985) defined eight species groups based on morphology, a number that was increased to 13 by Schwarzfeld et al. (2016) supported by molecular methods. Species groups that are of relevance for the Northern European fauna were defined for Ophion minutus, O. areolaris, O. scutellaris, O. parvulus, O. pteridis, O. luteus and O. obscuratus. Apart from the Nearctic part of the O. scutellaris species group (Schwarzfeld \& Sperling 2014), the other species groups, though defined on a molecular and partly also morphological level, have not been 
treated in detail in relation to type material and morphological variation. Schwarzfeld \& Sperling (2015) provide a detailed overview of aspects of species delimitation in relation to DNA sampling of Ophion, partly treating the Palaearctic fauna, but the morphological dimension still suffers from the lack of adequate delimitation and detailed revisions giving a morphological context to the barcoding results.

Unfortunately, all of the existing revisions and identification keys treating the European fauna use characters that are either simplified, complicated beyond usefulness, or partly erroneous due to misunderstanding species variation regarding certain commonly used characters. This study, which includes a very large amount of material collected during several decades in Sweden, provides a complete revision of and an identification key to the species occurring in Sweden. The study combines several methods, including DNA barcoding and morphological assessment of available specimens, as well as relevant type material. Morphological, molecular and ecological characters used in species delimitation are discussed.

\section{Material and methods}

Material of Swedish Ophion was obtained from various sources, primarily the long-lasting Lepidoptera survey with MV (Mercury-Vapour) light traps conducted by Nils Ryrholm and Clas Källander and samples from the Swedish Malaise trap project (SMTP) as well as specimens deposited in Evolutionsmuseet, Uppsala (UPSZ); Biologiska Museet, Lund (MZLU) and Naturhistoriska Riksmuseet, Stockholm (NHRS). In all, more than 4800 specimens were studied. The material was sorted and clustered into potential morphospecies by the first author and compared to available and relevant type material. Specimens of morphospecies were also barcoded in two main rounds. The aim of the first round was, apart from giving a generic overview, to partly solve and identify taxonomic difficulties. The second round focused on these obstacles and their solution.

DNA extraction from a single mid leg, PCR amplification and sequencing of a majority of the samples were conducted at the Canadian Centre for DNA Barcoding (CCDB) using standardized high throughput protocols (Ivanova et al. 2006; http://www.ibolproject.org/resources.php). The first pass primer pair in all plates was LepF1 and LepR1 (ATTCAACCAATCATAAAGATATTGG and TAAACTTCTGGATGTCCAAAAAATCA) and they all produced PCR products, but due to noise, possibly caused by Wolbachia infections, the results were not easily obtainable for some specimens. For some potentially closely related species around Ophion obscuratus for example, these presumed infections interacted with a long stretch of poly A-s (or T-s) midway, which the sequencing reaction failed to jump, which then resulted in the termination of the sequencing. For 49 specimens, a failure tracking was completed by re-processing the samples by two, smaller primer pairs (Suresh Naik, CCDB, pers. com.). The sequences were aligned using MUSCLE (Edgar 2004). The phylogeny of the barcoded specimens were then estimated by constructing a maximum likelihood (ML) phylogenetic tree (Fig. 1) with the software MEGA X (Kumar et al. 2018). The analysis is based on 150 bootstrap iterations using the General Time Reversible model. The DNA exctracts are stored at the CCDB and all specimen data is accessible in BOLD. BIN-codes, as well as specimen codes (STI-NJBC "X"), are given in the text for each species.

It shall hereby be noted, that the approach of the barcoding dimension of the study was that the existence of 'molecular entities' in the form of separate groups or aggregates, merely indicates the possible delimitation of a potential species. The main effort of the study was that of 'classical' analysis of morphology and when accessible, information on ecology, to define existing species and to identify and delimit previously undescribed species. 

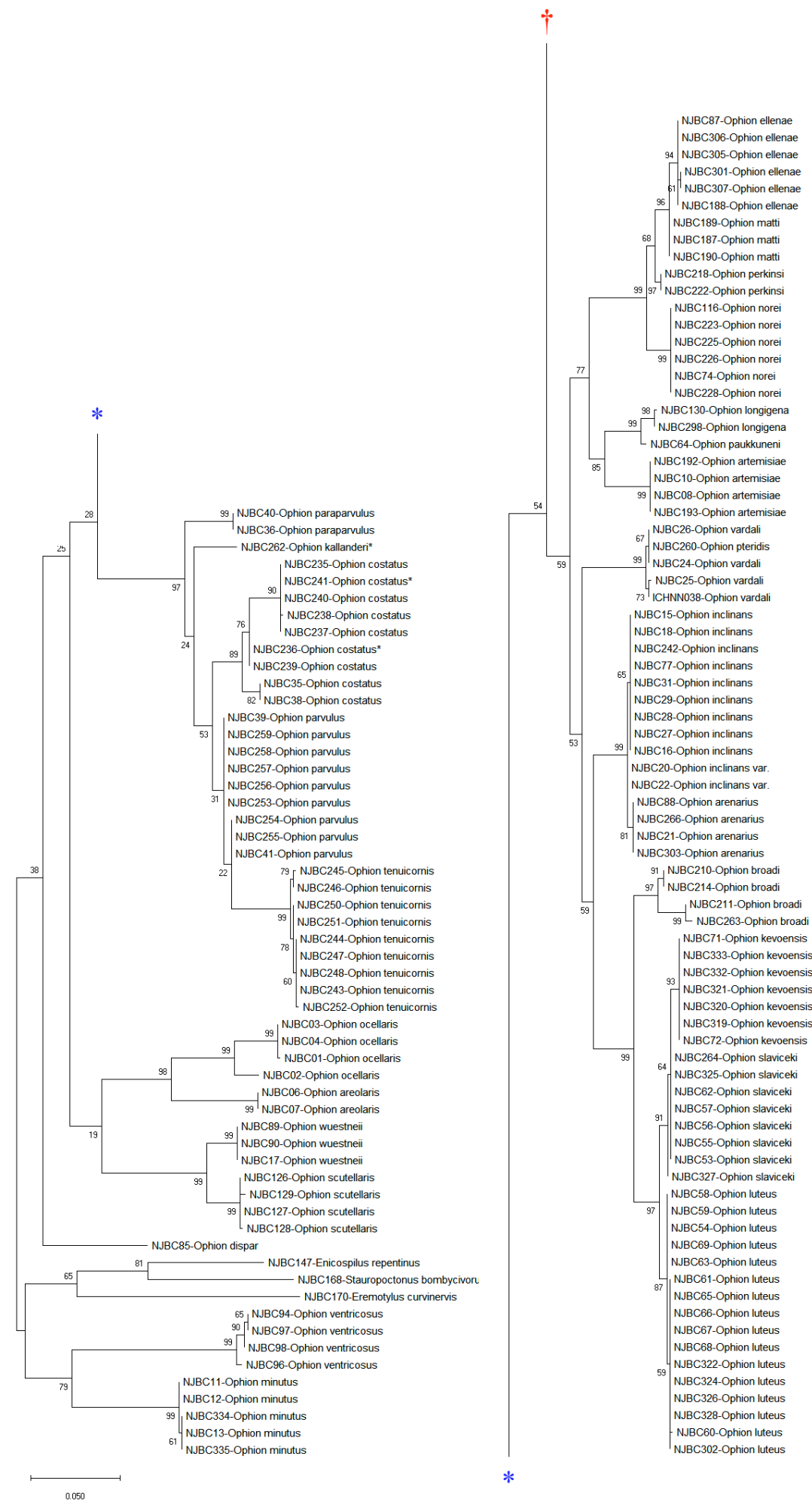

Fig. 1 (continued on next page). Phylogeny of Ophion Fabricius, 1798 as obtained from cytochrome oxidase 1 (COI) sequences. Maximum likelihood tree is shown with clade support including 234 Ophion and 3 outgroup specimens is shown based on 150 bootstrap iterations using the General Time Reversible model and analysed with MEGA-X. The sample ids "NJBC" refer to the BOLD database. 
NJBC265-Ophion confusus* NJBC229-Ophion confusust

NJBC341-Ophion confusus
NJBC296-Ophion confusus

N.JBC 185-Ophion contusus

NJBC50-Ophion confusus

NJBBC43-Ophion confusu

N.JBC48-Ophion confusus

NJBC51-Ophion confusus

NJEC233-Ophion confusus

NJEC133-Ophion confusus

NJBC42-Ophion splendens

N.BC44-Ophion splendens

N.JBC76-Ophion brock

NJBC136-Ophion brocki

N.JBC132-Ophion brock

NJBC134-Ophion brock

NJBBC171-Ophion brock

NJBC32-Ophion brocki

NJBC172-Ophion bro

N.JBC120-Ophion boreals

NJBC120-Ophion brevicornis

N.JBC118 Ophion brevicornis

NJBC118-Ophion brevicornis

NJBC114-Ophon bevicornis

N.JBC119-Ophion bevicomis

NJBC121-Ophion brevicornis

NJBC122-Ophion breviconnis

NJBC123-Ophion brevicornis

NJBC123-Ophion brevicornis

NJBC124-Ophion brevicornis
-NJBC125-Ophion brevicornis

NJBBC113-Ophion brevicornis

NJBC337-Ophion brevicornis

73. NJBC52-Ophion mocsaryi

NJBC234-Ophion mocsaryi*

NJBC180-Ophion mocsaryi

NJBC232-Ophion mocsaryi

NJBC179-Ophion mocsaryi

NJBC339-Ophion mocsaryi

NJBC178-Ophion moc saryi

NJBC175-Ophion mocsary

NJBC105-Ophion mocsary

NJBC174-Ophion mocsary

NJBC47-Ophion mocsaryi var

99 NJBC267-Ophion angularis

N.JBC186-Ophion angularis

NJBC70-Ophion crassicornis

NJBC80-Ophion crassicornis

NJBC81-Ophion crassicornis

NJBC82-Ophion crassicornis

NJBC183-Ophion crassicornis

81 NJBC184-Ophion crassicornis

NJBC217-Ophion crassicornis

NJBC300-Ophion crassicornis

NJBC309-Ophion crassicornis

NJBC46-Ophion crassicornis

NJBC331-Ophion crassic

(1)

NJBBC104-Ophion variegatus*

JBC101-Ophion variegatus"

- NJBC312-Ophion variegatus"

NJBC312-Ophion variegatu

NJBC200-Ophion variegatus ${ }^{*}$

N.JBC201-Ophion variegatus ${ }^{*}$

NJBC202-Ophion varieoatus

NJBBC210-Ophion variegatus

NJBC204-Ophion variegatus*

NJBC203-Ophion variegatus*

N.BBC205-Ophion variegatus

NJBC206-Ophion variegatus"

NJBC99-Ophion variegatus*

NJBC209-Ophion autur

$\left.{ }_{99}\right|_{\text {NJBC316-Ophion variegatus }} ^{\text {NJBC199-Ophion variegatus" }}$

${ }_{87}$ NJBC107-Ophion Sylvestris va

NJBC315-Ophion sylvestris v

NJBC299-Ophion sylvestris va

NJBC196-Ophion syvestris var.

NJBC208-Ophion sylvestris var. ${ }^{*}$

NJEC213-Ophion sylvestris val "

NJBC212-Ophion sylvestris

NJBC109-Ophion sylvestris

NJBC110-Ophion sylvestris

NJBC111-Ophion sylvestris

NJBC181-Ophion sylvestris

NJBC194-Ophion sylvestris

NJBC 198-Ophion sylvestris

NJBC215-Ophion sylvestris

NJBC106-Ophion sylvestris

NJBC318-Ophion sylvestris

4 NJBC317-Ophion sylvestris 
Synonyms are listed based mainly on type material studied by the authors of this paper, bearing in mind that additional data provided by a planned wider revision of the Western Palearctic species of Ophion might call for slight adjustments in nomenclature. Studies of type material have focused on species that are taxonomically weakly defined in available literature and original descriptions, and that are relevant in relation to previously undescribed taxa.

Morphological terminology mainly follows Broad et al. (2018) but some of the terminology for the wing venation follow Townes (1969). The morphological terminology used is labelled in Fig. 2. Fore wing length is measured as the greatest distance from the apex of the tegula to the wing tip. Close up photos by Alexander Berg (Figs 11A-D, 14A-F, 15A-G, 16E-F, 17A-F, 18A-F, 19A-F, 20A-F, 21A-F) was taken with a Canon EOS 6D with a reversed tube lens-Thorlabs ITL200 with either a Schneider Kreuznach Componon $28 \mathrm{~mm}$ f4 or a Schneider Kreuznach Componon-S $50 \mathrm{~mm}$ f2.8 and then stacked with Zerene stacker. All other photos and illustrations by the first author using an Olympus OMD M10 and an Olympus M. Zuiko $60 \mathrm{~mm} / \mathrm{f} .2 .8$ macro lens, except Figs 48A-F, 50A-D, 51 A-F by Hege Vårdal, 46A-C, 52A-F by Stefan Schmidt and 49 by Hans Mejlon.

\begin{tabular}{|c|c|c|}
\hline \multicolumn{3}{|c|}{ Abbreviations/Depositories (corresponding curator/contact) } \\
\hline BMNH & $=$ & $\begin{array}{l}\text { Natural History Museum (formerly British Museum of Natural History), London, } \\
\text { United Kingdom (Gavin Broad) }\end{array}$ \\
\hline CSA & $=$ & Collections of Stift Admont, Admont, Austria (Petr Heřman) \\
\hline HNHM & $=$ & Hungarian Natural History Museum, Budapest, Hungary (Zoltán Vas) \\
\hline HSC & $=$ & Heinz Schnee collection, Germany (Heinz Schnee) \\
\hline LSL & $=$ & Linnean Society, London, United Kingdom \\
\hline MNHN & $=$ & Muséum national d'Histoire naturelle, Paris, France (Agnièle Touret-Alby) \\
\hline MMUE & $=$ & The Manchester Museum of the University of Manchester (Dmitri Logunov) \\
\hline $\mathrm{MZH}$ & $=$ & Finnish Museum of Natural History, Helsinki, Finland (Juho Paukkunen) \\
\hline MZLU & $=$ & $\begin{array}{l}\text { Zoologiska Museet, Lunds Universitet, Lund, Sweden (Christer Hansson, Rune } \\
\text { Bygebjerg) }\end{array}$ \\
\hline NHML & $=$ & Natural History Museum Lausanne, Switzerland (Anne Freitag, Marion Podolak) \\
\hline NHMO & $=$ & Natural History Museum, University of Oslo (Lars Ove Hansen) \\
\hline NHMW & $=$ & Natural History Museum, Vienna, Austria (Dominique Zimmermann) \\
\hline NHRS & $=$ & Swedish Museum of Natural History, Stockholm, Sweden (Hege Vårdal) \\
\hline NMS & $=$ & $\begin{array}{l}\text { National Museums of Scotland, Edinburgh, United Kingdom (Mark Shaw, Ashleigh } \\
\text { Whiffin) }\end{array}$ \\
\hline RJC & $=$ & Dr. Jussila's collection, Turku, Finland (Reijo Jussila) \\
\hline SLU & $=$ & Collection of the Swedish University of Agricultural Sciences (Mats Jonsell) \\
\hline SMTP & $=$ & Swedish Malaise Trap Project, Station Linné, Öland, Sweden (Dave Karlsson) \\
\hline TUZ & $=$ & Natural History Museum, University of Tartu, Estonia (Villu Soon) \\
\hline UMB & $=$ & Ulster Museum, Belfast, Northern Irland (Ryan Mitchell) \\
\hline UPSZ & $=$ & Evolutionsmuseet, Uppsala University, Uppsala, Sweden (Hans Mejlon) \\
\hline ZIN & $=$ & $\begin{array}{l}\text { Zoological Institute, Russian Academy of Sciences, St Petersburg, Russia (Andrey } \\
\text { Khalaim) }\end{array}$ \\
\hline ZMHB & $=$ & Museum für Naturkunde, Berlin, Germany (Michael Ohl, Lukas Kirschey, Jutta Helbig) \\
\hline ZMUC & $=$ & $\begin{array}{l}\text { Zoological Museum, University of Copenhagen, Copenhagen, Denmark (Lars } \\
\text { Vilhelmsen) }\end{array}$ \\
\hline ZSM & & Zoologishe Staatsammlung München, Germany (Stefan Schmidt) \\
\hline
\end{tabular}




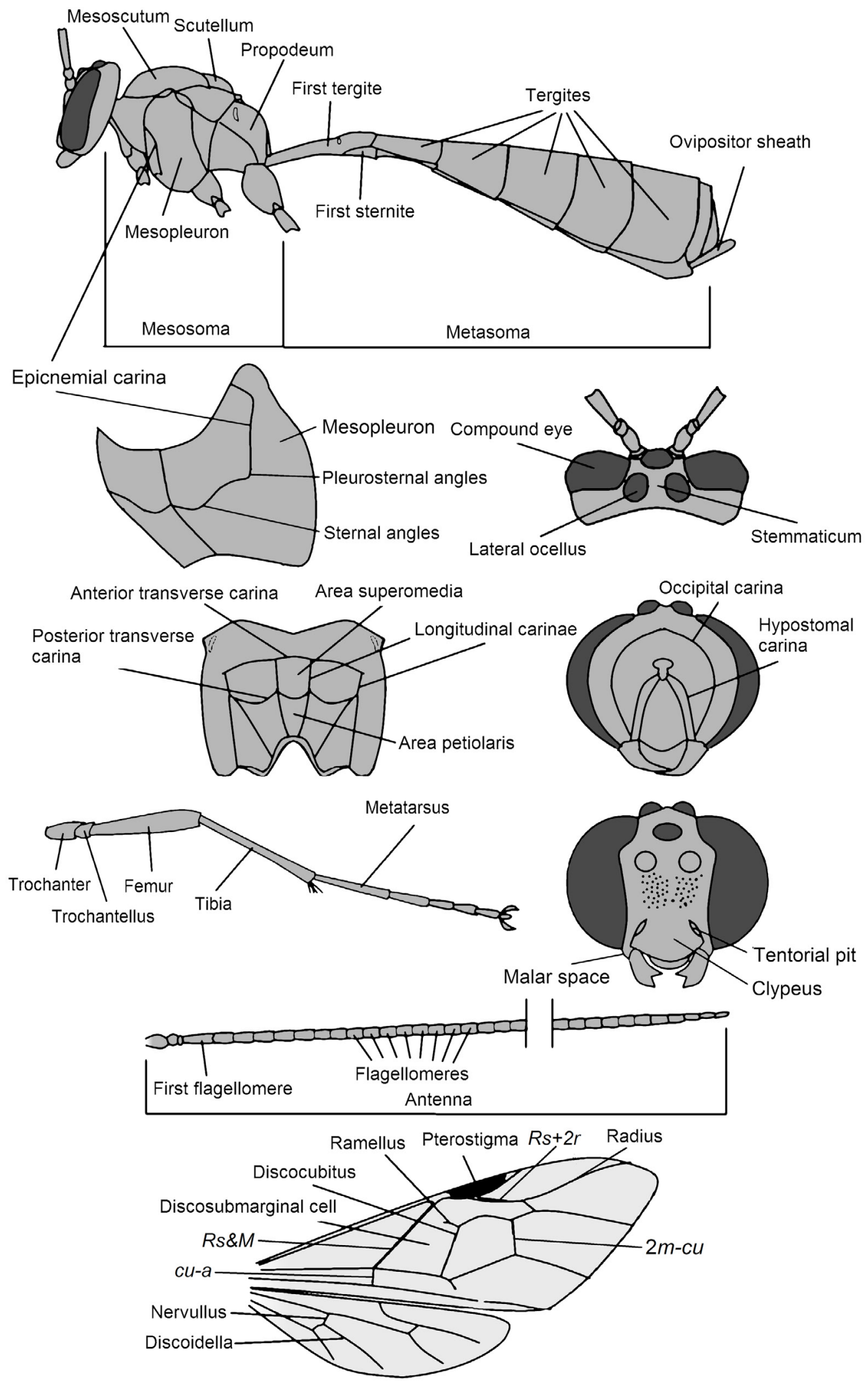

Fig. 2. Morphological terminology referred to in the text. 


\title{
Results
}

\author{
Class Hexapoda Blainville, 1816 \\ Order Hymenoptera Linnaeus, 1758 \\ Superfamily Ichneumonoidea Latreille, 1802 \\ Family Ichneumonidae Latreille, 1802 \\ Subfamily Ophioninae Shuckard, 1840
}

Genus Ophion Fabricius, 1798

In this study, more than 4800 specimens representing 41 species were studied. Eighteen species are described as new to science: Ophion angularis Johansson \& Cederberg sp. nov., Ophion arenarius Johansson sp. nov., Ophion autumnalis Johansson sp. nov., Ophion borealis Johansson sp. nov., Ophion broadi Johansson sp. nov., Ophion brocki Johansson sp. nov., Ophion confusus Johansson sp. nov., Ophion ellenae Johansson sp. nov., Ophion inclinans, Johansson sp. nov., Ophion kallanderi Johansson sp. nov., Ophion matti Johansson sp. nov., Ophion norei Johansson sp. nov., Ophion paraparvulus Johansson sp. nov., Ophion paukkuneni Johansson sp. nov., Ophion splendens Johansson sp. nov., Ophion sylvestris Johansson sp. nov., Ophion tenuicornis Johansson sp. nov. and Ophion vardali Johansson sp. nov. Eleven species are documented from Sweden for the first time; Ophion artemisiae, Ophion crassicornis, Ophion costatus, Ophion dispar, Ophion forticornis, Ophion kevoensis, Ophion ocellaris, Ophion perkinsi, Ophion subarcticus, Ophion variegatus and Ophion wuestneii.

\section{Barcoding results}

234 specimens produced barcodes (out of an attempted 284) (Fig. 1). A full barcode sequence (658 bp) was recovered from 115 specimens, sequences greater than $500 \mathrm{bp}$ from 95 specimens and shorter sequences from 24 specimens. Specimens included in the analysis with a barcode shorter than $500 \mathrm{bp}$ is marked with an * in Fig. 1. Full length barcodes or barcodes with more than $630 \mathrm{bp}$, were recovered from at least one specimen for all species except $O$. obscuratus, $O$. autumnalis Johansson sp. nov. and $O$. kallanderi Johansson sp. nov. A sequence from $O$. vardali Johansson sp. nov. containing $401 \mathrm{bp}$ was acquired from NorBOL project DS-ICHNN. No Swedish specimens of $O$. forticornis and $O$. subarcticus were sequenced due to the absence of material suitable for sampling. An additional sequence from Ophion forticornis retrieved from the dataset of Schwarzfeld et al. (2016) at https://datadryad.org/resource/doi:10.5061/dryad.49g98 was included in the phylogenetic analysis. Barcode records for the sampled specimens are available in the BOLD dataset "STI-NJBC". The barcoding in combination with the morphological analysis confirms and supports the existence of a majority of the species defined in this study and indicates the existence of at least three additional potentially cryptic species (Fig. 1). The sequencing also supports the aggregate nature of several species by small, but consistent genetic differences. This particularly concerns the aggregates around Ophion luteus (Fig. 3), O. perkinsi (Fig. 4) and O. inclinans Johansson sp. nov. (Fig. 5).

\section{Assessment of morphological characters used in species delimitation}

When it comes to morphological characters used in definition and separation of species, there are some new characters highlighted in this study that have been used in combination with more well known features used by previous authors to delimit species.

\section{Body size}

The size of the body is a character that can be used to identify some species in combination with other morphological features. As the metasoma often is bent in various postitions the size is usually indicated 
by the length of the fore wing. There is always some variation in size between individuals and frequently unusally small specimens are encountered. These are probably either the result of starved specimens or specimens reared from smaller host-species.

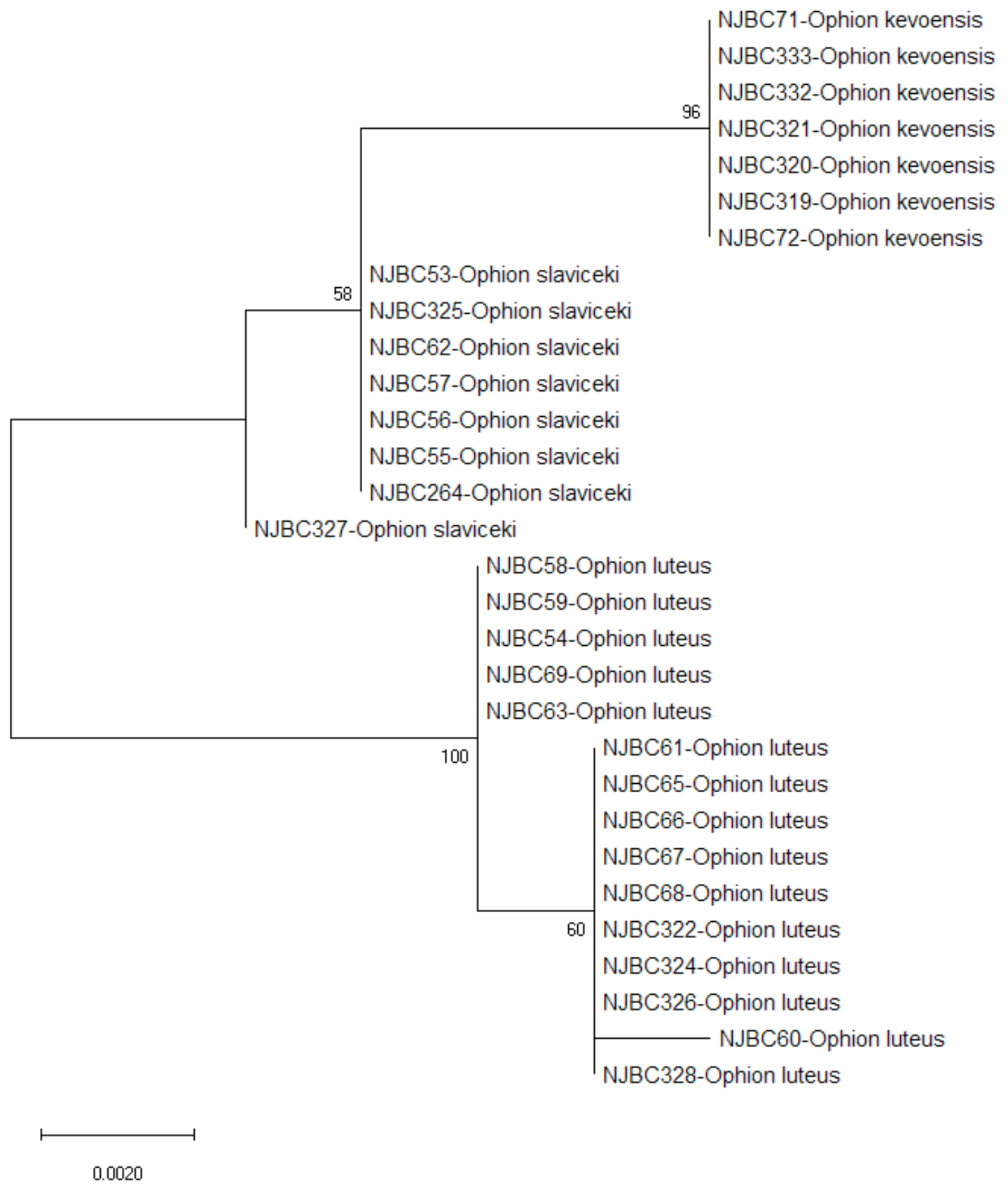

Fig. 3. Phylogeny of the Ophion luteus aggregate (BIN. BOLD:ACF9514) as obtained from cytochrome oxidase 1 (COI) sequences. Maximum likelihood tree is shown with clade support based on 150 bootstrap iterations using the General Time Reversible model and analysed with MEGA-X. The sample ids "NJBC" refer to the BOLD database. 


\section{Head}

The distance from the outer margin of the lateral ocellus to the nearest inner margin of the compound eye (the ocellar-ocular interspace) (Figs 14A-B, 18A-B) has been regarded as an important feature by several previous authors (Gauld 1973; Brock 1982; Broad 2012). The ocellar-ocular interspace is somewhat variable within species but in many species quite characteristic, indeed making it a rather useful character in species separation. The ocellar-ocular interspace often has a relation to the length of the temple/the length of the compound eye ratio, which is another useful feature (Figs 15E-G, 19B, $\mathrm{D}, \mathrm{F})$. The importance of this character has been underestimated by previous authors. While the shape and the length of the temple usually is assessed in dorsal view, this perspective and the percieved length of the temple can be strongly affected by only a slight change in the angle of view. A lateral view is often a better way to appreciate the ratio. The length of the malar space, i.e., the shortest distance between the lower margin of the compound eye to the mandibular base, in relation to the width of the mandibular base, is often used in species definition (Jussila 1965; Brock 1982). It is a quite consistent character within species, though sometimes hard to appreciate in detail and seemingly more variable in males than in females. The sulcus, i.e., the elongate groove, behind the lateral ocelli (Fig. 15B), can be diagnostic. In some species it is particularly well defined and useful as a complementary character in species definition (Brock 1982). The importance of the shape of the occipital carina (Fig. 7A-B) has been partly overlooked by previous authors and is quite useful in species definition, mainly used in combination with other characters. Dorsally it can be angled, medially dipped or straight. Also the

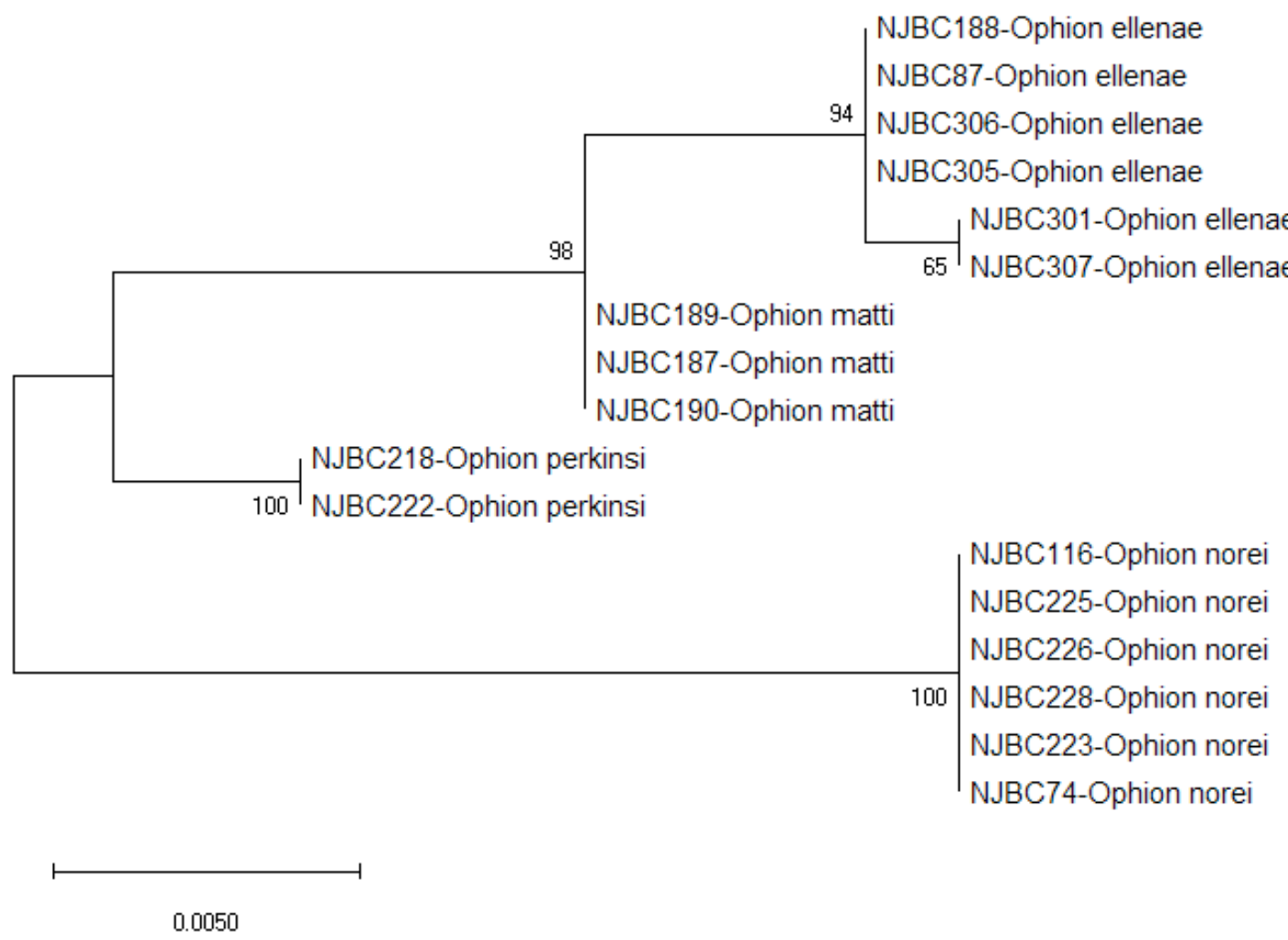

Fig. 4. Phylogeny of the Ophion perkinsi aggregate (BIN. BOLD: ADM6556) as obtained from cytochrome oxidase 1 (COI) sequences. Maximum likelihood tree is shown with clade support based on 150 bootstrap iterations using the General Time Reversible model and analysed with MEGA-X. The sample ids "NJBC" refer to the BOLD database. 
shape of occipital carina before the junction beween the occipital and hypostomal carina can be useful for some closely related species pairs (Izquierdo 1984).

A feature which is very useful, but rarely previously used to any extent in the diagnosis of Ophion species, is the shape of the head in anterior view and the relation between the width of the face and the compound eye, often also supported by the shape of the clypeal area (Schwarzfeld \& Sperling 2014). As the shape of the temples treated above, the importance of this character has been obscured by the aggregate nature of some species. The human ability of facial recognition can be a valuable asset when trying to separate closely related species. The sculpture of the face, i.e., the intensity and size of the punctation and the surface being more or less shagreened, is a somewhat variable character in many species, but nevertheless very useful in defining morphospecies if treated in combination with other characters.

The mandibular gape, i. e. the angle between the two mandibular teeth (Fig. 7H-I), is useful in separating some closely related species in some subgroups, but only when exhibiting a distinct difference, i.e., the gape forming an acute angle vs an obtuse or right angle (Morley 1915; Brock 1982; Broad 2012; Broad et al. 2015; ). A secondary character to be noted is that species attacking hosts pupating under ground often have the mandibles more or less worn from emerging through soil, indicating an ecological characterization that sometimes can be useful in indicating the species involved.

\section{Antennae}

The length and shape of the flagellomeres and the number of flagellomeres has been shown to be of significance in the separation of species in some aggregates (Figs $7 \mathrm{~N}-\mathrm{O}, 8 \mathrm{~A}-\mathrm{F}, 8 \mathrm{M}-\mathrm{O}$ ). The number of

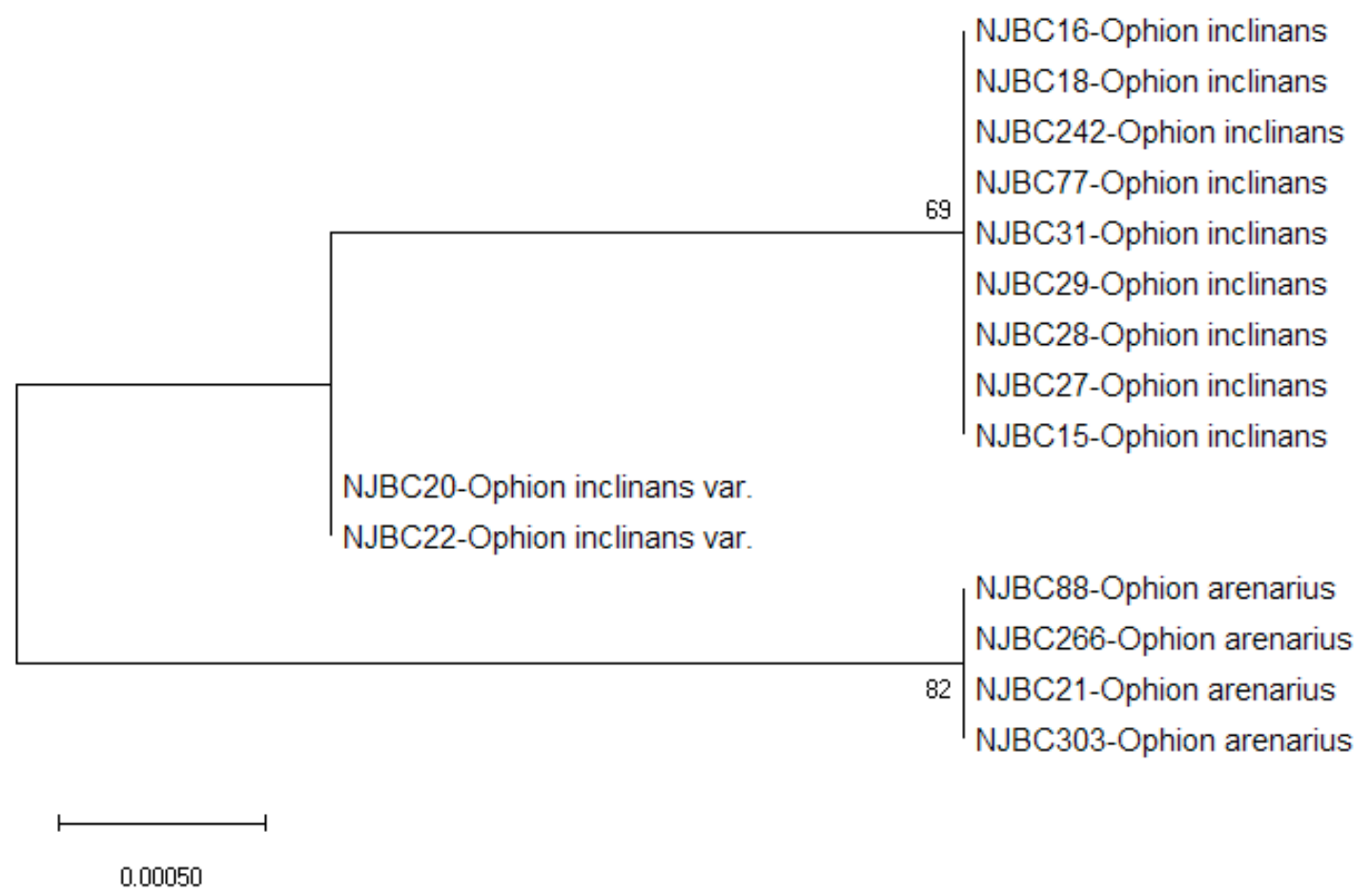

Fig. 5. Phylogeny of Ophion inclinans Johansson sp. nov. and Ophion arenarius Johansson sp. nov. (BIN. BOLD: AAH1753) as obtained from cytochrome oxidase 1 (COI) sequences. Maximum likelihood tree is shown with clade support based on 150 bootstrap iterations using the General Time Reversible model and analysed with MEGA-X. The sample ids "NJBC" refer to the BOLD database. 
flagellomeres, though slightly variable within species, seems to be a good way to delimit species groups and sometimes also closely related species (Brock 1982; Broad 2012). The relative length and width of the flagellomeres, as well as the pilosity of the flagellomeres seem to be quite consistent within some species and also between the sexes.

\section{Mesosoma}

The structure of the mesoscutum and mesopleuron is often quite typical, but not particularly often previously used for the separation and definition of species. Although variable to some extent within species, it is diagnostic in others and sometimes also useful in separating closely related species. The length of the scutellar carinae (Fig. 6A-D) have been of taxonomic importance primarly to separate species within the wider definition of the $O$. luteus group as defined by Gauld (1985). The extension of the carinae can be slightly variable within species but it is still an important character for species definition (Thomson 1888; Brock 1982; Gauld 1978). The shape of the scutellum in dorsal, and sometimes lateral view, can also contribute to the determination. The sides of the scutellum can be more or less converging and the scutellum more or less convex in lateral view.

A very useful character when it comes to definition of morphospecies is the shape of the epicnemial carina (Brock 1982; Broad 2012). The shape of the pleurosternal angles and their position in relation to the sternal angles in anteroventral view (Fig. 9A-I) is often typical and relatively constant within species groups or sometimes within single species (Brock 1982; Broad 2012). Another characteristic that can be used in species diagnostics is the shape of the propodeal carinae (Figs 10A-O, 14C-D, 18E-F). The carinae can be more or less well developed in single individuals, but the interspace and angles between the carinae are quite consistent within species. Due to the individual variation in the development of the carinae, its taxonomic use has been somewhat underestimated.

\section{Wings}

The presence/absence and relative length of the ramellus in the fore wing (Fig. 16A-B) and the nervellus in the hind wing being broken at, above or below the middle by the discoidella (Fig. 13E-F) have been used by previous authors (Brock 1982; Broad 2012; Broad et al. 2015) and especially the latter can be useful in the separation of species. Brock (1982) regards this character as unstable and thereby less useful, which is the result of the misinterpretation of some species by the author. The shape of the radius in the fore wing can be diagnostic as it can be evenly curved or more or less sinuous (Fig. 13A, C). This character seem to be more stable in females than in males.

\section{Legs}

The shape of the legs, e.g., the ration between the length and the width of the femur, tarsus and trochantellus, is often useful in separating som species or species groups (Gauld 1978; Brock 1982). Notable is also the length of the hind tibial spurs in relation to the length of the hind metatarsus (Brock 1982).

\section{Metasoma}

A character that is particularly useful when defining species is the relative positioning of the spiracle of the first tergite in relation to the hind margin of the sclerotised section of the first sternite (Fig. 6E-H) (Brock 1982; Broad 2012). The spiracle can be situated level with, or more or less posterior to the hind margin on the sclerotised part of the sternite. Some variability in this character will usually make it necessary to combine it with other characters, such as the carination of the lateral margins of the scutellum. The shape of the first tergite in lateral view (Fig. 20E-F) as well as the prescence or absence of a dorsal undulation is also quite consistent and useful. The shape of the male genitalia is usually quite similar between species and parameres are often deformed by being stored in ethanol or if dried up. However, in some cases the shape of the parameres in lateral view can be useful in the separation of species (Fig. 6I-J). 

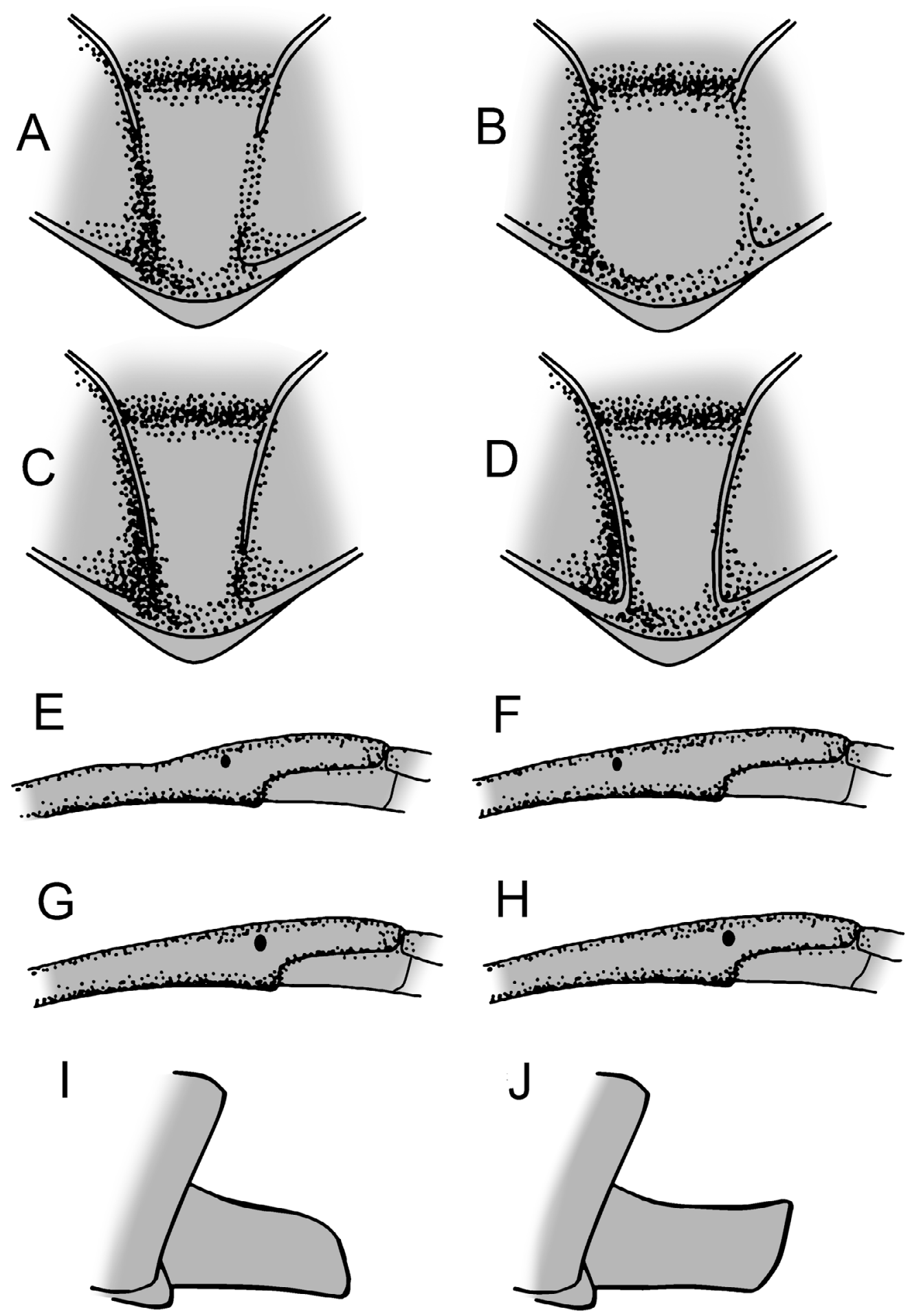

Fig. 6. A-D. Scutellum, dorsal view. A. Ophion luteus (Linnaeus, 1758). B. O. areolaris Brauns, 1889. C. O. inclinans Johansson sp. nov., holotype, q (NHRS-HEVA000008667). D. O. dispar Brauns, 1895. E-H. First tergite, lateral view. E. O. inclinans Johansson sp. nov., holotype, $q$ (NHRS-HEVA000008667). F. O. dispar. G. O. artemisiae Boie, 1855. H. O. luteus. I-J. Shape of male parameres, lateral view. I. Ophion sp. cf. pseudocostatus Meyer, 1935. J. O. artemisiae. 
A

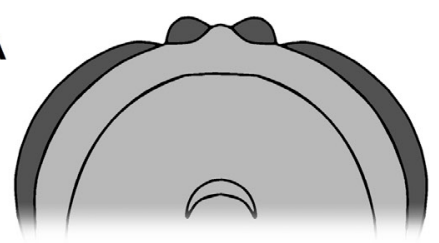

C

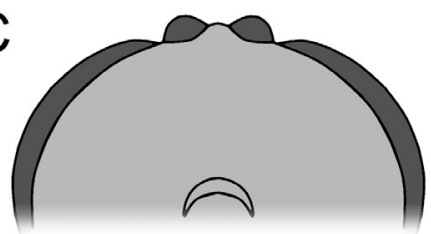

E

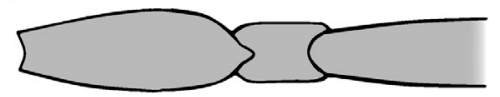

G

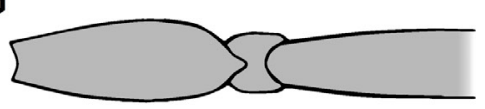

B
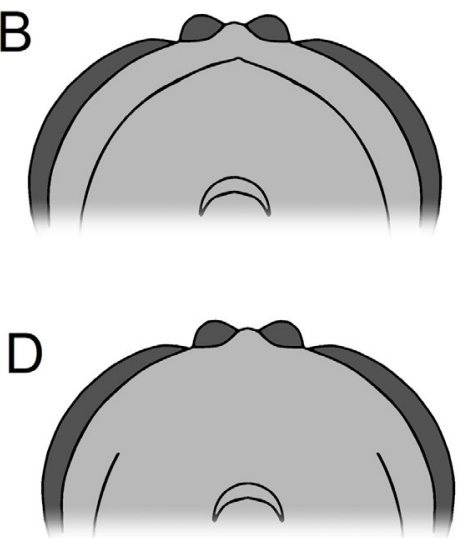

$\mathrm{F}$

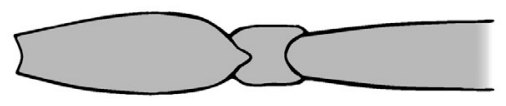

$\mathrm{H}$

I

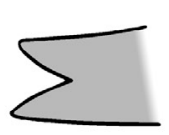

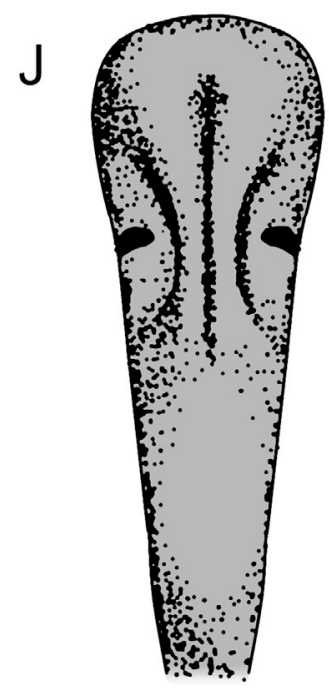

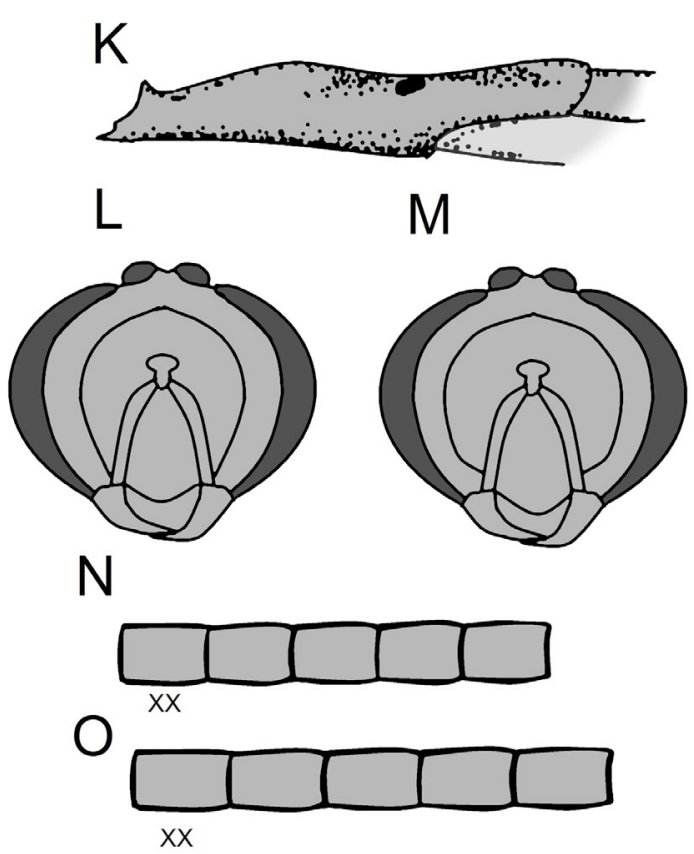

Fig. 7. A-D. Occipital carina posterior view. A. Ophion confusus Johansson sp. nov., holotype, $q$ (NHRS-HEVA000008637). B. O. mocsaryi Brauns, 1889. C. O. ocellaris Ulbricht, 1926. D. O. areolaris Brauns, 1889. E-G. Hind trochanter and trochantellus dorsal view. E. O. slaviceki Kriechbaumer, 1892. F. O. obscuratus Fabricius, 1798. G. O. costatus Ratzeburg, 1848. H-I. Mandible ventral view. H. O. obscuratus. I. O. slaviceki. J-K. First tergite, aberration $O$. artemisiae Boie, 1855. J. Dorsal view. K. Lateral view. L-M. Head in posterior view showing generalized shape of occipital carina. L. O. obscuratus. M. O. variegatus Rudow, 1883 . N-O. Central flagellomeres in males. N. O. obscuratus. O. O. variegatus. 

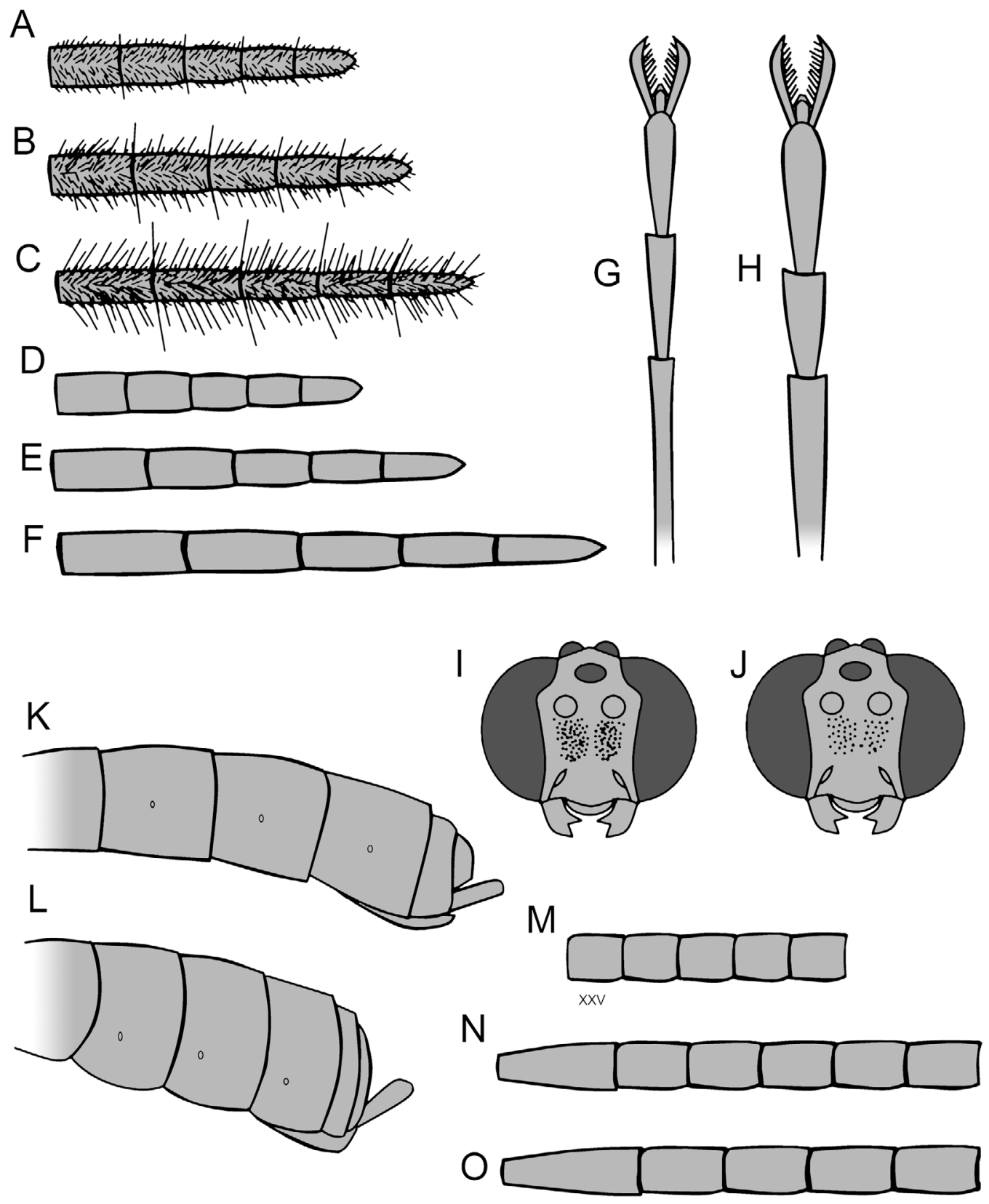

Fig. 8. A-C. Apical flagellomeres in female. A. Ophion parvulus Kriechbaumer, 1879. B. O. paraparvulus Johansson sp. nov., paratype, + (NHRS-HEVA000008696). C. O. tenuicornis Johansson sp. nov., paratype, + (NHRS-HEVA000008743). D-F. Apical flagellomeres in female (pilosity removed). D. O. ellenae Johansson sp. nov., paratype, + (NHRS-HEVA000008655). E. O. arenarius Johansson sp. nov., paratype, $q$ (NHRS-HEVA000008606). F. O. inclinans Johansson sp. nov., holotype, $q$ (NHRS-HEVA000008667). G-H. Apical hind tarsal segments dorsal view in female. G. O. parvulus. H. O. costatus Ratzeburg, 1848. I-J. Generalized punctation below antennal sockets in anterior view. I. O. confusus Johansson sp. nov., holotype, q (NHRS-HEVA000008637). J. O. mocsaryi Brauns, 1889. K-L. Posterior segments of female metasoma lateral view. K. O. areolaris Brauns, 1889. L. O. ocellaris Ulbricht, 1926. M. Central flagellomeres in female of O. brevicornis Morley, 1915. N-O. Basal flagellomeres. N. O. confusus Johansson sp. nov., holotype, o (NHRS-HEVA000008637). O. O. mocsaryi. 


\section{Colour}

Even though known for their lack of diagnostic colouration, there are some colour characters in Ophion that can provide information regarding the identification of certain species. The colouration of the head, mesosoma and metasoma have been used to primarily define species with extensive black or pale markings. For some species groups, the colour of the ovipositor sheath is a very useful distinguishing character used in this study. The colour of the stemmaticum can be of some importance when separating the two species within the subgenus Platophion Hellén, 1926. While the darker or brownish colouration of the mesosoma and coxae in some species can be rather variable it is found to be quite constant in others, thereby being partly diagnostic. In some species more subtle colour characters, such as the

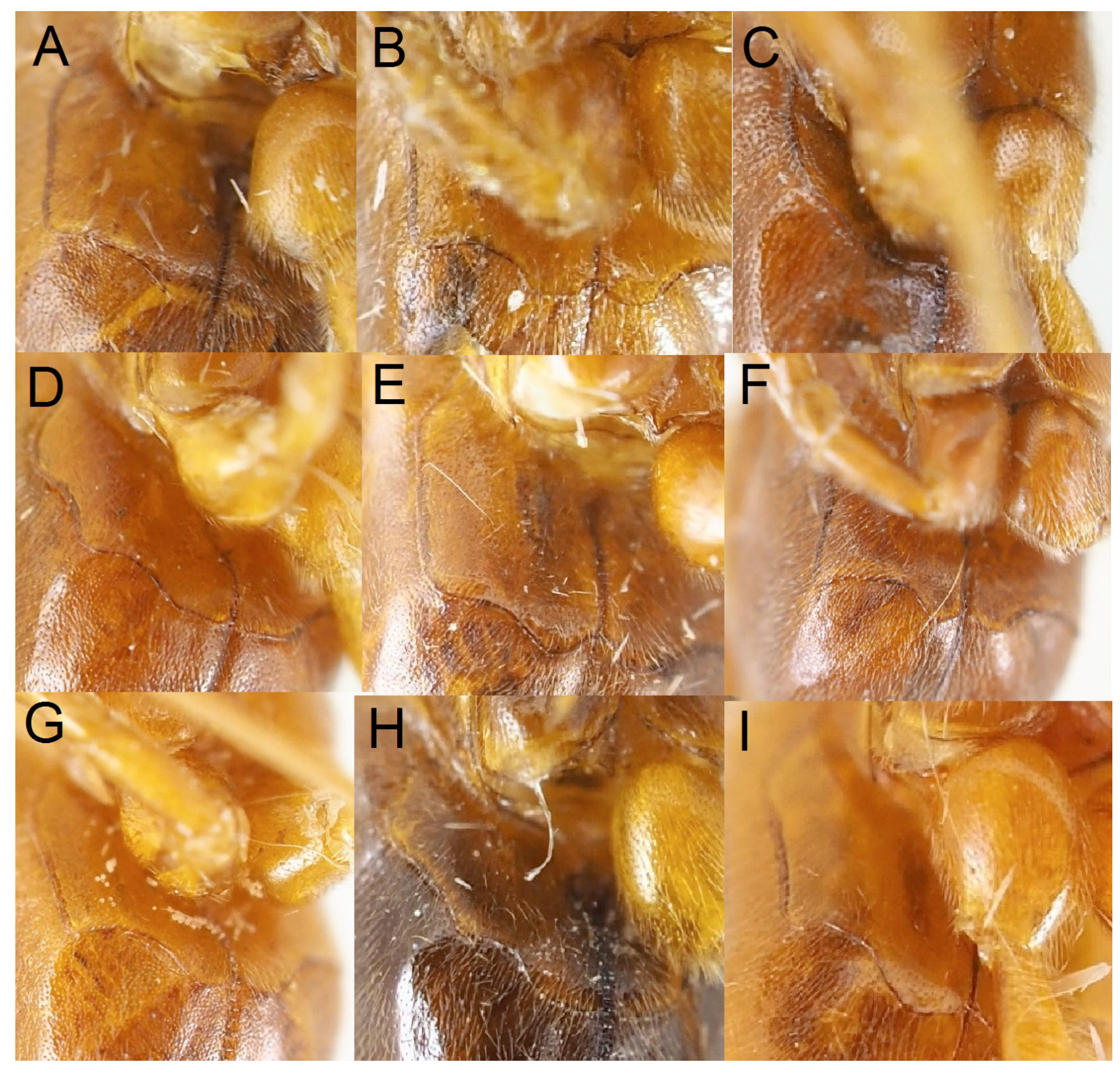

Fig. 9. Epicnemial carina, antero-ventral view of female. A. Ophion splendens Johansson sp. nov., paratype, + (NHRS-HEVA000008708). B. O. mocsaryi Brauns, 1889. C. O. dispar Brauns, 1895. D. O. parvulus Kriechbaumer, 1879. E. O. slaviceki Kriechbaumer, 1892. F. O. angularis Johansson \& Cederberg sp. nov., paratype, o (MZLU 6366:3). G. O. crassicornis Brock, 1982. H. O. areolaris Brauns, 1889. I. O. kallanderi Johansson sp. nov., paratype, o (MZLU 6371:5). 
A

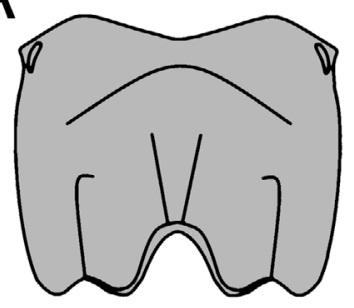

D

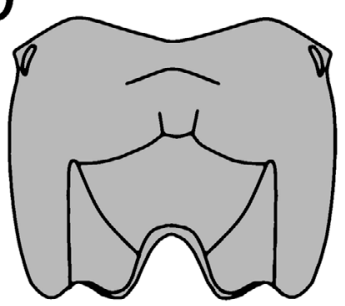

G

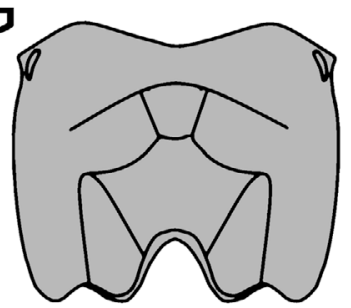

J

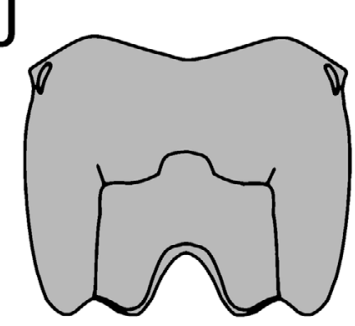

M

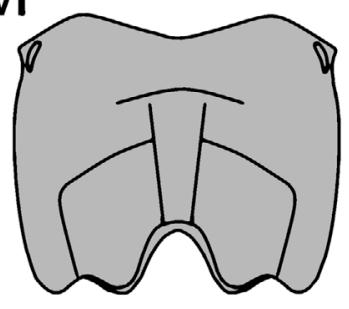

B

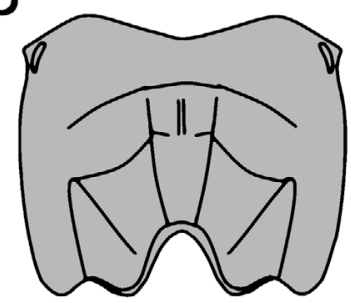

E

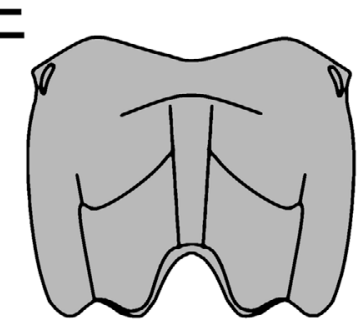

$\mathrm{H}$
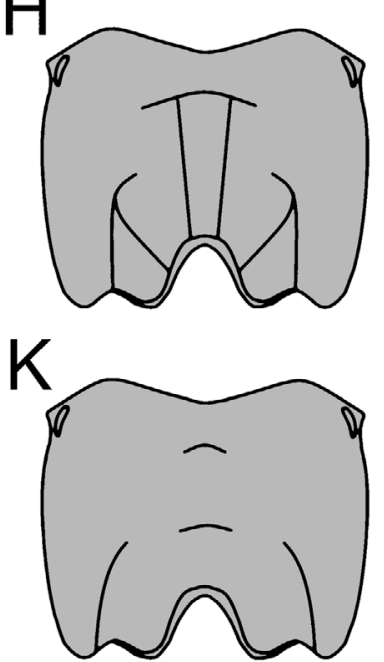

$\mathrm{N}$

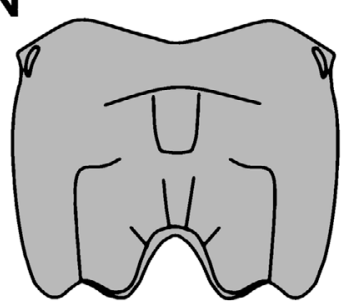

C

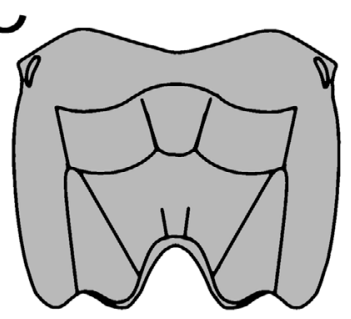

F

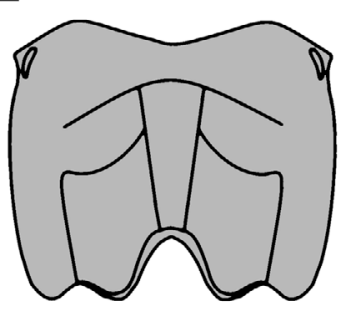

I
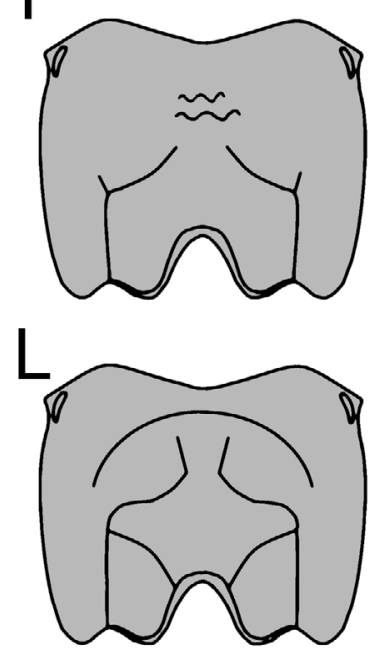

O

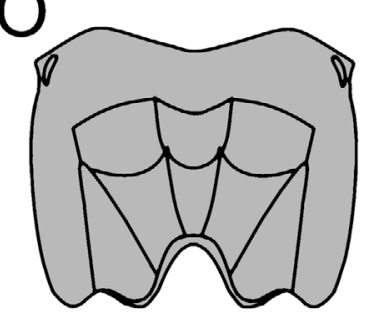

Fig. 10. Generalized carination of propodeum in females, posterodorsal view. A. Ophion luteus (Linnaeus, 1758)/O. scutellaris Thomson, 1888/O. obscuratus Fabricius, 1792. B. O. costatus Ratzeburg, 1848. C. O. brocki Johansson sp. nov., paratype, $q$ (NHRS-HEVA000008633). D. O. confusus Johansson sp. nov., holotype, o (NHRS-HEVA000008637). E. O. crassicornis Brock, 1982. F. O. artemisiae Boie, 1855. G. O. ellenae Johansson sp. nov., paratype, q (NHRS-HEVA000008655). H. O. perkinsi Brock, 1982. I. O. ocellaris Ulbricht, 1926. J. O. areolaris Brauns, 1889. K. O. dispar Brauns, 1895. L. O. tenuicornis Johansson sp. nov., paratype, $q$ (NHRS-HEVA000008743). M. O. longigena Thomson, 1888. N. O. brevicornis Morley, 1915. O. O. forticornis Morley, 1915. 
prescence/absence or the distribution of the paler areas around the compound eyes and scutellum, can provide some information that can contribute to species diagnostics.

\section{Identification key to the Swedish species of Ophion}

The key is constructed primarily to key out females (ovipositor present). In many cases both sexes can be keyed out, but generally males are less distinct when it comes to characters useful in separating species (the shape of the pleurosternal angles, head, flagellomeres etc.) and sometimes there is no satisfactory way to identify males with accuracy. It is important to bear in mind that all characters display some degree of variation and used individually they will often be found to overlap between species. It is therefore crucial that all determination of Ophion species (apart from a couple of distinct species) focus on the species 'unique combination of characters. This of course has implications for the construction of a useful key. If one is to cover every possible aspect of variation within species, the key would end up an

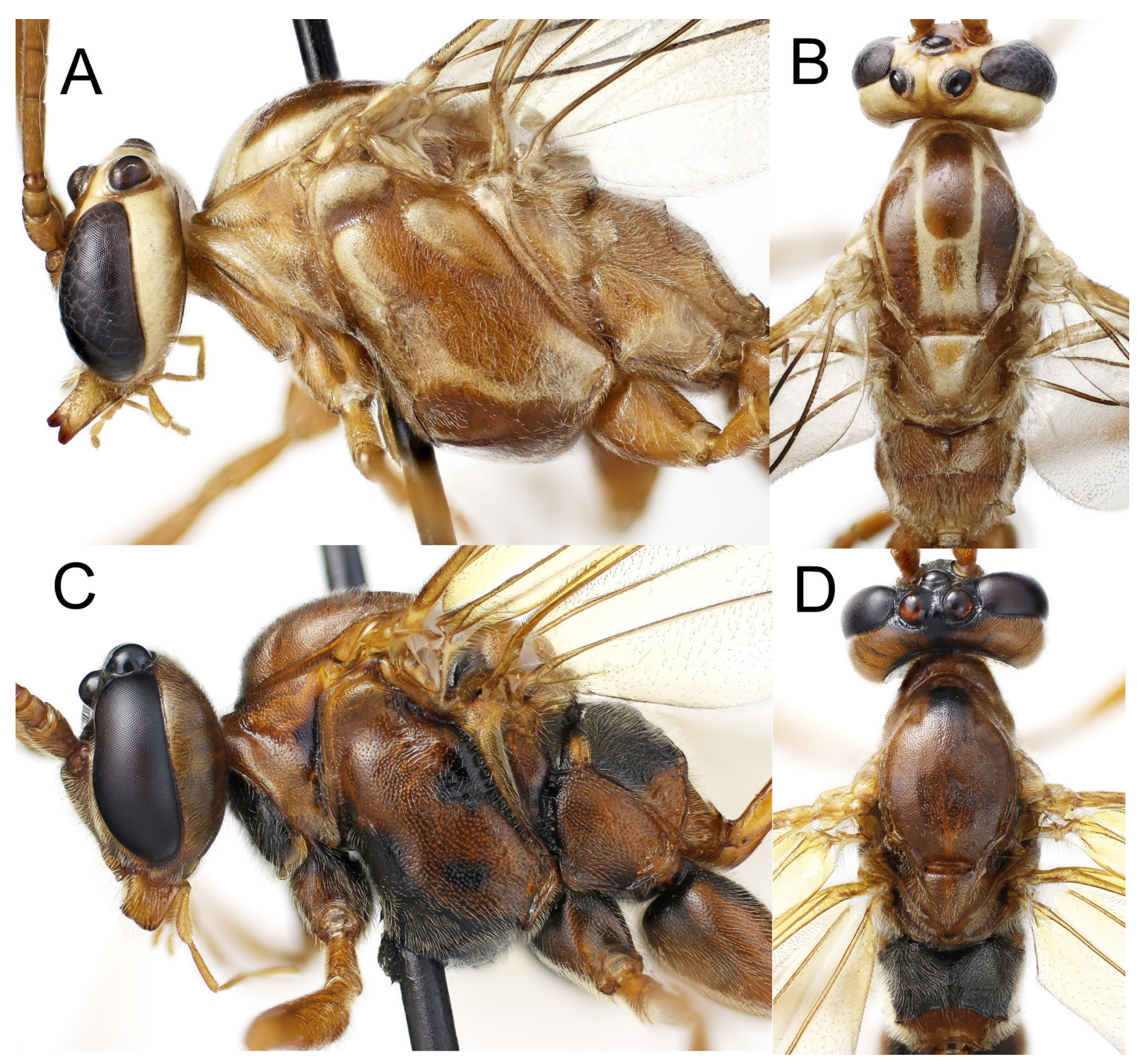

Fig. 11. Head and mesosoma, lateral and dorsal view of female. A-B. Ophion variegatus Rudow, 1883. C-D. O. ventricosus Gravenhorst, 1829. 
uncrossable marsh of 'or's' and 'and's' and 'if's'. It shall therefore be stated that the key presented here is simplified to some extent, but still fully sufficient for determining a majority of specimens. It is also necessary, if one is to determine specimens with accuracy, to build a reference collection of correctly determined material.

1. Occipital carina entirely absent centrally, at most weakly defined laterally (Fig. 7C-D); wing membrane strongly yellowish; scutellum rectangular without lateral carinae (Fig. 6B); epicnemial carina with pleurosternal and sternal angles indistinct (Fig. 9H) ................................................. 2

- Occipital carina present (Fig. 7A-B); wing membrane rarely strongly yellowish (but see O. ventricosus - couplet 3), usually colourless; scutellum with or without lateral carinae, narrowed apically (Fig. 6A, C-D); epicnemial carina with at least pleurosternal angles usually more prominent (Fig. 9A-B, E-G, I)

2. Stemmaticum black or dark brown; antenna with more than 50 flagellomeres; occipital carina completely absent (Fig. 7C); area superomedia usually absent with transverse wrinkles in its place (Fig. 10I); female with metasoma shorter, tergites $4-5$ in lateral view about 1.5 times as wide as long; spiracles on $4-5^{\text {th }}$ tergites closer to the base of the tergite (Fig. 8L); male with parameres elongate and evenly rounded in lateral view

O. ocellaris Ulbricht, 1926

- Stemmaticum testaceous, concolourous with head, very rarely brownish; antenna with fewer than 50 flagellomeres; occipital carina present laterally (Fig. 7D); area superomedia often well-defined, in the shape of a small arc (Fig. 10J); female with metasoma longer, tergites 4-5 almost square in lateral view; spiracles situated more or less at the center of the tergite (Fig. 8K); male with parameres stout and dorsally flattened in lateral view

O. areolaris Brauns, 1889

3. Head and mesosoma with conspicuous black marks and patches (Fig. 11C-D); wing membrane strongly yellowish O. ventricosus Gravenhorst, 1829

- Body usually without conspicuous black marks; wing membrane at most weakly yellowish. If the mesosoma displays fuscous or black areas, these are not forming distinct patterns as in Fig. 11C-D and the head has no black markings

4. A small species (fore wing length 7-11 mm); mesosoma in male with rich pale markings and in female more often uniformly testaceous with posterior segments of metasoma often infuscate and scutellum and head extensively yellow marked; propodeum largely without carinae, only posterior transverse carina indicated laterally; vein $R s+2 r$ usually distinctly thickened and curved at junction with pterostigma (Fig. 12)

O. minutus Kriechbaumer, 1879

- Usually larger species (fore wing length more than $12 \mathrm{~mm}$ ); propodeum usually with distinct carination; radius not distinctly thickened or curved at junction with pterostigma (Fig. 13A-D) ... 5

5. Propodeum with carinae complete and posterior transverse carina strongly raised (Fig. 10O); mesosoma with extensive pale markings (as in Fig. 11A-B); head strongly buccate; antenna with fewer than 50 flagellomeres. A very rare species occurring in sand dunes in Southern Sweden O. forticornis Morley, 1915

- Propodeum with carinae usually not strongly raised; if mesosoma has pale markings, then carinae of propodeum are not strongly raised and the antenna has more than 50 flagellomeres

6. Sclerotised section of first sternite ending level with or slightly posterior to the spiracle (Fig. 6G-H); scutellum with lateral carinae at most indicated anteriorly (Fig. 6A), rarely (in O. luteus, O. subarcticus, $O$. kevoensis, $O$. slaviceki and $O$. crassicornis) covering the anterior half or more of the scutellum; ovipositor sheath testaceous, concolourous with posterior metasomal segments, or brown-black, contrasting in colour with posterior metasomal segments 
- Sclerotised section of first sternite ending distinctly posterior to spiracle (Figs 6E-F, 20E-F) (the exceptions are $O$. artemisiae, a species with wrinkled mesopleuron and ramellus absent (Fig. 24A-B), and $O$. longigena, a distinct species with strongly buccate head (Fig. 35A-B); scutellum with lateral carinae always distinct in at least anterior half (Fig. 6C); ovipositor sheath always testaceous-brown, concolourous with posterior metasomal segments

7. Antenna with 50 or fewer flagellomeres; central flagellomeres in female short, square (Fig. $8 \mathrm{M}$ ), slightly longer in males; head strongly buccate with distinct gap between lateral ocellus and compound eye (Fig. 18A); malar space about 0.5 times as wide as mandibular base; head and mesosoma evenly testaceous, never with yellow markings on mesosoma or distinctly paler areas around the eyes

o. brevicornis Morley, 1915

- Antenna usually with 50 or more flagellomeres, if rarely with fewer than 50 flagellomeres, then the central flagellomeres are distinctly longer than wide (compare with Fig. 8N-O); malar space usually distinctly shorter than 0.5 times as wide as mandibular base

8. Epicnemial carina, in antero-ventral view, with pleurosternal angles rounded, distinctly anterior to sternal angles (Fig. 9D-E, I); pleurosternal angles obtuse or right-angled, very rarely slightly acute; anterior transverse carina of propodeum often complete (Fig. 10A, L); first flagellomere more than 3.5 times as long as wide; ovipositor sheath in all but one species (O. sylvestris Johansson sp. nov.) testaceous-brown, usually concolourous with posterior metasomal segments (note that the females of $O$. costatus and $O$. tenuicornis Johansson sp. nov. usually have the ovipositor sheath brownish, slightly contrasting with the posterior metasomal segments)

- Epicnemial carina, in antero-ventral view, with pleurosternal angles more conspicuous, in most cases in level or slightly anterior to sternal angles (Fig. 9A-B, F-G); pleurosternal angles acute or rightangled, rarely obtuse; anterior transverse carina of propodeum often weak laterally (Fig. 10D-E, $\mathrm{H}, \mathrm{M}$ ); first flagellomere usually about 3.0 times as long as wide; ovipositor sheath always black

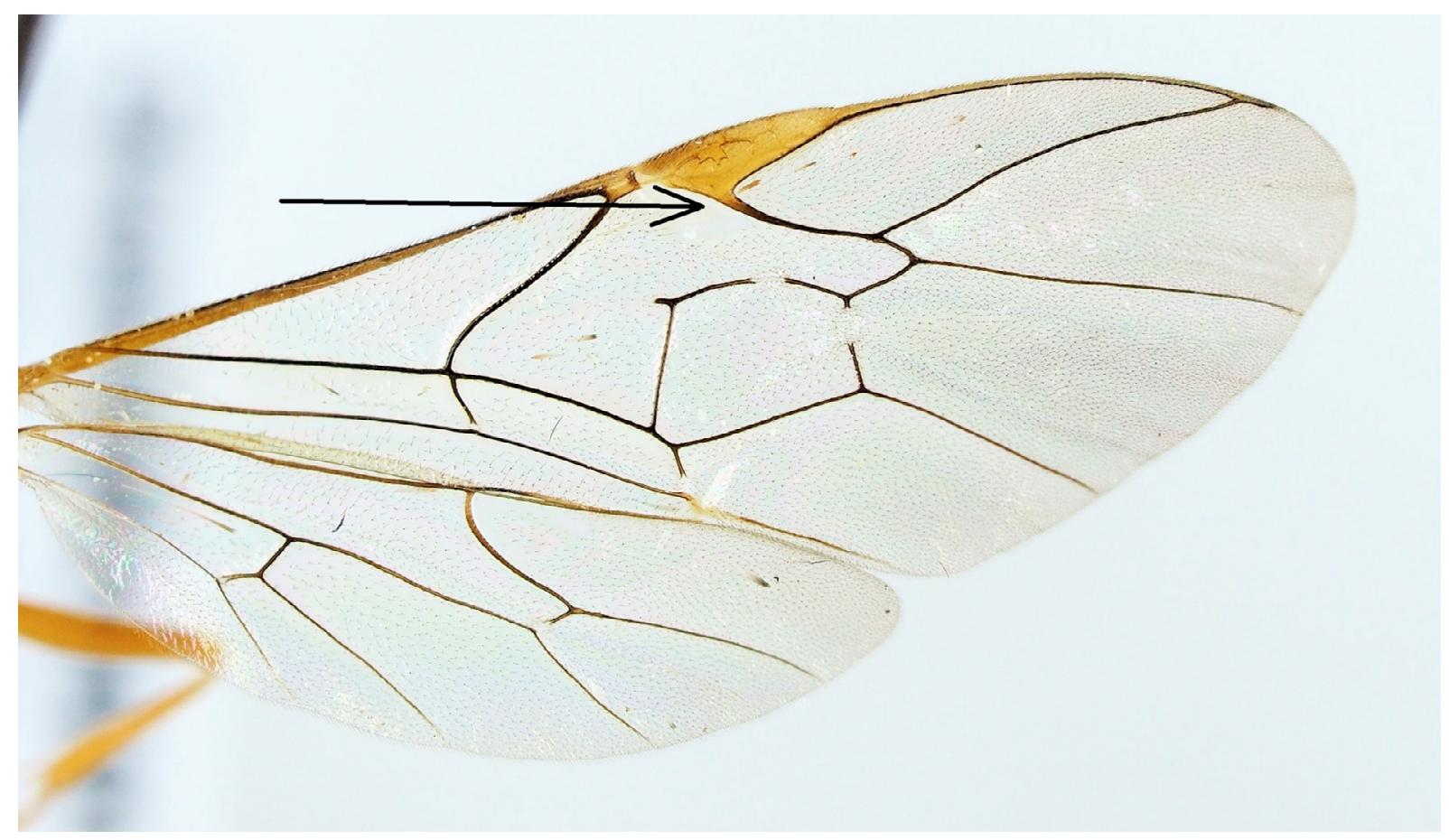

Fig. 12. Right wings: Ophion minutus Kriechbaumer, 1879, female. Junction between $R s+2 r$ and pterostigma arrowed. 
or dark brown, contrasting distinctly in colour with the more testaceous posterior segments of metasoma

9. Fore wing with radius evenly curved (Fig. 13A); posterior transverse carina of propodeum often complete, sometimes narrowly interrupted in the middle (Fig. 10B); head with lateral ocellus touching eye; hind trochantellus short, in dorsal view almost obscured by trochanter (Fig. 7G); antenna frequently with fewer than 50 flagellomeres

- Fore wing with radius sinuous (Fig. 13C); posterior transverse carina of propodeum usually widely interrupted in the middle; hind trochantellus usually longer in dorsal view (Fig. 7E-F); antenna rarely with fewer than 50 flagellomeres

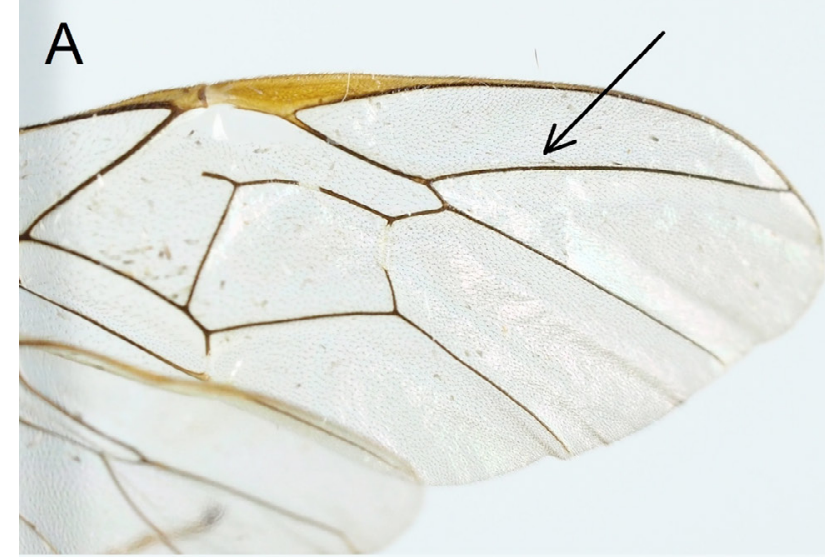

B
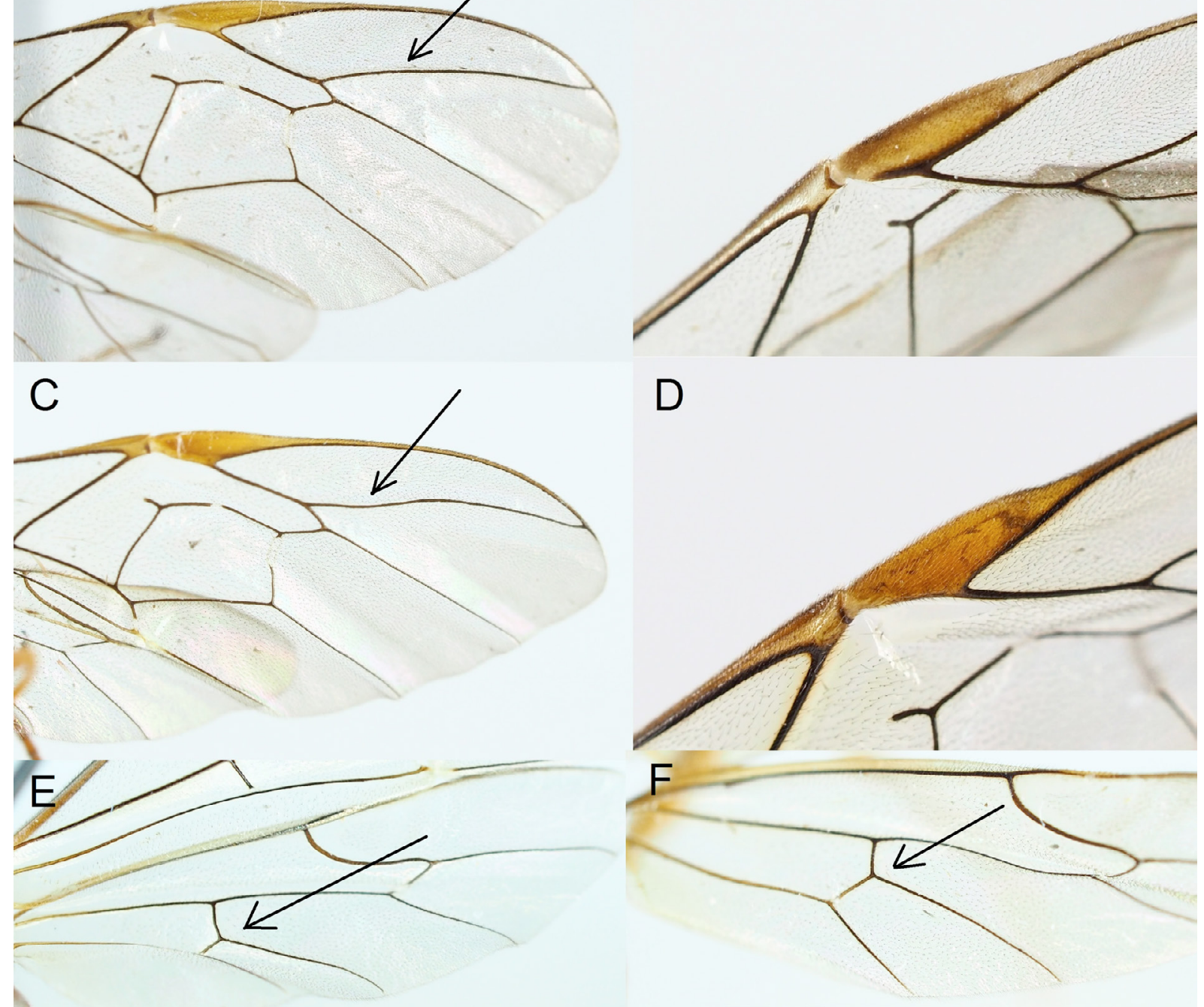

$\mathrm{D}$

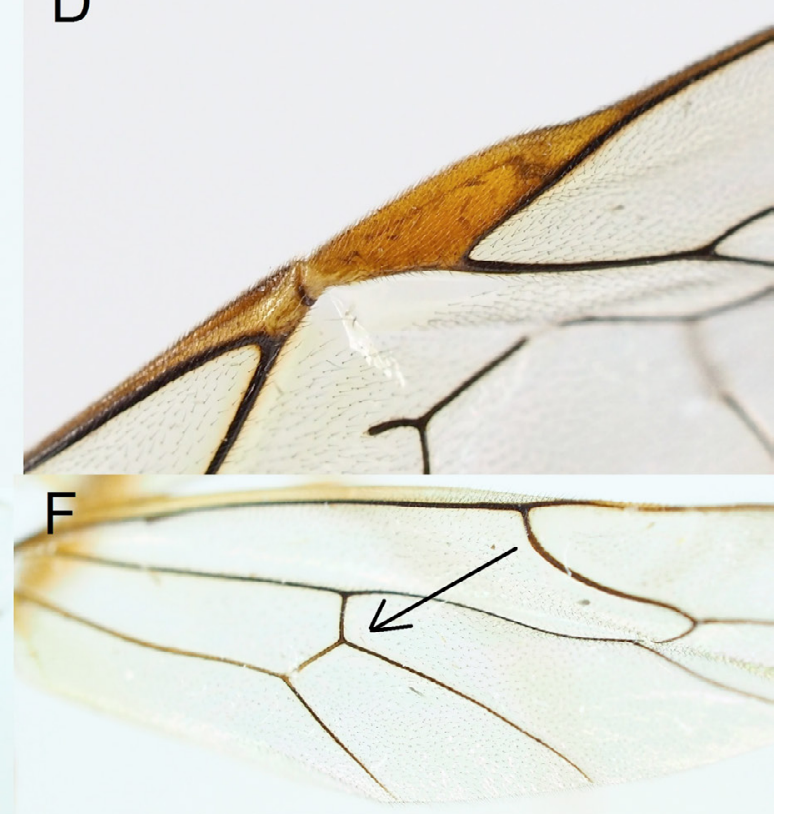

Fig. 13. A. Right fore wing Ophion tenuicornis Johansson sp. nov., paratype, $q$ (NHRS-HEVA000008743), the evenly curved radius arrowed. B. Pterostigma $O$. autumnalis Johansson sp. nov., holotype, $q$ (NHRS-HEVA000008620). C. Right fore wing O. inclinans Johansson sp. nov., holotype, o (NHRSHEVA000008667), the sinous radius arrowed. D. Pterostigma $O$. kevoensis Jussila, 1965. E-F. Hind wing nervellus, interception of discoidella arrowed. E. O. brocki Johansson sp. nov., paratype, $q$ (NHRSHEVA000008633). F. O. splendens Johansson sp. nov., paratype, $q$ (NHRS-HEVA000008708). 


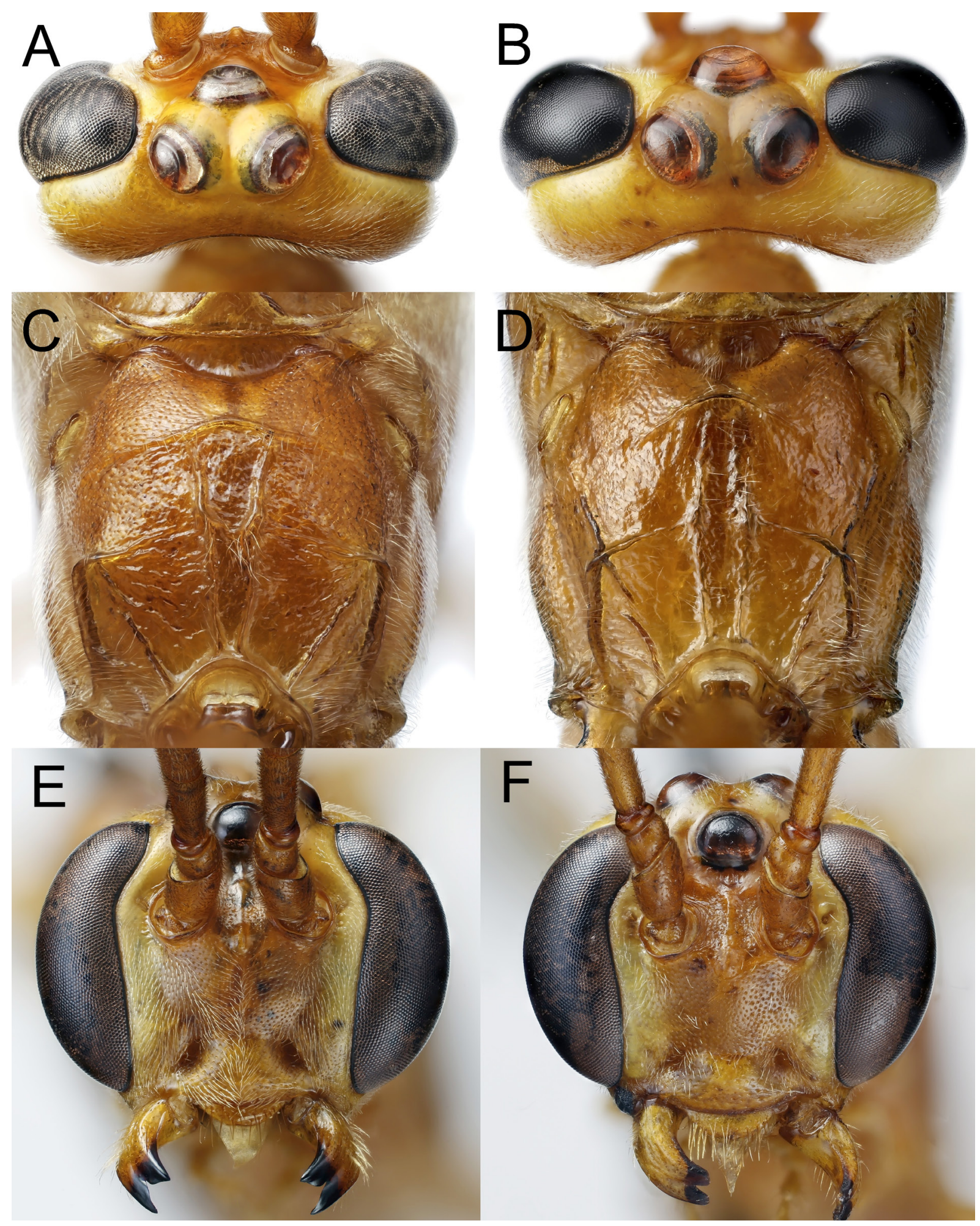

Fig. 14. A-B. Head, dorsal view of female. A. Ophion luteus (Linnaeus, 1758). B. O. slaviceki Kriechbaumer, 1892. C-D. Propodeum, posterodorsal view. C. O. borealis Johansson sp. nov., holotype, (NHRS-HEVA000008627). D. O. crassicornis Brock, 1982. E-F. Head, anterior view of female. E. O. borealis Johansson sp. nov., holotype, + (NHRS-HEVA000008627). F. O. crassicornis Brock, 1982. 

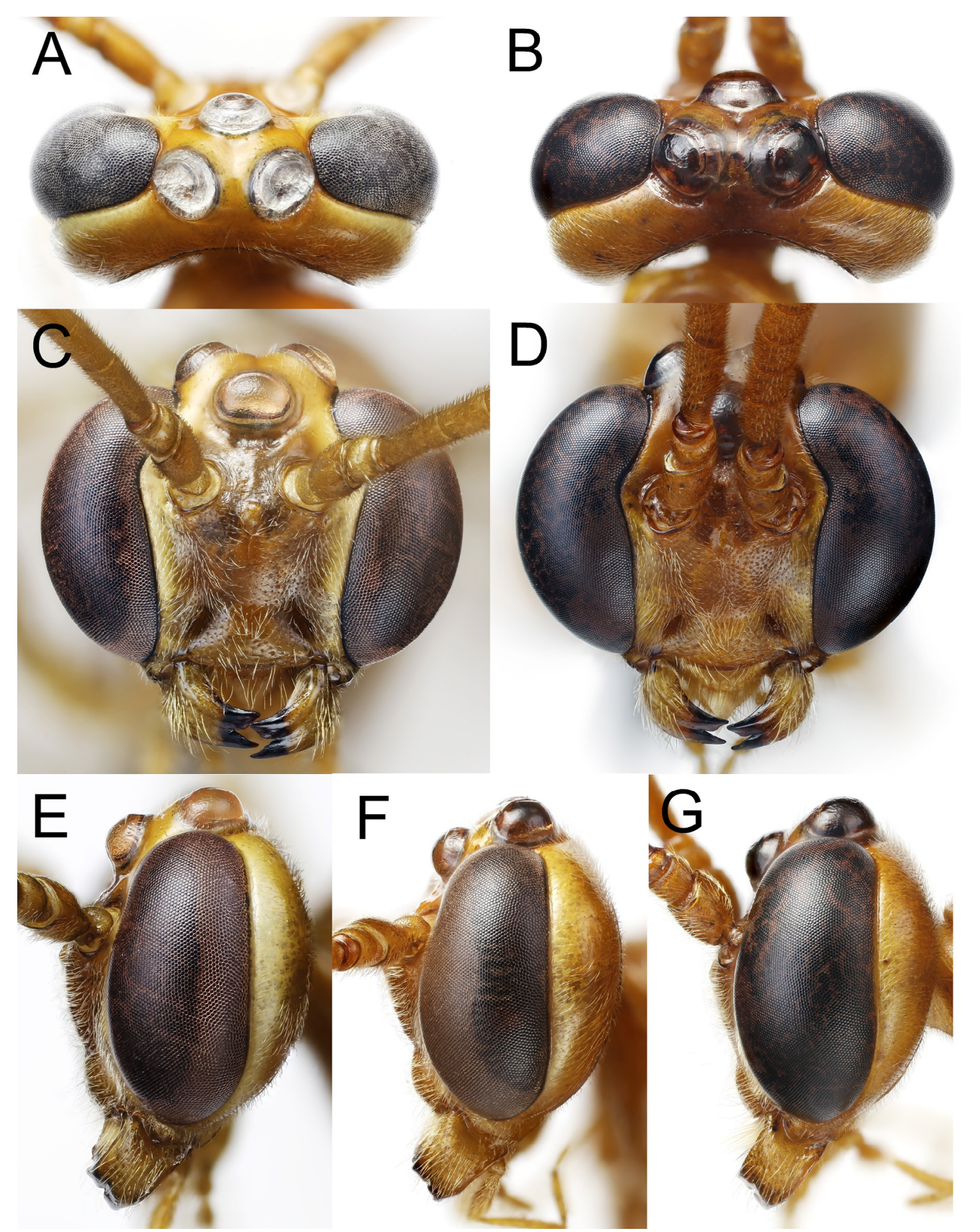

Fig. 15. A-B. Head, dorsal view of female. A. Ophion splendens Johansson sp. nov., paratype, $q$ (NHRS-HEVA000008708). B. O. brocki Johansson sp. nov., paratype, q (NHRS-HEVA000008633). C-D. Head anterior view of female. C. O. mocsaryi Brauns, 1889. D. O. brocki Johansson sp. nov., paratype, + (NHRS-HEVA000008633). E-G. Head, lateral view of female. E. O. mocsaryi Brauns, 1889. F. O. mocsaryi Brauns, 1889, var. G. O. brocki Johansson sp. nov., paratype, $ᄋ$ (NHRSHEVA000008633). 
10. Antenna very narrow; flagellomeres 2-4 strongly elongate, about 3.5-4.0 times as long as wide; subapical flagellomeres about 2.5-3.0 times as long as wide, in females with long prominent pilosity (Fig. 8C); anterior transverse carina of propodeum strongly raised and evenly curved (Fig. 10L); head in female in lateral view with temples short (as in Fig. 19F). Active in late summer/autumn in Sweden O. tenuicornis Johansson sp. nov.

- Antenna stouter; subapical flagellomeres, at most 2.0 times as long as wide (Fig. 8A-B); head in female in lateral view with temples usually slightly longer (as in Fig. 19D).....

11. Hind tarsal segments stout, fourth segment usually about 2.0 times as long as wide, fifth segment slightly longer than fourth (Fig. $8 \mathrm{H}$ ); mid-tarsus with fourth segment stout, 0.6 times as long as fifth segment; apical flagellomeres in females usually with long prominent pilosity (as in Fig. 8B); posterior transverse carina of propodeum strong; indicated area superomedia often with a central longitudinal fold (Figs 10B, 47A-B). Usually a large and stout species (fore wing length 18-19 mm) with slightly infuscate areas on mesosoma and weakly yellowish wing membrane. A late summer/ autumnal species in Sweden

O. costatus Ratzeburg, 1848

- Hind tarsus slender and elongate; fourth segment about 3.0 times as long as wide; fifth segment as long as fourth (Fig. 8G); mid-tarsus with fourth segment more slender 0.8-0.9 times as long as fifth segment; posterior transverse carina of propodeum sometimes reduced centrally. Usually smaller species with transparent wing membrane. Two early summer/summer species in Sweden

12. Flagellomere 30 onwards elongate, about 1.8-1.9 times as long as wide (Fig. 8B); posterior transverse carina of propodeum usually widely interrupted or weak centrally; head in lateral view with temple about 0.3 times as long as compound eye (as in Fig. 19F) ........ O. paraparvulus Johansson sp. nov.

- Flagellomere 30 onwards at most 1.5 times as long as wide, with short pilosity (Fig. 8A); posterior transverse carina of propodeum usually complete or only narrowly interrupted centrally; head in lateral view with temple about $0.4-0.5$ times as long as compound eye in lateral view (as in Fig. 19D) O. parvulus Kriechbaumer, 1879

13. Hind trochantellus as long as, or slightly longer than wide in dorsal view (Fig. 7E); mandibular gape more or less acute; internal angles weak or absent (Fig. 7I), teeth often worn, obtuse; mesosoma rarely in Swedish specimens with pale markings (Note that specimens of Ophion luteus frequently occurs with mandibles with distinct internal angles. These specimens may run out as Ophion kevoensis but has the temples more buccate and is active earlier in the season) 14

- Hind trochantellus shorter than wide in dorsal view (Fig. 7F-G); mandibular gape right-angled, with internal angles (Fig. 7H); mesosoma and often also metasoma in the most common species with conspicous pale markings (Fig. 11A-B) 15

14. Smaller species (fore wing $12-15 \mathrm{~mm}$ ); head with ocelli small and distinct gap between lateral ocellus and eye of about $0.4-0.5$ times the diameter of ocellus; temple in female buccate with distinct space between compound eye and lateral ocellus (Fig. 14A); male usually with temples testaceous. A rather rare but widespread spring/early summer species O. luteus (Linnaeus, 1758)

- Larger species (fore wing 14-17 mm); head with ocelli large and usually touching or almost touching inner margin of compound eye; temple in female slightly shorter (Fig. 14B); male usually with temples more or less yellow. A common species in open or semi-open localities in Southern Sweden during late summer O. slaviceki Kriechbaumer, 1892 stat. rev.

15. Mesosoma with extensive pale markings (Fig. 11A-B); temple in lateral view quite buccate in both sexes; face in females wide, about 2.0 times the width of compound eye in anterior view (Fig. 17A) ........ 16

- Mesosoma without pale markings; head often narrowed behind eyes but sometimes strongly buccate (Fig. 18B) 
16. Larger species (fore wing 16-18 mm); antenna with more than 60 flagellomeres; central flagellomeres in males 1.3-1.5 times as long as wide (Fig. $7 \mathrm{~N}$ ); occipital carina joining hypostomal carina at an angle of 45 degrees (Fig. 7L); scutellum usually wider posteriorly. Active during late autumn in Southern Sweden Ophion obscuratus Fabricius, 1798.

- Smaller species (fore wing 14-16 mm); antenna usually with 60 or fewer flagellomeres; central flagellomeres in males 1.5-1.6 times as long as wide (Fig. 7O); occipital carina joining hypostomal carina at an angle of 80-90 degrees (Fig. 7M); scutellum usually more narrowed posteriorly. Active during early summer Ophion variegatus Rudow, 1883 stat. rev.

17. Temple strongly bucccate with distinct gap between lateral ocellus and compound eye of 0.5-0.7 the diameter of ocellus (Fig. 18B); malar space long (Fig. 18D); mesopleuron between punctures shagreened, irregularly wrinkled; mesosoma more brownish, contrasting in colour with the more testaceous metasoma (Fig. 42). A very rare species in the subalpine areas of central Sweden

O. subarcticus Hellén, 1926

- Temple narrowed behind eyes; gap between lateral ocellus and compound eye at most 0.3 times the diameter of ocellus; malar space short; mesopleuron between punctures often polished, smooth; mesosoma testaceous or brownish, concolourous with metasoma

18. Antenna with 50 or fewer flagellomeres; second flagellomere 3.0 times as long as wide; hind trochantellus short (Fig. 7G); pleurosternal angles slightly protuding and acute (Fig. 9I); anterior transverse carina of propodeum evenly curved (as in Fig. 10L). Note that the male of this species always seems to have the radius evenly curved while it is weakly sinuate in the female O. kallanderi Johansson sp. nov.

- Antenna with more than 52 flagellomeres; second flagellomere 1.5-2.0 times as long as wide; hind trochantellus usually longer (Fig. 7F); pleurosternal angles obtuse or right angled; anterior transverse carina of propodeum slightly angled (as in Fig. 10A)

19. Head of female in anterior view with face narrow (Figs 16F, 17B)

- Head of female in anterior view with face wide (Figs 16E, 17A)

20. Ovipositor sheath black or dark brown, contrasting in colour with apical metasomal segments; smaller species (fore wing 13-14 mm)

O. sylvestris Johansson sp. nov.

- Ovipositor sheath testaceous, concolourous with apical metasomal segments; larger species (fore wing $15-17 \mathrm{~mm}$ )

O. broadi Johansson sp. nov.

21. Usually a larger species (fore wing $15-17 \mathrm{~mm}$ ); pterostigma evenly testaceous (Fig. 13D); wing membrane sometimes yellowish; male with malar space long (Fig. 21E); scutellum testaceous, concolourous with mesoscutum. Locally abundant in subalpine forest areas, very rare or absent in Central Sweden

O. kevoensis Jussila, 1965

- Usually a smaller species (fore wing $13-15 \mathrm{~mm}$ ); pterostigma brownish, posteriorly and apically distinctly pale (Fig. 13B); male with malar space shorter (as in Fig. 21F); scutellum distinctly paler than mesoscutum. In heathlands of Southern Sweden O. autumnalis Johansson sp. nov.

22. Temple buccate, behind eye in lateral view almost as wide as compound eye and usually with distinct gap between ocellus and eye (Fig. 30B)

- Temple not buccate, behind eye in lateral view distinctly narrower than compound eye; ocellus touching or nearly touching compound eye (Fig. 15A-B)

23. Epicnemial carina, in antero-ventral view, with pleurosternal angles acute and almost level with sternal angles (Fig. 9F); mesopleuron densely punctate with distinct microsculpture; face below 

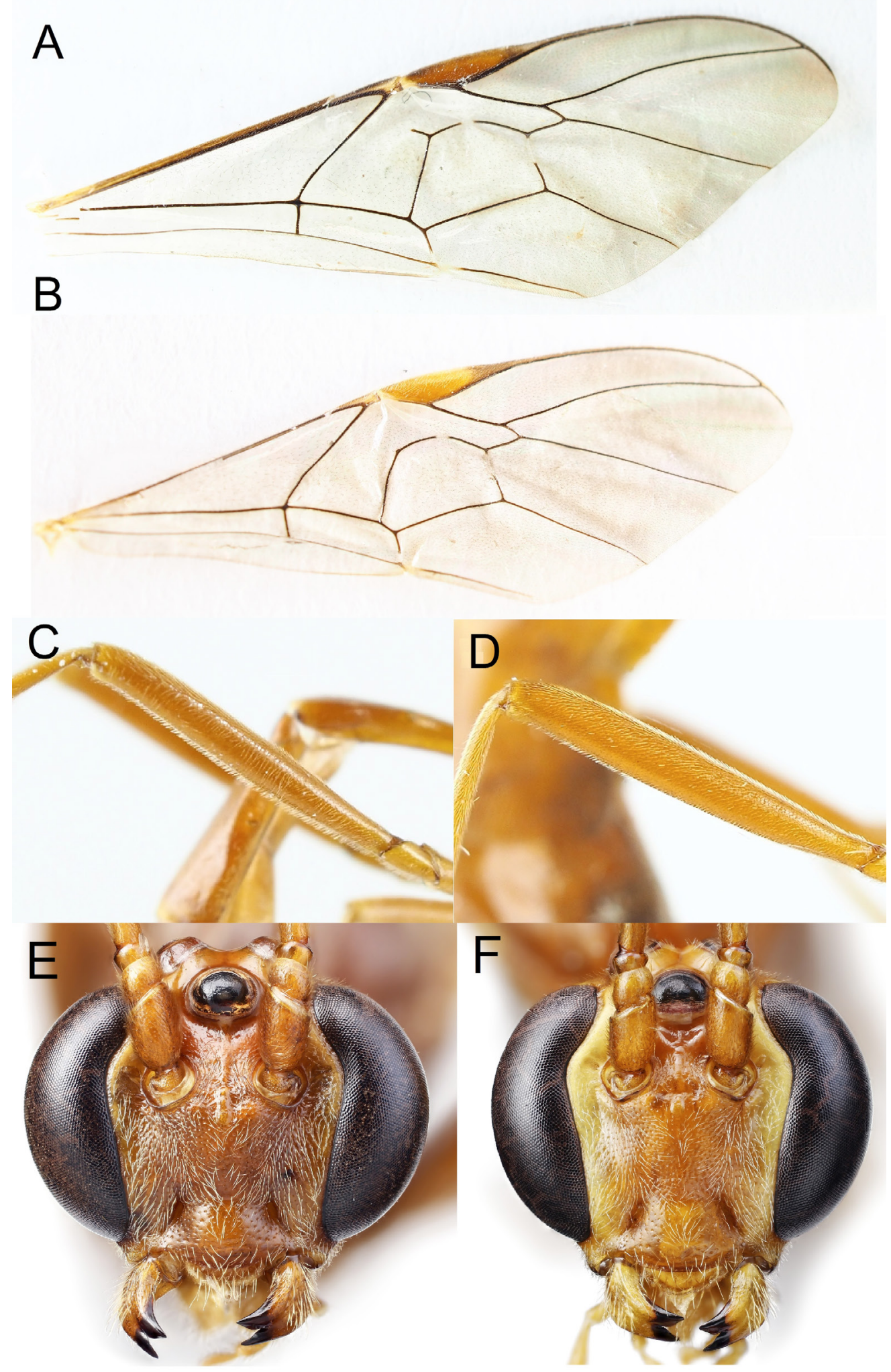

Fig. 16. A-B. Right fore wing. A. Ophion scutellaris Thomson, 1888. B. O. wuestneii Kriechbaumer, 1882. C-D. Right hind femur of female, lateral view. C. O. wuestneii. D. O. inclinans Johansson sp. nov., holotype, o (NHRS-HEVA000008667). E-F. Head, anterior view of female. E. Ophion kevoensis Jussila, 1965. F. Ophion broadi Johansson sp. nov. paratype, $q$ (NHRS-HEVA000008950). 

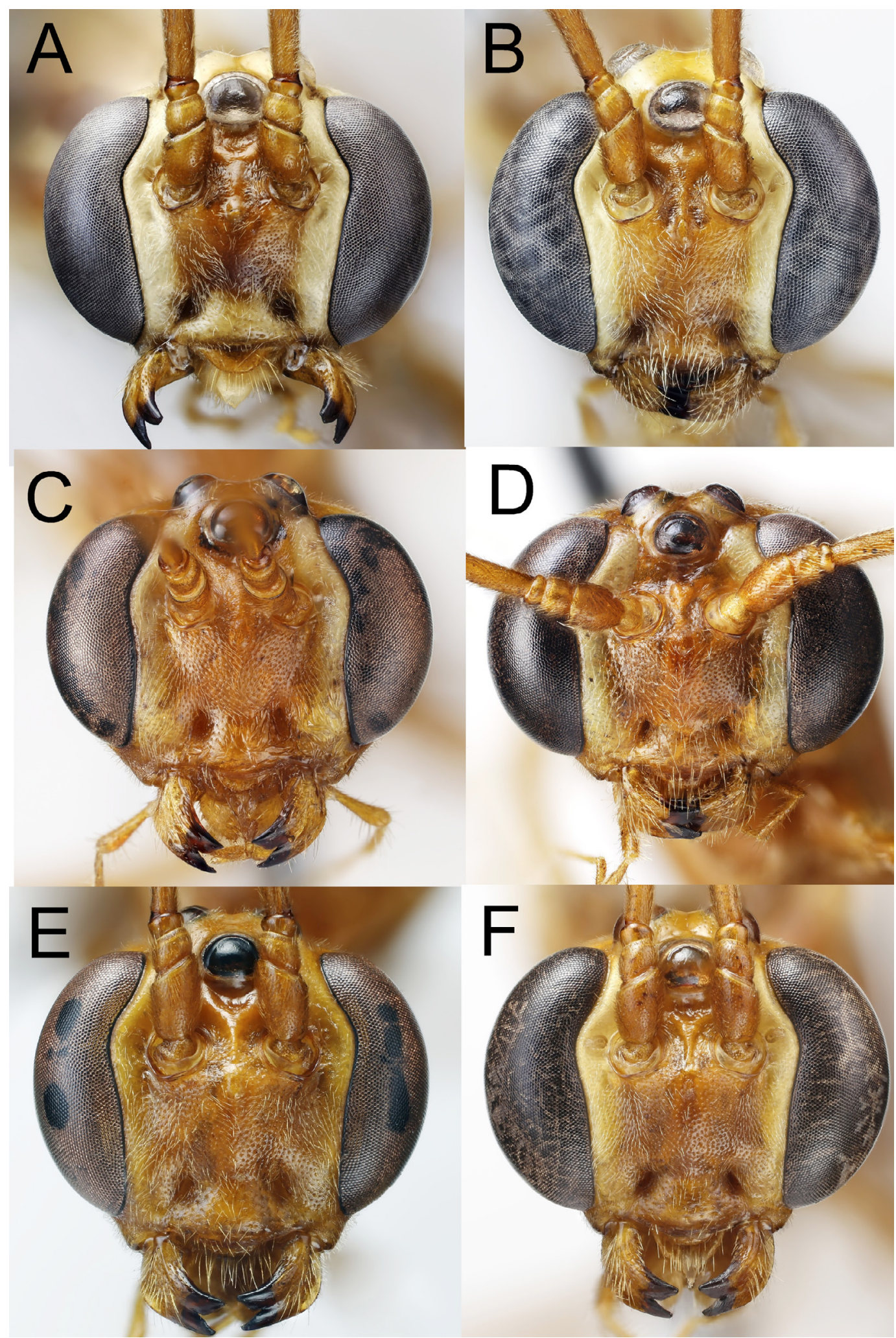

Fig. 17. Head, anterior view. A. Ophion variegatus Rudow, 1883, female. B. O. sylvestris Johansson sp. nov., paratype, o (NHRS-HEVA000008721). C. O. perkinsi Brock, 1982, ô. D. O. norei Johansson sp. nov., paratype, ${ }^{\lambda}$ (NHRS-HEVA000008687). E. O. perkinsi, ‥ F. O. norei Johansson sp. nov., paratype, + (NHRS-HEVA000008691). 


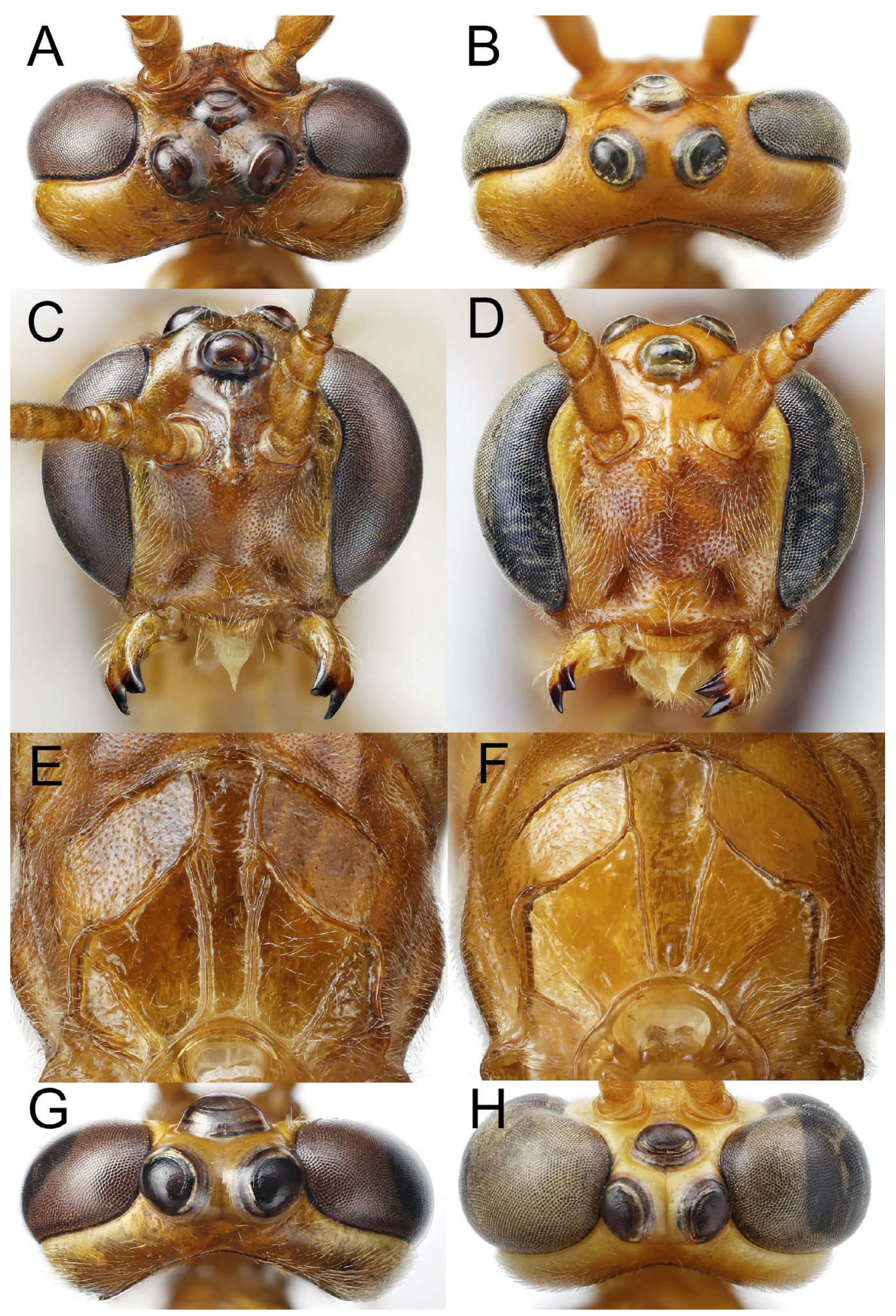

Fig. 18. A-B. Head, dorsal view of female. A. Ophion brevicornis Morley, 1915. B. O. subarcticus Hellén, 1926. C-D. Head anterior view of female. C. O. brevicornis. D. O. subarcticus. E-F. Propodeum posterodorsal view of female. E. O. matti Johansson sp. nov., paratype, + (NHRS-HEVA000008679). F. O. ellenae Johansson sp. nov., paratype, $q$ (NHRS-HEVA000008655). G-H. Head in dorsal view of Ophion pteridis Kriechbaumer, 1879. G. Female. H. Male. 


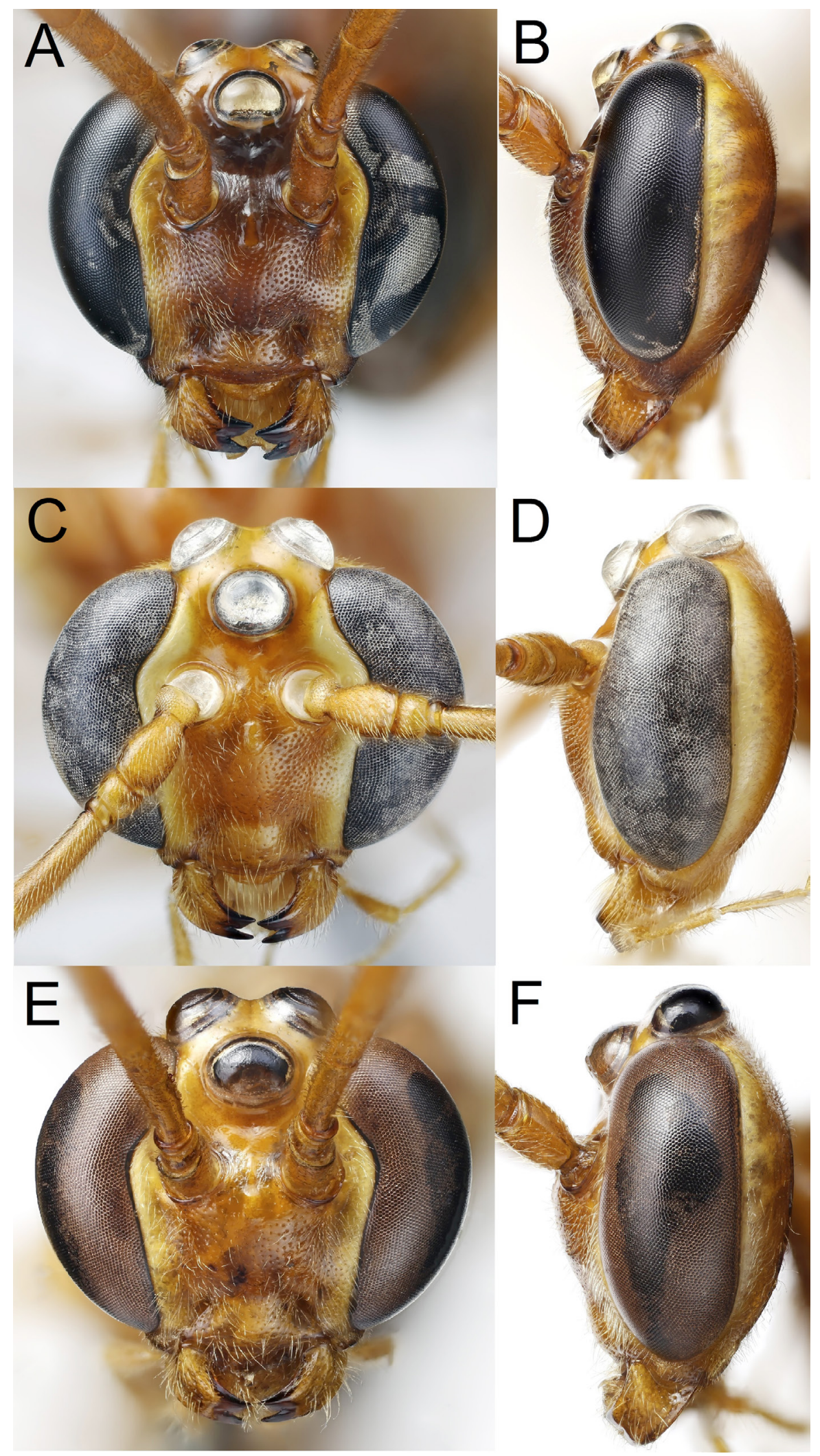

Fig. 19. Head in anterior and lateral view of female. A-B. Ophion vardali Johansson sp. nov., paratype, $q$ (NHRS-HEVA000008748). C-D. O. inclinans Johansson sp. nov., holotype, $q$ (NHRSHEVA000008667). E-F. O. pteridis Kriechbaumer, 1879. 

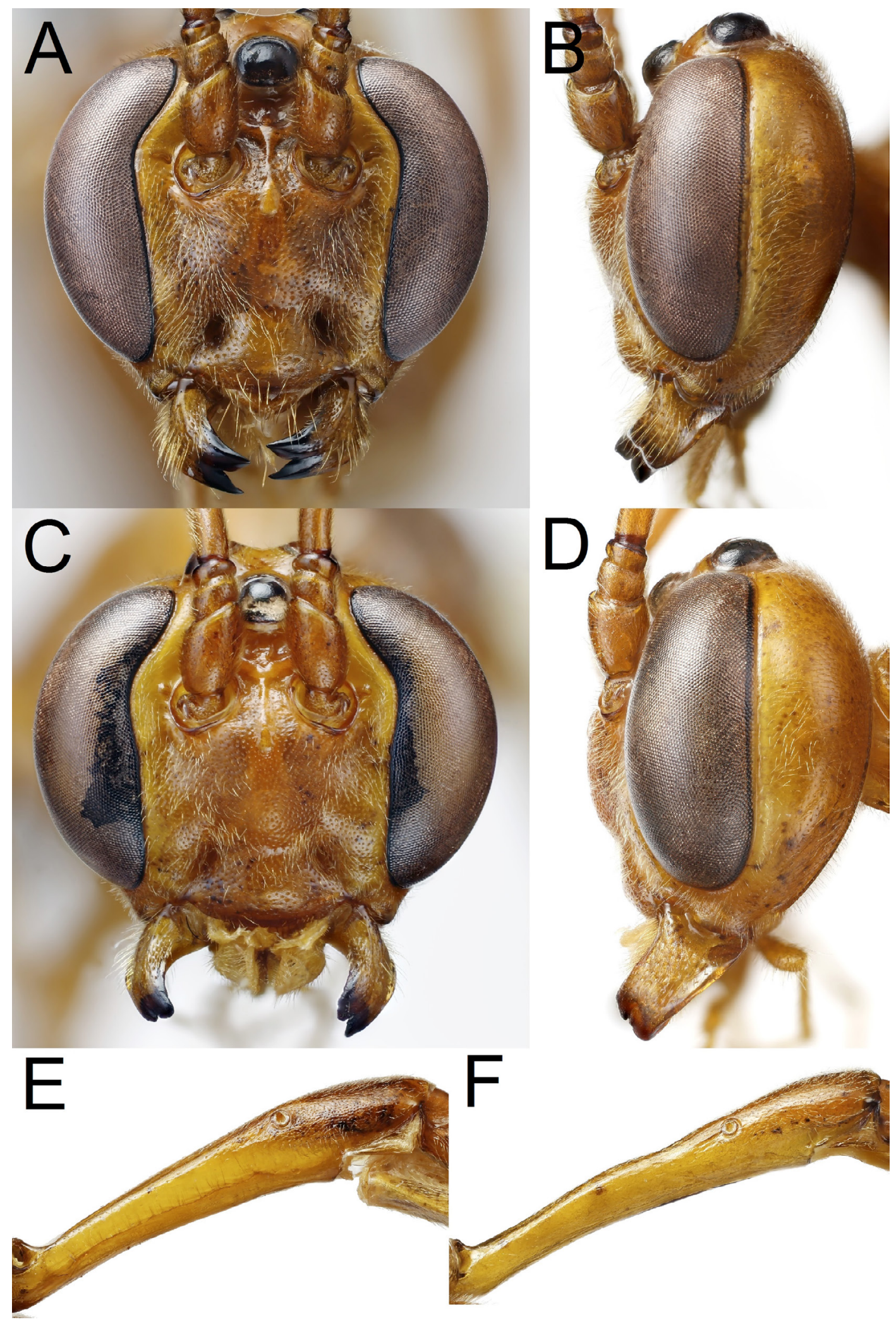

Fig. 20. A-D. Head in anterior and lateral view of female. A-B. O. paukkuneni Johansson sp. nov., holotype, $q$ (NHRS-HEVA000008701). C-D. O. longigena Thomson, 1888. E-F. First tergite in lateral view of female. E. O. norei Johansson sp. nov., paratype, + (NHRS-HEVA000008691). F. O. perkinsi Brock, 1982. 


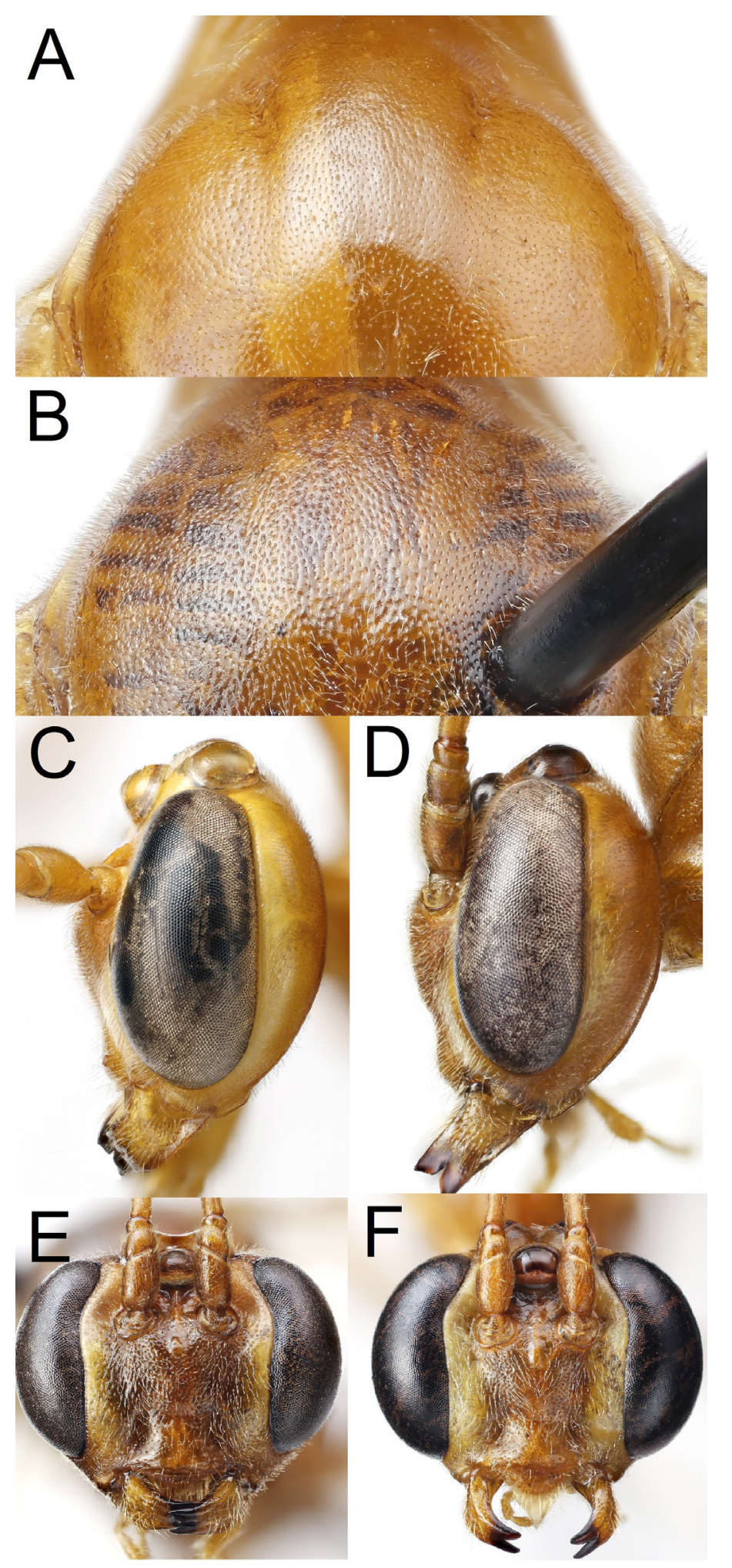

Fig. 21. A-B. Mesoscutum, anterior part of female, dorsal view. A. Ophion ellenae Johansson sp. nov., paratype, + (MZLU 6370:1). B. O. matti Johansson sp. nov., paratype, ㅇ (NHRS-HEVA000008679). C-D. Head of female, lateral view. C. O. ellenae Johansson sp. nov., paratype + (MZLU 6370:1). D. O. perkinsi Brock, 1982. E-F. Head of male, anterior view. E. O. kevoensis Jussila, 1965. F. O. slaviceki Kriechbaumer, 1892. 
antennal sockets densely punctate (as in Fig. 8I); antenna with 59 or more flagellomeres

o. angularis Johansson \& Cederberg sp. nov.

- Epicnemial carina, in antero-ventral view, with pleurosternal angles slightly anterior to sternal angles (Fig. 9A-B, G); pleurosternal angles obtuse, right angled or weakly acute; antenna frequently with fewer than 59 flagellomeres

24. Head slightly narrower in frontal view; clypeus wider; the distance between the upper end of the tentorial pits and compound eye about 0.5 times the distance between the pits (Fig. 14F); face with denser and larger punctures (as in Fig. 8I); mesopleuron usually slightly wrinkled, punctures larger; anterior transverse carina of propodeum strongly curved (Fig. 14D) ... O. crassicornis Brock, 1982

- Head slightly wider in frontal view; clypeus more narrow; the distance between the upper end of the tentorial pits and compound eye equal to the distance between the pits (Fig. 14E); face with smaller and sparserpunctures (as in Fig. 8J); mesopleuron with smaller punctures and without any obvious wrinkles; anterior transverse carina of propodeum more straight (Fig. 14C) ....O. borealis Johansson sp. nov.

25. Propodeum in females (less so in males) usually with carination complete, with anterior transverse carina distinct centrally and laterally; lateral longitudinal carinae usually distinct (Fig. 10C); surface between transverse carinae of propodeum often polished with irregular punctures; groove behind posterior ocellus deep and long, often diverging from the hind margin of ocellus (Fig. 15B); head of female in anterior and lateral view usually with compound eyes on average wide (Fig. 15D, G); occipital carina centrally evenly rounded (as in Fig. 7A); number of flagellomeres 59-64; nervellus broken distinctly below the middle (Fig. 13E)

o. brocki Johansson sp. nov.

- Propodeum with dorsal carinae usually partly incomplete, anterior transverse carina always absent laterally, very rarely with lateral longitudinal carinae; surface between transverse carinae of propodeum often dull, shagreened; groove behind posterior ocellus shallower, following hind margin of ocellus (Fig. 15A); head in female in anterior and lateral view with compound eyes on average less wide (at most as in Fig. 15C, E); frequently with head strongly transverse and face much wider; number of flagellomeres usually fewer than 59; if number of flagellomeres is in the range of 59-62, then nervellus broken at or above the middle

26. Larger species (fore wing 15-17 mm); epicnemial carina between tip of pleurosternal angles and sternal angles weakly concave, almost straight (Fig. 9A); pleurosternal angles obtuse; mesopleuron polished with very sparse and weak punctures; number of flagellomeres 59-63; nervellus broken at or above the middle (Fig. 13F). Mainly Southern Sweden

O. splendens Johansson sp. nov.

- Smaller species (fore wing 13-15 mm); epicnemial carina between tip of pleurosternal angles and sternal angles usually distinctly concave (Fig. 9B, G); pleurosternal angles acute or right-angled; mesopleuron frequently shagreened and with dense punctures; nervellus broken distinctly below the middle; number of flagellomeres fewer than 59. Two very similar species

27. Occipital carina in most cases centrally evenly rounded, straight or with central depression (Fig. 7A), face below antennal sockets more often strongly shagreened with quite dense deep punctures (Fig. 8I); longitudinal carinae delimiting area superomedia often weak or missing anteriorly; area superomedia more often elongate; anterior transverse carina more often almost complete or indicated laterally; propodeum dorsally less shining with coarser structure; basal flagellomeres usually stouter, $1.4-1.5$ times as long as wide (as in Fig. 8N)

O. confusus Johansson sp. nov.

- Occipital carina often centrally angled (Fig. 7B), sometimes with a small central arc; face below antennal sockets weakly shagreened or polished with scarce, shallower punctures (Fig. 8J); longitudinal carinae delimiting area superomedia often strong throughout their entire length; area superomedia more often as long as wide; anterior transverse carina usually absent laterally, only 
distinct adjacent to area superomedia; propodeum dorsally more shining; basal flagellomeres usually more elongate, 1.7-1.8 times as long as wide (as in Fig. 8O)

O. mocsaryi Brauns, 1889

28. Sclerotised section of first sternite ending posterior to spiracle at a distance about three times the distance between the spiracle and the lower margin of the first tergite (Fig. 6F); propodeum and face polished with very deep and large punctures (Fig. 31B); pleurosternal angles very weakly defined (Fig. 9C); scutellum with lateral carinae along its entire length (Fig. 6D); malar space in male very wide, about 0.8 times as wide as mandibular base. A very rare species only known from two localities in the eastern part of Central Sweden

O. dispar Brauns, 1895

- Sclerotised section of first sternite ending posterior to spiracle at a distance at most equal to the distance between the spiracle and the lower margin of the first tergite (Fig. 6E)

29. Mesopleuron and the entire propodeum infuscate (Figs 40, 45A-B, 52A, E); first tergite usually with median dorsal undulation (as in Fig. 6E) 30

- Mesosoma usually entirely testaceous, if infuscate areas are present they do not cover the above stated areas; first tergite with or without median dorsal undulation 31

30. Temple in lateral view about 0.8 times as long as compound eye (Fig. 19B); malar space long, about 0.4 times as long as mandibular base in female and about 0.4-0.5 times in male; head in anterior view with compound eyes narrow and face wide (Fig. 19A); hind coxa and mesosternum largely infuscate (Fig. 45A-B)

O. vardali Johansson sp. nov.

- Temple strongly narrowed behind eyes, about 0.3 times as long as compound eye (Figs 19F, 52D-E), malar space short, about $0.1-0.2$ times as long as mandibular base in female and about 0.2 times in male; ocellus large, lateral ocelli partly covering compound eye in dorsal view (Fig. 18G-H); head in anterior view with compound eye wide and face narrow (Fig. 19E); hind coxa and mesosternum usually entirely testaceous (Figs 40, 52E)

O. pteridis Kriechbaumer, 1879

31. Hind femur very slender, at least 8.0 times longer than wide (Fig. 16C); the longest spur of hind tibia distinctly shorter than 0.5 times as long as first hind tarsal segment (two early spring species) $\quad$... 32

- Hind femur less slender, at most 7.0 times longer than wide (Fig. 16D); the longest spur of hind tibia about 0.5 times as long as first hind tarsal segment (species active during summer or autumn) ... 33

32. Larger species (fore wing 15-19 mm); pterostigma narrow, about 3.5-4.0 times longer than wide; ramellus distinct (Fig. 16A); antenna with 60 or more flagellomeres, central flagellomeres about 2.0 times as long as wide; face narrower

O. scutellaris Thomson, 1888

- Smaller species (fore wing 12-13 mm); pterostigma stouter, about 2.5-3.0 times longer than wide; ramellus short or absent (Fig. 16B); antenna with 55-60 flagellomeres, usually 56-57; central flagellomeres 1.5 times as long as wide; face wider

O. wuestneii Kriechbaumer, 1892

33. Subapical flagellomeres narrow and long, distinctly more than 2.0 times as long as wide (Fig. $8 \mathrm{~F}$ ); central flagellomeres about 2.0 times as long as wide; first tergite in lateral view with slight or distinct median undulation (Fig. 6E); pleurosternal angles distinctly anterior to sternal angles; pleurosternal angles obtuse (as in Fig. 9E); temple behind eyes quite narrow and lateral ocellus touching compound eye (Fig. 19C-D)

O. inclinans Johansson sp. nov.

- Subapical flagellomeres stout, at most 2.0 times as long as wide (Fig. 8D-E); central flagellomeres about 1.3-1.5 times as long as wide; temple behind eyes narrow with ocellus touching compound eye or buccate with distinct gap between lateral ocellus and compound eye

34. Head very strongly buccate, in lateral view head behind eyes at least as wide as compound eye (Fig. 20D); face in anterior view usually wide (Fig. 20C); female usually with posterior segments of metasoma often more or less infuscate (Fig. 35A); sclerotised section of first sternite ending 
level or slightly posterior to spiracle (Fig. 6G-H); mandibles usually worn due to parasitising Cucullia-species pupating under ground. A rare species in semi-open areas in Southern Sweden O. longigena Thomson, 1888

- Head less buccate or narrowed behind eyes, in lateral view usually narrower than compound eye; female with posterior segments of metasoma at most slightly infuscate ventrally; sclerotised section of first sternite ending slightly or distinctly posterior to spiracle (Fig. 6E, G); mandibles never worn

35. Smaller species (fore wing 12-14 (15) $\mathrm{mm}$ ); antenna with 50 or fewer flagellomeres; central flagellomeres square (as in Fig. 8M); anterior transverse carina of propodeum absent or weak laterally; temple buccate in lateral view (Fig. 21D) and head with distinct gap between eye and lateral ocellus

- Larger species (fore wing 14-16 mm); central flagellomeres elongate, if rarely as long as wide, then antenna with 52 or more flagellomeres; anterior transverse carina of propodeum usually complete

36. Face in anterior view with face wider in relation to compound eyes; head more rounded; malar space long, 0.4 times as wide as mandibular base in female and about 0.7 times in male (Fig. 17C, E); first tergite more elongate in lateral view, with median dorsal undulation (Fig. 20F); mesopleuron and metapleuron in Swedish specimens with distinct microsculpture between punctures; area superomedia more often elongate, about 1.3-1.5 times as long as wide. A rare species possibly connected to deciduous forests

O. perkinsi Brock, 1982

- Face in anterior view with face narrower in relation to compound eyes; head more transverse; malar space short in both sexes, at most 0.2 times as wide as mandibular base (Fig. 17D-F); first tergite stouter in lateral view, without dorsal median undulation (Fig. 20E); mesopleuron and metapleuron without distinct microsculpture between punctures; area superomedia more often as long as wide. A rare species mostly known from semi-open xerothermic habitats the southern provinces

O. norei Johansson sp. nov.

37. Temple strongly buccate, just slightly shorter than compound eye in lateral view (Fig. 20B): head with distinct gap between eye and lateral ocellus; propodeum distinctly punctate between the transverse carinae; first tergite often with more or less distinct dorsal undulation (as in Fig. 6E); antenna with 50-53 flagellomeres

O. paukkuneni Johansson sp. nov.

- Temple more narrowed behind eye, distinctly shorter than compound eye in lateral view: head rarely with gap between lateral ocellus and compound eye; antenna usually with more than 54 flagellomeres 38

38. Ramellus usually entirely absent (as in Fig. 16B), sometimes indicated by a small denticle; mesopleuron centrally distinctly depressed, the depression centrally with irregular wrinkles (Fig. 24B); sclerotised section of first sternite ending slightly posterior to spiracle, the distance at most equal to 0.5 times the distance between spiracle and ventral margin of first sternite, usually shorter (Fig. 6G); face below antennal sockets with dense punctures without interstices; antenna with 55-59 flagellomeres; nervellus broken distinctly above the middle. Rare, only known from Gotland (the Baltic Sea), Skåne and Blekinge (older records) and Kosteröarna (islands on the west coast of Sweden), probably slightly more common on Gotland O. artemisiae Boie, 1855

- Ramellus distinct, reaching at least 0.2 times the width of the discosubmarginal cell; mesopleuron centrally only slightly depressed, the structure of the depression centrally without irregular wrinkles; sclerotised section of first sternite ending distinctly posterior to spiracle, the distance equal to the distance between spiracle and ventral margin of first sternite (as in Fig. 6E); antenna with 50-56 flagellomeres; nervellus broken slightly above or below the middle 39 
39. Pleurosternal angles right-angled or obtuse, distinctly anterior to sternal angles (as in Fig. 9E); subapical flagellomeres more elongate, about 1.8-1.9 times as long as wide (Fig. 8E); scutellum narrow; carination of propodeum indistinct with anterior transverse carina weaker laterally and central longitudinal carinae delimiting area superomedia weak or absent (some specimens of $O$. kevoensis might run out here, for separation of species see diagnosis) ............ O. arenarius Johansson sp. nov.

- Epicnemial carina, in antero-ventral view, with pleurosternal angles slightly anterior to sternal angles (in females, less so in males); pleurosternal angles acute or right-angled, rarely obtuse (as in Fig. 9G); subapical flagellomeres stouter, about 1.5 times as long as wide (as in Fig. 8D); scutellum wider; carination of propodeum with anterior transverse carina raised laterally and longitudinal carinae delimiting area superomedia distinct 40

40. Mesoscutum more shining with more irregular and weak punctures; interstices between punctures about equal to their diameter or more (Fig. 21A); anterior and posterior transverse carinae of propodeum closer, thereby making the shape of the area superomedia about as long as wide (Figs 10G, 18F); second and third flagellomere more elongate, about 2.2 times as long as wide; nervellus usually broken slightly below the middle. A parasitoid of Hadena in open xerothermic grasslands, mostly in Eastern Sweden

O. ellenae Johansson sp. nov.

- Mesoscutum less shiny with very dense and distinct punctures; interstices distinctly smaller than the diameter of punctures or absent (Fig. 21B); anterior and posterior transverse carinae of propodeum more separated, thereby making the shape of the area superomedia about two times as long as wide (Fig. 18E); second and third flagellomeres stouter, about 1.8 times as long as wide; nervellus broken slightly above the middle. Possibly a rare parasitoid of Hadena caesia (Denis \& Shiffermüller, 1775) in coastal localities along the West coast of Sweden

O. matti Johansson sp. nov.

\title{
Systematics
}

\author{
Ophion angularis Johansson \& Cederberg sp. nov. \\ urn:Isid:zoobank.org:act:BB40BE24-344A-40B6-AF63-078ED2FFCDB3
}

Figs 9F, 22

\section{Diagnosis}

The combination of the shape of the pleurosternal angles, the buccate temples and the number of flagellomeres separates this species from all other known Swedish species of Ophion. Ophion angularis Johansson \& Cederberg sp. nov. is most likely to be confused with Ophion crassicornis Brock, 1982 and Ophion borealis Johansson sp. nov., but has more prominent pleurosternal angles, usually more numerous flagellomeres, slightly less buccate temples, entirely uncarinated scutellum and more densely punctate face.

\section{Etymology}

The pleurosternal angles are very prominent in this species.

\section{Material examined}

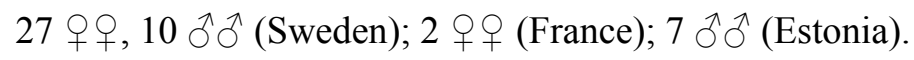

\section{Type material}

\section{Holotype}

SWEDEN • ; Östergötland, Norrköping, Kimstad; $58.551^{\circ}$ N, $15.962^{\circ}$ E; 1 May-1 Jul. 2012; M. Stahre leg.; Yellow pan trap in gravelpit close to pine and oak forest; STI-NJBC79; NHRSHEVA000008581. 
Paratypes

SWEDEN • 1 क; Öland, Borgholm, 0.6 km SW Borgholm church; 56.876 ${ }^{\circ}$ N, $16.648^{\circ}$ E; 22 May 1974; S. Johansson leg.; MV-light in garden surrounded by oak forest; MZLU Type no. 6366:1 • 1 क; Öland, Mörbylånga, Räpplinge; $56.827^{\circ} \mathrm{N}, 16.660^{\circ} \mathrm{E} ; 18$ Jun. 1964; S. Johansson leg.; MV-light; MZLU Type no. 6366:2 - 1 +; Skåne, Ystad, Kåseberga; $55.385^{\circ} \mathrm{N}, 14.066^{\circ}$ E; 21 May-28 July 2016; N. Ryrholm and C. Källander leg.; MV-light trap in warm coastal sandslopes; NHRS-HEVA000008582 • 1 क ; Skåne, Simrishamn, Örnahusen; 55.450 ${ }^{\circ}$ N, $14.261^{\circ}$ E; 4-26 Jun. 2006; N. Ryrholm and C. Källander leg.; MVlight trap in coastal meadow; NHRS-HEVA000008583 - 2 우; Blekinge, Karlskrona, Tullaretorpet; $56.227^{\circ} \mathrm{N}, 15.647^{\circ} \mathrm{E}$; 2-3 Jun. 2016; C. Philipsson leg.; MV-light in deciduous forest; 1 \& STI-NJBC78; NHRS-HEVA000008584, NHRS-HEVA000008585 • 1 o; Gotland, Roleks; 57.536 ${ }^{\circ} \mathrm{N}, 18.339^{\circ} \mathrm{E}$; 2-18 Jun. 2004; SMTP leg.; Malaise trap in grazed calcareous pine forest (Trap id 28, coll ev. id. 497); NHRS-HEVA000008586 • 1 क; Gotland, Roleks; 10 Apr.-6 Jun. 2005; SMTP leg.; Malaise trap in grazed calcareous pine forest (Trap id 28, coll ev. id. 1464); NHRS-HEVA000008587 - 1 ऊ; Öland, Mörbylånga, Strandskogen; 56.702 ${ }^{\circ} \mathrm{N}, 16.494^{\circ} \mathrm{E} ; 22$ May 2016; B. Andersson leg.; MV-light trap in garden on sand close to deciduous forest; NHRS-HEVA000008588 • 1 q; Skåne, Ystad, Spraggehusen; $55.442^{\circ} \mathrm{N}, 14.066^{\circ} \mathrm{E} ; 27$ May-28 Jul. 2016; N. Ryrholm and C. Källander leg.; MV-light trap in coastal sanddunes; NHRS-HEVA000008589 • 1 \%; Gotland, Sundre, Hallbjäns; $56.938^{\circ}$ N, $18.146^{\circ}$ E; 21 Jun.-22 Jul. 2006; N. Ryrholm and C. Källander leg.; MV-light trap in coastal rocky, calcareous heath; NHRS-HEVA000008590 • 1 \%; Gotland, Hamra, Tuvlandet; 56.966 N, $18.378^{\circ}$ E; 24 Aug. 27 Aug. 2007; N. Ryrholm and C. Källander leg.; MV-light trap in abandoned farmland/gardens; NHRSHEVA000008591 3 우 ; same locality as for preceding; $56.966^{\circ} \mathrm{N}, 18.308^{\circ} \mathrm{E} ; 26$ Aug. -24 Sep. 2007; N. Ryrholm and C. Källander leg.; MV-light trap in abandoned farmland/gardens; NHRS-HEVA000008592 to NHRS-HEVA000008594 • 2 우; Småland, Ljungby, Agunnaryd, Nockarp; $56.767^{\circ} \mathrm{N}, 14.167^{\circ} \mathrm{E}$; 10 Jul. 1966; N. Burreau leg.; MZLU Type no. 6366:3, MZLU Type no. 6366:4 • 1 §ో; same data as

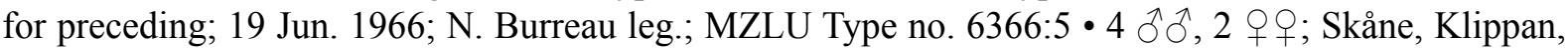
Bonnarpshed; $56.087^{\circ} \mathrm{N}, 13.176^{\circ} \mathrm{E} ; 8-13 \mathrm{Jun} .2007$; N. Ryrholm and C. Källander leg.; MV-light trap in grazed heathland; NHRS-HEVA000008595 to NHRS-HEVA000008600 • 2 ठో $\sigma^{\lambda}$; Skåne, Höganäs, Mölle; 56.289 N, $12.498^{\circ}$ E; 1 Jun. 1965; N. Burreau leg.; MZLU Type no. 6366:6, MZLU Type no. 6366:7 • 1 ○ं; Halland, Halmstad, Steninge; $56.758^{\circ}$ N, $12.637^{\circ}$ E; 29 Jun. 1941; B. Hanström leg.; MZLU Type no. 6366:8 • 1 क; Uppland, Väddö, Ytterskär; 59.938 ${ }^{\circ} \mathrm{N}, 18.920^{\circ}$ E; 23 May-26 Jun. 2017; N. Ryrholm and C. Källander leg.; MV-light trap; STI-NJBC186; NHRS-HEVA000008601 • 1 \%; Öland, Mörbylånga, Torslunda Ekologiska Station; $56.619^{\circ}$ N, $16.497^{\circ}$ E; 5 Jun. 1977; B. Cederberg leg.; Sweepnet in dry grassland, NHRS-HEVA000008602 - 1 o ; same data as for preceding; 12 Jun. 1977; B. Cederberg leg.; Sweepnet in dry grassland; NHRS-HEVA000008603.

\section{Description}

Fore wing length 15-17 mm. Antenna in both sexes with 59-67 flagellomeres. First flagellomere 2.5-3.0 times as long as wide. Central flagellomeres stout, about 1.2-1.3 times as long as wide. Apical flagellomeres approximately 1.5 times as long as wide. Temple in female and male strongly buccate, in lateral view $0.7-0.8$ times as long as compound eye. Head with distinct gap between lateral ocellus and inner margin of compound eye. Face below antennal sockets very densely punctate, interstices about 0.2 times diameter of punctures. Malar space about 0.2 times as long as mandibular base in female and male. Mandibular gape right-angled, with internal angles. Wing membrane clear. Ramellus reaching $0.2-0.3$ times the width of the discosubmarginal cell. Radius sinuous. Mesopleuron shagreened with very dense punctures which often merge centrally. Epicnemial carina, in antero-ventral view, with pleurosternal angles nearly in level with sternal angles, pleurosternal angles acute (Fig. 9F). Epicnemial carina between tip of pleurosternal angle and sternal part strongly concave. Scutellum without distinct lateral carinae in basal half. Propodeum distinctly punctate and coriaceous in front of anterior transverse carina, between transverse carina more often quite shiny, weakly rugose. Anterior transverse carina sometimes absent or weak laterally and posterior transverse often interrupted centrally, in continental 
specimens the anterior carina sometimes more strongly raised. Longitudinal carinae delimiting area superomedia and petiolar carinae often strong. Area superomedia quite narrow, about two times as long as wide. Hind trochantellus shorter than wide in dorsal view. Legs normal with hind femur about 7.0 times as long as wide. Sclerotised section of first sternite ending level to spiracle (as in Fig. 5H). Inner spur of hind tibia 0.4 times as long as hind metatarsus.

\section{Colour}

Body testaceous. Mandibular teeth black. Head with inner and outer eye margins widely yellow. Ovipositor sheath black or dark brown, contrasting in colour with posterior metasomal segments.

\section{DNA barcode}

The DNA barcode sequences of four Swedish specimens of Ophion angularis Johansson \& Cederberg sp. nov. are available at the BOLD systems database (www.boldsystems.org, BIN. BOLD:ADG2027. Specimen codes: STI-NJBC: 78-79, 186, 267).

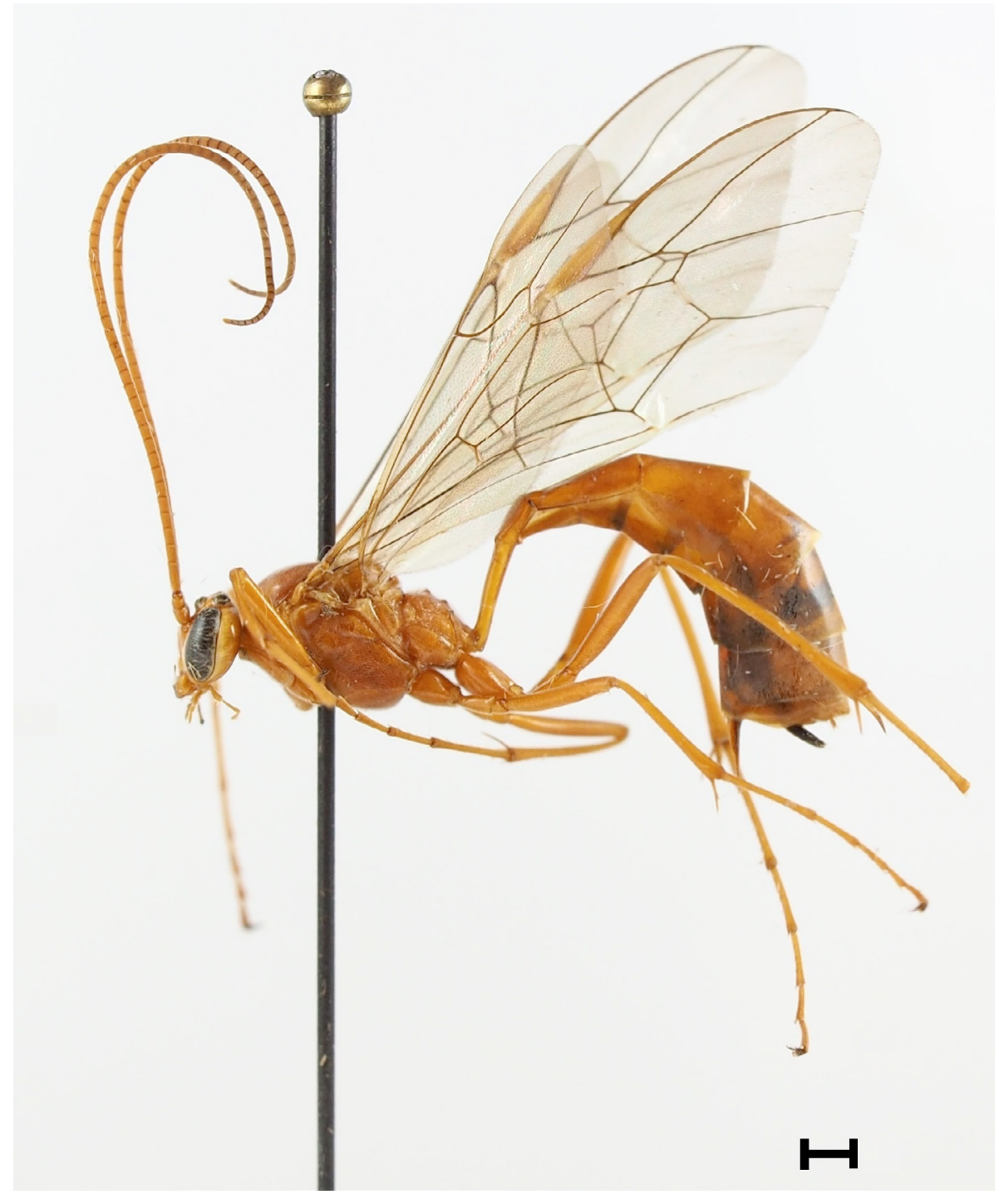

Fig. 22. Ophion angularis Johansson \& Cederberg sp. nov., paratype, $q$ (MZLU 6366:3). Scale bar $=$ $1 \mathrm{~mm}$. 


\section{Ecology}

The species seems to occur in open or semi-open habitats and is active during late June-August. Other than that, nothing is known about the biology.

\section{Distribution in Sweden}

Rare but widespread in Southern Sweden.

\section{Remarks}

This species has been confused with Ophion crassicornis Brock, 1982 and was also probably partly included in the description of that species. Ophion angularis Cederberg \& Johansson sp. nov. is, however, both morphologically and genetically distinct.

Ophion arenarius Johansson sp. nov. urn:1sid:zoobank.org:act:70C3C785-54E2-4B53-AAC0-04F401704FF1

Figs 8E, 23

\section{Diagnosis}

Superficially similar to and obviously closely related to Ophion inclinans Johansson sp. nov. (Fig. 5), but with stouter flagellomeres and head and face usually slightly more transverse in anterior view. Also easily confused with Ophion ellenae Johansson sp. nov., but with slightly more elongate flagellomeres and less prominent pleurosternal angles.

\section{Etymology}

The species seems to occur mainly in open dry, sandy grasslands.

\section{Material examined}

18 우, 2 $\widehat{\jmath}$ (Sweden); 3 우 (Lithuania).

\section{Type material}

\section{Holotype}

SWEDEN • O; Skåne Ystad, Kåseberga; 55.385 N, 14.066 E; 24 May-22 Jul. 2016; N. Ryrholm and C. Källander leg.; MV-light trap in warm coastal sandlopes; STI-NJBC88; NHRS-HEVA000008604.

\section{Paratypes}

SWEDEN • 1 q; Öland Mörbylånga, Frösslunda alvar, north eastern part; $56.647^{\circ} \mathrm{N}, 16.577^{\circ} \mathrm{E}$; 5 Jul.-2 Aug. 2005; SMTP leg.; Malaise trap in alvar, calcareous heath (Trap id 20, coll ev. id. 1498); STI-NJBC21; NHRS-HEVA000008605 • 1 \%; Gotland, Sundre, Hallbjäns; $56.938^{\circ} \mathrm{N}, 18.146^{\circ}$ E; 19-28 Aug. 1996; N. Ryrholm and C. Källander leg.; MV-light trap in coastal, rocky, calcareous heath; NHRSHEVA000008606 • 1 q; Öland, Mörbylånga, Arontorp; $56.646^{\circ} \mathrm{N}, 16.516^{\circ}$ E; 12 Jul. 1977; L- $\AA$. Janzon leg.; NHRS-HEVA000008607 • 2 우; Öland, Mörbylånga, Räpplinge; $56.827^{\circ} \mathrm{N}, 16.660^{\circ} \mathrm{E}$; 27 Jul. 1975; L-Å. Janzon leg.; NHRS-HEVA000008608, NHRS-HEVA000008609 • 1 đో; Skåne, Kristianstad, Nosaby; $56.050^{\circ}$ N, $14.200^{\circ}$ E; Aug. 2009; H. Rosén leg.; NHRS-HEVA000008610 •

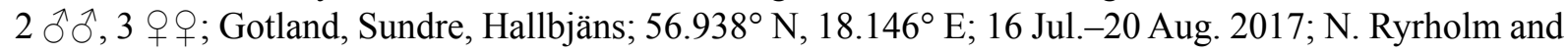
C. Källander leg.; MV-light trap in coastal, rocky calcareous heath; NHRS-HEVA000008611 to NHRSHEVA000008615 • 1 क ; Skåne, Simrishamn, Spraggehusen; 55.442 ${ }^{\circ}$ N, $14.246^{\circ}$ E; 26 Jul.-25 Aug. 2017; N. Ryrholm and C. Källander leg.; MV-light trap in sand dunes, pine forest; NHRS-HEVA000008616 - 1 O; Gotland, Sundre, Hallbjäns; 56.938 N, 18.146 E; 16 Jun.-15 Jul. 2017; N. Ryrholm and C. Källander leg.; MV-light trap in coastal, rocky calcareous heath; NHRS-HEVA000008617 • 1 ; 
Skåne, Simrishamn, Ravlunda; 55.754 N, $14.187^{\circ}$ E; 14 Aug. 1933; N. Burreau leg.; MZLU Type no. 6367:1 • 2 우; Gotland, Buttle, Nordkalk; 57.396 N, 18.508 E; 19 Jul.-1 Aug. 2016; A. Pettersson leg.; Malaise trap in calcareous pine heath; STI-NJBC266, STI-NJBC303; NHRS-HEVA000008618, NHRS-HEVA000008619.

\section{Description}

Fore wing length $15-16 \mathrm{~mm}$. Antenna with $50-55$ flagellomeres. First flagellomere 3.5 times as long as wide. Central flagellomeres stout, about 1.2-1.3 times as long as wide. Subapical flagellomeres approximately 1.8-1.9 times as long as wide (Fig. 8E). Head relatively wide in frontal view (width/ height measured from the apical margin of clypeus to the top of head about 1.30). Temple in lateral view $0.5-0.6$ times as long as compound eye. Gap between compound eye and lateral ocellus about 0.1 times the diameter of ocellus. Face below antennal sockets with weak punctures, interstices about equal to diameter of punctures. Occipital carina centrally usually evenly curved. Malar space about 0.2 times as long as mandibular base in female and male. Mandibular gape right-angled, with internal angles. Wing membrane clear. Ramellus usually short, reaching $0.1-0.3$ times the width of the discosubmarginal cell. Radius sinuous. Mesopleuron weakly shagreened with distinct punctures, space between punctures equal

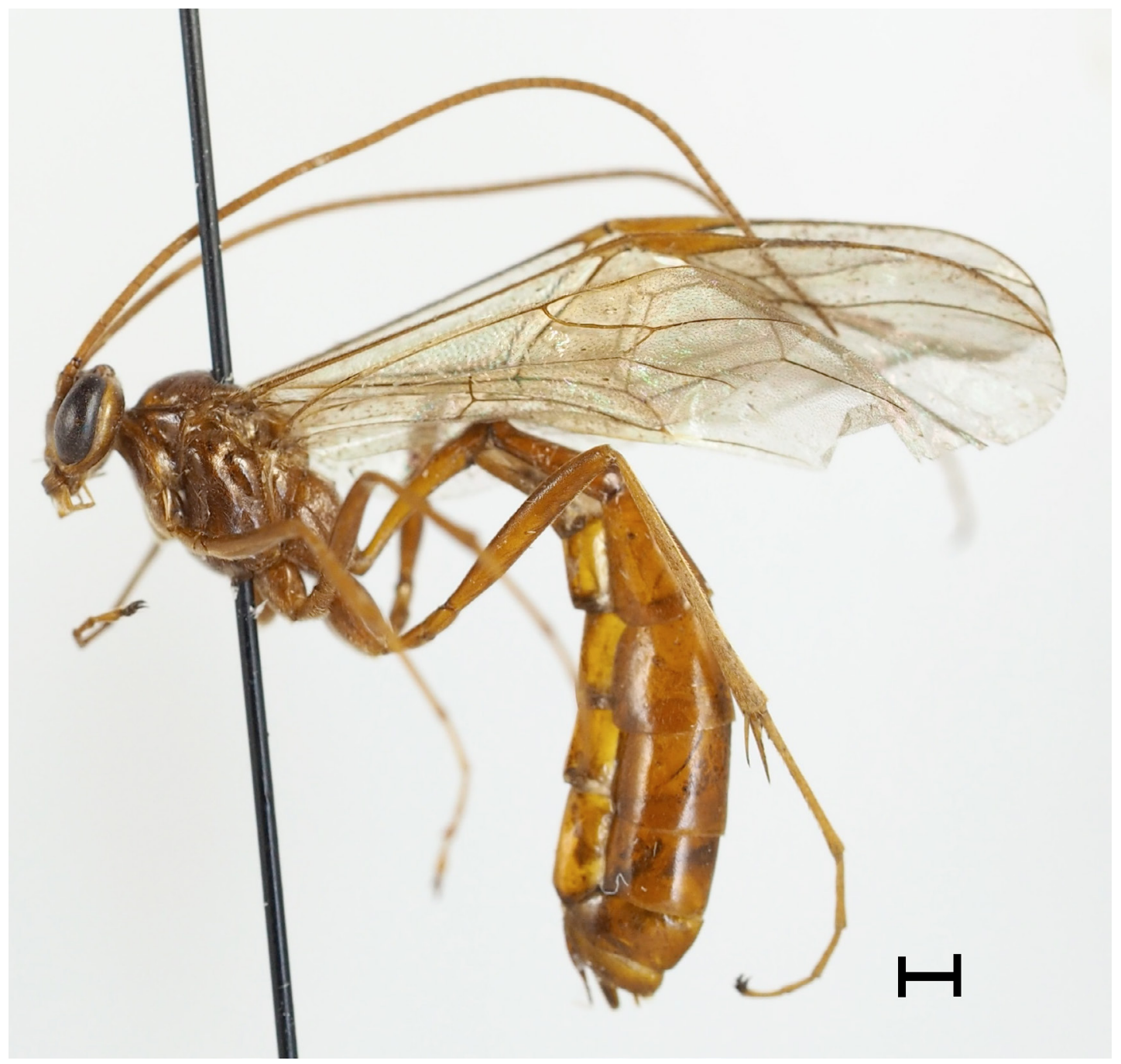

Fig. 23. Ophion arenarius Johansson sp. nov., paratype, $q$ (NHRS-HEVA000008606). Scale bar $=$ $1 \mathrm{~mm}$. 
to their diameter. Epicnemial carina, in antero-ventral view, with pleurosternal angles distinctly anterior to sternal angles. Pleurosternal angles right angled or obtuse. Scutellum with distinct lateral carinae in basal 0.8-0.9. Propodeum with very weak rugose structure, shining with anterior transverse carina quite strongly raised. Anterior transverse carina often absent or weak centrally. Central longitudinal carinae weak but usually present. Lateral longitudinal carinae absent. Hind trochantellus shorter than wide in dorsal view. Legs normal with hind femur about six times as long as wide. Sclerotised part of first sternite ending distinctly posterior to spiracle at a distance equal to that between hind margin of first sternite and hind margin of first tergite (as in Fig. 6E). Inner spur of hind tibia as long as 0.5 times metatarsus.

\section{Colour}

Body testaceous. Mandibular teeth black. Head with inner and outer eye margins broadly marked with yellow. Ovipositor sheath testaceous.

\section{DNA barcode}

The DNA barcode sequences of four Swedish specimens of Ophion arenarius Johansson sp. nov. are available at the BOLD systems database (www.boldsystems.org, BIN. BOLD: AAH1753. Specimen codes: STI-NJBC: 21, 88, 266, 303).

\section{Ecology}

All of the known localities in Sweden consist of open, herb-rich dry grassland on sand or calcareous bedrock. The sites in Sweden and Lithuania are also known to harbour many southern faunistic elements and nationally scarce or threatened termo-xerophilous species. Ophion arenarius sp. nov. is active during July-August in Sweden.

\section{Distribution in Sweden}

The available data suggest a southern distribution in Sweden. Older records from Central Sweden (Västergötland, Dalarna) indicate a wider historical area of occurrence.

\section{Remarks}

This species is very closely related to Ophion inclinans Johansson sp. nov. (Fig. 5). The evidence in the form of a small but consistent genetic differentiation, morphological distinguishing features as well as an apparent ecological differentiation motivates the description of a separate species.

Ophion areolaris Brauns, 1889

Figs $6 \mathrm{~B}, 7 \mathrm{D}, 8 \mathrm{~K}, 9 \mathrm{H}, 10 \mathrm{~J}$

Ophion areolaris Brauns, 1889: 92-93.

Ophion frontalis Strobl, 1904: 53-54. Syn. nov.

\section{Material examined}

Holotype, + , of Ophion areolaris (ZMHB); holotype, + , of Ophion frontalis (CSA); 54 우, 3 ๙ぇ (Sweden); 5 우 (Norway); 4 우 (Lithuania).

\section{Diagnosis}

Fore wing length 14-16 mm. Antenna in both sexes with 41-47 flagellomeres. First flagellomere 3.5 times as long as wide. Head narrowed behind eyes. Occipital carina widely interrupted dorsally, weak laterally (Fig. 7D). Mandibular gape right-angled, with internal angles. Malar space about 0.1 times as 
long as mandibular base in female and male. Wing membrane yellowish. Mesopleuron polished and punctate. Interstices between punctures 1-2 times their diameter. Pleurosternal angles strongly obtuse, weakly defined and obviously anterior to sternal angles (Fig. 9H). Scutellum without lateral carinae with parallel sides (Fig. 6B), strongly convex in lateral view. Propodeum coriaceous with carina strongly reduced anterior to posterior transverse carina. Area superomedia often present as a central convex arch (Fig. 10J). Female with metasoma elongate, tergite $4-5$ almost square in lateral view (Fig. 8K). Hind trochantellus shorter than wide in dorsal view. Spiracles placed more or less at the center of the tergites. Male with parameres short, about as long as wide and almost straight dorsally in lateral view.

\section{Colour}

Body testaceous, sometimes with irregular brownish areas on meso- and metasoma. Mandibular teeth black. Stemmaticum testaceous or brown, very rarely black or dark brown. Ovipositor sheath black, contrasting in colour with posterior metasomal segments.

\section{DNA barcode}

The DNA barcode sequences of two Swedish specimens of Ophion areolaris are available at the BOLD systems database (www.boldsystems.org, BIN. BOLD: ADF9243. Specimen codes STI-NJBC: 06-07).

\section{Ecology}

This species, as its sibling species $O$. ocellaris, occurs in late summer and autumn, August-September, and the hosts seem to be various species of Thyatirinae (family Drepanidae) (Brock 1982). It occurs mainly in boreal woodland habitats but has also been attracted to light in semi-open environments.

\section{Distribution in Sweden}

This species occurs in Southern and Central Sweden and its range doesn't seem to extend quite as far north as $O$. ocellaris.

\section{Remarks}

This species is sometimes confused with $O$. ocellaris. It is however easily distinguished from that species by the characters given in the key and the diagnosis. For further comments see $O$. ocellaris below. The female holotype of $O$. frontalis Strobl, 1904 in CSA was studied and it is a miscoloured specimen of $O$. areolaris with stemmaticum, frons and left side of the dorsal part of the head black. Ophion frontalis Strobl, 1904 is therefore to be regarded as a junior synonym of Ophion areolaris Brauns, 1889 syn. nov.

Ophion artemisiae Boie, 1855

Figs $6 \mathrm{G}, \mathrm{J}, 7 \mathrm{~J}-\mathrm{K}, 10 \mathrm{~F}, 24 \mathrm{~A}-\mathrm{B}$

\section{Material examined}

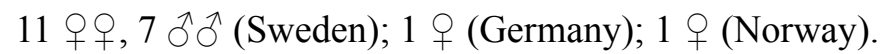

\section{Diagnosis}

Fore wing length 14-16 mm. Antenna in both sexes with 55-59 flagellomeres. First flagellomere 3.0-3.5 times as long as wide. Central flagellomeres stout, about 1.2-1.3 times as long as wide. Subapical flagellomeres approximately 1.5 times as long as wide. Temples in female and male buccate, in lateral view temple $0.6-0.7$ times as long as compound eye. Face below antennal sockets very densely punctured and shagreened, almost rugose. Punctures often merging. Malar space about $0.1-0.2$ times as long as mandibular base in female and about 0.3 times in male. Mandibular gape right-angled, with internal 
angles. Wing membrane weakly yellowish to clear. Discocubitus evenly curved and ramellus usually entirely absent (Fig. 24A), rarely indicated as a small denticle. Radius weakly sinuous. Nervellus broken above or at the middle by the discoidella. Mesopleuron strongly shagreened with deep large punctures. Interstices between punctures $0.5-1$ times their diameter. Mesopleuron centrally-posteriorly depressed.

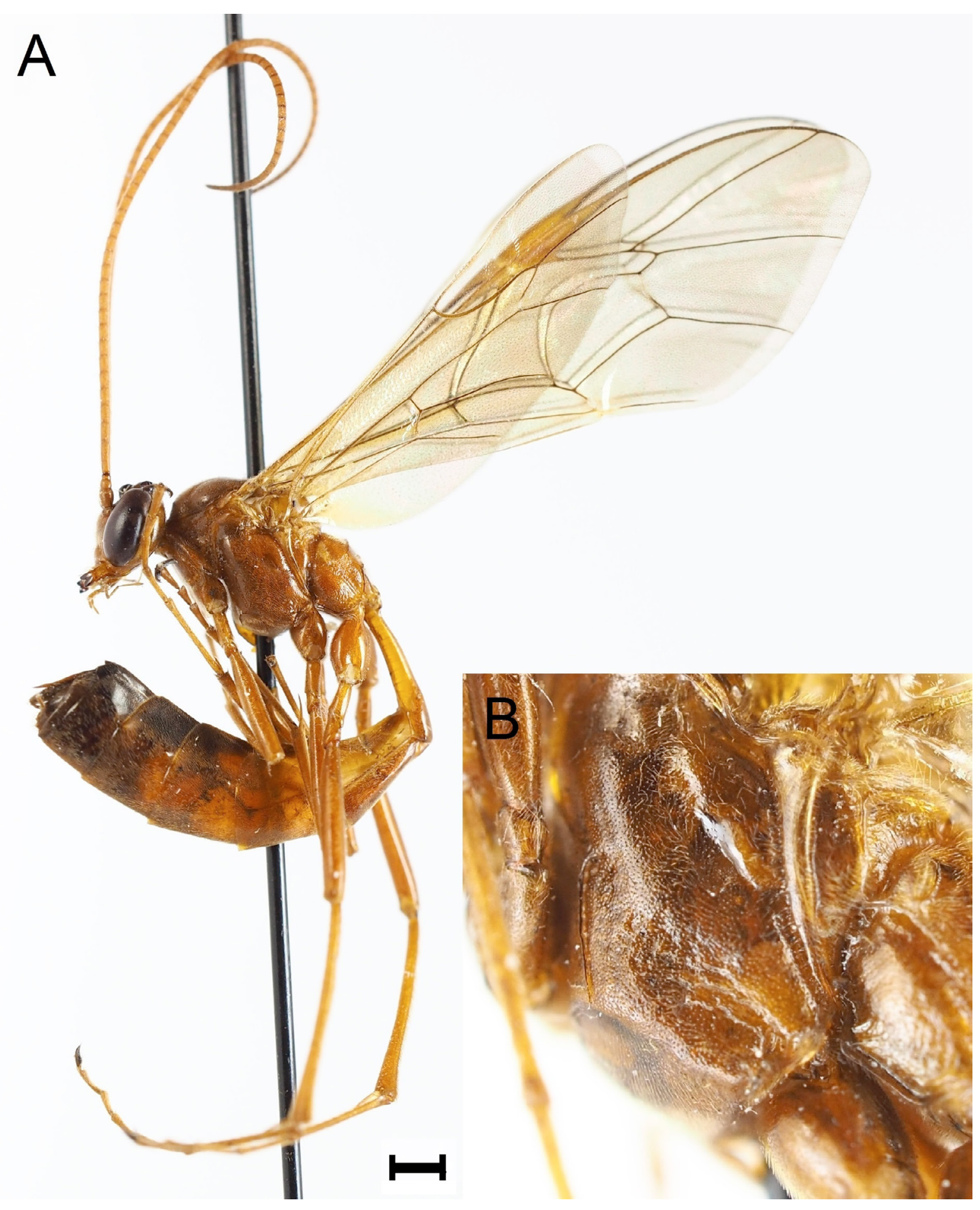

Fig. 24. Ophion artemisiae Boie, 1855, + . A. Habitus, lateral view. B. Mesopleuron, lateral view. Scale bar: $\mathrm{A}=1 \mathrm{~mm}$. 
The depression more or less rugose or wrinkled with irregular punctures (Fig. 24B). Epicnemial carina, in antero-ventral view, with pleurosternal angles prominent, nearly in level with sternal angles. Pleurosternal angles slightly acute. Scutellum usually with distinct lateral carinae in basal 0.4-0.7 (as in Fig. 6C) but sometimes less distinct (as in Fig. 6A). Propodeum distinctly to weakly punctate, often quite polished with anterior and posterior transverse carina strong. The latter often narrowly interrupted centrally. Longitudinal carinae delimiting area superomedia usually weak (Fig. 10F) but sometimes stronger, forming a distinct area superomedia. Hind trochantellus shorter than wide in dorsal view. Legs normal with hind femur about 6.0 times as long as wide. Sclerotised part of first sternite ending slightly posterior to spiracle (Fig. 6G). One series of reared specimens from Blekinge with first tergite dorsally with three dinstinct grooves (Fig. 7J), spiracles of first tergite placed almost dorsally on the tergite and first tergite in lateral view strongly inflated anteriorly (Fig. 7K). Male genitalia as in Fig. 6J. Inner spur of hind tibia as long as 0.3 times metatarsus.

\section{Colour}

Body testaceous. Mandibular teeth black. Head with inner and outer eye margins yellow. Posterior metasomal segments sometimes infuscate in the ventral part. Ovipositor sheath testaceous or slightly infuscate, concolourous with apical metasomal segments.

\section{DNA barcode}

The DNA barcode sequences of four Swedish specimens of Ophion artemisiae are available at the BOLD systems database (www.boldsystems.org, BIN. BOLD: ADG2760. Specimen codes: STI-NJBC: $08,10,192-193)$.

\section{Ecology}

The series in NHRS mentioned above is reared from C. absinthii (Linnaeus, 1761). The original description by Boie refers to a rearing from Cucullia artemisiae (Hufnagel, 1877). Brauns (1889) mentions a rearing from Cucullia formosa Rogenhofer, 1860. One female, a potential future neotype, collected in Rügen, Northern Germany in HSC was reared from Cucullia argentea (Hufnagel, 1766). The available data suggest that the species mainly occurs in semi-open grasslands in coastal areas in Southern Sweden. The species is active during late July to September in Sweden.

\section{Distribution in Sweden}

Rare in Central and Southern Sweden, only known from Skåne and one island in the Baltic Sea (Gotland) and one in the Atlantic (Koster).

\section{Remarks}

A morphologically distinct species easily separated from all other Ophion species in Northern Europe by the combination of the very prominent pleurosternal angles, almost level with the sternal angles (almost as prominent as in $O$. angularis Johansson \& Cederberg sp. nov.), the posteriorly/centrally depressed and rugose-wrinkled mesopleuron, the absent or very short ramellus, the densely punctured face, the nervellus broken above the middle and the sclerotised section of first sternite ending obviously posterior to the spiracle. As the type material of Boie, probably collected in Northern Germany, is presumably lost, the current interpretation of this species depends solely on the original description. Boie (1855: 107) refers to a rearing of seven specimens on the $15^{\text {th }}$ of August from Cucullia artemisiae and mentions the absence of the ramellus as a defining character. He also refers to a rearing of a series of Ophion reared from $C$. absinthii but regrets that these specimens are no longer available for study. The first author has seen material from Croatia (Dalmatia) of a closely related species, that potentially also could fit the description given by Boie. This species, which possibly is conspecific with Ophion pseudocostatus Meyer, 1935 (type lost), is active in early summer in open rocky heathlands of Mediterranean type where 
it occurs alongside several Southern European Ophion species such as Ophion andalusicus Shestakov, 1926 and Ophion neglectus Habermehl, 1930. The presumed O. pseudocostatus is darker in colour, has the mesopleuron more strongly wrinkled, the nervellus broken distinctly below the middle, the face less densely punctate, the ramellus usually present and the shape of the male genitalia different (Fig. 6I). As the southern species occurs in spring and early summer and seems to be restricted to Southern Europe, it is unlikely that it is conspecific with $O$. artemisiae as defined in this study. All Swedish records, as well as the original description, refer to a species active during late July-September.

Ophion artemisiae, as defined here, is also the Ophion costatus sensu Brauns (collected in Hungary). The description in Brauns (1889) mentions the absence of a ramellus, the evenly curved discocubitus, the shorter antennae (in relation to $O$. costatus as defined in this study) and the nervellus broken above the middle. Brauns's Ophion artemisae (O. costatus auct.) was reared from Cucullia formosa, which is a member of the species group feeding mainly on Artemisia L. The interpretation presented in this study is that Ophion artemisiae is a species specialised in parasiting Cucullia Schrank, 1802 species feeding on Artemisia, bearing in mind that additional information of rearing records, as well as barcoding of potential sibling species, might call for adjustments in nomenclature. It is also uncertain that the type material of Boie is really lost (Heinz Schnee, Markleeberg, pers. com.). Therefore a neotype is not designated for this species at the present stage. Notable is a series of one female and three males in NHRS from Blekinge that have the labels "Blekinge, Juni 1942 ex Cucullia absinthii, leg. Allander". Two males have the metasoma missing but the female and the remaining male have three conspicous grooves dorsally on the first tergite (Fig. 7J-K). All specimens are also smaller than all other specimens of $O$. artemisiae studied and have stouter legs. In this study these specimens are treated as anomalies due to an aberration caused by rearing conditions but it shall be noted that Hellén (1926) has an interesting interpretation of $O$. mocsaryi (spelled moczaryi) found in two localities in Finland: "An dem vollständig gefeldertern Mediansegment und dem stark verbreiterten Postpetiolus, der mit einer Mittel- und zwei gebogenen Seitenfurchen versehen ist, zeimlich leicht zu erkennen.". This description seems likely to refer to an aberration similar to that present in the Swedish specimens of $O$. artemisiae. Hellén's material of $O$. mocsaryi is unfortunately lost (Gergely Várkonyi, Finnish Environment Institute, pers. com.; Juho Paukkunen, MZH, pers. com.) so no further studies could be made to exclude this as a species potentially differentiated from $O$. artemisiae.

Ophion autumnalis Johansson sp. nov. urn:1sid:zoobank.org:act:6A2AA4E5-7561-4E8F-863A-BF19DCD642ED

Figs 13B, 25

\section{Diagnosis}

Ophion autumnalis Johansson sp. nov. is most similar to Ophion obscuratus but is lacking extensive pale markings and has the temples more narrowed behind the eyes. The occipital carina usually joins the hypostomal carina at a strongly acute angle (as in Fig. 7L) while in O. variegatus and O. sylvestris Johansson sp. nov. it is just slightly acute (as in Fig. 7M). Also similar to O. kevoensis, but with the pterostigma apically and posteriorly distinctly pale (Fig. 13B). The result of the molecular analysis, which is based on quite weak sampling, does not indicate any distinction towards the closely related Ophion variegatus, but the morphological and ecological evidence motivates the description of a new species.

\section{Etymology}

The species is active during late autumn.

\section{Material examined}

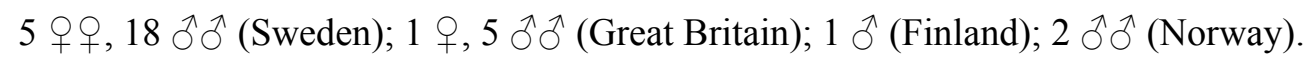




\section{Type material}

\section{Holotype}

SWEDEN • +; Skåne, Ystad, Järahusen; 55.396 N, $14.207^{\circ}$ E; 13 Oct.-12 Nov. 2007; N. Ryrholm and C. Källander leg.; MV-light trap in coastal sanddunes in mixed oak and pine woodland; NHRSHEVA000008620.

\section{Paratypes}

SWEDEN - 1 , 1 O’; Skåne, Ystad, Hagestad; $55.386^{\circ}$ N, $14.137^{\circ}$ E; 10 Oct.-27 Nov. 2016; N. Ryrholm and C. Källander leg.; MV-light trap in sandy coastal heath; NHRS-HEVA000008621, NHRS-HEVA000008622 - 1 đ̊; Skåne, Ystad, Järahusen; $55.396^{\circ} \mathrm{N}, 14.207^{\circ}$ E; 13 Oct.-12 Dec. 1997; N. Ryrholm and C. Källander leg.; MV-light trap in coastal sanddunes in mixed oak and pine woodland; NHRS-HEVA000008623 • 1 , 1 đ; same data as for preceding; 1 Sep.-31 Nov. 1997; N. Ryrholm and C. Källander leg.; MV-light trap in coastal sanddunes in mixed oak and pine woodland; NHRS-HEVA000008624, NHRS-HEVA000008625・1 ○’; Skåne, Simrishamn, Örnahusen; $55.450^{\circ}$ N, $14.261^{\circ}$ E; 2-28 Aug. 1996; N. Ryrholm and C. Källander leg.; MV-light trap in sandy coastal heath; NHRS-HEVA000008626 • 1 क, 1 §`; Uppland, Bälinge, Ryggmossen; $60.038^{\circ} \mathrm{N}, 17.342^{\circ} \mathrm{E}$; 21 Sep. 1965; U. Lohm leg.; UPSZ: 178596, UPSZ: 178598.

FINLAND • 1 đ̊; Uusimaa, Porvoo (Porvoon maalaiskunta), Åminsby; $60.346^{\circ} \mathrm{N}, 25.537^{\circ} \mathrm{E} ; 27$ Sep. 1980; E. Suomalainen leg.; MV-light; MZLU Type no. 6368:1.

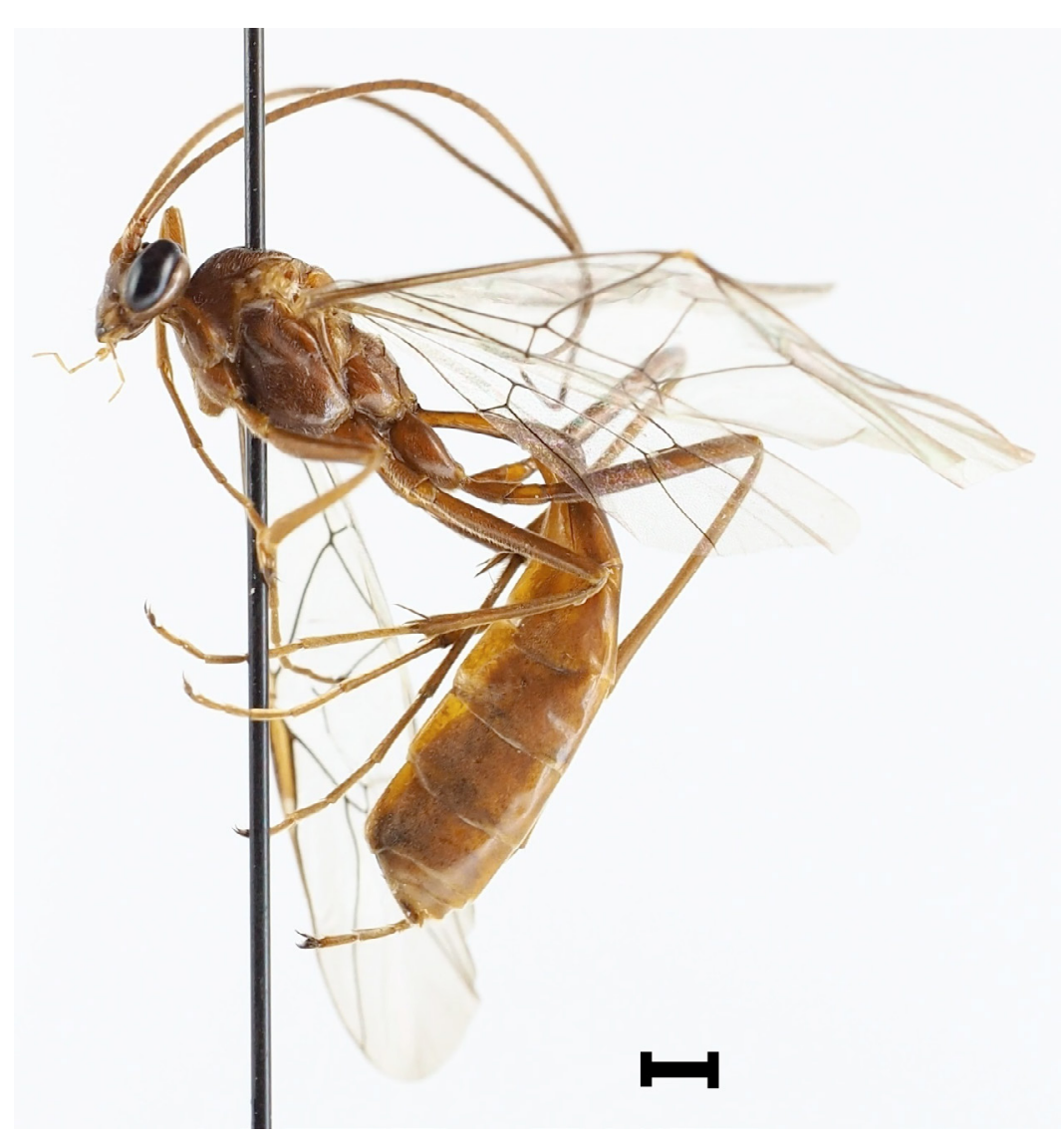

Fig. 25. Ophion autumnalis Johansson sp. nov., holotype, $q$ (NHRS-HEVA000008620). Scale bar $=$ $1 \mathrm{~mm}$. 


\section{Description}

Fore wing length $13-15 \mathrm{~mm}$. Antenna with 53-55 flagellomeres. First flagellomere about 3.0-3.5 times as long as wide. Central flagellomeres about 1.3-1.5 times as long as wide. Apical flagellomeres approximately 1.5-1.6 times as long as wide. Head strongly narrowed behind eyes (almost as in Ophion pteridis Kriechbaumer, 1879), in lateral view with temple 0.3-0.4 times as long as compound eye. Gap between compound eye and lateral ocellus usually distinct, about 0.2 times the diameter of ocellus. Junction between occipital and hypostomal carina strongly acute, about 45 degrees (as in Fig. 7L). Malar space about 0.1 times as long as mandibular base in female and about 0.1-0.2 times in male. Mandibular gape right-angled, with internal angles. Wing membrane clear. Ramellus usually short, reaching $0.1-0.3$ times the width of the discosubmarginal cell. Radius sinuous. Structure of mesopleuron similar to that of Ophion obscuratus, shining or weakly shagreened with weak, very regular punctation consisting of small punctures. Interstices between punctures about equal to their diameter up to 2.0 times their diameter. Epicnemial carina, in antero-ventral view, with pleurosternal angles obviously anterior to sternal angles. Pleurosternal angles rounded, obtuse to right angled. Scutellum without lateral carinae (as in Fig. 6A). Structure of propodeum similar to that of O. obscuratus, posterior to anterior transverse carina mostly shining. Anterior transverse carina always present centrally, anterior to area superomedia, but often also present laterally, though rarely strongly raised (as in Fig. 10A). Posterior transverse carina usually only present laterally, widely interrupted centrally. Central longitudinal carinae weak or absent, when present, forming a narrow triangular area. Sclerotised part of first sternite ending level with spiracle. Legs normal with hind femur about 6.0-7.0 times as long as wide. Hind trochantellus usually longer than in other species except $O$. luteus and $O$. slaviceki, slightly shorter than wide in dorsal view. Inner spur of hind tibia long about $0.3-0.4$ times as long as hind metatarsus.

\section{Colour}

Body colour usually more brownish than most other Ophion species, inner and outer orbits paler, whitishyellow. Mandibular teeth black. Scutellum pale. Pterostigma apically and posteriorly pale. Ovipositor sheath testaceous, of the same colour as posterior metasomal segments.

\section{DNA barcode}

The DNA barcode sequences of two Swedish specimens of Ophion autumnalis Johansson sp. nov. are available at the BOLD systems database (www.boldsystems.org, Specimen codes: STI-NJBC: 104, 209).

\section{Ecology}

Ophion autumnalis Johansson sp. nov. is active during late autumn and early winter, SeptemberDecember in open or semi-open heathlands on sandy or rocky ground. A likely host, as indirectly proposed by Brock, is Anarta myrtilli (Linnaeus, 1761).

\section{Distribution in Sweden}

Rare but locally in numbers in semi-open and open heathlands in Southern and Central Sweden but probably overlooked due to the late flight period.

\section{Remarks}

This species has previously partly been regarded as an autumnal generation of Ophion obscuratus s. lat. (Brock, 1982). Material of this species from heathlands in Scotland and England (BMNH) has been studied and fits very well with the species here described. This is most likely the species referred to by Brock (1982) as "autumnal dwarfs". For further details, see Discussion; The Ophion obscuratus aggregate. 


\section{Ophion borealis Johansson sp. nov. urn:1sid:zoobank.org:act:FD4E1CFA-420C-4058-9814-8343D1554BBA}

Figs 14C, E, 26

\section{Diagnosis}

Superficially very similar to and easily confused with Ophion crassicornis, but with face generally wider and punctures below antennal sockets and on clypeus sparser and smaller with larger interstices. The distance between the tentorial pits and compound eye is almost equal to the distance between the cavities, while it is smaller in $O$. crassicornis. The sides of the scutellum in known specimens are concolourous with the rest of the scutellum, while they are usually paler in $O$. crassicornis. The anterior transverse carina of propodeum is straighter.

\section{Etymology}

The species is of northern distribution.

\section{Material examined}

4 우우 (Sweden); 2 우 (Finland).

\section{Type material}

Holotype

SWEDEN • + ; Småland, Jönköping, Dummemosse; $57.783^{\circ}$ N, $14.017^{\circ}$ E; 10 Jul. 2017; M. Andersson leg.; sweepnet in sandy pine-forest; STI-NJBC182; NHRS-HEVA000008627.

\section{Paratypes}

SWEDEN • 1 \%; Gotland, Sundre, Hallbjäns; $56.938^{\circ}$ N, 18.146 E; 21 Jun.-22 Aug. 2008; N. Ryrholm and C. Källander leg.; MV-light trap in coastal, rocky calcareous heath; NHRS-HEVA000008628 • 1 \%; Gotland, Sundre, Suders; 56.945 N, $18.303^{\circ}$ E; 29 Jul.-18 Sep. 2017; N. Ryrholm and C. Källander leg.; MV-light trap in deciduous woodland; NHRS-HEVA000008629 • 1 क; Småland, Nybro, Grytsjön, banvallen; $56.932^{\circ} \mathrm{N}, 16.086^{\circ} \mathrm{E}$; 15 Jun. 2019; M. Tholin leg.; MV-light in mixed forest; NHRSHEVA000008630.

FINLAND • 1 q; Uusimaa, Porvoo (Porvoon maalaiskunta), Åminsby; $60.346^{\circ} \mathrm{N}, 25.537^{\circ} \mathrm{E} ; 29 \mathrm{Jun}$. 1980; E. Suomalainen leg.; MV-light; MZLU Type no. 6369:1 • 1 q; Uusimaa, Porvoo (Porvoon maalaiskunta), Åminsby; 4 Jul. 1980; E. Suomalainen leg.; MV-light; MZLU Type no. 6369:2.

\section{Description}

Fore wing length $16 \mathrm{~mm}$. Antenna with 56-61 flagellomeres. First flagellomere 3.0 times as long as wide. Central flagellomeres stout, about 1.2-1.3 times as long as wide. Subapical flagellomeres approximately 1.5 times as long as wide. Temple strongly buccate (as in Fig. 30A). Head in lateral view with temple 0.9 times as long as compound eye. Gap between lateral ocellus and inner margin of compound eye distinct, about $0.1-0.2$ times the diameter of ocellus. Face below antennal sockets quite polished with distinct interstices between the relatively small punctures. Punctures of clypeus shallower and smaller than in O. crassicornis. Head wide with clypeus relatively narrow in relation to O. crassicornis (Fig. 14E). Malar space about 0.2 times as long as mandibular base. Mandibular gape right-angled, with internal angles. Wing membrane clear to slightly yellowish. Ramellus distinct, reaching about 0.5 the width of the discosubmarginal cell. Radius sinuous. Mesopleuron shagreened with rather dense, punctures that occasionally merge centrally. Punctures smaller and scarcer than in O. crassicornis. Epicnemial carina, in antero-ventral view, with pleurosternal angles slightly anterior to sternal angles (as in Fig. 9G). Pleurosternal angles sharp and slightly obtuse. Scutellum occasionally with distinct lateral 
carinae in basal half but sometimes only in basal 0.2 (as in Fig. 6A). Propodeum distinctly punctate and coriaceous in front of anterior transverse carina. Between transverse carina more often quite shiny, weakly rugose. Anterior transverse carina sometimes absent laterally, rather straight, slightly convex in front of area superomedia (Fig. 14C) but sometimes laterally bent forwards, thereby creating an undulation. Posterior transverse carina often widely interrupted centrally. Central longitudinal carinae delimiting area superomedia and area petiolaris strong. Area superomedia quite narrow, about two times as long as wide. Sclerotised part of first sternite ending level to spiracle. Hind trochantellus shorter than wide in dorsal view. Legs normal with hind femur about 7.0 times as long as wide. Inner spur of hind tibia as long as 0.4 times metatarsus. Male unknown.

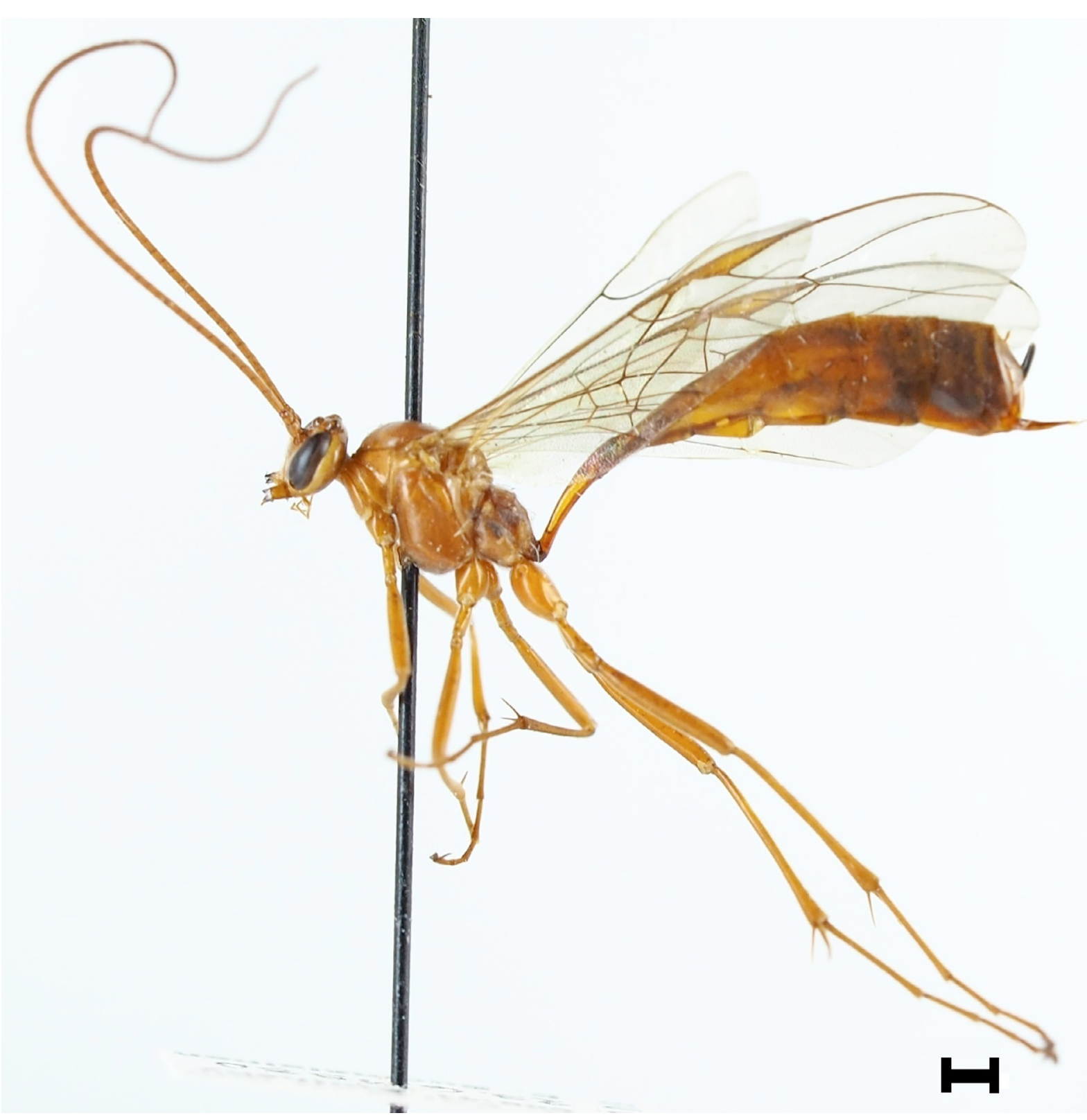

Fig. 26. Ophion borealis Johansson sp. nov., holotype, $q$ (NHRS-HEVA000008627). Scale bar $=1 \mathrm{~mm}$. 


\section{Colour}

Body testaceous. Mandibular teeth black. Head with inner and outer eye margins yellow. Ovipositor sheath black or dark brown, contrasting in colour with posterior metasomal segments.

\section{DNA barcode}

The DNA barcode sequence of one Swedish specimen of Ophion borealis Johansson sp. nov. is available at the BOLD systems database (www.boldsystems.org, BIN. BOLD: ADM5451. Specimen code: STINJBC: 182).

\section{Ecology}

The species occurs during summer, June-August, in semi open areas dominated by scots pine Pinus sylvestris L. forests.

\section{Distribution in Sweden}

Only a few scattered records (see type series) but probably overlooked.

Ophion brevicornis Morley, 1915

Figs $8 \mathrm{M}, 10 \mathrm{~N}, 18 \mathrm{~A}, \mathrm{C}$

Ophion brevicornis Morley, 1915: 274.

\section{Material examined}

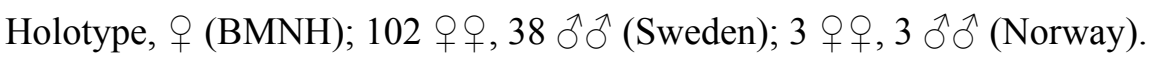

\section{Diagnosis}

Fore wing length $12-13 \mathrm{~mm}$. Antenna in both sexes with $45-50$ flagellomeres. First flagellomere stout, 2.5-3.0 times as long as wide. Central flagellomeres square (Fig. 8M) in females, about 1.2-1.3 times as long as wide in males. Temple buccate with distinct gap between ocellus and compound eye of about 0.3 times diameter of ocellus (Fig. 18A) in lateral view about 0.8 times as long as compound eye. Head in anterior view with face quite wide (Fig. 18C). Malar space about 0.5 times as long as mandibular base in female and male. Mandibular gape right-angled, with internal angles. Wing membrane clear. Ramellus often distinct but rather short, reaching about 0.2 times the distance of the submarginal cell, but sometimes shorter. Radius sinuous. Mesopleuron mostly polished with small, shallow punctures ranging to densely irregularly punctate, almost rugose. Pleurosternal angles weakly acute, well defined, slightly anterior to sternal angles. In this respect reminiscent of $O$. mocsaryi and $O$. confusus Johansson sp. nov. Scutellum strongly convex in lateral view with no trace of lateral carinae. Propodeum coriaceous or more polished and indistinctly punctate, to almost rugose in structure. Anterior and posterior transverse carina often strong, but sometimes weaker. Posterior transverse carina often interrupted centrally. Longitudinal carinae delimiting area superomedia often strong, but occasionally missing or weak. Hind trochantellus shorter than wide in dorsal view. Sclerotised part of first sternite ending slightly posterior to spiracle (as in Fig. 6G). Inner spur of hind tibia 0.3 times as long as metatarsus.

\section{Colour}

Body testaceous. Mandibular teeth black. Inner and outer orbits very rarely paler than the face, usually concolourous with body and the rest of the head. Ovipositor sheath testaceous-brown, often slightly darker than posterior metasomal segments. 


\section{DNA barcode}

The DNA barcode sequences of 13 Swedish specimens of Ophion brevicornis are available at the BOLD systems database (www.boldsystems.org, BIN. BOLD: ACR2872. Specimen codes: STI-NJBC: 113-114, 117-125, 336-337).

\section{Ecology}

This species is active in early summer from the middle of May to the beginning of July. Oosterbroek (1978) lists Cosmia trapezina (Linnaeus, 1758) as a host.

\section{Distribution in Sweden}

Widespread but quite local in Southern Sweden.

\section{Remarks}

Ophion brevicornis is a distinct species with its strongly convex scutellum, short flagellomeres, antenna with relatively few flagellomeres and buccate temples. Males can be difficult to identify, especially when attempting to separate them from $O$. mocsaryi and $O$. confusus Johansson sp. nov., but are easily identified by the smaller number of flagellomeres, the apparent gap between compound eye and lateral ocellus and the strongly convex scutellum. Females are similar to Ophion subarcticus, but with flagellomeres stouter, gap between ocellus and eye narrower (Fig. 18A) and face narrower (Fig. 18C).

\section{Ophion broadi Johansson sp. nov. urn:lsid:zoobank.org:act:3F3D4D37-F034-450E-8F64-41D9E2B2094E}

Figs 16F, 27

\section{Diagnosis}

The species is most similar to Ophion kevoensis but has the face and head in anterior view narrower. Also similar to Ophion sylvestris Johansson sp. nov. but larger and with ovipositor sheath testaeous (black or dark brown in O. sylvestris Johansson sp. nov.). The barcoded specimens form two groups, but no morphological evidence supports the presence of two separate species at this point.

\section{Etymology}

This species is named in honour of the British hymenopterist Gavin Broad.

\section{Material examined}

8 우우 (Sweden).

\section{Type material}

\section{Holotype}

SWEDEN • O ; Öland, Mörbylånga, Strandskogen; $56.702^{\circ}$ N, $16.494^{\circ}$ E; 10 Jun. 2017; B. Andersson leg.; MV-light in garden close to mixed forest; STI-NJBC263; NHRS-HEVA000008946.

\section{Paratypes}

SWEDEN • 1 q; Södermanland, Haninge, Tyresta nationalpark, Urskogsslingan; $59.176^{\circ} \mathrm{N}, 18.248^{\circ} \mathrm{E}$; 21 Jun.-20 Jul. 2004; SMTP leg.; Malaise trap in Norway spruce forest with blueberry (Trap id 4, coll ev. id. 809); STI-NJBC211; NHRS-HEVA000008948 • 1 क; same data as for preceding; 8 Jun.-2 Jul. 2003; SMTP leg.; Malaise trap in Norway spruce forest with blueberry (Trap id 3, coll ev. id. 84); STINJBC210; NHRS-HEVA000008949 • 1 q; Västergötland, Klippan, Björketorp; $57.689^{\circ} \mathrm{N}, 12.481^{\circ} \mathrm{E}$; 5 Jul. 2017; M. Oomen leg.; MV-light; STI-NJBC214; NHRS-HEVA000008950 • 1 q; Västergötland, 
Habo, Gustaf Adolf, Aspåsen; 58.013 N, 14.133 E; 1 Aug.-1 Sep. 2017; N. Johansson leg.; Malaise trap between wet deciduous forest and sandy meadow; NHRS-HEVA000008952 - 1 ; Västergötland, Habo, Gustaf Adolf, Bockagölarna; 58.048 N $14.118^{\circ}$ E; 16 Jun.-1 Jul. 2018; N. Johansson leg.; Malaise trap in sandy scots pine forest; NHRS-HEVA000008949 • 1 ㅇ; Småland, Nybro, Brantehallar; $56.956^{\circ} \mathrm{N}, 15.995^{\circ}$ E; 5 Jun.-15 Jun. 2018; O. Persson and S. Björn leg.; Malaise trap in rocky scots pine forest; NHRS-HEVA000008951 • 1 \%; Norrbotten, Boden, Åträsk, Roknäs; $66.104^{\circ} \mathrm{N}, 21.579^{\circ} \mathrm{E}$; 21 Aug.-14 Oct. 2017; N. Ryrholm and C. Källander leg.; MV-light trap; NHRS-HEVA000008953.

\section{Description}

Fore wing length $15-17 \mathrm{~mm}$. Antenna with 52-55 flagellomeres. First flagellomere about 3.5-4.0 times as long as wide. Central flagellomeres about 1.5-1.6 times as long as wide. Subapical flagellomeres approximately 1.5 times as long as wide. Temple in lateral view $0.4-0.5$ times as long as compound eye. Head in dorsal view with gap between compound eye and lateral ocellus about $0.1-0.3$ times the diameter of

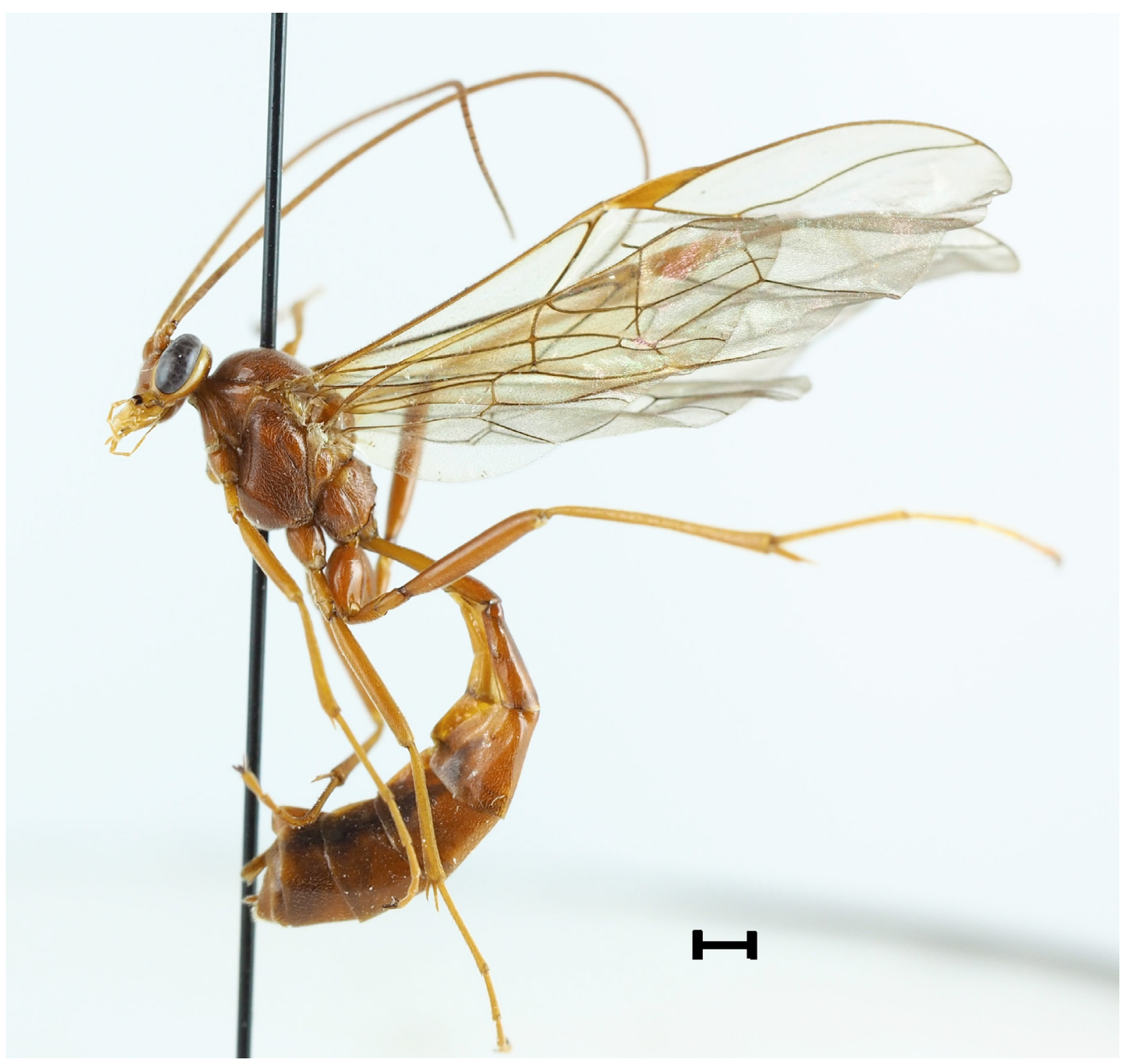

Fig. 27. Ophion broadi Johansson sp. nov., holotype, + (NHRS-HEVA000008946). Scale bar $=1 \mathrm{~mm}$. 
the ocellus. Malar space slightly longer than in $O$. slaviceki, in female about 0.3 times as long as mandibular base. Face below antennal sockets narrow (Fig. 16F) with quite scarce and shallow punctures. Gap between mandibles obtuse or right angled, with internal angles present. Wing membrane transparent. Ramellus long, 0.3 times the width of the discosubmarginal cell. Radius sinuous. Structure of mesopleuron weakly shagreened with distinct punctures. Interstices between punctures about equal to their diameter. Epicnemial carina, in antero-ventral view, with pleurosternal angles obviously anterior to sternal angles. Pleurosternal angles rounded, obtuse to right angled (as in Fig. 9E). Scutellum with lateral carinae present in basal 0.2. Anterior transverse carina of propodeum present. Posterior transverse carina only present laterally, widely interrupted centrally. Petiolar carina and longitudinal carina delimiting area superomedia weak. Sclerotised part of first sternite ending level to spiracle. Hind trochantellus shorter than wide in dorsal view. Legs normal, with hind femur about 6.0-6.5 times as long as wide. Hind trochantellus shorter than wide in dorsal view. Inner spur of hind tibia about $0.3-0.4$ times as long as hind metatarsus. Male unknown.

\section{Colour}

Body dark testaceous. Outer eye margins yellow. Inner eye margins usually only yellow above antennal sockets. Mandibular teeth black. Ovipositor sheath testaceous, concolourous with posterior metasomal segments.

\section{DNA barcode}

The DNA barcode sequences of four Swedish specimens of Ophion broadi Johansson sp. nov. are available at the BOLD systems database (www.boldsystems.org. Specimen codes: STI-NJBC: 210-211, 214, 263).

\section{Ecology}

The species occurs in open pine forests on sandy or rocky ground. The main period of activity in Sweden seems to be early summer, May-June.

\section{Distribution in Sweden}

Probably a quite common species, but partly overlooked.

\section{Remarks}

Some males that were collected alongside the females from Västergötland resemble the males of Ophion kevoensis but have the malar space shorter. The specimens could represent the males of this species but the connection to the females is too vague to found a formal description on.

Ophion brocki Johansson sp. nov. urn:Isid:zoobank.org:act:D38092CC-5A67-43A6-9722-7A76774F16B1

Figs 10C, 13E, 15B, D, G, 28

\section{Diagnosis}

This species belongs to the Ophion mocsaryi aggregate and is distinguished from other Swedish species in this aggregate by the number of flagellomeres, the enlarged compound eyes, the deep groove behind the posterior ocelli, the nervellus being broken distinctly below the middle and the usually strong carination of the propodeum.

\section{Etymology}

This species is named in honor of the British hymenopterist Jim Brock who, by his meticulous studies of the British fauna of Ophion, has contributed greatly to the taxonomy of the genus in Northwestern Europe and indirectly assisted in the definition of this species. 


\section{Material examined}

3 우우, $11 \widehat{\partial} \widehat{\partial}$ (Sweden); $1 \hat{\jmath}$ (Italy); 1 ㅇ, $1 \hat{\partial}$ (Germany); 9 웅, $25 \hat{\jmath} \widehat{\partial}$ (Great Britain).

\section{Type material}

\section{Holotype}

SWEDEN • ; B Blekinge, Karlskrona, Tullaretorpet; 56.227 N, $15.647^{\circ}$ E; 2-3 Jun. 2016; C. Philipsson leg.; MV-light trap in deciduous forest; STI-NJBC172; NHRS-HEVA000008630.

\section{Paratypes}

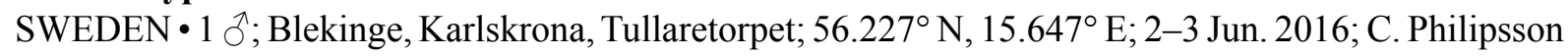
leg.; MV-light trap in deciduous forest; STI-NJBC136; NHRS-HEVA000008631 - 1 \%; Blekinge, Karlskrona, Tullaretorpet; 56.227 ${ }^{\circ}$ N, $15.647^{\circ}$ E; 23-24 May 2016; C. Philipsson leg.; MV-light trap in deciduous forest; STI-NJBC135; NHRS-HEVA000008632 - 1 क ; Blekinge, Karlskrona, Tullaretorpet; 56.227 ${ }^{\circ}$ N, $15.647^{\circ}$ E; 28-29 May 2016; C. Philipsson leg.; MV-light trap in deciduous forest; STI-

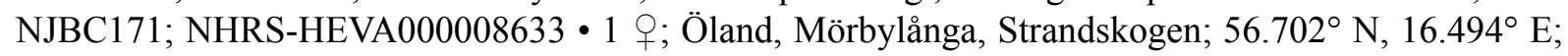
12 Jun. 2017; B. Andersson leg.; MV-light in garden close to deciduous forest; STI-NJBC173; NHRSHEVA000008634 • $1{ }^{\top}$; Blekinge, Karlskrona, Tullaretorpet; $56.227^{\circ} \mathrm{N}, 15.647^{\circ}$ E; 31 May-1 Jun. 2016; C. Philipsson leg.; MV-light trap in deciduous forest; STI-NJBC134; NHRS-HEVA000008635

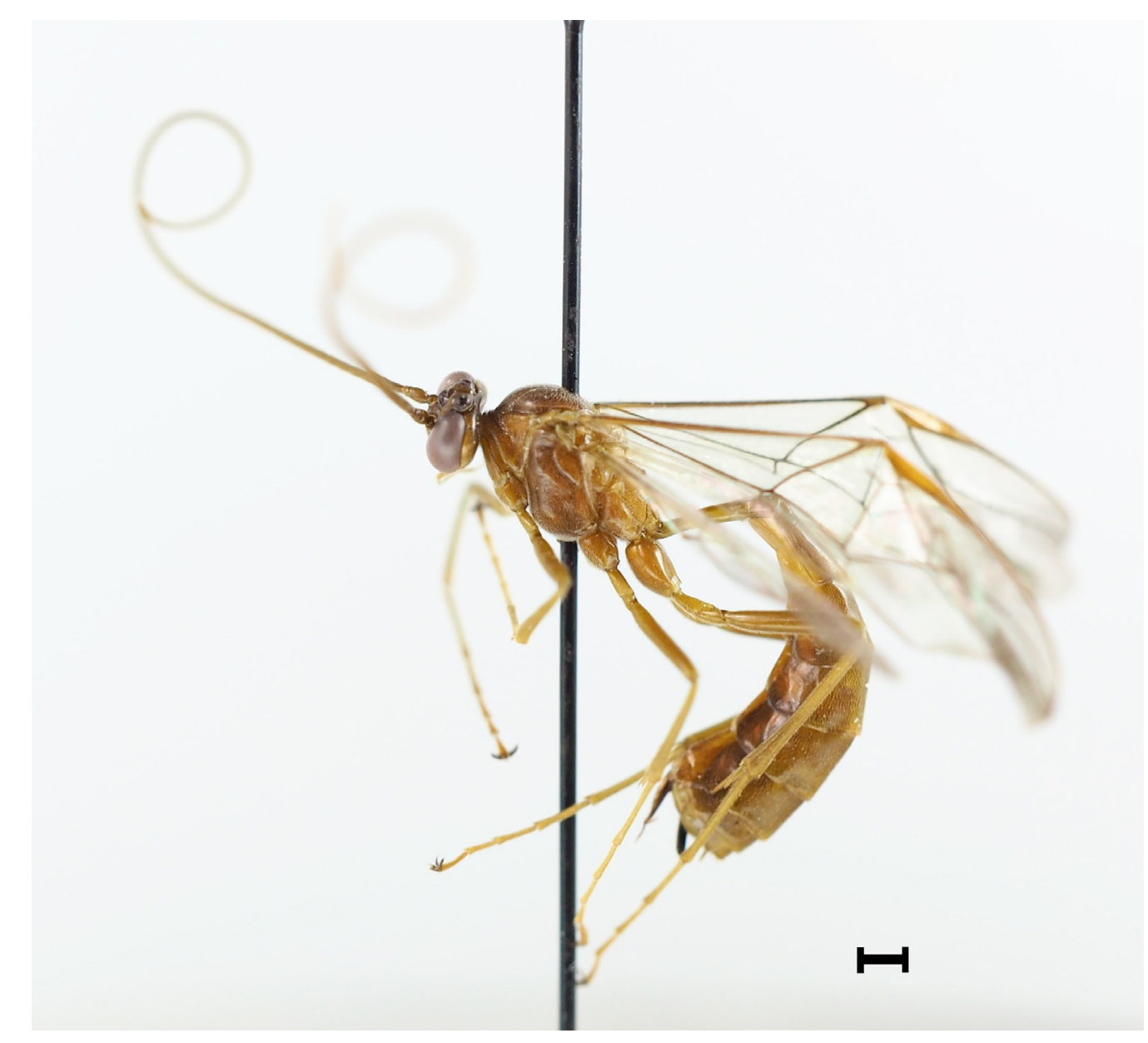

Fig. 28. Ophion brocki Johansson sp. nov., paratype, $q$ (NHRS-HEVA000008633). Scale bar $=1 \mathrm{~mm}$. 
- 1 ว ; Öland, Mörbylånga, Arontorp, Trollvägen; $56.646^{\circ} \mathrm{N}, 16.516^{\circ} \mathrm{E}$; T. Lindberg leg.; MV-light in garden close to deciduous forest; STI-NJBC132; NHRS-HEVA000008636.

\section{Description}

Fore wing length 15-16 mm. Antenna with 59-64 flagellomeres. First flagellomere 3.0 times as long as wide. Central flagellomeres stout, about 1.2-1.3 times as long as wide. Apical flagellomeres approximately 1.5 times as long as wide. Head quite narrowed behind eyes. Temple in lateral view 0.3-0.4 times as long as compound eye (Fig. 15G). Space between compound eye and lateral ocellus narrow, at most 0.1 times the diameter of ocellus. Head in anterior view transverse with compound eye large (Fig. 15D). Groove behind lateral ocellus usually very deep and distinct (Fig. 15B). Occipital carina centrally evenly rounded, sometimes very weakly angled. Face below antennal sockets shagreened with scarce punctures. Malar space about 0.1 times as long as mandibular base in female and about 0.1-0.2 times in males. Mandibular gape right-angled, with internal angles. Wing membrane clear. Ramellus very long, reaching $0.4-0.5$ the width of the discosubmarginal cell. Radius sinuous. Nervellus broken distinctly below the middle by the discoidella (Fig. 13E). Mesopleuron shagreened with punctures quite dense, space between punctures about equal to their diameter. Epicnemial carina, in antero-ventral view, with pleurosternal angles level to or slightly anterior to sternal angles. Pleurosternal angles slightly acute or right angled. Scutellum without lateral carinae. Propodeum with very weak rugose structure, shining, with anterior and posterior transverse carina usually strongly raised (Fig. 10C). In small males the anterior transverse carina is weak or absent laterally. Central and lateral longitudinal carinae usually strong, but sometimes lateral longitudinal carinae weaker. Sclerotised part of first sternite ending level to spiracle. Hind trochantellus shorter than wide in dorsal view. Legs normal with hind femur about six times as long as wide. Inner spur of hind tibia long about 0.4 times as long as hind metatarsus.

\section{Colour}

Body testaceous. Inner and outer eye margins sometimes yellow. Mandibular teeth black. Ovipositor sheath black or dark brown, contrasting in colour with posterior metasomal segments.

\section{DNA barcode}

The DNA barcode sequences of eight Swedish specimens of Ophion brocki Johansson sp. nov. are available at the BOLD systems database (www.boldsystems.org, BIN. BOLD: AAW9160. Specimen codes: STI-NJBC: 32, 76, 132, 134-136, 171-172).

\section{Ecology}

The taxonomic history of this species with frequent misidentifications makes it hard to draw any definitive conclusions regarding the host species and no rearing records are known. The main period of activity in Sweden seems to be early summer, May-June.

\section{Distribution in Sweden}

A very rare species known from two areas in the southeastern part of the country.

Ophion confusus Johansson sp. nov. urn:1sid:zoobank.org:act:0619F1A2-3A6F-494F-AA8D-95E19990DF3C

Figs 7A, 8I, N, 10D, 29

\section{Diagnosis}

Very similar and closely related to Ophion mocsaryi, but with occipital carina centrally rounded, straight or with a central depression and face below antennal socket shagreened, usually with denser and deeper 
punctures. Lateral carinae delimiting area superomedia often weaker or missing anteriorly and area superomedia narrower. In Swedish specimens the flagellomeres are also usually slightly stouter.

\section{Etymology}

This species has, together with Ophion brocki Johansson sp. nov., been confused with Ophion mocsaryi in collections.

\section{Material examined}

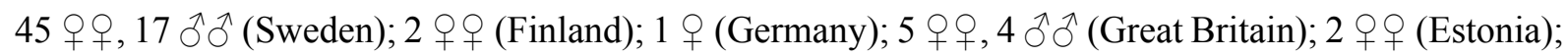
4 웅, 6 ठํํ (Norway).

\section{Type material}

\section{Holotype}

SWEDEN • + ; Skåne, Ystad, Kåseberga; 55.385 N, 14.066 E; 24 May-28 Jul. 2016; N. Ryrholm and C. Källander leg.; MV-light trap in sandy coastal grassland; STI-NJBC133; NHRS-HEVA000008637.

\section{Paratypes}

SWEDEN • 1 ㅇ, 1 ○; Bohuslän, Tossene, Nordens ark/Tiger; $58.440^{\circ} \mathrm{N}, 11.435^{\circ} \mathrm{E}$; 11 Mar.-30 Aug. 2014; N. Ryrholm and C. Källander leg.; MV-light trap in rocky mixed forest; STI-NJBC50, 296; NHRS-

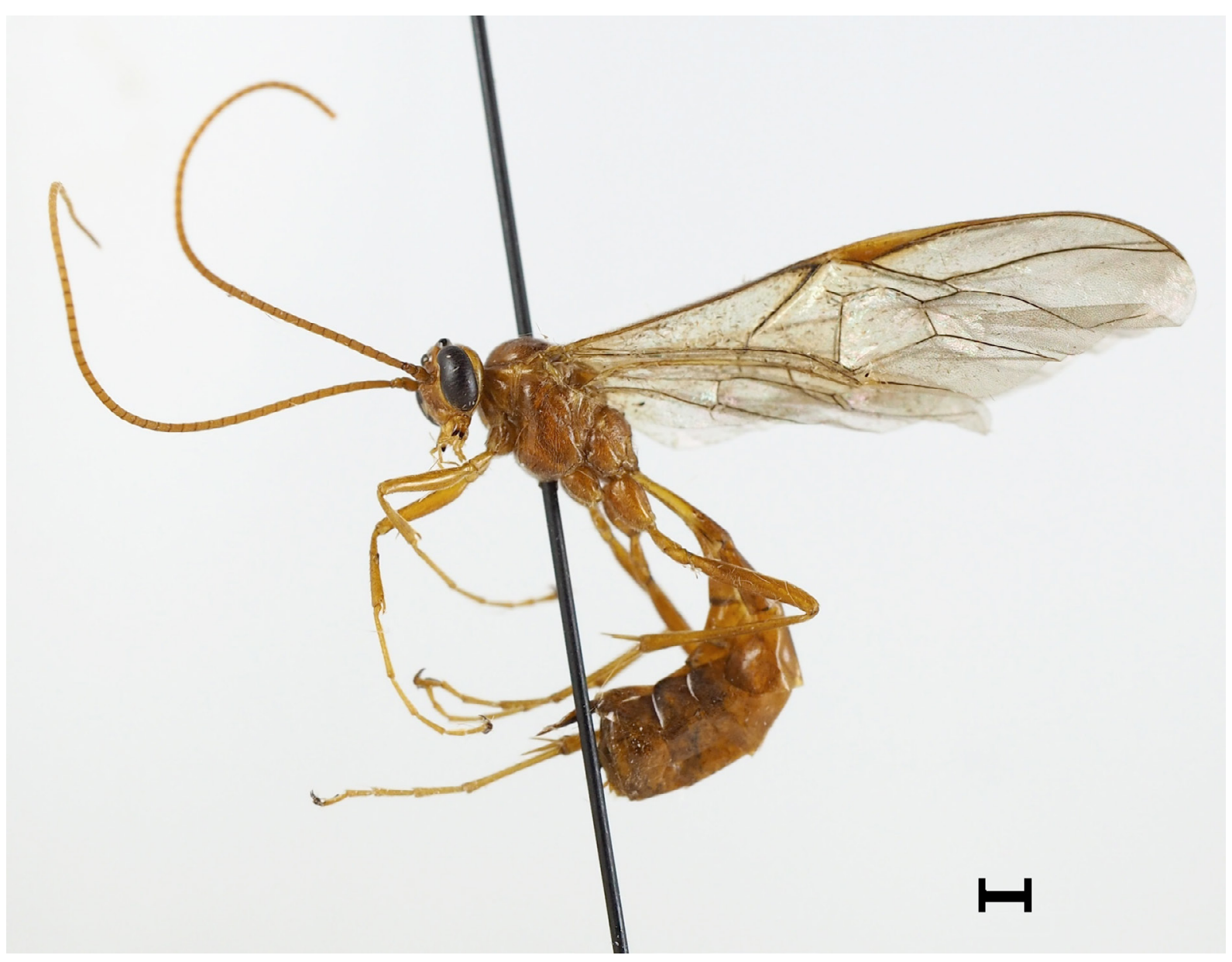

Fig. 29. Ophion confusus Johansson sp. nov., holotype, $q$ (NHRS-HEVA000008637). Scale bar $=1 \mathrm{~mm}$. 
HEVA000008638, NHRS-HEVA000008639 • 1 ㅇ, 1 ภ̊; Blekinge, Karlskrona, Vallgatan; $56.158^{\circ} \mathrm{N}$, $15.589^{\circ} \mathrm{E}$; 28 May 2016; T. Lindberg leg.; MV-light in garden close to deciduous forest; $\sigma^{\lambda}$ STINJBC51; NHRS-HEVA000008640, NHRS-HEVA000008641 • 1 q; Skåne, Simrishamn, Spraggehusen; $55.442^{\circ}$ N, $14.246^{\circ}$ E; 15 May-9 Jul. 2017; N. Ryrholm and C. Källander leg.; MV-light trap in sand dunes, pine forest; NHRS-HEVA000008642 - 1 q; Öland, Mörbylånga, Strandskogen; $56.702^{\circ} \mathrm{N}$, $16.494^{\circ} \mathrm{E}$; 20 Jun. 2015; M. Andersson leg.; MV-light trap in garden on sand close to deciduous forest; NHRS-HEVA000008643 • 1 O ; Västergötland, Habo, Gustaf Adolf, Aspåsen; 58.013 ${ }^{\circ} \mathrm{N}, 14.133^{\circ} \mathrm{E}$; 22 May-15 Jun. 2017; N. Johansson leg.; Malaise trap between wet deciduous forest and sandy meadow; NHRS-HEVA000008644 • 1 \%; Blekinge, Karlskrona, Tullaretorpet; $56.227^{\circ} \mathrm{N}, 15.647^{\circ} \mathrm{E}$; 31 May-1 Jun. 2016; C. Philipsson leg.; MV-light in deciduous oak dominated forest; NHRS-HEVA000008645 • 1 ; ; Blekinge, Karlskrona, Ingatorp; $56.239^{\circ} \mathrm{N}, 15.617^{\circ} \mathrm{E}$; 22-23 Jun. 2016; C. Philipsson leg.; MV-light in deciduous forest; NHRS-HEVA000008646 • 1 \%; Blekinge, Karlskrona, Tullaretorpet; $56.227^{\circ} \mathrm{N}$, $15.647^{\circ}$ E; 2-3 Jun. 2016; C. Philipsson leg.; MV-light in oak dominated forest; STI-NJBC43; NHRSHEVA000008647 • 2 q 9 ; Blekinge, Karlskrona, Vallgatan; 2 Jun. 2016; T. Lindberg leg.; MV-light in garden close to deciduous forest; STI-NJBC48, 233; NHRS-HEVA000008648, NHRS-HEVA000008649 - 1 O; Blekinge, Karlskrona, Vallgatan; $56.158^{\circ}$ N, $15.589^{\circ}$ E; 1 Jun. 2016; T. Lindberg leg.; MV-light in garden close to deciduous forest; NHRS-HEVA000008650 - 1 ; Södermanland, Haninge, Tyresta nationalpark, Urskogsslingan; 59.176 ${ }^{\circ} \mathrm{N}, 18.248^{\circ} \mathrm{E}$; 21 Jun.-20 Jul. 2004; SMTP leg.; Malaise trap in Norway spruce forest with blueberry (Trap id 4, coll ev. id. 809); STI-NJBC341; NHRS-HEVA000008651 - 1 O; Bohuslän, Tossene, Stora Hultet; 58.446 ${ }^{\circ}$ N, 11.409 ${ }^{\circ}$ E; 27 May-19 Nov. 2014; N. Ryrholm and C. Källander leg.; MV-light trap; STI-NJBC229; NHRS-HEVA000008652 • 1 q; Blekinge, Karlskrona, Stora Boråkra; $56.217^{\circ} \mathrm{N}, 15.589^{\circ} \mathrm{E}$; $18-19$ Jun. 2016; C. Philipsson leg.; MV-light in deciduous forest; STI-NJBC185; NHRS-HEVA000008653.

\section{Description}

Fore wing length $12-13 \mathrm{~mm}$. Antenna in both sexes with 53-59 flagellomeres. First flagellomere about 3.0 times as long as wide. Subbasal flagellomeres 1.4-1.5 times as long as wide (Fig. 8N). Central flagellomeres about 1.2-1.3 times as long as wide. Subapical flagellomeres approximately 1.5 times as long as wide. Head in female and male weakly buccate behind eye. Temple in lateral view $0.4-0.5$ as long as compound eye. Lateral ocellus usually touching inner margin of compound eye. Occipital carina centrally rounded, straight or with central depression (Fig. 7A). Face below antennal socket shagreened with dense deep punctures (Fig. 8I). Malar space about 0.1 times as long as mandibular base in female and male. Mandibular gape right-angled, with internal angles. Wing membrane clear. Ramellus distinct, $0.3-0.5$ times the width of the discosubmarginal cell. Radius sinuous, but often evenly curved in males. Nervellus broken distinctly below the middle. Mesopleuron weakly shagreened, distinctly punctate. Interstices between punctures about 1.0-2.0 times their diameter. Epicnemial carina, in antero-ventral view, with pleurosternal angles slightly anterior to sternal angles. Pleurosternal angles slightly acute (Fig. 9B). Scutellum without distinct lateral carinae in basal half. Structure of propodeum quite shiny and slightly rugose, basally and laterally with distinct punctures. Anterior transverse carina often absent laterally but frequently complete. Posterior transverse carina interrupted centrally and often weak laterally. Longitudinal carinae delimiting area superomedia weaker anteriorly, often dissolving against the shagreened or rugose background. Area superomedia slightly longer than wide. Hind trochantellus shorter than wide in dorsal view. Legs normal with hind femur 6.0-7.0 times as long as wide. Sclerotised part of first sternite ending level to spiracle (as in Fig. $6 \mathrm{H}$ ). Inner spur of hind tibia as long as 0.4 times metatarsus.

\section{Colour}

Body testaceous. Mandibular teeth black. Head with inner and outer eye margins broadly yellow. Ovipositor sheath black or dark brown, contrasting in colour with posterior metasomal segments. 


\section{DNA barcode}

The DNA barcode sequences of 11 Swedish specimens of Ophion confusus Johansson sp. nov. are available at the BOLD systems database (www.boldsystems.org, BIN. BOLD: ABV8262. Specimen codes: STI-NJBC: 43, 48, 50-51, 133, 185, 229, 233, 265, 296, 341).

\section{Ecology}

According to Brock (1982) O. mocsaryi s. lat. (most likely including O. confusus sp. nov.) has been reared from several species of Noctuidae. Several of these records probably refer to closely related species in the aggregate. One female in NHRS is reared from Agrochola lota (Clerck, 1759) which is also one of relatively few hosts listed by Brock. Ophion confusus Johansson sp. nov. seems to be most frequently collected in or near to semi-open forests. It is active mainly during May and June.

\section{Distribution in Sweden}

A quite common species in Southern Sweden, but rarer or absent in the Central and Northern parts of the country.

\section{Remarks}

According to BOLD the species also occurs in Britain, the Netherlands and Germany.

Ophion costatus Ratzeburg, 1848

Figs $7 \mathrm{G}, 8 \mathrm{H}, 10 \mathrm{~B}, 47 \mathrm{~A}-\mathrm{B}$

Ophion costatus Ratzeburg, 1848: 79-80.

\section{Material examined}

82 우우, $17 \widehat{\jmath} \widehat{\partial}$ (Sweden); $2 \widehat{\partial}$ (Great Britain); 1 q (Germany); $1 \widehat{\partial}$ (Hungary); 2 우 (Norway); 3 우 (Lithuania).

\section{Diagnosis}

Fore wing length (15) 17-19 mm. Antenna with 48-55 flagellomeres. First flagellomere 4.0 times as long as wide. Second flagellomere about 2.0 times as long as wide. Central flagellomeres about 1.5-1.6 times as long as wide. Apical flagellomeres approximately 1.5 times as long as wide. Flagellomeres in females, less so in males, with rather long prominent pilosity. Length of pilosity about 0.5 width of flagellomere (Fig. 8B). Head narrowed behind eyes, in lateral view temple $0.4-0.5$ as long as compound eye, more buccate in males, 0.6-0.7 times as wide as compound eye. Lateral ocellus touching compound eye. In female lateral ocelli quite large, the distance between lateral ocelli about 0.4 times the diameter of ocellus. Malar space about 0.1 times as long as mandibular base in female and about $0.2-0.3$ times in males. Mandibular gape right-angled, with internal angles. Wing membrane weakly yellowish. Ramellus distinct, reaching $0.2-0.3$ the width of discosubmarginal cell. Radius evenly curved (as in Fig. 13A). Mesopleuron polished or sometimes weakly shagreened with quite weak punctures, interstices between punctures about equal or slightly larger than their diameter. Epicnemial carina, in antero-ventral view, with pleurosternal angles obviously anterior to sternal angles. Pleurosternal angles rounded, strongly obtuse. Scutellum with lateral carinae only indicated basally (as in Fig. 6A). Propodeum with very weak rugose structure, shiny with anterior and posterior transverse carina strongly raised in female (Figs 10B, 47A-B). Anterior transverse carina in males often weak or absent laterally. Petiolar carinae usually strong. Longitudinal carinae delimiting area superomedia in large specimens rather strong, in smaller specimens frequently weak or absent, but normally clearly indicated at the junction with the posterior transverse carina. Propodeum centrally, 
between anterior and posterior transverse carina, usually with a distinct longitudinal fold in both males and females (Figs 10B, 47A). Hind trochantellus shorter than wide in dorsal view. Legs, especially in females, normally quite stout with hind femur about 6.0 times as long as wide. Hind tarsus stout, fourth segment about 2 times as long as wide; fifth segment slightly longer than fourth (Fig. 8H), mid tarsus with fourth segment stout 0.6 times as long as fifth segment. Sclerotised part of first sternite ending slightly posterior to spiracle (as in Fig. $6 \mathrm{G}-\mathrm{H}$ ). Inner spur of hind tibia as long as 0.4 times hind metatarsus.

\section{Colour}

Body testaceous, frequently with distinct brownish patches on mesosternum, mesopleuron, propodeum and three stripes on mesoscutum. Mandibular teeth black. Inner and outer eye margins yellowish. First tergite often distinctly paler anterior to spiracle. Antennae bright orange. Ovipositor sheath often infuscate, slightly contrasting with posterior metasomal segments, in specimens with infuscate markings frequently brownish.

\section{DNA barcode}

The DNA barcode sequences of nine Swedish specimens of Ophion costatus are available at the BOLD systems database (www.boldsystems.org, BIN. BOLD: ADG0653. Specimen codes: STI-NJBC: 35, 38, 235-241).

\section{Ecology}

The species occurs primarily in forest landscapes and is active during August-October. The known hosts are Acronicta Ochsenheimer, 1816 species. Ophion costatus has been reared from Acronicta leporina (Linnaeus, 1758) and the original description refers to a rearing from A. aceris (Linnaeus, 1758), both of which have very hairy final instar larvae.

\section{Distribution in Sweden}

A common species in Southern and Central Sweden, rarer in the north.

\section{Remarks}

The type material of Ophion costatus is lost and the species has historically been the subject of numerous misinterpretations. This study shows that the name applies to one of the species in an aggregate previously treated under the name Ophion parvulus (see Discussion). Ophion costatus is distinguished from the other species in the aggregate currently known from Sweden on the stouter tarsal segments in the female, the usually typical carination of the propodeum and the generally larger size. The flagellomeres have approximately the same shape as in Ophion parvulus but usually have slightly longer pilosity. The barcoded specimens (Fig. 1) forms three separate groups that share the same distinguishing characters.

Ophion crassicornis Brock, 1982

Figs 9G, 10E, 14D, F, 30A-B

Ophion crassicornis Brock, 1982: 84-85.

\section{Material examined}

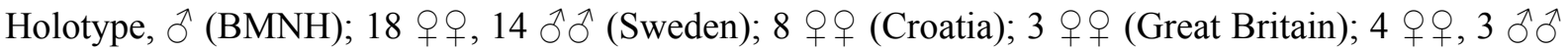
(France). 


\section{Diagnosis}

Fore wing length 15-16 mm. Antenna in both sexes with (55) 57-61 flagellomeres. First flagellomere 3.0 times as long as wide. Central flagellomeres stout, about 1.2-1.3 times as long as wide. Subapical flagellomeres approximately 1.5 times as long as wide. Temple in female and male strongly buccate (Fig. 30A-B). Head in lateral view with temple $0.9-1.0$ as long as compound eye. Gap between lateral ocellus and inner margin of compound eye distinct, about $0.1-0.2$ times the diameter of ocellus. Face below antennal sockets quite polished with distinct interstices between punctures. Malar space about 0.2 times as long as mandibular base in female and about 0.2-0.3 times in male. Mandibular gape right-angled, with internal angles. Wing membrane clear to slightly yellowish. Ramellus distinct, reaching about 0.5 times the width of the discosubmarginal cell. Radius sinuous. Mesopleuron shagreened with very dense, large punctures that often merge centrally. Epicnemial carina, in antero-ventral view, with pleurosternal angles slightly anterior to sternal angles (Fig. 9G). Pleurosternal angles acute to slightly obtuse. Scutellum occasionally with distinct lateral carinae in basal half, but sometimes only in basal 0.2 (as in Fig. 6A). Propodeum distinctly punctate and coriaceous in front of anterior transverse carina. Between transverse carina more often quite shiny, weakly rugose. Anterior transverse carina often absent laterally in Nordic specimens, evenly and rather strongly curved (Figs 10E, 14D) and posterior transverse carina often widely interrupted

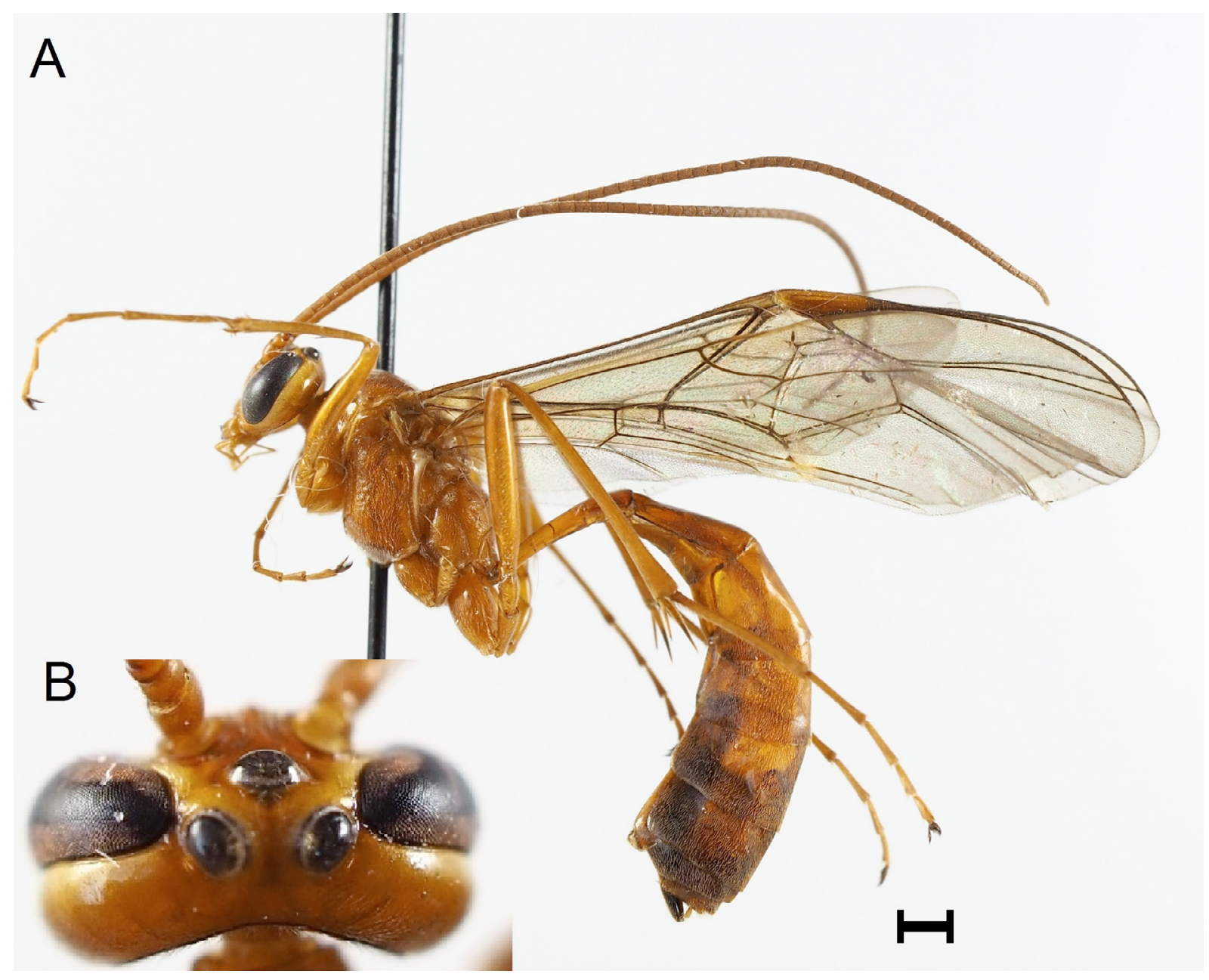

Fig. 30. Ophion crassicornis Brock, 1982, ․ A. Habitus lateral view. B. Head dorsal view. Scale bar: $\mathrm{A}=1 \mathrm{~mm}$. 
centrally. Central longitudinal carinae delimiting area superomedia and area petiolaris often strong but sometimes weaker before joining the anterior transverse carina. Area superomedia usually quite narrow (Fig. 14D). Hind trochantellus shorter than wide in dorsal view. Legs normal with hind femur about 7.0 times as long as wide. Sclerotised part of first sternite ending level to spiracle. Inner spur of hind tibia as long as 0.4 times hind metatarsus.

\section{Colour}

Body testaceous. Head with inner and outer eye margins yellow. Mandibular teeth black. Ovipositor sheath black or dark brown, contrasting in colour with posterior metasomal segments. Posterior abdominal segments and apical half of antennae in males frequently infuscate. Scutellum laterally in basal part usually pale in females.

\section{DNA barcode}

The DNA barcode sequences of 11 Swedish specimens of Ophion crassicornis are available at the BOLD systems database (www.boldsystems.org, BIN. BOLD: ACI6839. Specimen codes: STI-NJBC: $46,70,80-82,183-184,217,300,309,331)$.

\section{Ecology}

Brock (1982) refers to a reputed rearing from Aporophyla nigra (Haworth, 1809), a species not known from the Swedish fauna. The population on the Swedish mainland is active primarily during June and the species mainly occurs in open or semi-open environments.

\section{Distribution in Sweden}

Quite rare but widespread in the southern and central parts of the country.

\section{Remarks}

According to BOLD the species also probably occurs in central Europe (France, Britain, Germany and Bulgaria) and Croatian specimens have also been studied by the first author. Brock (1982) also refers to the existence of a 'northern morph' occurring in the northern parts of the British islands. No such northern crassicornis morph has been detected in this study, but through British material kindly provided by Gavin Broad at the BMNH it might be suspected that Brock's observations refer to Ophion kevoensis as interpreted in this study or Ophion broadi Johansson sp. nov., a conclusion also supported by the statement that $O$. crassicornis is said to have the hind trochantellus "sometimes agreeing with luteus" (Brock 1982). Ophion crassicornis is very similar to and easily confused with Ophion borealis Johansson sp. nov., but is distinguished by the less transverse head in anterior view, the wider clypeus, the larger punctures on the mesopleuron, the more densely punctate face and the shape of the anterior transverse carina of the propodeum. Also similar to Ophion angularis Johansson \& Cederberg sp. nov., but with less prominent pleurosternal angles, usually fewer flagellomeres, slightly more buccate temples, partly carinated scutellum and face less densely punctate.

Ophion dispar Brauns, 1895

Figs 6D, F, 9C, 10K, 31A-B

Ophion dispar Brauns, 1895: 42.

\section{Material examined}

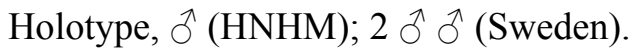




\section{Diagnosis}

Fore wing length $11 \mathrm{~mm}$. Antenna with 44 flagellomeres. First flagellomere 3.0 times as long as wide. Central flagellomeres stout, about 1.2-1.3 times as long as wide. Subapical flagellomeres approximately 1.4 times as long as wide. Temple quite buccate, in lateral view 0.7 times as long as compound eye. Gap between compound eye and lateral ocellus 0.3 times the diameter of ocellus. Face below antennal sockets polished with very large and deep punctures (Fig. 31B). Malar space very long, about 0.8 times as long as mandibular base in male. Mandibular gape right-angled, with internal angles. Wing membrane clear. Ramellus very long, reaching 0.6 times the width of the discosubmarginal cell. Radius evenly curved. Nervellus broken above the middle by the discoidella. Mesopleuron polished with deep, large, regular punctures, space between punctures equal to their diameter. Epicnemial carina, in antero-ventral view, with pleurosternal angles distinctly anterior to sternal angles. Pleurosternal angles weakly defined and obtuse (Fig. 9C). Scutellum with strongly raised lateral carinae along its entire length (Fig. 6D). Propodeum with large distinct punctures, shining. Posterior transverse carina complete but weak in the Swedish specimens (stronger in the holotype). Anterior transverse carina absent laterally, only present centrally. Longitudinal carinae entirely absent (Fig. 10K). Hind trochantellus shorter than wide in dorsal view. Legs normal with hind femur about 7.0 times as long as wide. Inner spur of hind tibia long, about 0.5 times as long as metatarsus. Sclerotised part of first sternite ending distinctly posterior to spiracle at a distance about three times the distance between the spiracle and the lower margin of the first tergite (Fig. 6F).

\section{Colour}

Body testaceous. Head with inner and outer eye margins yellow (Fig. 31A-B). Mandibular teeth black.

\section{DNA barcode}

The DNA barcode sequence of one Swedish specimens of Ophion dispar is available at the BOLD systems database (www.boldsystems.org, BIN. BOLD: ADG0606. Specimen code: STI-NJBC: 85).

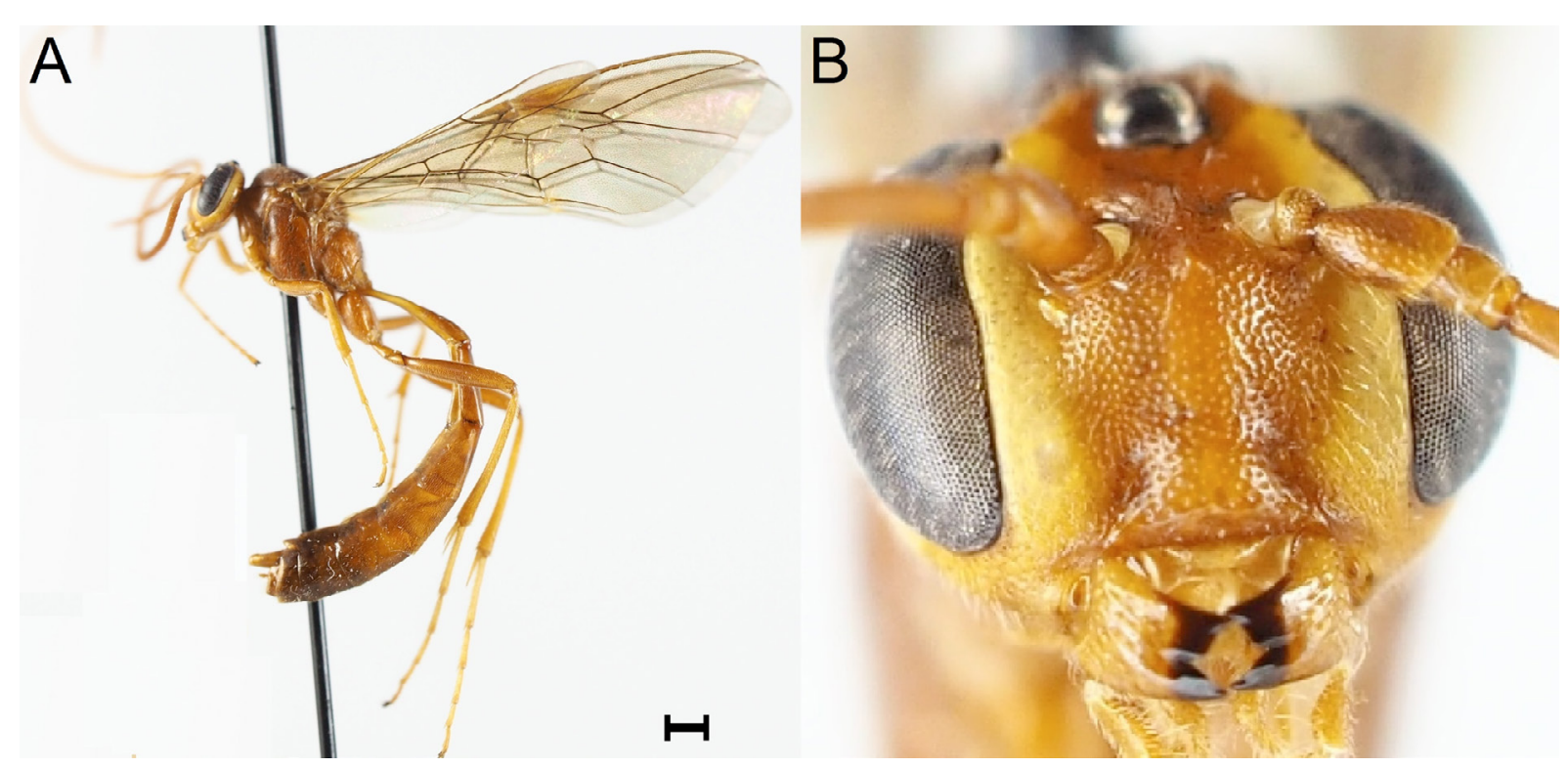

Fig. 31. Ophion dispar Brauns, 1895, đ̂. A. Habitus lateral view. B. Head frontal view. Scale bar: A = $1 \mathrm{~mm}$. 


\section{Ecology}

The two known Swedish males were collected by a light trap during June in a semi-open mixed forest. Otherwise, nothing is known about the ecology of this species.

\section{Distribution in Sweden}

Very rare and only known from the province of Uppland in the eastern part of Central Sweden.

\section{Remarks}

Easily distinguished from other Ophion species by the placement of the spiracle on the very elongate first tergite, the carination of the propodeum, the shape of the epicemial carina and the densely and deeply punctate mesosoma and face. The first author has studied a potential female of this species from Croatia. The specimen has 52 flagellomeres and the lateral carinae of scutellum weaker, but still clearly present. The posterior margin of the first sternite is further away from the posterior margin of the first tergite than in the studied males, but the first sternite is still ending posterior to the spiracle at a distance of about 2.0 times of the distance between hind margin of the first sternite and hind margin of the first tergite. In other respects similar to the male described here.

Ophion ellenae Johansson sp. nov. urn:1sid:zoobank.org:act:66D1B37B-DDE5-44DA-8B9E-968A65D91769

Figs $8 \mathrm{D}, 10 \mathrm{G}, 18 \mathrm{~F}, 21 \mathrm{~A}, \mathrm{C}, 32$

\section{Diagnosis}

Superficially similar to Ophion inclinans Johansson sp. nov. and $O$. arenarius Johansson sp. nov., but never with the dorsal undulation on the first tergite. Usually more densely punctured face below the antennal sockets, more prominent and sharper pleurosternal angles and stouter flagellomeres. Closely related and very similar to $O$. perkinsi and $O$. norei Johansson sp. nov., but with the head more narrowed behind the eyes, no gap between the eye and lateral ocellus, complete anterior transverse carina of the

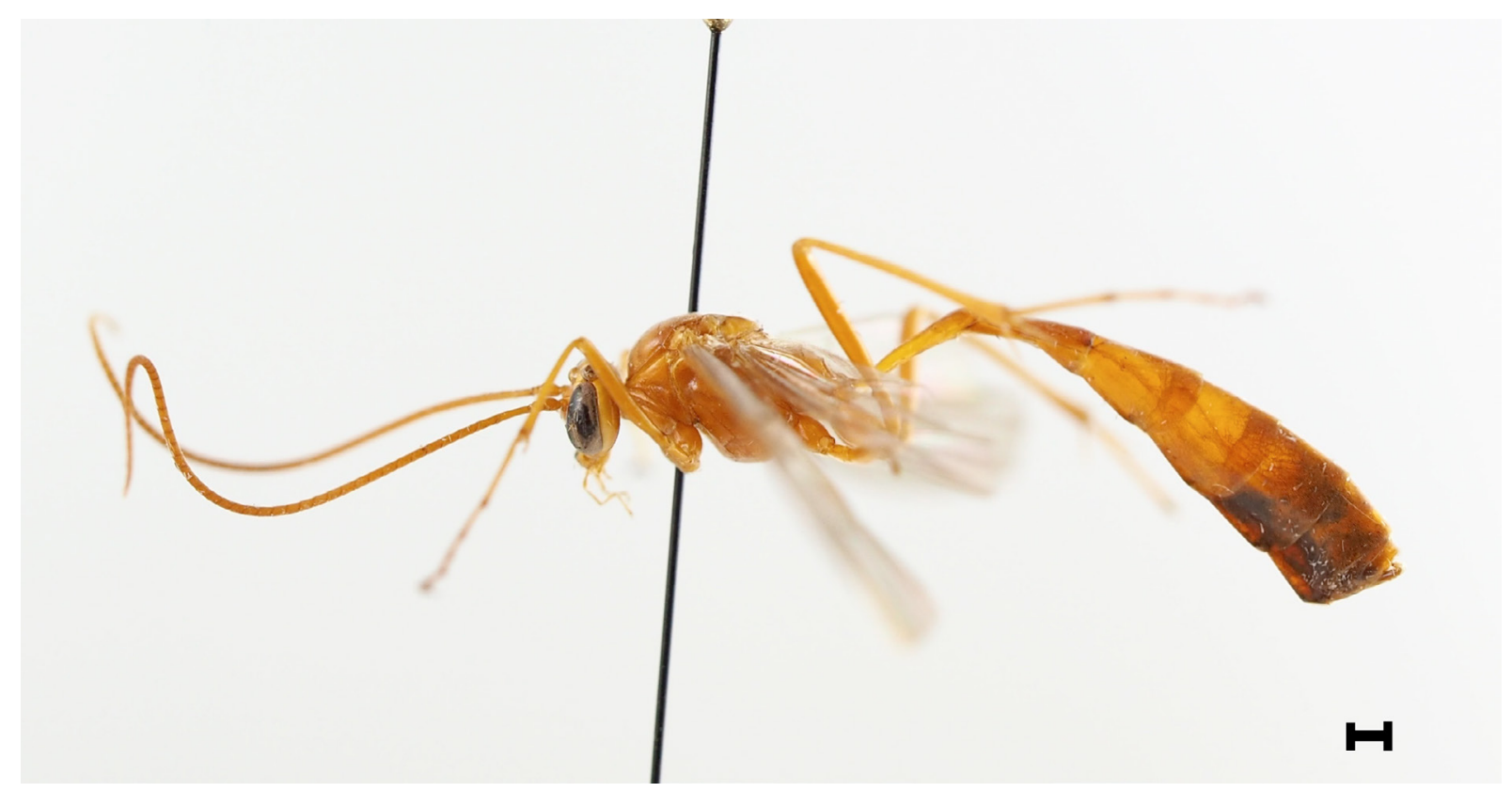

Fig. 32. Ophion ellenae Johansson sp. nov., paratype, $q$ (MZLU Type no. 6370:1). Scale bar $=1 \mathrm{~mm}$. 
propodeum and more numerous flagellomeres. Most closely related, however, to O. matti Johansson sp. nov., but distinguished by the more shining and less densely punctate mesoscutum, the shorter area superomedia and the more elongate basal flagellomeres.

\section{Etymology}

The species is named in honour of the authors' wife, Ellen Nystedt.

\section{Material examined}

30 우, 1 Љ (Sweden); 2 우 (Finland); 1 (

\section{Type material}

\section{Holotype}

SWEDEN • O; Närke, Lerbäck, Hugghult; 58.949 N, 15.045 E; 15 Aug. 2003; A. Larsson leg.; Sweepnet; STI-NJBC188; NHRS-HEVA000008654.

\section{Paratypes}

SWEDEN • 1 क; Gotland, Sundre, Suders; $56.945^{\circ}$ N, $18.303^{\circ}$ E; 14 Jul.-17 Aug. 2017; N. Ryrholm

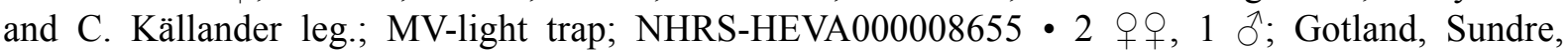
Suders; $56.945^{\circ} \mathrm{N}, 18.303^{\circ}$ E; 29 Jul.-18 Sep. 2017; N. Ryrholm and C. Källander leg.; MV-light trap in deciduous woodland; STI-NJBC307, STI-NJBC301; NHRS-HEVA000008656 to NHRSHEVA000008658 • 1 क; Gotland, Tofta, Nasume myr; $57.537^{\circ} \mathrm{N}, 18.129^{\circ} \mathrm{E} ; 23$ Jul. 2016; J. Törnvall leg.; MV-light by mire; NHRS-HEVA000008659 • 1 \%; Skåne, Klippan, Bonnarpshed; $56.087^{\circ} \mathrm{N}$, $13.176^{\circ}$ E; 5-30 Aug. 2007; N. Ryrholm and C. Källander leg.; MV-light trap in open grazed heathland; STI-NJBC87; NHRS-HEVA000008660 • 1 O ; Gotland, Sundre, Barrshage; $56.922^{\circ} \mathrm{N}, 18.186^{\circ} \mathrm{E}$; 28 Aug.-22 Sep. 2017; N. Ryrholm and C. Källander leg.; MV-light trap in wet meadows surrounded by deciduous forest; NHRS-HEVA000008661 • 1 \%; Öland, Borgholm, Halltorps hage; $56.794^{\circ} \mathrm{N}$, 16.573 ${ }^{\circ}$ E; 24-30 Jul. 1938; N. Bruce leg.; NHRS-HEVA000008662 • 1 \%; same data as for preceding; 1-5 Aug. 1939; N. Bruce leg.; NHRS-HEVA000008663 • 1 q; Uppland, Rådmansö, Bergholmen; 59.708 ${ }^{\circ}$ N, $18.955^{\circ}$ E; 29 Jul.-18 Sep. 2017; N. Ryrholm and C. Källander leg.; MV-light trap in coastal mixed forest; NHRS-HEVA000008664 • 1 O ; Öland, Mörbylånga, Räpplinge; $56.827^{\circ} \mathrm{N}$, $16.660^{\circ}$ E; 27 Jul.1975; L.-Å. Janzon leg.; MV-light; MZLU Type no. 6370:1 • 4 q $q$; same data as for preceding; 26 Jul. 1980; L.-Å. Janzon leg.; MV-light; MZLU Type no. 6370:2 to MZLU Type no. 6370:5 - 1 क; Gotland, Hamra, Långmyre; $56.962^{\circ} \mathrm{N}, 18.292^{\circ} \mathrm{E} ; 2-25$ Aug. 1997; N. Ryrholm and C. Källander leg.; MV-light trap; STI-NJBC305; NHRS-HEVA000008665 • 1 q; Gotland, Hamra, Tuvlandet; $56.966^{\circ}$ N, $18.308^{\circ}$ E; 15 Jul.-18 Aug. 2017; N. Ryrholm and C. Källander leg.MV-light trap in abandoned farmland; STI-NJBC306; NHRS-HEVA000008666.

\section{Description}

Fore wing length $15-16 \mathrm{~mm}$. Antenna with 52-54 flagellomeres. First flagellomere 3.5 times as long as wide. Second flagellomere about 2.2 times as long as wide. Central flagellomeres stout, about 1.2-1.3 times as long as wide. Subapical flagellomeres approximately 1.5 times as long as wide (Fig. 8D). Temple relatively short. Head in lateral view with temple $0.4-0.5$ times as long as compound eye (Fig. 21C). Gap between compound eye and lateral ocellus 0.1 times the diameter of ocellus. Face below antennal sockets with dense punctures. Interstices between punctures 0.5 times their diameter. Malar space about $0.1-0.2$ times as long as mandibular base in female and male. Mandibular gape rightangled, with internal angles. Wing membrane clear. Ramellus short, reaching $0.2-0.4$ times the width of the discosubmarginal cell. Radius sinuous. Mesoscutum shining with irregular and weak punctures, interstices between punctures about equal to their diameter (Fig. 21A). Mesopleuron shagreened with deep, dense punctures, space between punctures 0.5 times their diameter. Epicnemial carina, in antero- 
ventral view, with pleurosternal angles almost in level with sternal angles, pleurosternal angles right angled. Scutellum quite wide with distinct lateral carinae in basal 0.8-0.9 (as in Fig. 6C). Propodeum with very weak rugose structure, shining with anterior and posterior transverse carina often strongly raised. Central longitudinal carinae strong, lateral longitudinal carina absent. Area superomedia relatively short, almost square (Figs 10G, 18F). Hind trochantellus shorter than wide in dorsal view. Legs normal with hind femur about 6.0 times as long as wide. Sclerotised part of first sternite ending distinctly posterior to spiracle at a distance equal to that between hind margin of the sclerotised part of the first sternite and hind margin of the first tergite. Inner spur of hind tibia as long as 0.5 times metatarsus.

\title{
Colour
}

Body testaceous. Mandibular teeth black. Head with inner and outer orbits yellow. Ovipositor sheath testaceous.

\section{DNA barcode}

The DNA barcode sequences of six Swedish specimens of Ophion ellenae Johansson sp. nov. are available at the BOLD systems database (www.boldsystems.org, BIN. BOLD: ADM4635. Specimen codes: STI-NJBC: 87, 188, 301, 305-307).

\section{Ecology}

One male and one female kept in NHRS (Sweden, Upl, Sandhamn, Ljungdahl leg.) have been reared from the rare moth Hadena bicruris (Hufnagel, 1766). The available data for the parasitoid suggests a connection to open dry, sandy or rocky grassland, which also is the main habitat of the known host and some of its close relatives. Ophion ellenae Johansson sp. nov. is active from late July to early September.

\section{Distribution in Sweden}

Most frequently collected in coastal areas of the eastern parts of Central Sweden where it can be locally abundant. Older records are known from a wider area in Central Sweden (Uppland, Västmanland and Dalsland) indicating a decline during the last century.

\section{Remarks}

This species is very closely related to $O$. matti Johansson sp. nov. (Fig. 4). The two species are very similar and also share the same BIN. The slight but distinct morphological differences, supported by the barcoding results motivates the description of a separate species.

Ophion forticornis Morley, 1915

Fig. 100

Ophion forticornis Morley, 1915: 270-271.

Ophion baueri Habermehl, 1930: 114-115.

\section{Material examined}

\author{
$1 \uparrow, 1 \precsim$ (Sweden).
}

\section{Diagnosis}

Fore wing length $13 \mathrm{~mm}$. Antenna with 49 flagellomeres. First flagellomere 3.5 times as long as wide. Central flagellomeres about 1.2 times as long as wide. Temple strongly buccate. Head in lateral view temple 0.9 times as long as compound eye. Head in dorsal view with distinct gap between lateral ocellus and compound eye. Gap about 0.5 times ocellar diameter. Malar space about 0.1 times as long as 
mandibular base in female and about 0.1-0.2 times in male. Mandibular gape right-angled, with internal angles. Wing membrane clear. Ramellus distinct, reaching $0.2-0.3$ times the width of the discosubmarginal cell. Mesopleuron shiny, or sometimes weakly shagreened, with quite weak punctures, space between punctures about equal or slightly larger than their diameter. Epicnemial carina, in antero-ventral view, with pleurosternal angles slightly anterior to sternal angles. Pleurosternal angles rounded, obtuse. Scutellum with lateral carinae absent. Propodeum with carination very strong. Posterior transverse carina forming four prominent spines at junctions with longitudinal carinae (Fig. 10O). Hind trochantellus shorter than wide in dorsal view. Legs normal with hind femur about 6.0 times as long as wide. Sclerotised part of first sternite ending distinctly posterior to spiracle. Inner spur of hind tibia as long as 0.3 times hind metatarsus.

\section{Colour}

Body testaceous with rich pale pattern on mesoscutum, mesopleuron, head and scutellum (as in Fig. 7A-B). Mandibular teeth black.

\section{Ecology}

This species occurs in early summer, May-early June, in sand dune areas. Brock (1982) lists a possible rearing through Actebia praecox (Linnaeus, 1758).

\section{Distribution in Sweden}

Very rare, only known from a couple of specimens from sand dunes in Southern Sweden. Only one recent record from Koster, an island on the West coast of Sweden.

Ophion inclinans Johansson sp. nov. urn:1sid:zoobank.org:act:53FE412C-94FB-4D9B-A4EF-10EA7145189A

Figs 6C, E, 8F, 13C, 16D, 19C-D, 33

\section{Diagnosis}

Separated from other Ophion species by the combination of the carinated scutellum, the dorsal undulation of the first tergite, the shape of the head and placement and size of the ocelli. Very similar to Ophion pteridis and $O$. vardali Johansson sp. nov., but without infuscate areas on the mesosoma, slightly wider head in anterior view and the occipital carina usually centrally rounded or straight. From $O$. pteridis it is also distinguished by the usually widely interrupted posterior transverse carina of the propodeum with the area posterior to the carina rather smooth. In all studied specimens of $O$. pteridis the posterior transverse carina is complete and the area delimited by it strongly wrinkled. Also quite similar to Ophion paukkuneni Johansson sp. nov. but with less buccate head and the lateral ocellus touching the compound eye. Perhaps most easily confused with Ophion arenarius Johansson sp. nov., but with the flagellomeres more elongate and the head usually slightly narrower in anterior view.

\section{Etymology}

Inclinans from the dorsal undulation of the first tergite in this species.

\section{Material examined}

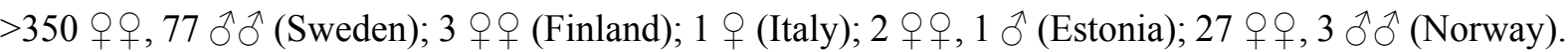

\section{Type material}

\section{Holotype}

SWEDEN • ; Norrbotten, Haparanda, Reikkola; $65.818^{\circ}$ N, $24.140^{\circ}$ E; 9 Sep.-8 Oct. 2016; N. Ryrholm and C. Källander leg.; MV-light trap in boreal forest, meadow; STI-NJBC28; NHRS-HEVA000008667. 
Paratypes

SWEDEN • 1 ; ; Bohuslän, Tossene, Stora Hultet; $58.446^{\circ}$ N, $11.409^{\circ}$ E; 24 Jul.-14 Sep. 2014; N. Ryrholm and C. Källander leg.; MV-light trap in farmland; NHRS-HEVA000008668 • 1 \%; Norrbotten, Haparanda, Santasaari; $65.817^{\circ}$ N, 24.133 ${ }^{\circ}$ E; 9 Aug. -8 Oct. 2016; N. Ryrholm and C. Källander leg.; MV-light trap; STI-NJBC29; NHRS-HEVA000008669・1 ○; Bohuslän, Tossene, Stora Hultet; $58.446^{\circ} \mathrm{N}, 11.409^{\circ} \mathrm{E}$; 15 Sep.-16 Oct. 2014; N. Ryrholm and C. Källander leg.; MV-light trap in framland; STI-NJBC18; NHRS-

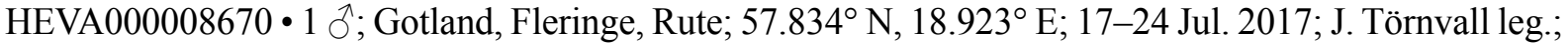
MV-light; NHRS-HEVA000008671 • 1 ○ं; Gotland, Sundre, Suders; $56.945^{\circ}$ N, $18.303^{\circ}$ E; 14 Jul. -17 Aug. 2017; N. Ryrholm and C. Källander leg.; MV-light trap in deciduous woodland; NHRS-HEVA000008672 - 1 Oे; Uppland, Norrtälje, Rådmansö; $59.708^{\circ}$ N, $18.955^{\circ}$ E; 10 Oct.-15 Nov. 1991; N. Ryrholm and C. Källander leg.; MV-light trap in mixed coastal forest; NHRS-HEVA000008673 • 1 \&; Norrbotten, Haparanda, Reikkola; $65.818^{\circ}$ N, 24.140 E; 9 Sep.-8 Oct. 2016; N. Ryrholm and C. Källander leg.; MVlight trap in boreal forest, meadow; NHRS-HEVA000008674.

\section{Description}

Fore wing length $13-17 \mathrm{~mm}$. Antenna in both sexes with 50-59 flagellomeres. First flagellomere 3.5-4.0 times as long as wide. Central flagellomeres 1.8-2.0 times as long as wide (Fig. 8F). Subapical

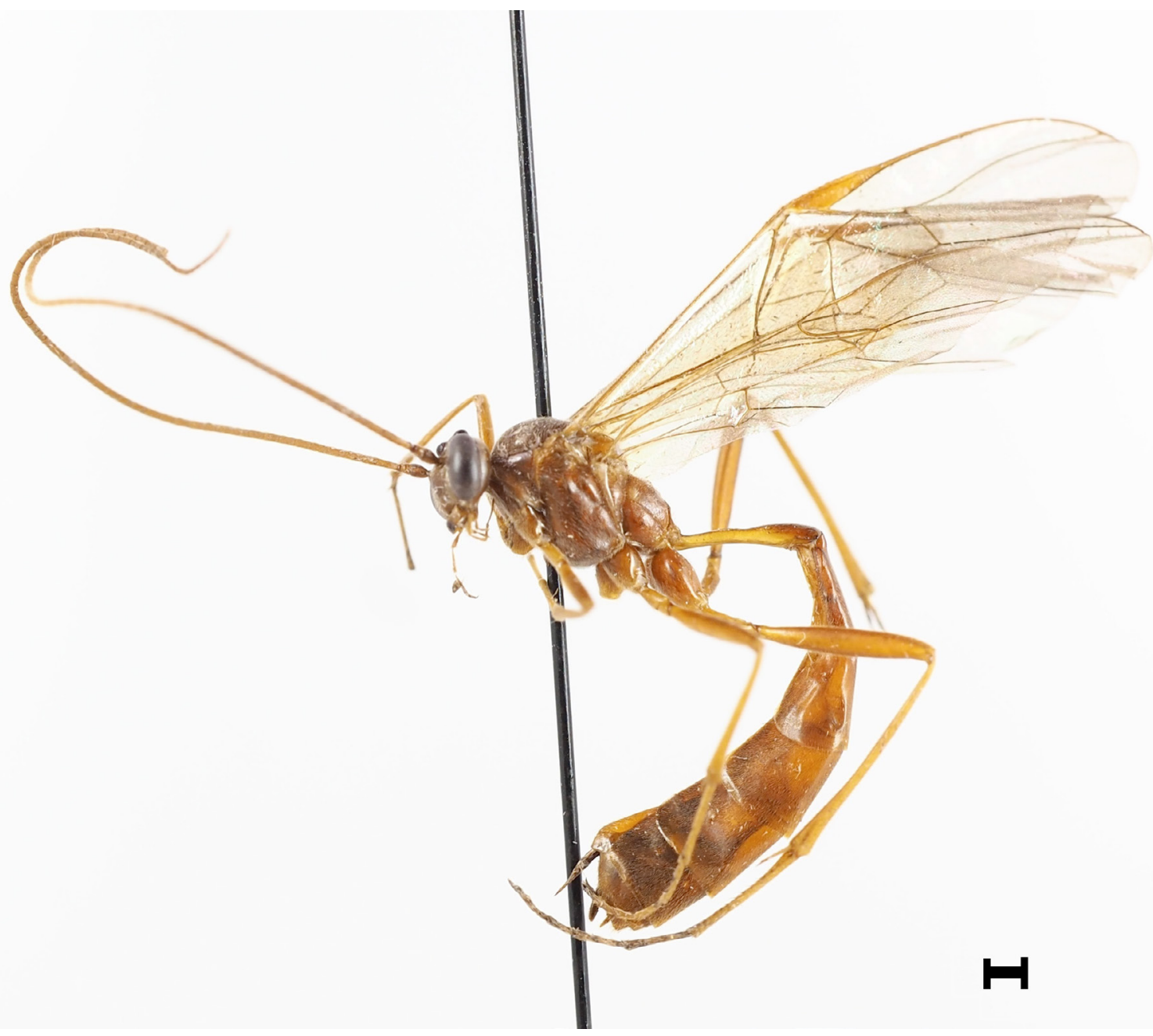

Fig. 33. Ophion inclinans Johansson sp. nov., holotype,, (NHRS-HEVA000008667). Scale bar $=1 \mathrm{~mm}$. 
flagellomeres long and slender, about 3.0 times as long as wide with long prominent pilosity. Temple slightly buccate. Head in lateral view about $0.4-0.6$ times as long as compound eye. Head slightly wider than long in frontal view (width/height measured from the apical margin of clypeus to the top of head about 1.25) (Fig. 19C-D). Ocelli in dorsal view touching compound eye in female, in male with small interstice between posterior ocellus and compound eye. Ocelli smaller than in O. pteridis, the distance between posterior ocelli usually about $0.6-0.8$ times the diameter of ocellus. Occipital carina in a majority of specimens centrally straight or rarely evenly rounded, in this respect differing from the more angled carina in $O$. pteridis and $O$. vardali Johansson sp. nov. Malar space about $0.1-0.2$ times as long as mandibular base in female and about $0.2-0.3$ times in male. Mandibular gape right-angled, with internal angles. Wing membrane clear. Ramellus distinct, reaching about $0.2-0.3$ times the width of the discosubmaginal cell. Radius sinuous. Face below antennal sockets with quite scarce punctures, polished or weakly shagreened. Wing membrane clear. Mesopleuron shagreened and distinctly punctate. Spaces between punctures about equal to their diameter. Pleurosternal angles weakly obtuse to right angled, obviously anterior to sternal angles. Scutellum with distinct lateral carinae (Fig. 6C). Propodeum slightly coriaceous, often quite polished with anterior transverse carina strong but sometimes partly absent laterally. Posterior transverse carina often widely interrupted centrally (as in Fig. 10A) and the area delimited by it quite smooth without any obvious wrinkles. Area superomedia often with lateral and anterior carinae. Central longitudinal carinae often distinct. Sclerotised part of first sternite ending obviously posterior to spiracle. First tergite in lateral view with slight or distinct median undulation (Fig. 6E). Hind trochantellus shorter than wide in dorsal view. Legs quite slender with hind femur about 7.0 times as long as wide (Fig. 16D). Inner spur of hind tibia 0.5 times as long as hind metatarsus.

\section{Colour}

Body testaceous. Head with inner and outer orbits yellow. Mandibular teeth black. Ovipositor sheath testaceous, of same colour as posterior metasomal segments.

\section{DNA barcode}

The DNA barcode sequences of ten Swedish specimens of Ophion inclinans Johansson sp. nov. are available at the BOLD systems database (www.boldsystems.org, BIN. BOLD: AAH1753. Specimen codes: STI-NJBC: 15-16, 18, 20, 22, 27-29, 77, 242).

\section{Ecology}

Ophion inclinans Johansson sp. nov. is active in late summer and autumn, August-October, in semiopen agricultural landscapes and light forests. Due to confusion with other species the host records are difficult to interpret. A female in NHRS was reared from Lacanobia contigua (Denis \& Schiffermüller, 1775). According to Brock (1982) it has been been reared from Hadena sp. Schrank, 1802, Ceramica pisi (Linnaeus, 1758) and Lacanobia oleracea (Linnaeus, 1758). Some of these host records might refer to other previously undescribed species similar to $O$. inclinans Johansson sp. nov.

\section{Distribution in Sweden}

This species is the most widely distributed of all Ophion species in Sweden, but seems to be rarer in the south.

\section{Remarks}

This species has widely been treated under the name Ophion pteridis due to a misinterpretation of the lectotype and original description of that species (see remarks under O.pteridis and Discussion). Ophion inclinans Johansson sp. nov. forms a very closely related species pair with $O$. arenarius Johansson sp. nov. Specimens from subalpine areas in central and northern Sweden have the clypeus narrower and entirely shagreened, while it is wider and polished in typical specimens. These specimens also shows 
a small but consistent genetical difference from typical $O$. inclinans (Fig. 5) and cluster with some Finnish specimens forming two quite distinct groups. Further research is needed to clearify if these forms represent different taxa.

Ophion kallanderi Johansson sp. nov. urn:1sid:zoobank.org:act:9D7922E7-EC2C-40EE-8CCD-FAF3739F463E

Figs 9I, 34

\section{Diagnosis}

Ophion kallanderi Johansson sp. nov., which according to the barcoding results (Fig. 1) belongs to the Ophion parvulus aggregate, is one of the trickier Ophion species to identify. It is superficially similar to the species around Ophion slaviceki, but is easily distinguished by the shorter hind trochantellus, the right angled gap between the mandibular teeth, the lower number of flagellomeres and the strongly elongate second flagellomere. The latter character is only otherwise present in Ophion tenuicornis Johansson sp. nov. and Ophion scutellaris. The primary risk of confusion is with Ophion parvulus, Ophion paraparvulus Johansson sp. nov. and Ophion tenuicornis Johansson sp. nov., because of the very weakly sinuate radius in the female that sometimes can be perceived to be evenly curved. Another feature that is frequently present in $O$. kallanderi Johansson sp. nov., but frequently missing in the other species of the aggregate, is that the pleurosternal angles are more distinct and often slightly protruding (Fig. 9I). In all known specimens, the posterior transverse carina of the propodeum is widely interrupted or only weakly raised centrally, a feature otherwise only frequently occurring in Ophion paraparvulus Johansson sp. nov. within the $O$. parvulus aggregate. The best diagnostic character is, however, the shape of the flagellomeres. The second flagellomere is distinctly longer than in $O$. parvulus and $O$. paraparvulus Johansson sp. nov. and the apical flagellomeres are stouter than in $O$. tenuicornis Johansson sp. nov. Another distinguishing feature is the shape of the temples. In O. kallanderi Johansson sp. nov. the head is about $0.4-0.5$ times as long as the compound eye in lateral view, while it is narrower, 0.3 , in both $O$. paraparvulus and $O$. tenuicornis Johansson sp. nov. (Table 1). The few known males have the radius evenly curved but are distinguished from the other species in the $O$. parvulus aggregate on the shape of the flagellomeres.

\section{Etymology}

This species is named in honor of the Swedish lepidopterologist Clas Källander who by donating a large number of Ophion specimens has contributed greatly to this study.

\section{Material examined}

14 우, $1 \lesssim$ (Sweden); $1 \lesssim$ (Great Britain); 5 우, $3 \widehat{\diamond}$ (Lithuania).

\section{Type material}

Holotype

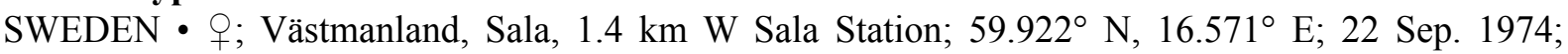
S. Johansson leg.; MV-light; MZLU Type no. 6371:1.

\section{Paratypes}

SWEDEN • 1 q; same data as for holotype; 21 Sep. 1974; S. Johansson leg., MV-light; MZLU Type no. 6371:2 - 1 q; Västmanland, Fläckebo, $0.3 \mathrm{~km} \mathrm{NE}$ Fläckebo church; $59.889^{\circ} \mathrm{N}, 16.359^{\circ} \mathrm{E} ; 18 \mathrm{Sep}$. 1974; S. Johansson leg.; MV-light; MZLU Type no. 6371:3 • 1 q; Dalarna, Säterdalen, Näsåkerspussen; 59.734 ${ }^{\circ}$ N, $17.720^{\circ}$ E; 4-26 Aug. 2003; SMTP leg.; Malaise trap in alder swamp wood, (Trap id. 10, coll. ev id 399); NHRS-HEVA000008675 • 2 ○ $\circ$; Gästrikland, Gävle, Grinduga; $60.641^{\circ}$ N, $17.299^{\circ}$ E; 10-17 Sep. 2013; N. Ryrholm and C. Källander leg.; MV-light trap in mixed woodland/farmland; 
NHRS-HEVA000008676, NHRS-HEVA000008677 • 1 q; Skåne, Kullen, Brunkulla; 56.301 N, 12.455 E; 24 Aug. 1975; C.-H. Lindroth leg.; MV-light; MZLU Type no. 6371:4 • 1 क; same data as for preceding; 22 Aug. 1974; C.-H. Lindroth leg.; MV-light; MZLU Type no. 6371:5 • 2 ㅇ 우 ; same data as for preceding; 28 Aug. 1975; C.-H. Lindroth leg.; MV-light; MZLU Type no. 6371:6 • 1 क; same data as for preceding; 31 Aug. 1974; C.-H. Lindroth leg.; MV-light; MZLU Type no. 6371:7 •1 §; same data as for preceding; 28 Aug. 1974; C.-H. Lindroth leg.; MV-light; MZLU Type no. 6371:8.

\section{Description}

Fore wing length $15 \mathrm{~mm}$. Antenna with 47-50 flagellomeres. First flagellomere about 4.0-4.5 times as long as wide. Second flagellomere about 3.0 times as long as wide. Central flagellomeres about 2.0-2.5 times as long as wide. Subapical flagellomeres approximately 1.6-1.7 times as long as wide. Head relatively narrowed behind eyes, in lateral view temple $0.4-0.5$ times as long as compound eye. Lateral ocellus touching compound eyes. In female the ocelli rather small, not covering the inner margin of compound eye in dorsal view. The distance between lateral ocelli about $0.5-0.6$ times as wide as ocellus. Malar space about 0.2 times as long as mandibular base in female and about 0.4 times in male. Mandibular gape right-angled, with internal angles. Wing membrane clear. Ramellus usually quite

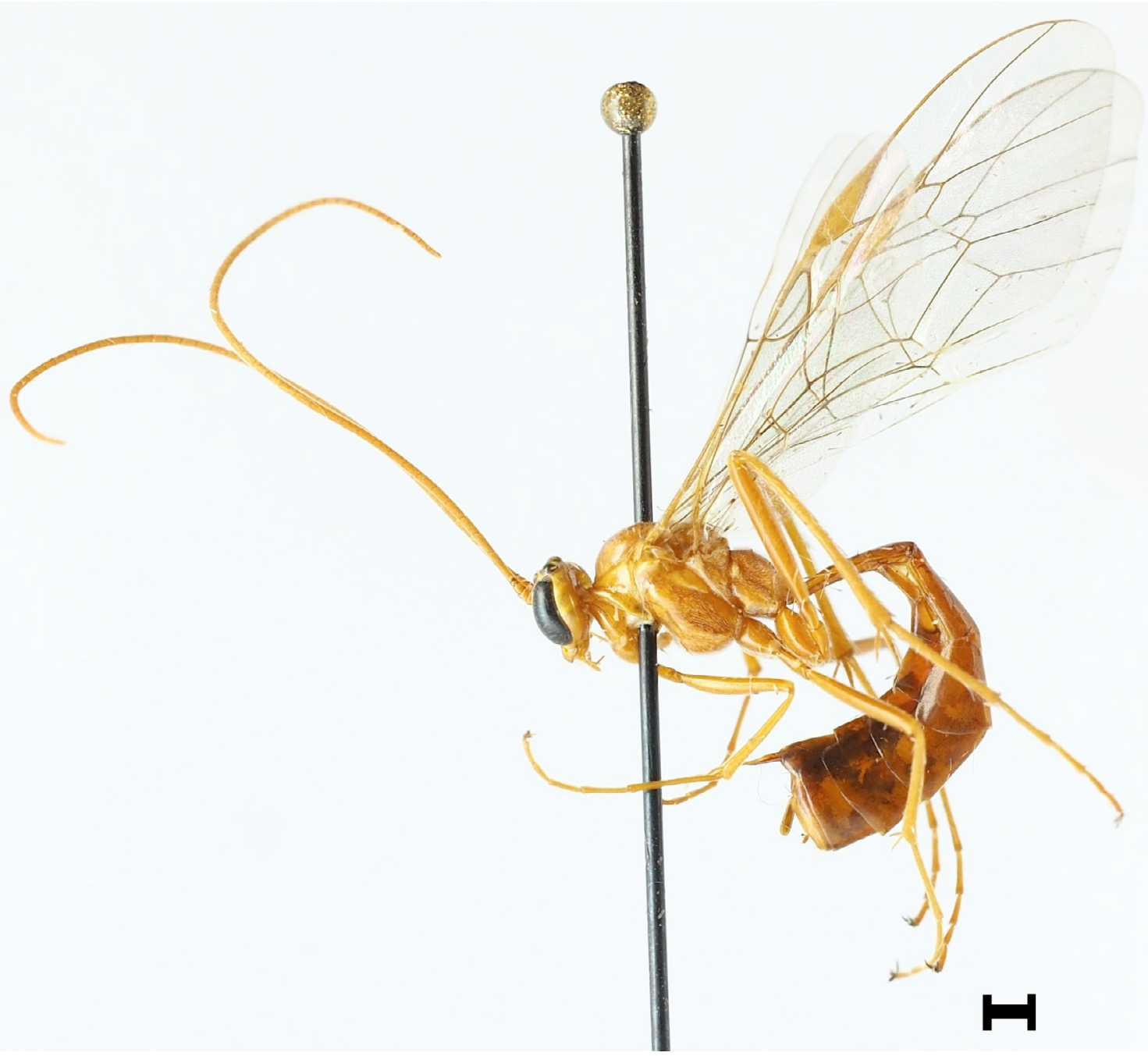

Fig. 34. Ophion kallanderi Johansson sp. nov., paratype, $q$ (MZLU 6371:5). Scale bar $=1 \mathrm{~mm}$. 
short, reaching $0.2-0.4$ times the width of the discosubmarginal cell. Radius weakly sinuate, sometimes even more or less straight in the basal part in the female and evenly curved in the male. Structure of mesopleuron shining or weakly shagreened with weaker, very regular punctation consisting of small punctures. Interstices between punctures about equal to their diameter up to two times their diameter. Epicnemial carina, in antero-ventral view, with pleurosternal angles obviously anterior to sternal angles. Pleurosternal angles acute, rarely right angled (Fig. 9I). Scutellum without lateral carinae (as in Fig. 6A). Structure of propodeum similar to that of $O$. obscuratus, posterior to anterior transverse carina mostly shining. Anterior transverse carina complete, quite strongly raised. Posterior transverse carina usually only present laterally, widely interrupted centrally. Sclerotised part of first sternite ending level to spiracle. Central longitudinal carinae weak or absent. Hind trochantellus shorter than wide in dorsal view. Legs normal with hind femur 7.0 times as long as wide. Hind trochantellus shorter than in other similar species. Inner spur of hind tibia short, about 0.3 times as long as hind metatarsus. First sternite ending in level with spiracle (as in Fig. 6H).

\section{Colour}

Body testaceous, inner and outer eye margins yellow. Mandibular teeth black. Ovipositor sheath testaceous.

\section{DNA barcode}

The DNA barcode sequences of one Swedish specimens of Ophion kallanderi Johansson sp. nov. is available at the BOLD systems database (www.boldsystems.org, Specimen code: STI-NJBC: 262).

\section{Ecology}

All specimens have been collected in woodlands during August-September.

\section{Distribution in Sweden}

Rare but probably overlooked in Central Sweden. Older records from Southern Sweden (MZLU) indicates a wider distribution.

\section{Remarks}

Despite the slightly sinuate radius and the more pronounced pleurosternal angles, this species is most likely a member of the $O$. parvulus aggregate. However the barcode sequence obtained was quite weak and the more detailed phylogenetic position is somewhat uncertain.

Ophion kevoensis Jussila, 1965

Figs 13D, 16E, 21E

Ophion kevoensis Jussila, 1965: 97-98.

\section{Material examined}

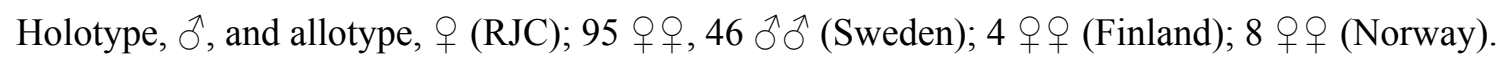

\section{Diagnosis}

Fore wing length $15-17 \mathrm{~mm}$. Antenna with 52-57 flagellomeres. First flagellomere about 3.5-4.0 times as long as wide. Central flagellomeres about 1.5-1.6 times as long as wide. Subapical flagellomeres approximately 1.5 times as long as wide. Temple buccate, in lateral view $0.6-0.8$ times as long as compound eye. Head in dorsal view with gap between compound eye and lateral ocellus about 0.2-0.3 times the diameter of the ocellus. Malar space in both sexes, especially in the male, slightly longer than in O. slaviceki (Fig. 21E), in female about 0.3 times as long as mandibular base and $0.5-0.7$ in males. Face 
wide (Fig. 16E) below antennal sockets densely and deeply punctate. Gap between mandibles obtuse or right angled, with internal angles present. Wing membrane usually yellowish. Ramellus long, 0.3 times the width of the discosubmarginal cell. Radius sinuous. Structure of mesopleuron weakly shagreened with distinct punctures. Interstices between punctures about equal to their diameter. Epicnemial carina, in antero-ventral view, with pleurosternal angles obviously anterior to sternal angles. Pleurosternal angles rounded, obtuse to right angled (as in Fig. 9E). Scutellum with lateral carinae present in basal 0.5-0.6. Anterior transverse carina of propodeum present, quite strong. Posterior transverse carina only present laterally, widely interrupted centrally. Petiolar carina and longitudinal carina delimiting area superomedia weak. Sclerotised part of first sternite ending level or slightly posterior to spiracle. Hind trochantellus shorter than wide in dorsal view. Legs normal, with hind femur about 6.0-6.5 times as long as wide. Hind trochantellus shorter than wide in dorsal view. Inner spur of hind tibia about $0.3-0.4$ times as long as hind metatarsus.

\section{Colour}

Mesosoma usually brownish testaceous. Mandibular teeth black. Head with inner and outer orbits reddish-yellow, distinctly darker than in O. slaviceki. Apical flagellomeres in male slightly infuscate. Pterostigma evenly testaceous (Fig. 13D). Ovipositor sheath of the same colour as posterior segments of metasoma.

\section{DNA barcode}

The DNA barcode sequences of seven Swedish specimens of Ophion kevoensis are available at the BOLD systems database (www.boldsystems.org, BIN. BOLD: ACF9514. Specimen codes: STI-NJBC: 71-72, 319-321, 332-333).

\section{Ecology}

The species occurs in semi-open coniferous forests with Vaccinium L. during August-October in Central and Northern Sweden.

\section{Distribution in Sweden}

Widespread and locally very abundant in subalpine taiga forests where it is the dominant Ophion species.

\section{Remarks}

A rather variable species. Closely related to $O$. slaviceki, but easily distinguished from that species by the partly carinated scutellum, the generally longer ramellus, the right angled mandibular gape, the generally shorter hind trochantellus, the usually yellowish wing membrane, the longer malar space, especially in the male, and the usually darker colour. Also very similar to $O$. autumnalis Johansson sp. nov., but on average larger and with the pterostigma evenly testaceous (Fig. 13D). Sometimes the carinae of the propodeum can be quite distinct and the sclerotised part of first sternite end posterior to spiracle in which case the species can be mistaken for Ophion arenarius. Ophion kevoensis is distinguished from that species by the more buccate head with a distinct gap between the lateral ocellus and the inner margin of the compound eye. The barcoded specimens form a group that is closely related to $O$. slaviceki (Fig. 3). The allotype female (Jussila 1966) is smaller, has a narrow face and the ovipositor sheath black, contrasting with the posterior metasomal segments. The specimen probably represents a different species, most likely Ophion sylvestris Johansson sp. nov. (see further comments under Discussion'additional comments on type material'). It is important to note that the interpretation of this species in this study is based on detailed drawings made by the second author when he gained access to the type material in the 1970-s. For the present paper, the types were unavailable for detailed examination as they were on loan for a study of Ophion species in Finland (Gergely Várkonyi, Finnish Environment Institute, pers. com.). 


\section{Ophion longigena Thomson, 1888}

Figs $10 \mathrm{M}, 20 \mathrm{C}-\mathrm{D}, 35 \mathrm{~A}-\mathrm{B}$

Ophion longigena Thomson, 1888: 1191.

\section{Material examined}

Lectotype, $\widehat{\partial}$ (ZMLU); 20 qq, $7 \widehat{\partial} \widehat{\partial}$ (Sweden); 11 q,$+ 7 \widehat{\partial} \widehat{\partial}$ (Germany); $1 \hat{\partial}$ (Estonia).

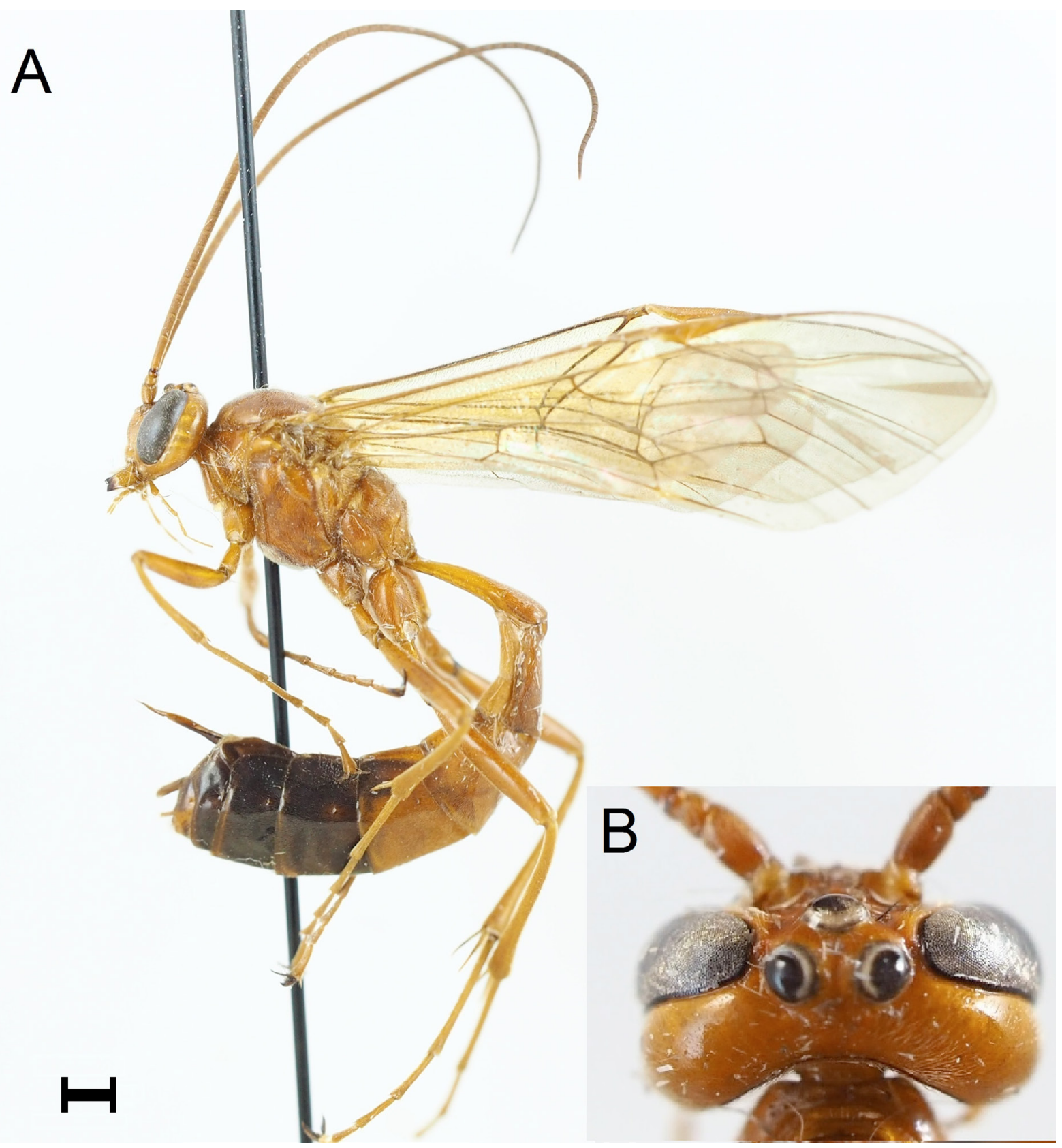

Fig. 35. Ophion longigena Thomson, 1888, ․ A. Habitus, lateral view. B. Head, dorsal view. Scale bar: $\mathrm{A}=1 \mathrm{~mm}$. 


\section{Diagnosis}

Fore wing length 14-16 mm. Antenna in females with (52) 54-58 flagellomeres, 47-52 in males. First flagellomere 3.0-3.5 times as long as wide. Temple in female, and especially male, very strongly buccate, in lateral view temple at least as long as compound eye (Figs 20D, 35A-B). Head in frontal view distinctly transverse (width/height measured from the apical margin of clypeus to the top of head $=1.40-1.45$ (Fig. 20C). Face relatively wide, inner orbits almost parallel. Face densely punctate, the interstices $0.2-0.5$ times the diameter of punctures. Malar space about 0.4 times as long as mandibular base in female and about 0.6- 0.7 times in male. Mandibles in about $90 \%$ of the studied specimens more or less worn. Wing membrane weakly yellowish. Ramellus relatively short, reaching $0.1-0.3$ times the width of the discosubmarginal cell. Radius sinuous. Mesopleuron polished or weakly shagreened and densely punctate with small punctures. Interstices between punctures about equal to their diameter. Pleurosternal angles slightly anterior to sternal angles, quite distinct, right angled or slightly acute, but apically rounded. Scutellum with distinct lateral carinae at least in basal half (as in Fig. 6C). Propodeum distinctly punctate, often polished with anterior and posterior transverse carina often strong. Longitudinal carinae delimiting area superomedia often weak or absent (Fig. 10M). Central longitudinal carinae often distinct basally. Hind trochantellus shorter than wide in dorsal view. Sclerotised part of first sternite ending level to spiracle. First metasomal segment in lateral view rather stout (as in Fig. 20E). Inner spur of hind tibia as long as 0.5 times hind metatarsus.

\section{Colour}

Body testaceous. Mandibular teeth black. Head with inner and outer eye margins yellow. In female metasoma with posterior segments from fifth segment onwards mostly infuscate, dark brown or black at least in the ventral 0.5 (Fig. 35A). Ovipositor sheath brownish-blackish, concolourous with posterior metasomal segments.

\section{DNA barcode}

The DNA barcode sequences of two Swedish specimens of Ophion longigena are available at the BOLD systems database (www.boldsystems.org, BIN. BOLD: ADF9569. Specimen codes: STI-NJBC: 130, 298).

\section{Ecology}

Brock (1982) refers to rearings from Cucullia chamomillae (Denis \& Schiffermüller, 1775), which is also confirmed by multiple Swedish rearings (by H. Elmqvist in NHRS). In the studied material there are also additional rearings from Cucullia lychnitis (Rambur, 1833) and Cucullia scrophulariae (Denis \& Schiffermüller, 1775). Schmidt et al. (2012) refers to a rearing from Cucullia verbasci (Linnaeus, 1758). The species is active during late May-July.

\section{Distribution in Sweden}

Rare in Southern Sweden including Öland and Gotland. Older records from Central Sweden (Uppland) which indicate a wider distribution.

\section{Remarks}

In its typical appearance a distinct species. Closely related to Ophion paukkuneni Johansson sp. nov., but with head and face usually wider in anterior view, temple slightly more buccate and first metasomal segment stouter. The face below the antennal sockets is more densely punctate than in O. paukkuneni Johansson sp. nov., distinctly denser than on the clypeus, while the punctation on the clypeus and face below the antennal sockets is of almost the same intensity and size in $O$. paukkuneni Johansson sp. nov. The females usually have more flagellomeres, in the range of 54-55 while O. paukkuneni usually has 50-51. A frequent characteristic is that the mandibles in $O$. longigena are worn, while they are unworn in all known specimens of $O$. paukkuneni Johansson sp. nov. 
Ophion luteus (Linnaeus, 1758) stat. rev.

Figs 6A, H, 10A, 14A

Ichneumon luteus Linnaeus, 1758: 566.

Ophion distans Thomson, 1888: 1191.

\section{Material examined}

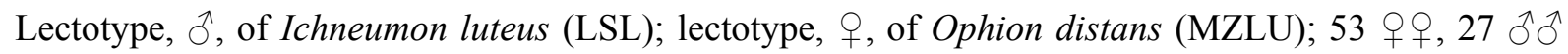
(Sweden); 1 + (Estonia); 1 ๆ (Norway).

\section{Diagnosis}

Fore wing length $12-15 \mathrm{~mm}$. Antenna with $47-53$ flagellomeres. First flagellomere about 4.0 times as long as wide. Central flagellomeres about 1.5-1.6 times as long as wide. Subapical flagellomeres approximately 1.5 times as long as wide. Temple buccate. Head in lateral view with temple about 0.8-0.9 times as long as compound eye in both females and males (Fig. 14A). Gap between compound eye and lateral ocellus always distinct, $0.3-0.4$ times the diameter of ocellus. Ocelli small. Central ocellus in female in anterior view as wide as distance between central ocellus and inner eye margins. Malar space about 0.3-0.4 times as long as mandibular base in female and about 0.5 times in male. Mandibles often worn, usually with the gap between teeth acute angled and internal angles absent (as in Fig. 10I), but specimens from coastal localities in Southern Sweden frequently with internal angles present. Wing membrane transparent. Ramellus usually short, reaching 0.1-0.3 times the width of the discosubmarginal cell. Radius sinuous. Structure of mesopleuron in most cases shining or weakly shagreened with distinct, very regular punctation consisting of small punctures. Interstices between punctures about equal to their diameter. Epicnemial carina, in antero-ventral view, with pleurosternal angles obviously anterior to sternal angles (as in Fig. 9E). Pleurosternal angles rounded, obtuse to right angled. Scutellum without distinct lateral carinae (Fig. 6A). Propodeum posterior to anterior transverse carina mostly shining. Anterior transverse carina always present centrally anterior to area superomedia, but often also present laterally though rarely strongly raised. Posterior transverse carina usually only present laterally, widely interrupted centrally (Fig. 10A). Legs normal with hind femur about 6.0-6.5 times as long as wide. Hind trochantellus usually as long as wide in dorsal view (as in Fig. 7E). Inner spur of hind tibia long about 0.3-0.4 times as long as first hind tarsal segment. Sclerotised part of first sternite ending level to spiracle (Fig. 6H).

\section{Colour}

Body testaceous. Mandibular teeth black. Head with inner and outer orbits yellow. Ovipositor sheath testaceous, concolourous with posterior metasomal segments.

\section{DNA barcode}

The DNA barcode sequences of 16 Swedish specimens of Ophion luteus are available at the BOLD systems database (www.boldsystems.org, BIN. BOLD: ACF9514. Specimen codes: STI-NJBC: 54, 58-61, 63, 65-69, 302, 322, 324, 326, 328).

\section{Ecology}

Ophion luteus is active in late spring and during early summer, May-June in a variety of habitats. Brock (1982) refers to a rearing from Actebia praecox.

\section{Distribution in Sweden}

Rare but widespread in Southern Sweden and the southern parts of Central Sweden. 


\section{Remarks}

See Discussion: "The Ophion luteus aggregate”.

Ophion matti Johansson sp. nov.

urn:1sid:zoobank.org:act:515CEEAD-824B-43BB-986C-BA08669504EA

Figs 18E, 21B, 36

\section{Diagnosis}

Superficially similar to Ophion inclinans Johansson sp. nov. and $O$. arenarius Johansson sp. nov., but never with the dorsal undulation on the first tergite. The face is usually more densely punctate below the antennal sockets, with more well defined and sharper pleurosternal angles and stouter flagellomeres. Very closely related to Ophion ellenae Johansson sp. nov., but distinguished by the more densely and distinctly punctate and less shiny mesoscutum, the more elongate area superomedia and the stouter basal flagellomeres.

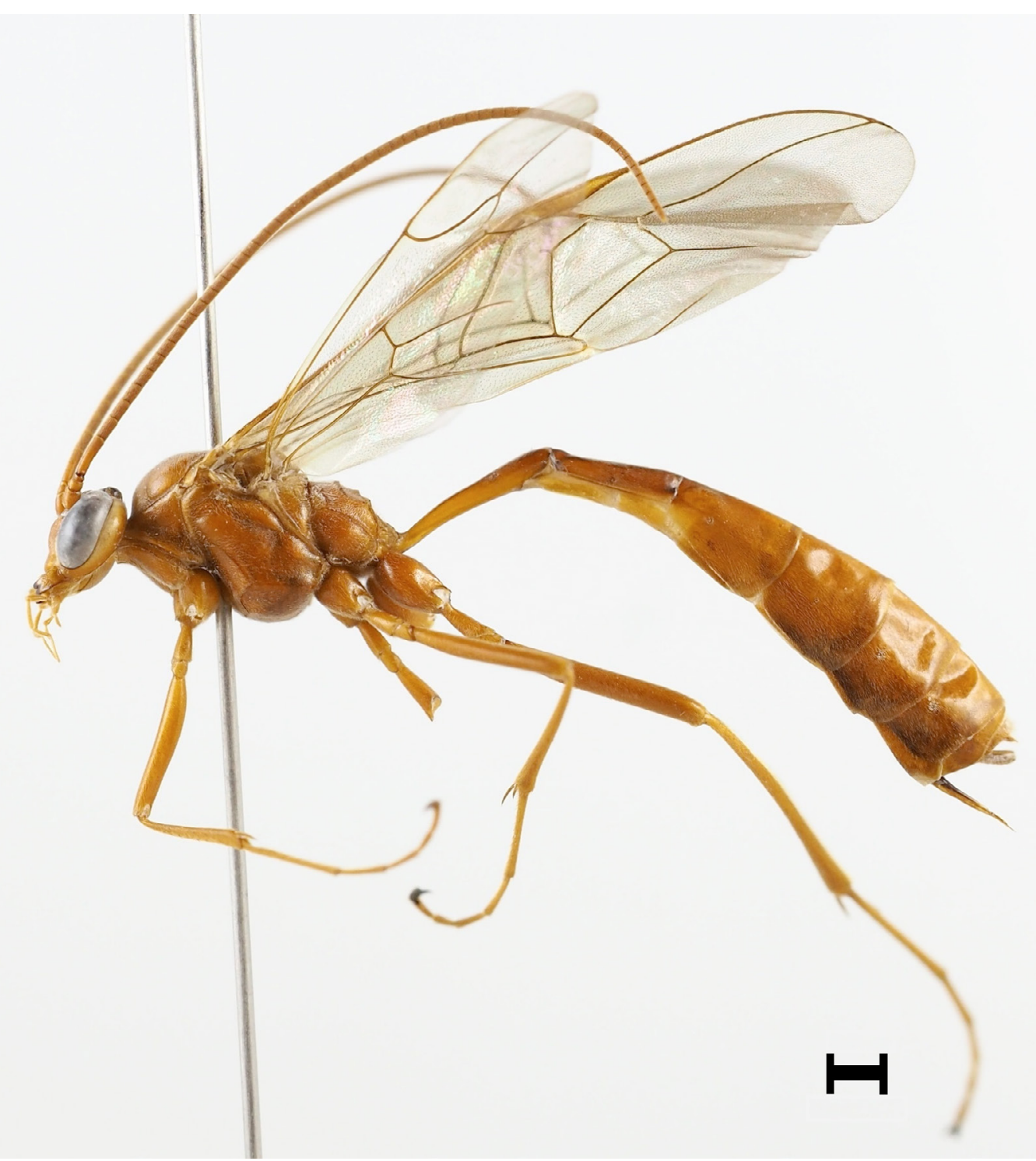

Fig. 36. Ophion matti Johansson sp. nov., paratype, $q$ (NHRS-HEVA000008679). Scale bar $=1 \mathrm{~mm}$. 


\section{Etymology}

The species is named after the first author's son, Matti Nystedt.

\section{Material examined}

4 우, 3 ふึ (Sweden); 1 † (Norway).

\section{Type material}

\section{Holotype}

SWEDEN • ; ; Halland, Kungsbacka, Nidingen; $57.302^{\circ}$ N, $11.900^{\circ}$ E; 8 Aug. 2017; M. Oomen leg.; MV-light in coastal heath; STI-NJBC189; NHRS-HEVA000008678.

\section{Paratypes}

SWEDEN • 1 q; Bohuslän, Tanums kommun, Hamburgsund, Stora Snixholmen; $58.564^{\circ} \mathrm{N}, 11.251^{\circ} \mathrm{E}$; 17 Sep.-3 Oct. 2005; SMTP leg.; Malaise trap in semi-exposed coastal flat rock (coll, ev. id. 1535); STI-NJBC187; NHRS-HEVA000008679 • 1 O ; same data as for preceding; STI-NJBC190; NHRS-

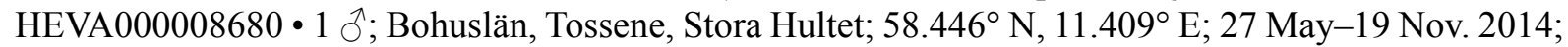
N. Ryrholm and C. Källander leg.; MV-light trap in farmland; NHRS-HEVA000008681 • 1 q, 2 ๙ $\sigma^{\wedge}$; Halland, Kungsbacka, Nidingen; $57.302^{\circ}$ N, $11.900^{\circ}$ E; 10 Jul. 2018; U. Unger leg.; MV-light in coastal heath; NHRS-HEVA000008682 to NHRS-HEVA000008684.

NORWAY • 1 q; Vest Agder, Søgne, Trysnes; 58.061 N, 7.703 E; 5-6 Aug. 1996; E. Helbo and O. Lønnve leg.; coastland; NHMO:601.

\section{Description}

Fore wing length $15-16 \mathrm{~mm}$. Antenna with 54-56 flagellomeres. First flagellomere 3.5 times as long as wide. Second flagellomere about 1.8 times as long as wide. Central flagellomeres stout, about 1.2-1.3 times as long as wide. Subapical flagellomeres approximately 1.5 times as long as wide (as in Fig. 8D). Temple quite short. Head of female in lateral view with temple $0.4-0.5$, in males about $0.5-0.6$, times as long as compound eye. Gap between compound eye and lateral ocellus 0.1 times the diameter of ocellus. Face below antennal sockets with dense punctures. Malar space about $0.1-0.2$ times as long as mandibular base in female and about 0.3 times in male. Mandibular gape right-angled, with internal angles. Wing membrane clear. Ramellus disitinct, reaching 0.2-0.4 times the width of the discosubmarginal cell. Radius sinuous. Mesoscutum weakly shagreened with dense and distinct punctures, interstices distinctly smaller than the diameter of punctures or absent (Fig 21B). Mesopleuron strongly shagreened with deep, dense punctures, space beween punctures 0.5 times their diameter, Epicnemial carina, in antero-ventral view, with pleurosternal angles in level with sternal angles, pleurosternal angles right angled. Scutellum relatively wide with distinct lateral carinae in basal $0.8-0.9$ (as in Fig. 6C). Propodeum with very weak rugose structure, shining with anterior and posterior transverse carina often strongly raised. Central longitudinal carinae strong, lateral longitudinal carina absent. Area superomedia more elongate than in $O$. ellenae Johansson sp. nov. (Fig. 18E). Hind trochantellus shorter than wide in dorsal view. Legs normal with hind femur about 6.0 times as long as wide. Sclerotised part of first sternite ending distinctly posterior to spiracle at a distance equal to that between hind margin of the sclerotised part of the first sternite and hind margin of the first tergite (as in Fig. 6D). Inner spur of hind tibia as long as 0.5 times metatarsus.

\section{Colour}

Body testaceous. Mandibular teeth black. Head with inner and outer orbits yellow. Ovipositor sheath testaceous. 


\section{DNA barcode}

The DNA barcode sequences of three Swedish specimens of Ophion matti Johansson sp. nov. are available at the BOLD systems database (www.boldsystems.org, BIN. BOLD: ADM4635. Specimen codes: STI-NJBC: 187, 189-190).

\section{Ecology}

The species might have a connection to the noctuid moth Hadena caesia which in Sweden feeds exclusively on sea campion Silene uniflora Roth. Ophion matti Johansson sp. nov. occurs in coastal areas in Western Sweden and is active during late summer-early autumn.

\section{Distribution in Sweden}

Rare in the western coastal areas of Central Sweden.

\section{Remarks}

In the sequencing this species forms a separate group adjacent to O. ellenae Johansson sp. nov. (Fig. 4), but the two species share the same BIN. While the known host of O. ellenae is Hadena bicruris a possible host of $O$. matti Johansson sp. nov is Hadena caesia, which is the only abundant and resident noctuid species occuring on the island of Nidingen, where three females and two males were collected. The species status is motivated by a distinct genetic difference and the consistent morphological differences.

Ophion minutus Kriechbaumer, 1879

Fig. 12

Ophion minutus Kriechbaumer, 1879c: 105-106.

Ophion eremotyloides Ceballos, 1962: 200, fig. 2 O.

\section{Material examined}

51 우우, $47 \hat{\jmath} \widehat{\partial}$ (Sweden); 11 우, $8 \hat{\jmath} \widehat{\partial}$ (France); 1 ㅇ, $1 \hat{\jmath}$ (Norway).

\section{Diagnosis}

The smallest species in the genus. Fore wing length $8-11 \mathrm{~mm}$. Antenna in both sexes with $40-48$ flagellomeres. First flagellomere 3.5-4.0 times longer than wide. Head buccate behind eyes, temple in lateral view about $0.6-0.7$ times as long as compound eye. Malar space about 0.1 times as long as mandibular base in female and male. Mandibular gape right-angled, with internal angles. Wing membrane clear. Ramellus very short or absent. Mesopleuron weakly shagreened or polished, distinctly punctate, spaces between punctures about equal to their diameter. Pleurosternal angles strongly obtuse, obviously anterior to sternal angles. Scutellum without lateral carinae. Vein $R s+2 r$ of forewing distinctly thickened and bent near junction with pterostigma (Fig. 12). Ramellus short. Propodeum coriaceous with carinae strongly reduced or absent anterior to the posterior transverse carina, which is present at least laterally.

\section{Colour}

Body testaceous. Mandibular teeth black. Head mainly yellow, in female testaceous around occipital carina and area around antennal sockets. Mesosoma in males with conspicuous yellow markings. In females often yellow markings reduced to subalar prominence, scutellum and postscutellum. Metasoma in females often with posterior segments infuscate. 


\section{DNA barcode}

The DNA barcode sequences of five Swedish specimens of Ophion minutus are available at the BOLD systems database (www.boldsystems.org, BIN. BOLD: AAI1095. Specimen codes STI-NJBC: 11-13, 334-335).

\section{Ecology}

This species occurs during early summer, mainly May, in oak (Quercus) dominated landscapes. It has been reared from several species of Erannis Hübner, 1825 (Lepidoptera: Geometridae) (Brock 1982).

\section{Distribution in Sweden}

In Sweden this is predominantly a southern species with scattered records also in central Sweden following the distribution of Quercus species and known hosts.

\section{Remarks}

A species easy to identify on the basis of its size and colour. The thickening of the radius is frequently missing.

Ophion mocsaryi Brauns, 1889

Figs 7B, 8J, O, 9B, 15C, E-F, 48A-F

Ophion mocsaryi Brauns, 1889: 89.

\section{Material examined}

Paratype, $\widehat{\delta}$ (ZMHB) and holotype, $q$ (HNHM); 42 우, 19 $\widehat{\delta}$ (Sweden); 3 우 (Croatia); 1 ㅇ

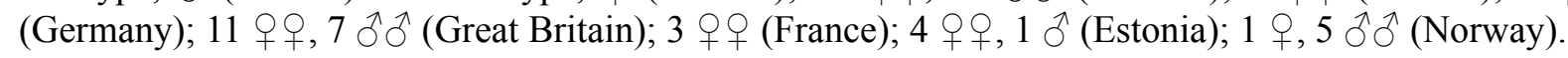

\section{Diagnosis}

Fore wing length $12-13 \mathrm{~mm}$. Antenna in both sexes with $51-55$ flagellomeres. First flagellomere about 3.5 times as long as wide. Basal flagellomeres 1.7-1.8 times as long as wide (Fig. 8O). Central flagellomeres about 1.6 times as long as wide. Subapical flagellomeres approximately 1.5-1.6 times as long as wide. Head in female and male weakly buccate behind eye. Temple in lateral view $0.4-0.5$ as long as compound eye (0.6 in Ophion mocsaryi var.) (Fig. 15E-F). Lateral ocellus usually touching inner margin of compound eye. Occipital carina centrally angled, sometimes with a central arc (Fig. 7B). Face below antennal socket only weakly shagreened with scarce, shallow punctures (Fig. 8J). Malar space about 0.1-0.2 times as long as mandibular base in female and male. Mandibular gape rightangled, with internal angles. Wing membrane clear. Ramellus distinct, reaching 0.5 times the width of the discosubmarginal cell. Radius sinuous, but often evenly curved in males. Nervellus broken below the middle by the discoidella. Mesopleuron distinctly punctate. Interstices between punctures about 1.5-2.0 times their diameter. Epicnemial carina, in antero-ventral view, with pleurosternal angles slightly anterior to sternal angles. Pleurosternal angles slightly acute and sharp (Fig. 9B). Scutellum without lateral carinae in basal half. Structure of propodeum quite shiny and only slightly rugose, basally and laterally with distinct punctures. Anterior transverse carina often entirely absent laterally and posterior transverse carina interrupted centrally (Fig. 10D) (very rarely, but evident in holotype and paratype, all carinae of propodeum strongly raised as in Fig. 10C). Longitudinal carinae delimiting area superomedia and area petiolaris often strong and complete. Area superomedia slightly longer than wide. Sclerotised part of first sternite ending level to spiracle. Hind trochantellus shorter than wide in dorsal view. Legs normal with hind femur 6.0-7.0 times as long as wide. Inner spur of hind tibia 0.4 times as long as hind metatarsus. 


\section{Colour}

Body testaceous. Mandibular teeth black. Head with inner and outer eye margins yellow. Ovipositor sheath black or dark brown, contrasting in colour with posterior metasomal segments (Fig. 48F).

\section{DNA barcode}

The DNA barcode sequences of ten Swedish specimens of Ophion mocsaryi are available at the BOLD systems database (www.boldsystems.org, BIN. BOLD: ADK8264. Specimen codes: STI-NJBC: 47 (var.), 52, 105, 174-175, 179-180, 232, 234, 339).

\section{Ecology}

The type material was reared from Atethmia (as Cosmia) ambusta (Denis \& Schiffermüller, 1775), a species that does not occur in Sweden. One male in NMS was reared from Dryobotes eremita (Fabricius, 1775), an additional host that fits well with the distribution and phenology of $O$. mocsaryi in Sweden. Ophion mocsaryi is active from late May to early July.

\section{Distribution in Sweden}

Quite frequently collected in Southern Sweden, but becoming rare or absent in the central and northern parts of the country.

\section{Remarks}

Closely related and morphologically very similar to Ophion confusus Johansson sp. nov. but with flagellomeres more elongate. The occipital carina is usually centrally angled (sometimes with a small central arc) and the face below the antennal socket is only weakly shagreened with sparse, shallower punctures and the area superomedia more distinctly delimited. For further taxonomic details, see Discussion: "The Ophion mocsaryi aggregate". One barcoded specimen, here under the name O. mocsaryi var., is genetically separated and forms a quite distinct clade with some specimens from Great Britain. This specimen is the only one known from Central Sweden and has the temple slightly more buccate in lateral view than material from Southern Sweden (Fig. 15F). It might represent a valid species but more material is needed to evaluate variation in the shape of the head and other potential characters. Specimens from Southern Europe (France, Croatia) that have been studied are slightly larger (fore wing length 14-15 $\mathrm{mm}$ ) and have more numerous flagellomeres (55-61).

Ophion norei Johansson sp. nov. urn:1sid:zoobank.org:act:5425028E-9DCF-4D80-99F9-59ECDA17AC00

Figs 17D, F, 20E, 37

\section{Diagnosis}

Most closely related and similar to Ophion perkinsi, from which it is distinguished by the more transverse head in anterior view, shorter malar space, the weaker microsculpture of the meso- and metapleuron and the stouter first tergite, usually lacking a median dorsal undulation. Also very similar to Ophion ellenae Johansson sp. nov. and Ophion matti Johansson sp. nov., from which it is separated by fewer flagellomeres, the more buccate temple, the head in dorsal view having a distinct gap between the eyes and lateral ocellus, the more distinctly punctate propodeum and the usually weaker carination of the propodeum. Also very similar to Ophion paukkuneni Johansson sp. nov., but with shorter flagellomeres, slightly less buccate temples and no dorsal undulation on the first tergite.

\section{Etymology}

Named after the son of the first author, Nore Nystedt. 


\section{Material examined}

8 우, $1 \widehat{\jmath}$ (Sweden).

\section{Type material}

\section{Holotype}

SWEDEN • P; Öland, Mörbylånga, Hönstorp; $56.662^{\circ} \mathrm{N}, 16.554^{\circ} \mathrm{E} ; 10$ Jul. 2018; K. Alexandersson leg.; MV-light in garden; NHRS-HEVA000008685.

\section{Paratypes}

SWEDEN • 1 \%; same data as for holotype; NHRS-HEVA000008686 • 1 đ’; Skåne, Ystad, Kåseberga; 55.385 ${ }^{\circ}$ N, $14.066^{\circ}$ E; 24 May-28 Jul. 2016; N. Ryrholm and C. Källander leg.; MV-light trap in warm coastal sandslopes; STI-NJBC074; NHRS-HEVA000008687 - 2 우; same data as for preceding; STI-NJBC116, STI-NJBC223; NHRS-HEVA000008688, NHRS-HEVA000008689 • 2 우; Skåne, Ystad, Kåseberga; $55.385^{\circ}$ N, $14.066^{\circ}$ E; 17 Jul.-14 Sep. 2013; N. Ryrholm and C. Källander leg.; MV-light trap in warm coastal sandslopes; 1 \%; STI-NJBC228; NHRS-HEVA000008690, NHRS-

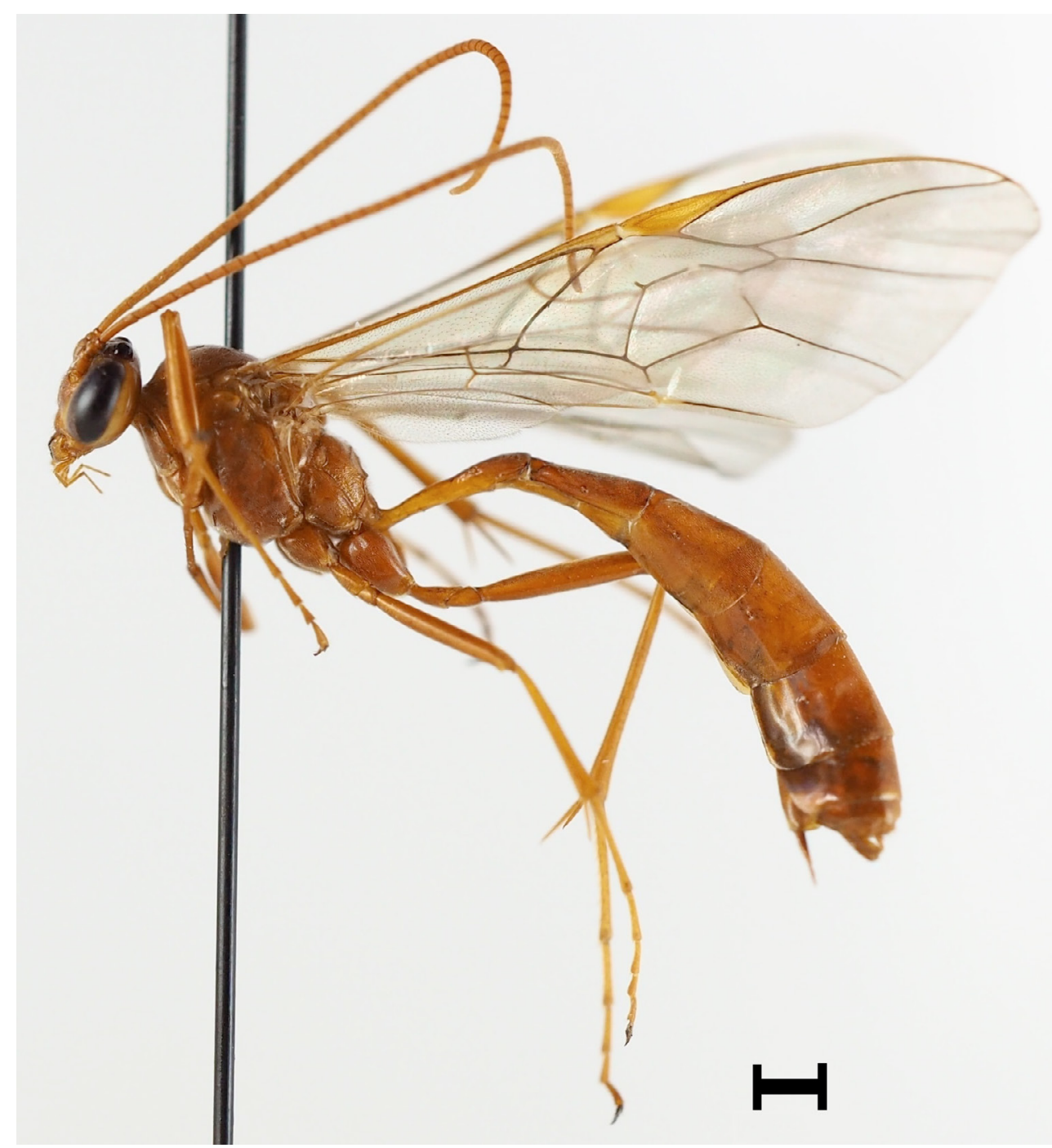

Fig. 37. Ophion norei Johansson sp. nov., holotype, $q$ (NHRS-HEVA000008685). Scale bar $=1 \mathrm{~mm}$. 
HEVA000008691 • 1 q; Gotland, Sundre, Hallbjäns; 56.938 N, 18.146 E; 21 Jun.-22 Jul. 2008; N. Ryrholm and C. Källander leg.; MV-light trap in rocky calcareous coastal heath; STI-NJBC225; NHRS-HEVA000008692 • 1 O ; Skåne, Ystad, Kåseberga; 55.385 N, 14.066 E; 29 Jul.-10 Oct. 2016; N. Ryrholm and C. Källander leg.; MV-light trap in warm coastal sandslopes; STI-NJBC226; NHRSHEVA000008693 • 1 q; Öland, Mörbylånga, Räpplinge; $56.827^{\circ} \mathrm{N}, 16.660^{\circ}$ E; 26 Jul.1980; L.-Å. Janzon leg.; MV-light; MZLU Type no. 6372:1.

\section{Description}

Fore wing length $12-13 \mathrm{~mm}$. Antenna in both sexes with 48-50 flagellomeres. First flagellomere 3.0-3.5 times as long as wide. Central flagellomeres almost square to slightly longer than wide. Head buccate behind eyes, in dorsal view with distance between inner margin of compound eye and lateral ocellus 0.2-0.3 times diameter of ocellus. Head in anterior view strongly transverse (Fig. 17D, F). Temple in lateral view about 0.7-0.8 times as long as compound eye (as in Fig. 21D). Malar space short, about 0.2 times the basal width of the mandible (Fig. 17D, F). Mandibular gape right-angled, with internal angles. Wing membrane clear. Ramellus distinct. Radius sinuous. Mesopleuron and metapleuron punctate with microsculpture weak or absent. Interstices between punctures about equal to their diameter. Pleurosternal angles rounded, often sharp, well defined and slightly anterior to sternal angles. Scutellum with distinct lateral carinae at least in basal half. Propodeum coriaceous and distinctly punctate. Anterior and transverse carina present centrally, often weak or absent laterally. Posterior transverse carina strongly raised, interrupted centrally. Longitudinal carinae delimiting area superomedia sometimes weak or absent (as in Fig. 10H). Area superomedia usually as long as wide. Hind trochantellus shorter than wide in dorsal view. First tergite in lateral view rather stout without or with only a shallow dorsal undulation centrally (Fig. 20E). Sclerotised part of first sternite ending distinctly posterior to spiracle. Inner spur of hind tibia as long as 0.5 times metatarsus.

\section{Colour}

Body testaceous. Mandibular teeth black. Inner and outer orbits slightly yellowish. Ovipositor sheath testaceous.

\section{DNA barcode}

The DNA barcode sequences of six Swedish specimens of Ophion norei Johansson sp. nov. are available at the BOLD systems database (www.boldsystems.org, BIN. BOLD: ADF8593. Specimen codes: STINJBC: 74, 116, 223, 225-226, 228).

\section{Ecology}

The species is active from late June to early September and occurs in open or semi-open grasslands in Southern Sweden.

\section{Distribution in Sweden}

Rare in Southern Sweden in areas with dry and hot climate.

Ophion obscuratus Fabricius, 1798

Figs 7F, H, L, N, 10A

Ophion obscuratus Fabricius, 1798: 237.

Ophion obscurus Fabricius, 1804: 132.

Ophion flavolineatus Brullé, 1846: 147-148. 


\section{Material examined}

Lectotype, $\hat{\jmath}$, of $O$. obscuratus (ZMC); lectotype, unsexed, of Ophion flavolineatus (MNHN); 12 9 ,

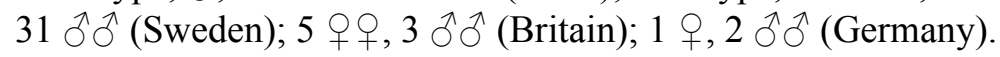

\section{Diagnosis}

Fore wing length $16-18 \mathrm{~mm}$. Antenna with 62-66 flagellomeres. Central flagellomeres in males about 1.3 times as long as wide (Fig. $7 \mathrm{~N}$ ). Subapical flagellomeres approximately $1.5-1.6$ times as long as wide. Temples slightly buccate. Head in lateral view with temple $0.7-0.8$ times as long as compound eye in females and 0.5-0.6 times in males. Gap between compound eye and lateral ocellus usually distinct, about 0.3 times the diameter of ocellus. Occipital carina almost straight in its lower part joining hypostomal carina at an angle of 45-60 degrees (Fig. 7L). Malar space about 0.2 times as long as mandibular base in female and male. Mandibular gape right-angled, with internal angles. Wing membrane clear. Ramellus usually short, reaching $0.1-0.3$ times the width of the discosubmarginal cell. Radius sinuous. Structure of mesopleuron similar to that of Ophion slaviceki, shining or weakly shagreened with weaker, very regular punctation consisting of small punctures. Interstices between punctures about equal to their diameter, up to 2 times their diameter. Epicnemial carina, in antero-ventral view, with pleurosternal angles obviously anterior to sternal angles. Sternal angles rounded, epicnemial carina between sternal and pleurosternal angles usually less concave than in O. variegatus. Pleurosternal angles rounded, obtuse, rarely right angeled. Scutellum wide, without lateral carinae. Structure of propodeum similar to that of O. luteus (Fig. 10A). Posterior to anterior transverse carina mostly shining. Anterior transverse carina always present centrally anterior to area superomedia, but often also present laterally, though rarely strongly raised. Posterior transverse carina usually only present laterally, widely interrupted centrally (Fig. 10A). Central longitudinal carinae weak or absent, when present forming a narrow triangular area. Hind trochantellus shorter than wide in dorsal view. Legs normal with hind femur about 6.0-7.0 times as long as wide. Hind trochantellus usually longer than in other species except O. luteus, O. slaviceki and O. variegatus (Fig. 7F). Slightly shorter than wide in dorsal view. Inner spur of hind tibia long about 0.3-0.4 times as long as metatarsus. Sclerotised section of first sternite ending level with spiracle.

\section{Colour}

Body usually more brownish than other species and with extensive whitish pattern on thorax (as in Fig. 11A-B) and metasoma. Mandibular teeth black. Ovipositor sheath testaceous.

\section{Ecology}

Ophion obscuratus occurs in areas with favorable climate in Southern and Central Sweden, preferably in open or semi-open grasslands and heaths during October to December. Due to the late period of flight it has been overlooked and the relatively low number of collected specimens probably does not reflect the real abundance of this species.

\section{Distribution in Sweden}

Probably widespread, at least in Southern Sweden.

\section{Remarks}

This species has often been treated as conspecific with Ophion variegatus and the two species have been regarded as two different, but slightly morphologically different generations. Ophion obscuratus is usually easily separated from $O$. variegatus by the shape of the junction between the occipital and hypostomal carinae (Fig. 7L), larger size (fore wing length 16-18 mm), more numerous flagellomeres (62-66), the usually wider scutellum and the shape of the flagellomeres. Brock (1982) refers to Ophion obscuratus as "autumnal giants". The interpretation of the lectotype male of Ophion obscuratus, despite 
the rather poor shape of the specimen, is that it represents the larger autumnal species based on the large size and shape of the occipital carina. For further taxonomic comments, see Discussion: "The Ophion obscuratus aggregate".

Ophion ocellaris Ulbricht, 1926

Figs 7C, 8L, 10I

Ophion ocellaris Ulbricht, 1926: 17.

Ophion fuscicollis Hellén, 1926: 14?

\section{Material examined}

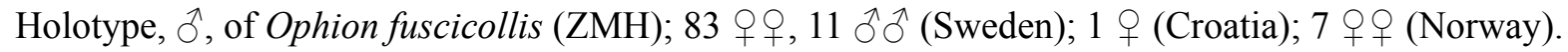

\section{Diagnosis}

Fore wing length $13-15 \mathrm{~mm}$. Antenna in both sexes with 51-55 flagellomeres. First flagellomere 3.5 times as long as wide. Head narrowed behind eyes. Occipital carina entirely absent (Fig. 7C). Malar space about 0.1 times as long as mandibular base in female and male. Mandibular gape right-angled, with internal angles. Wing membrane strongly yellowish. Mesopleuron polished and punctate. Interstices between punctures 1-2 times their diameter. Pleurosternal angles strongly obtuse, weakly defined and obviously anterior to sternal angles (as in Fig. 9H). Scutellum without lateral carinae, rectangular with parallel sides (as in Fig. 6B). Propodeum coriaceous with carina strongly reduced and only posterior transverse carina present and often interrupted or weak centrally. Propodeum centrally with transverse wrinkles (Fig. 10I). Female metasoma shorter than in $O$. areolaris. Tergite $4-5$ in lateral view about 0.75 times as long as wide. Spiracles of tergite 2-7 more close to the base of the tergite (Fig. 8L). Male parameres longer, about 1.5 times as long as wide and more rounded dorsally in lateral view than in O. areolaris.

\section{Colour}

Body testaceous, sometimes with fuscous areas on meso- and metasoma. Mandibular teeth black. Stemmaticum black or dark brown, ovipositor sheath black.

\section{DNA barcode}

The DNA barcode sequences of four Swedish specimens of Ophion ocellaris are available at the BOLD systems database (www.boldsystems.org, BIN. BOLD: ADG0270/ADG3721. Specimen codes: STINJBC: Clade 1; 02, Clade 2; 01, 03-04).

\section{Ecology}

This species occurs in late summer and autumn, late June-early September and the hosts seem to be various species of Drepanidae (subfamily Thyatirinae) according to Brock (1982). It has mainly been collected in boreal woodland habitats, but has also been attracted to light in semi-open habitats.

\section{Distribution in Sweden}

This species is quite common and occurs over most of the country, but is apparently missing in high alpine areas in the north.

\section{Remarks}

The holotype male of Ophion fuscicollis was studied and although access to the type of O. ocellaris was denied, the opinion presented here is that the species are synonymous. However, the actual date of publication for the description of either of the species is uncertain and the question of which name has 
priority over the other remains. In this study the more commonly used name $O$. ocellaris is used. Also of interest, is that one of the four barcoded specimens forms a separate BIN with a series of specimens from Great Britain. The existence of two distinct clades could indicate the existence of a cryptic species. Despite studying a rather large amount of material, no reliable morphological differences have been detected. The discovery of a presumably cryptic species could of course also mean that the proposed synonymy between $O$. ocellaris and $O$. fuscicollis is more complicated. Therefore this study refrains from a formal publication of the synonymy at this time.

Ophion paraparvulus Johansson sp. nov. urn:1sid:zoobank.org:act:27180696-5ED4-4907-9603-0584ACEE7B66

Figs $8 \mathrm{~B}, 38$

\section{Diagnosis}

Ophion paraparvulus Johansson sp. nov. is one of the species in an aggregate previously treated under the name Ophion parvulus. Ophion paraparvulus Johansson sp. nov. is morphologically intermediate between Ophion parvulus and Ophion tenuicornis Johansson sp. nov. and has the flagellomeres stouter and less pilose than $O$. tenuicornis Johansson sp. nov., but longer and more pilose than $O$. parvulus. It is also easily confused with $O$. kallanderi Johansson sp. nov., but distinguished by the shorter temples and the stouter central flagellomeres. The posterior transverse carina is, as in $O$. kallanderi, usually widely interrupted in the middle with only the lateral parts distinct (Table 1).

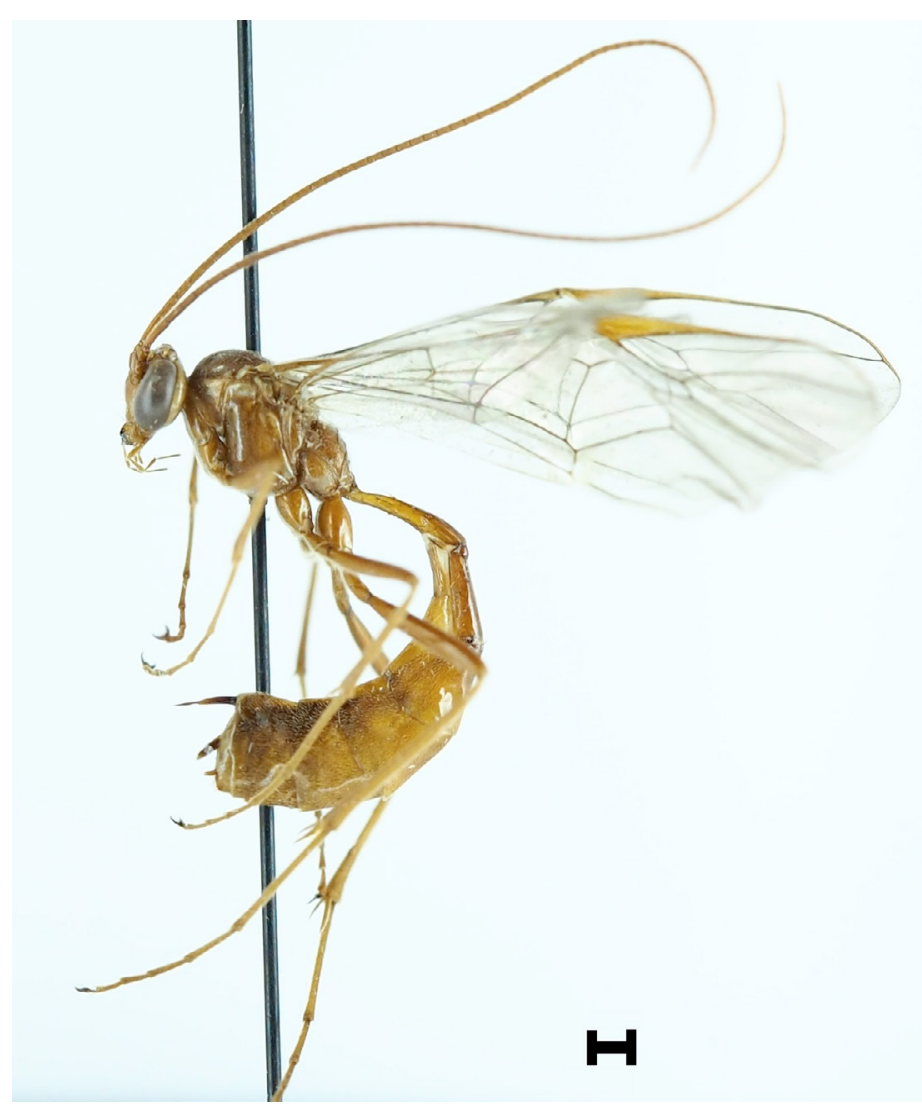

Fig. 38. Ophion paraparvulus Johansson sp. nov., paratype, + (NHRS-HEVA000008696). Scale bar $=$ $1 \mathrm{~mm}$. 


\title{
Etymology
}

The species is very similar and closely related to Ophion parvulus.

\section{Material examined}

\author{
17 우 (Sweden); 2 우 (Estonia); 1 (Norway).
}

\section{Type material}

\section{Holotype}

SWEDEN • ; B Blekinge, Karlskrona, Tullaretorpet; $56.227^{\circ}$ N, $15.647^{\circ}$ E; 13-14 Jun. 2016; C. Philipsson leg.; MV-light trap in oak dominated deciduous forest; STI-NJBC40; NHRS-HEVA000008694.

\section{Paratypes}

SWEDEN • 1 q; same data as for holotype; 20-21 Jun. 2016; C. Philipsson leg.; MV-light trap; STINJBC36; NHRS-HEVA000008695 • 1 क; Bohuslän, Tossene, Stora Hultet; 58.446 N, $11.409^{\circ}$ E; 31 May-7 Jun. 2016; N. Ryrholm and C. Källander leg.; MV-light trap in farmland; NHRSHEVA000008696 • 1 O; Småland, Nybro, Bjällingsmåla; 56.930 N, 15.909 E; 1 May-1 Jul. 2015; N. Johansson leg.; Malaise trap in old mixed forest; NHRS-HEVA000008697 • 1 क ; Blekinge, Svängsta, Bökemåla (Bökasmåla); 56.241 ${ }^{\circ} \mathrm{N}, 14.736^{\circ} \mathrm{E}$; 5-7 Jul. 2015; M. Sjödahl leg.; MV-light; NHRSHEVA000008698 • 1 우 Skåne, Kullen, Brunkulla; $56.301^{\circ}$ N, $12.455^{\circ}$ E; 16 Jul. 1974; C.-H. Lindroth leg.; MV-light; MZLU Type no. 6373:1 • 1 क; Östergötland, Boxholm, Björneberg; 58.195 ${ }^{\circ} \mathrm{N}, 14.909^{\circ} \mathrm{E}$; 4-20 Jun. 2018; N. Johansson leg.; Malaise trap in old mixed forest; NHRS-HEVA000008699 • 1 q; Bohuslän, Uddevalla, Älje-Porsen; $58.355^{\circ} \mathrm{N}, 12.031^{\circ}$ E; 5 Jun. 2017; M. Oomen leg.; MV-light trap; NHRS-HEVA000008700 • 1 क; Skåne, Kullen, Brunkulla; 56.301 N, $12.455^{\circ}$ E; 20 Jun. 1973; C.-H. Lindroth leg.; MV-light; MZLU Type no. 6373:2.

\section{Description}

Fore wing length $16 \mathrm{~mm}$. Antenna with 53-54 flagellomeres. First flagellomere 4.0 times as long as wide.Second-fourth flagellomere about 2.5-3.0 times as long as wide. Central flagellomeres elongate, about 2.0 times as long as wide. Apical flagellomeres 1.8-1.9 times as long as wide. Flagellomeres with quite long prominent pilosity. Length of pilosity in females at least 0.5 width of flagellomere (Fig. 8B). Head narrow behind eyes, in lateral view with temple 0.3 times as long as compound eye. Ocelli in female large, in dorsal view covering the inner margin of compound eye. The distance between lateral ocelli in female about 0.3 times the diameter of the ocellus. Malar space about 0.1 times as long as mandibular base. Mandibular gape right-angled, with internal angles. Wing membrane clear. Ramellus distinct, reaching $0.2-0.4$ the width of discosubmarginal cell but sometimes small or absent. Radius evenly curved. Mesopleuron weakly shagreened with deep distinct punctures. Interstices between punctures about equal to their diameter. Epicnemial carina, in antero-ventral view, with pleurosternal angles obviously anterior to sternal angles. Pleurosternal angles rounded, slightly obtuse. Scutellum with lateral carinae only indicated basally. Propodeum with very weak rugose structure, shining with anterior transverse carina strongly raised. Posterior transverse carina usually widely interrupted centrally. Longitudinal carinae delimiting area superomedia and lateral longitudinal carinae often weak or absent, but normally clearly indicated at the junction with the posterior transverse carina. Hind trochantellus shorter than wide in dorsal view. Legs normal with hind femur about 6.0-7.0 times as long as wide. Sclerotised part of first sternite ending level or slightly posterior to spiracle. Inner spur of hind tibia as long as 0.4 times first hind metatarsus. Male unknown.

\section{Colour}

Body light testaceous, frequently with diffuse pale markings as in O. parvulus. Mandibular teeth black. Ovipositor sheath usually concolourous with posterior metasomal segments. 


\section{DNA barcode}

The DNA barcode sequences of two Swedish specimens of Ophion paraparvulus Johansson sp. nov. are available at the BOLD systems database (www.boldsystems.org, BIN. BOLD: ADG1399. Specimen codes: STI-NJBC: 36,40 ).

\section{Ecology}

Very little is known about the biology of this species. It has been collected in areas with mature semiopen mixed forests. The flight period seems to be mid June to mid July. It is active earlier in the season than its sibling species $O$. tenuicornis Johansson sp. nov. and $O$. costatus.

\section{Distribution in Sweden}

Rare and possibly confined to areas with favourable climate in Southern Sweden.

Ophion parvulus Kriechbaumer, 1879

Figs $8 \mathrm{~A}, 8 \mathrm{G}, 9 \mathrm{D}, 51 \mathrm{~A}-\mathrm{F}$

Ophion parvulus Kriechbaumer, 1879b: 104-105.

\section{Material examined}

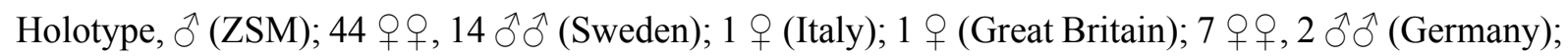
2 우우 (Estonia).

\section{Diagnosis}

Fore wing length $15-16 \mathrm{~mm}$. Antenna with 45-52 flagellomeres. First flagellomere 4.0 times as long as wide. Second flagellomere about 2.5 times as long as wide. Central flagellomeres about 1.5-1.6 times as long as wide. Apical flagellomeres approximately 1.4-1.5 times as long as wide. Apical flagellomeres with short dense quite adpressed pilosity (Fig. 8A). Length of pilosity distinctly shorter than 0.5 times the width of flagellomere. Temple short. Head in lateral view with temple $0.4-0.5$ times as long as compound eye in females, slightly wider, 0.6, in males. Distinctly wider than in Ophion paraparvulus Johansson sp. nov. and $O$. tenuicornis Johansson sp. nov. In female ocelli rather small, touching or nearly touching inner margin of compound eye, the distance between lateral ocelli about 0.5 times the diameter of ocellus. Malar space about 0.1 times as long as mandibular base in female and about 0.2 times in male. Mandibular gape right-angled, with internal angles. Wing membrane clear. Ramellus often distinct, reaching $0.2-0.3$ the distance of discosubmarginal cell but sometimes smaller or entirely absent. Radius evenly curved. Mesopleuron shiny or sometimes weakly shagreened with quite weak punctures. Interstices between punctures about equal or slightly larger than their diameter. Epicnemial carina, in antero-ventral view, with pleurosternal angles obviously anterior to sternal angles. Pleurosternal angles rounded, strongly obtuse (Fig. 9D). Scutellum with lateral carinae only indicated basally. Propodeum with very weak rugose structure, quite shiny with anterior and posterior transverse carina strongly raised in females. Anterior transverse carina in males often weak or absent laterally. Petiolar carinae usually weak. Longitudinal carinae delimiting area superomedia and lateral longitudinal carinae often rather strong, but sometimes only indicated at the junction with the posterior transverse carina. Hind trochantellus shorter than wide in dorsal view. Hind tarsus in male and female slender and elongate (Fig. 8G). Fourth segment about 3.0 times as long as wide. Fifth segment as long as fourth. Mid tarsus with fourth segment slender, 0.8-0.9 times as long as fifth segment. Sclerotised part of first sternite ending level or slightly posterior to spiracle. Inner spur of hind tibia as long as 0.4 times metatarsus. 


\section{Colour}

Body light testaceous. Often with diffuse pale markings on mesoscutum, propleuron, mesopleuron, scutellum and first tergite anterior to spiracle. Mandibular teeth black. Ovipositor sheath testaceous, concolourous with posterior abdominal segments.

\section{DNA barcode}

The DNA barcode sequences of nine Swedish specimens of Ophion parvulus are available at the BOLD systems database (www.boldsystems.org, BIN. BOLD: ACU9407. Specimen codes: STI-NJBC: 39, 41, 253-259).

\section{Ecology}

In NHRS there is a series consisting of one female and three males reared from the noctuid moth Fissipunctia ypsillon (Denis \& Schiffermüller, 1775). The type series was reared from Ipimorpha retusa (Linnaeus, 1761). This indicates that $O$. parvulus is using several hosts, potentially with similar ecology, that are feeding on Salix, among them larvae which live in joined leaves of the host plant. Ophion parvulus is mainly active earlier than $O$. tenuicornis Johansson sp. nov. and $O$. costatus, during JuneJuly, at the same time as $O$. paraparvulus Johansson sp. nov.

\section{Distribution in Sweden}

Together with Ophion paraparvulus Johansson sp. nov. the least common of the species previously known under the name $O$. parvulus in Sweden, occurring primarily in the southern parts of the country.

\section{Remarks}

The female of Ophion parvulus is distinguished from Ophion tenuicornis Johansson sp. nov. by the stouter flagellomeres and the slightly more buccate head, from Ophion costatus by the slenderer tarsal segments and from Ophion paraparvulus Johansson sp. nov. by the stouter and less pilose subapical flagellomeres, the usually more distinct posterior transverse carina on the propodeum and the more buccate head (Table 1). Males are usually separable by the shape of the flagellomeres, the carination of the propodeum and the shape of the temples. The species is usually distinctly smaller than $O$ costatus. and the flagellomeres have approximately the same appearance, but have shorter more adpressed pilosity in the female. See Discussion: "The Ophion parvulus aggregate", for further information on the species status.

Ophion paukkuneni Johansson sp. nov. urn:1sid:zoobank.org:act:166B3CC0-E787-4045-885B-7DB3E9E4BA6C

Figs 20A-B, 39

\section{Diagnosis}

Similar to and closely related to Ophion longigena, but with the temple usually less buccate and the lower side of temple less strongly convex in lateral view. Face usually narrower below the antennal sockets, with the clypeus almost square and the first metasomal segment more elongate and in most known specimens with a distinct dorsal undulation. The metasoma is posteriorly entirely testaceous and the sclerotised section of first sternite ends distinctly posterior to the spiracle. The punctation of the face centrally and the clypeus is of almost the same intensity, while the face is more densely punctate than the clypeus in $O$. longigena. The mandibles in known specimens show no sign of wear as is common in O. longigena. Ophion paukkuneni is also reminiscent of Ophion crassicornis, but with the ovipositor sheath testaceous (black in O. crassicornis), central flagellomeres more elongate, and with a lower number of flagellomeres. The species is also easily confused with the species around Ophion perkinsi Brock, but is usually larger in size, has a higher number of flagellomeres and the central flagellomeres more elongate. 


\section{Etymology}

The species is named in honour of the Finnish hymenopterist Juho Paukkunen.

\section{Material examined}

$5 q q$ (Sweden); $1 q$ (Norway).

\section{Type material}

\section{Holotype}

SWEDEN • +; Bohuslän, Tossene, Stora Hultet; $58.446^{\circ}$ N, $11.409^{\circ}$ E; 24 Mar.-23 Jul. 2014; N. Ryrholm and C. Källander leg.; MV-light trap in farmland; STI-NJBC64; NHRS-HEVA000008701.

\section{Paratypes}

SWEDEN • 1 q; Dalsland, Åmål; 59.048 N, 12.681 E; 16 Aug. 1907; S. Bengtsson leg.; MZLU Type no. 6374:1 • 1 क ; Gästrikland, Grinduga; $60.641^{\circ}$ N, $17.299^{\circ}$ E; 9-16 Jul. 2013; N. Ryrholm and C. Källander leg.; MV-light trap in mixed forest; NHRS-HEVA000008702 • 1 क; Bohuslän, Tossene, Nordens Ark; $58.443^{\circ}$ N, $11.435^{\circ}$ E; 17 Jul.-16 Aug. 2016; N. Ryrholm and C. Källander leg.; MV-light trap in mixed forest; NHRS-HEVA000008703 • 1 q; Bohuslän, Koster, Myren; $58.899^{\circ} \mathrm{N}, 11.011^{\circ} \mathrm{E}$; 10-16 Jul. 2006; N. Ryrholm and C. Källander leg.; MV-light trap in semi open deciduous woodland; NHRS-HEVA000008704.

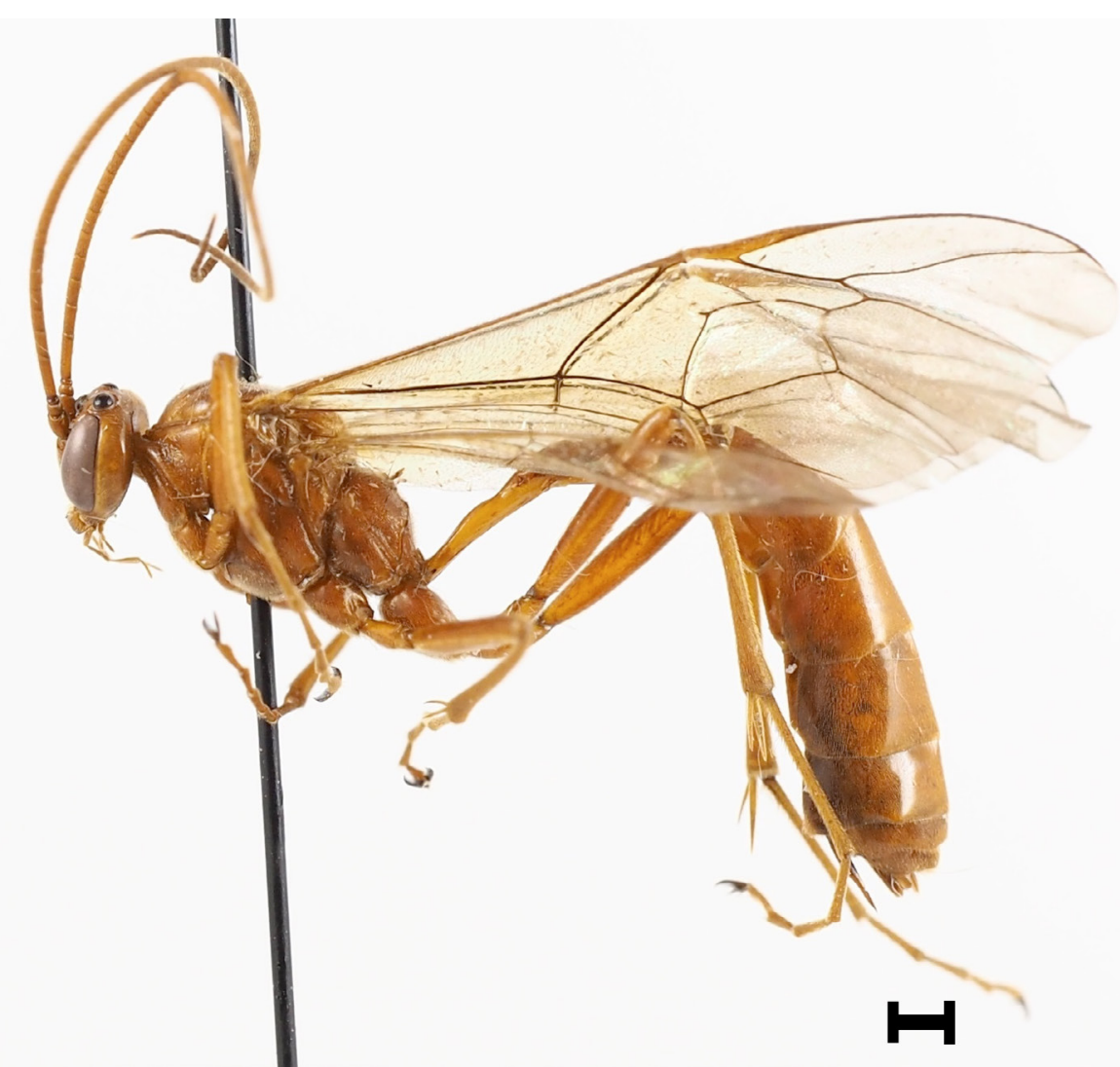

Fig. 39. Ophion paukkuneni Johansson sp. nov., holotype, $q$ (NHRS-HEVA000008701). Scale bar $=$ $1 \mathrm{~mm}$. 
NORWAY • 1 q; Aust-Agder ytre, Arendal, Spornes; 58.264 N, 8.613 E; 7 Jul. 2018; J. Austevik leg.; NHRS-HEVA000008705.

\section{Description}

Fore wing length 14-15 mm. Antenna in both sexes with 50-53 flagellomeres. First flagellomere 3.0-3.5 times as long as wide. Temple in female strongly buccate. Head in lateral view temple slightly shorter than compound eye (Fig. 20B). Head in dorsal view with distinct gap between lateral ocellus and eyes. Head in frontal view rounded (width/height measured from the apical margin of clypeus to the top of head $=1.15-1.20)$. Face in frontal view narrower than in $O$. longigena, with clypeus approximately as long as wide (Fig. 20A). Punctation on face scarce in relation to O. longigena, interstices between punctures usually equal to diameter of punctures. Malar space long, about $0.4-0.5$ times as long as mandibular base. Mandibles with inner angles, unworn. Wing membrane clear. Ramellus distinct, reaching 0.3 times the width of the discosubmarginal cell. Radius sinuous. Mesopleuron usually weakly shagreened and densely punctate with small punctures, spaces between punctures about equal to their diameter. Pleurosternal angles almost in level with sternal angles, right angled or slightly acute but apically rounded. Scutellum with distinct lateral carinae at least in basal half. Propodeum distinctly punctate, often quite polished, with anterior and posterior transverse carina usually strong. Longitudinal carinae delimiting area superomedia often weak or absent. Central longitudinal carinae often distinct basally. Sclerotised part of first sternite ending distinctly posterior to spiracle. First tergite elongate with distinct dorsal undulation (as in Fig. 20F). Hind trochantellus shorter than wide in dorsal view. Inner spur of hind tibia about as long as 0.5 times hind metatarsus. Male unknown.

\section{Colour}

Body testaceous. Head with inner and outer eye margins yellow. Mandibular teeth black. Ovipositor sheath testaceous, concolourous with posterior metasomal segments.

\section{DNA barcode}

The DNA barcode sequence of one Swedish specimens of Ophion paukkuneni Johansson sp. nov. is available at the BOLD systems database (www.boldsystems.org, BIN. BOLD: ADF9569. Specimen code STI-NJBC: 64).

\section{Ecology}

The species is active during late July-August. Other than that, nothing is known about the ecology of this species.

\section{Distribution in Sweden}

Very rare in Central Sweden, seemingly having a more pronounced northern distribution than O. longigena.

Ophion perkinsi Brock, 1982

Figs 10H, 17C, E, 20F, 21D

Ophion perkinsi Brock, 1982: 87-88.

\section{Material examined}

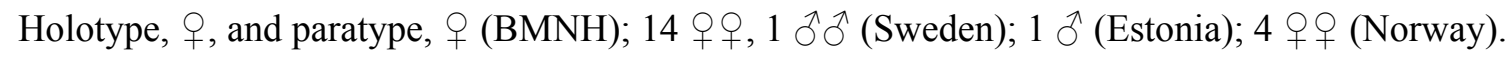




\section{Diagnosis}

Fore wing length 12-13 mm. Antenna in both sexes with 45-49 flagellomeres. First flagellomere 3.0-3.5 times as long as wide. Central flagellomeres almost square to slightly longer than wide. Head buccate behind eyes (Fig. 21D), in dorsal view with distance between inner margin of compound eye and lateral ocellus $0.2-0.3$ times the diameter of ocellus. Malar space in female about $0.3-0.4$ times (Fig. 17E), and in male 0.8 times the length of mandibular basis (Fig. 17C). Head in anterior view rounded. Temple in lateral view about 0.7-0.8 times as long as compound eye. Mandibular gape rightangled, with internal angles. Wing membrane clear. Ramellus distinct. Radius sinuous. Mesopleuron and metapleuron distinctly punctate with obvious microsculpture between punctures. Interstices between punctures about equal to their diameter. Pleurosternal angles rounded, approximately right angled, well defined and obviously anterior to sternal angles. Scutellum with distinct lateral carinae at least in basal half. Propodeum coriaceous and usually distinctly punctate. Anterior and transverse carina present centrally, often weak or absent laterally. Posterior transverse carina strongly raised, interrupted centrally. Longitudinal carinae delimiting area superomedia often weak or absent (Fig. 10H) and area superomedia usually elongate. First tergite narrow and strongly elongate in lateral view, with a dorsal undulation (Fig. 20F). Sclerotised part of first sternite ending distinctly posterior to spiracle. Hind trochantellus shorter than wide in dorsal view. Inner spur of hind tibia as long as 0.5 times hind metatarsus.

\section{Colour}

Body testaceous. Inner and outer orbits slightly yellowish. Mandibular teeth black. Ovipositor sheath testaceous, concolourous with posterior metasomal segments.

\section{DNA barcode}

The DNA barcode sequences of two Swedish specimens of Ophion perkinsi are available at the BOLD systems database (www.boldsystems.org, BIN. BOLD: ADM6556. Specimen codes: STI-NJBC: 218, 222).

\section{Ecology}

No details are known about the ecology of this species. It seems to occur mainly in deciduous forests in Southern Sweden. The main flight period is July.

\section{Distribution in Sweden}

Rare but widespread in the southern part of Sweden.

\section{Remarks}

Very similar and closely related to Ophion norei Johansson sp. nov., but with the malar space considerably longer in both male and female and the head more rounded in anterior view. The first tergite is slenderer and with a dorsal undulation centrally in lateral view. Generally the mesopleural angles are less prominent and the meso- and metapleuron have distinct microsculpture between punctures.

Ophion pteridis Kriechbaumer, 1879

Figs $18 \mathrm{G}-\mathrm{H}, 19 \mathrm{E}-\mathrm{F}, 40,52 \mathrm{~A}-\mathrm{F}$

Ophion pteridis Kriechbaumer, 1879a: 89-98.

Ophion albistylus Szépligeti, 1905: 521. Syn. nov.

\section{Material examined}

Lectotype, + , of Ophion pteridis (ZSM); holotype, $\odot$, of Ophion albistylus (NHMH); 6 + $q$ (Sweden); 1 ㅇ (Germany); 2 우, 1 ภ (Estonia); 1 ภ (Lithuania). 


\section{Diagnosis}

Fore wing length $16-17 \mathrm{~mm}$. Antenna in both sexes with 57-58 flagellomeres. First flagellomere 3.5-4.0 times as long as wide. Central flagellomeres about 1.6-1.7 times as long as wide. Apical flagellomeres with dense pilosity. Pilosity as long as the width of flagellomeres. Head very strongly narrowed behind eyes. Temple in lateral view of female about 0.3 times as long as compound eye (Fig. 19F) and in male about 0.6 times as wide as compound eye. In frontal view almost round (width/height measured from the apical margin of clypeus to the top of head $=1.15-1.20)$ (Fig. 19E). Ocelli large, in dorsal view covering part of the compound eye in females and males (Fig. 18G-H). The distance between posterior ocelli about $0.3-0.4$ times the width of ocellus in female. Occipital carina centrally more angled than in $O$. inclinans Johansson sp. nov. (as in Fig. 7B). Face below antennal sockets with quite scarce punctures, polished or weakly shagreened. Malar space about

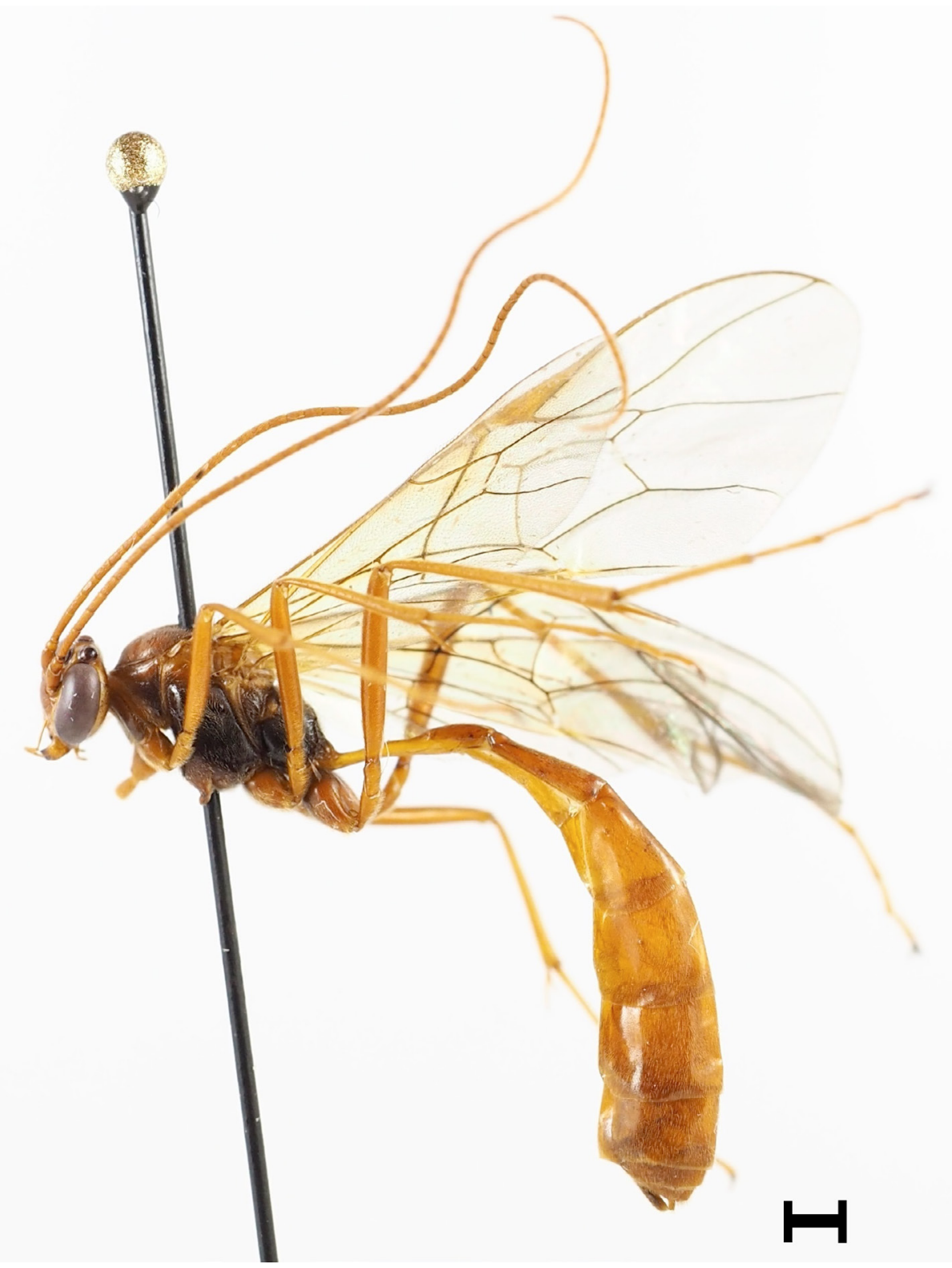

Fig. 40. Ophion pteridis Kriechbaumer, 1879, ㅇ. Scale bar $=1 \mathrm{~mm}$. 
0.1-0.2 times as long as mandibular base in female and about 0.2 times in male. Mandibular gape right-angled, with internal angles. Wing membrane weakly yellowish. Ramellus distinct, reaching abut 0.3 times the width of the discosubmarginal cell. Radius sinuous. Mesopleuron shagreened and distinctly punctate. Interstices between punctures about equal to their diameter. Pleurosternal angles weakly obtuse to right angled, obviously anterior to sternal angles. Scutellum with distinct lateral carinae. Propodeum coriaceous, often quite polished with anterior transverse carina strong, but sometimes partly absent laterally. Posterior transverse carina complete and the area behind it strongly sculptured with distinct wrinkles emanating radially from the petiolar incision. Area superomedia often indicated by carinae. Central longitudinal carinae often distinct. Sclerotised part of first sternite ending distinctly posterior to spiracle. First tergite in lateral view with slight or distinct median dorsal undulation. Hind trochantellus shorter than wide in dorsal view. Inner spur of hind tibia as long as 0.5 times hind metatarsus.

\section{Colour}

Body testaceous. Mandibular teeth black. Mesopleuron, propleuron and propodeum infuscate, black or dark brown (Fig. 40). All coxae and mesosternum usually testaceous, coxae only weakly infuscate basally. Head with inner and outer orbits yellow. Ovipositor sheath testaceous.

\section{DNA barcode}

The DNA barcode sequences of one Swedish specimen of Ophion pteridis is available at the BOLD systems database (www.boldsystems.org. Specimen code: STI-NJBC: 260).

\section{Ecology}

Kriechbaumer refers to a rearing from Callopistria juvetina (Stoll, 1782) in his original description of the species. This noctuid moth has only recently been reported from Sweden and is not reported anywhere near the known localities for Ophion pteridis. One female in HSC was reared from Melanchra persicariae (Linnaeus, 1761) which might be an additional host also used in Sweden. Ophion pteridis is active from August to September.

\section{Distribution in Sweden}

Ophion pteridis is a rare but very widespread species in Sweden and known from only a couple of localities in the eastern part of Central Sweden, one record from Northern Sweden and one from the Baltic island of Gotland.

\section{Remarks}

This species has been misinterpreted and confused with the species here described as Ophion inclinans Johansson sp. nov. Brock (1982) noted the aberrant colour of the holotype female but overlooked several aspects of the original description, such as the large ocelli and strongly narrowed temples, features that are evident in the holotype (Fig. 52A-F). The hypothesis that the darker colour is due to decay of internal organs or any killing agent, as presented by Brock (1982) is erroneous and the darker colour is part of the species diagnosis. The holotype of Ophion albistylus in NHMH was studied and this species is synonymous with Ophion pteridis syn. nov., a fact already noted by Scaramozzino by the labels attached to the specimen. The synonymy was however never formally published. One reared female in HSC has the flagellomeres very stout, reminiscent of $O$. arenarius Johansson sp. nov. Some of the basal flagellomeres are deformed and the shape of the flagellomeres are most likely an aberration caused by deviant rearing conditions. According to the molecular analysis the species is closely related to Ophion vardali Johansson sp. nov., but based on the distinct morphological characters, both species are regarded as valid. 
Ophion scutellaris Thomson, 1888

Figs 10A, 16A

Ophion scutellaris Thomson, 1888: 1192.

Ophion longicornis Brauns, 1889: 92.

Ophion stigmaticus Morley, 1915: 271.

\section{Material examined}

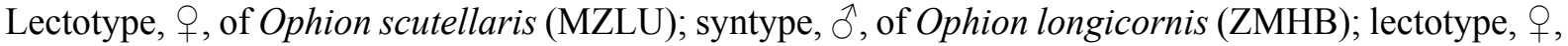

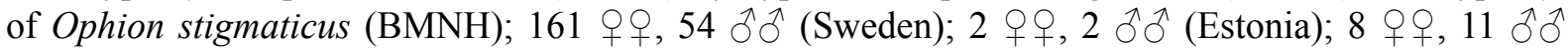
(Norway).

\section{Diagnosis}

Fore wing length $15-19 \mathrm{~mm}$. Antenna in both sexes with 60-71 flagellomeres. First flagellomere 4.0-4.5 times as long as wide. Central flagellomeres 2.0 times as long as wide. Head in females narrowed behind eyes. Temples more buccate in males. Face in anterior view slightly narrower than in $O$. wuestneii. Malar space about 0.2 times as long as mandibular base in female and about 0.3 times in male. Mandibular gape right-angled, with internal angles. Wing membrane clear. Pterostigma elongate, about 3.5 times as long as wide. Ramellus distinct, reaching about 0.3 times the width of the discosubmarginal cell (Fig. 16A). Radius sinuous. Mesopleuron polished and weakly punctate. Interstices between punctures about 1.5-2.0 times their diameter. Pleurosternal angles obtuse, well defined, obviously anterior to sternal angles. Scutellum with distinct lateral carinae (as in Fig. 6C). Propodeum shagreened-coriaceous, often quite shiny with anterior transverse carina partly absent laterally. Posterior transverse carina often widely interrupted centrally. Area superomedia usually absent, only weakly indicated posteriorly (Fig. 10A). Hind trochantellus shorter than wide in dorsal view. Hind femur strongly elongate about 9.0 times as long as wide (as in Fig. 16C). Sclerotised part of first sternite ending distinctly posterior to spiracle. Inner spur of hind tibia as long as 0.3 times metatarsus.

\section{Colour}

Body testaceous. Mesoscutum, especially in males frequently with three brownish longitudinal stripes. Head with inner and outer orbits yellow. Mandibular teeth black. Ovipositor sheath testaceous, concolourous with posterior metasomal segments.

\section{DNA barcode}

The DNA barcode sequences of four Swedish specimens of Ophion scutellaris are available at the BOLD systems database (www.boldsystems.org, BIN. BOLD: AAW9169. Specimen codes: STI-NJBC: 126-129).

\section{Ecology}

Ophion scutellaris occurs in early spring, sometimes as early as late March, and is active to early June. It has been reared from Noctuidae larvae which overwinter in their larval stage (Brock 1982).

\section{Distribution in Sweden}

A common species in Southern and Central Sweden.

\section{Remarks}

The series under the label "Ophion scutellaris" in the Thomson collection in the ZMLU contains at least four different Ophion species. Apart from the lectotype only one specimen belongs to O. scutellaris. 
Ophion slaviceki Kriechbaumer, 1892 stat. rev.

Figs 7E, I, 9E, 14B, 21F, 46A-C

Ophion slaviceki Kriechbaumer, 1892b: 233-234.

Ophion pictus Kokujev, 1906a: 159-160.

Ophion calcaratus Morley, 1915: 269.

\section{Material examined}

Lectotype, $\widehat{O}$, of Ophion slaviceki (ZSM); lectotype, + , of Ophion calcaratus (BMNH); $>750$ 우,

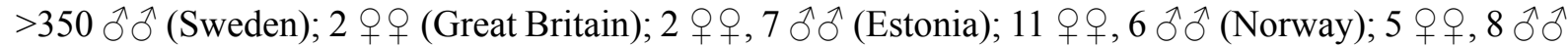
(Lithuania).

\section{Diagnosis}

Fore wing length 13-17 mm. Antenna with 49-59 flagellomeres. First flagellomere about 4.0 times as long as wide. Central flagellomeres about $1.5-1.6$ times as long as wide. Subapical flagellomeres approximately 1.5 times as long as wide. Temples slightly buccate in females. Head in lateral view with temple about 0.4-0.6 times as long as compound eye, more buccate in males. Gap between compound eye and lateral ocellus small or absent, at most 0.2 times the diameter of ocellus (Fig. 14B). Ocellus large, central ocellus in female 2.0 times as wide as distance between margin of central ocellus and inner eye margins. Malar space about 0.2 times as long as mandibular base in female and about 0.2-0.3 times in male (Fig. 21F). Mandibles often worn, with the gap between teeth acute angled and internal angles absent (Fig. 7I). Wing membrane transparent. Ramellus usually short, but occasionally longer, reaching $0.1-0.5$ times the width of the discosubmarginal cell. Radius sinuous. Structure of mesopleuron in most cases shining or weakly shagreened, with distinct, very regular punctation consisting of small punctures. Interstices between punctures about equal to their diameter. Epicnemial carina, in antero-ventral view, with pleurosternal angles obviously anterior to sternal angles. Pleurosternal angles rounded, obtuse to right angled (Fig. 9E). Scutellum usually without lateral carinae, but rarely with lateral carinae in basal half. Propodeum posterior to anterior transverse carina mostly shining. Anterior transverse carina always present centrally, anterior to area superomedia, but often also present laterally, though rarely strongly raised (as in Fig. 10A). The part adjacent to area superomedia often distinctly convex. Posterior transverse carina usually only present laterally, widely interrupted centrally. Petiolar carina and longitudinal carina delimiting area superomedia often strong and forming a narrow triangular area. Sclerotised part of first sternite ending level to spiracle. Legs normal with hind femur about 6.0-6.5 times as long as wide. Hind trochantellus usually as long as wide in dorsal view (Fig. 7E). Inner spur of hind tibia about 0.3-0.4 times as long as hind metatarsus.

\section{Colour}

Body testaceous. Head with inner and outer orbits often distinctly and broadly yellow, especially in males. Mandibular teeth black. Frequently in southern males with narrow yellow stripes on mesoscutum reminiscent of Ophion obscuratus but more yellow in colour. Ovipositor sheath testaceous, concolourous with posterior metasomal segments.

\section{DNA barcode}

The DNA barcode sequences of eight Swedish specimens of Ophion slaviceki are available at the BOLD systems database (www.boldsystems.org, BIN. BOLD: ACF9514. Specimen codes: STI-NJBC: 53, $55-57,62,264,325,327)$.

\section{Ecology}

This species occurs from July to October in a variety of habitats, but seems to prefer open or semiopen areas. Broad et al. (2015) list Agrotis exclamationis (Linnaeus, 1758) and A. segetum (Denis \& 
Schiffermüller, 1775) as hosts. In Swedish collections (NHRS, MZLU) there are several specimens reared from $A$. exclamationis.

\title{
Distribution in Sweden
}

A very common species in Southern Sweden, becoming rare or absent further north.

\section{Remarks}

The oldest available, and therefore correct name for the species with an acute angled mandibular gape, long hind trochantellus and quite narrow head in lateral view with a small gap between the lateral ocellus and compound eye, widely known as Ophion luteus by modern authors, is Ophion slaviceki Kriechbaumer, 1892. One specimen from Sölkäsaari in Haparanda (NJBC327) in Northern Sweden is slightly genetically different from the southern population (Fig. 3). The locality is far beyond the northern distribution limit for any of the known hosts of $O$. slaviceki and this specimen might represent a northern form of the species. For further comments, see Discussion: "The Ophion luteus aggregate".

\author{
Ophion splendens Johansson sp. nov. \\ urn:1sid:zoobank.org:act:C4C67AA3-D220-487F-9DE3-16244C907BC9 \\ Figs 9A, 13F, 15A, 41
}

\section{Diagnosis}

The result of the barcoding indicates that this species is closely related to Ophion confusus (Fig. 1), but morphologically distinguishable from that species by the following: body size larger (fore wing 15-17 mm); usually a higher number of flagellomeres; epicnemial carina between the tip of the pleurosternal angles and the sternal part almost straight; pleurosternal angles obtuse; nervellus broken at or above the middle and the mesopleuron polished with very scarce and weak punctures.

\section{Etymology}

The species is large, often exhibits beautiful variations in brown and yellow colours and has a strongly polished and shining mesosoma.

\section{Material examined}

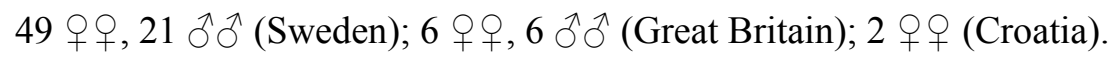

\section{Type material}

\section{Holotype}

SWEDEN • P; Öland, Mörbylånga, Gamla skogsby, Diversitetsängen; $56.619^{\circ} \mathrm{N}, 16.497^{\circ} \mathrm{E} ;$ 15-29 $^{2}$ Jun. 2005; SMTP leg.; Malaise trap in alvar meadow with bushes (Trap id 22, coll ev. id. 1314); STINJBC45; NHRS-HEVA000008705.

\section{Paratypes}

SWEDEN • 5 웅 Skåne, Ystad, Kåseberga; $55.385^{\circ}$ N, 14.066 E; 24 May-28 Jul. 2016; N. Ryrholm and C. Källander leg.; MV-light trap in warm coastal sandslopes; STI-NJBC42, STI-NJBC44 (barcodes for two of the five females); NHRS-HEVA000008706 to NHRS-HEVA000008710 - 1 के; Öland, Borgholm, Borgehage; $56.852^{\circ} \mathrm{N}, 16.626^{\circ} \mathrm{E}$; 12 Jun. 2017; N. Johansson leg.; MV-light in garden close to alvar and deciduous forest; NHRS-HEVA000008711 • 1 \%; Skåne, Simrishamn, Örnahusen; $55.451^{\circ} \mathrm{N}, 14.253^{\circ}$ E; 2-28 Aug. 1996; N. Ryrholm and C. Källander leg.; MV-light trap in sandy meadow; NHRS-HEVA000008712 • 1 \%; Blekinge, Karlskrona, Tullaretorpet; $56.227^{\circ} \mathrm{N}, 15.647^{\circ} \mathrm{E}$; 7-8 Jun. 2016; C. Philipsson leg.; MV-light in oak dominated deciduous forest; NHRS-HEVA000008713 


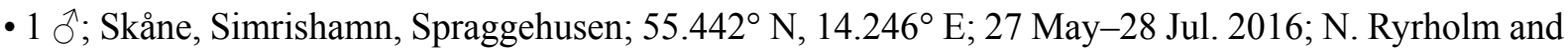
C. Källander leg.; MV-light trap in coastal sanddunes; NHRS-HEVA000008714 • 1 q; Gotland, Sundre, Suders; 56.945 ${ }^{\circ}$ N, $18.303^{\circ}$ E; 29 Jul.-18 Sep. 2017; N. Ryrholm and C. Källander leg.; MV-light trap in deciduous woodland; NHRS-HEVA000008716 • 1 \%; Skåne, Simrishamn, Spraggehusen; $55.442^{\circ}$ N, 14.246 ${ }^{\circ}$ E; 27 May-28 Jul. 1997; N. Ryrholm and C. Källander leg.; MV-light trap in coastal sanddunes; NHRS-HEVA000008715.

\section{Description}

Fore wing length 15-17 mm. Antenna in both sexes with 59-63 flagellomeres. First flagellomere about 3.0 times as long as wide. Central flagellomeres about 1.2-1.3 times as long as wide. Subapical flagellomeres approximately 1.5 times as long as wide. Temple in female and male weakly buccate. Temple in lateral view $0.4-0.6$ as long as compound eye. Lateral ocellus often touching inner margin of compound eye (Fig. 15A). Malar space about 0.1 times as long as mandibular base in female and about 0.2-0.3 times in male. Mandibular gape right-angled, with internal angles. Wing membrane usually distinctly yellowish. Ramellus distinct $0.3-0,5$ times the width of the discosubmarginal cell. Radius sinuous. Nervellus broken at or above the middle by the discoidella (Fig. 13F). Mesopleuron in most cases polished, sometime very weakly shagreened, with very weak and scattered punctures. Interstices between punctures about 3.0-5.0 times their diameter. Epicnemial carina between tip of pleurosternal angles and sternal angles almost straight. Pleurosternal angles obtuse (Fig. 9A). Scutellum without distinct lateral carinae (as in Fig. 6A). Structure of propodeum quite shiny and slightly rugose, basally

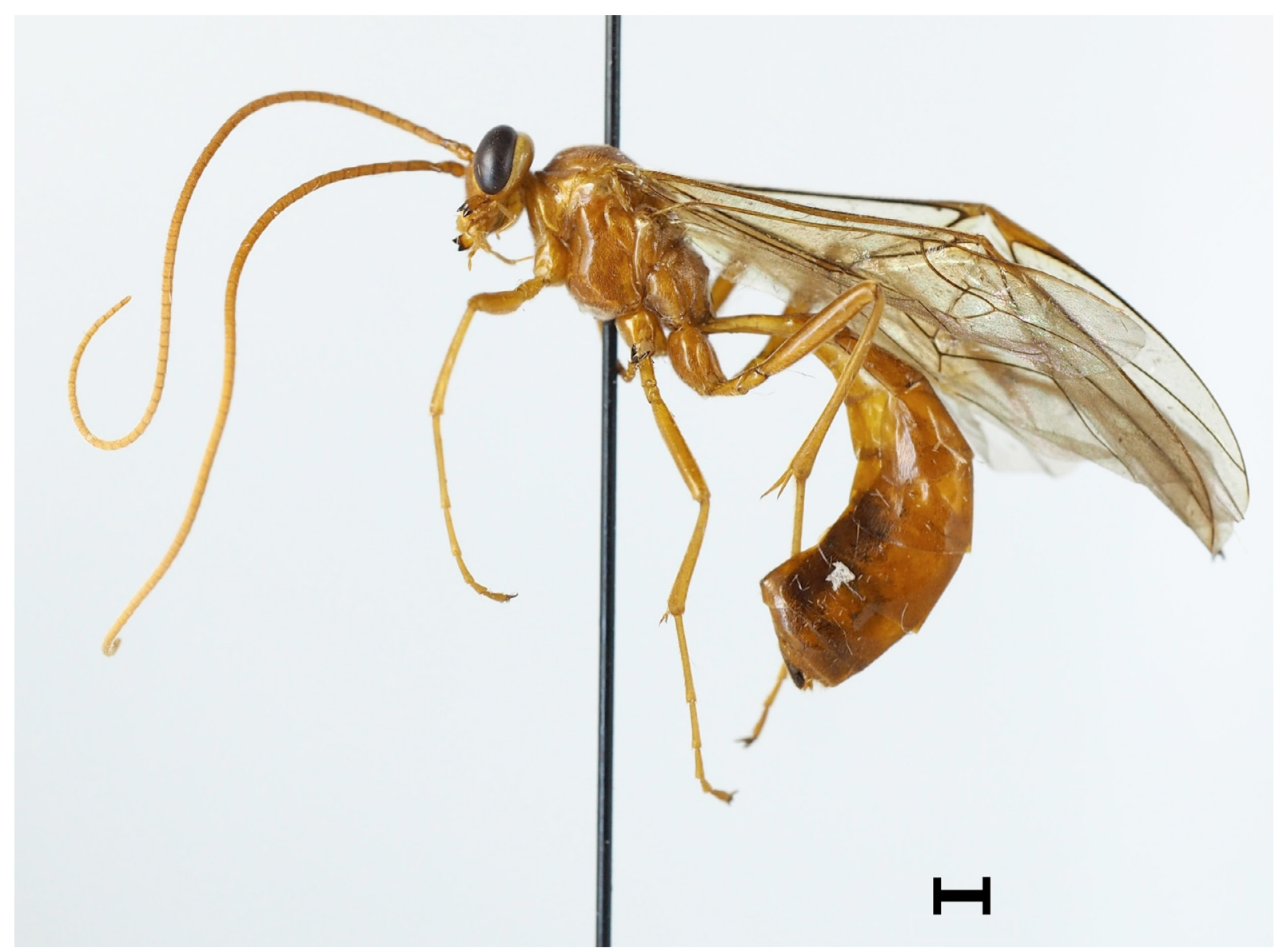

Fig. 41. Ophion splendens Johansson sp. nov., paratype, ㅇ (NHRS-HEVA000008708). Scale bar $=$ $1 \mathrm{~mm}$. 
and laterally with distinct punctures. Anterior transverse carina often absent laterally and posterior transverse carina interrupted centrally. Longitudinal carinae delimiting area superomedia and area petiolaris often weak. Sclerotised part of first sternite ending level to spiracle. Hind trochantellus shorter than wide in dorsal view. Legs normal with hind femur 6.0-7.0 times as long as wide. First sternite ending in level to spiracle. Inner spur of hind tibia as long as 0.4 times metatarsus.

\section{Colour}

Body testaceous. Head with inner and outer eye margins yellow. Mandibular teeth black. Mesosoma often with slightly infuscate areas in front of central ocellus, on mesopleuron and in the form of three brownish stripes on mesoscutum. Ovipositor sheath black or dark brown, contrasting in colour with posterior metasomal segments.

\section{DNA barcode}

The DNA barcode sequences of three Swedish specimens of Ophion splendens Johansson sp. nov. are available at the BOLD systems database (www.boldsystems.org, BIN. BOLD: ABV8262. Specimen codes: STI-NJBC: 42, 44-45).

\section{Ecology}

This species has been reared from Noctua interjecta Hübner, 1803 (Mark Shaw, NMS, pers. com., see also Brock 1982). It has primarily been collected from open or semi-open areas adjacent to deciduous forests during early summer, May-early July.

\section{Distribution in Sweden}

This seems to be a quite rare and local species in Southern Sweden where it primarily occurs in areas with favourable climate in the vicinity of mature deciduous forests. One male from Uppland (Central Sweden) in NHRS was collected indoors and according to the label it was probably rearded from an unregistered host. The collector (Håkan Elmqvist) frequently visits and collects in Southern Sweden including Gotland.

\section{Remarks}

According to British material studied by the first author this species is, together with Ophion brocki Johansson sp. nov., the O. costatus auct. sensu Brock (1982).

Ophion subarcticus Hellén, 1926

Figs $18 \mathrm{~B}, \mathrm{D}, 42$

Ophion subarcticus Hellén, 1926: 12-13.

\section{Material examined}

Lectotype, + , and paralectotype, $q$ (MZH); 2 $q$ (Sweden).

\section{Diagnosis}

Fore wing length 14-15 mm. Antenna with 48-52 flagellomeres. First flagellomere about 3.5-4.0 times as long as wide. Central flagellomeres about 1.5-1.6 times as long as wide. Subapical flagellomeres approximately 1.5 times as long as wide. Temple buccate. Head in lateral view with temple 0.8 times as long as compound eye. Head in anterior view with face wide in relation to the compound eyes (Fig. 18D). Gap between compound eye and lateral ocellus very wide, about $0.6-0.7$ times the diameter of ocellus (Fig. 18B). Malar space about 0.5-0.6 times as long as mandibular base. Gape between mandibles obtuse with internal angles present. Wing membrane yellowish. Ramellus distinct, 0.3 times the width of 
the discosubmarginal cell. Radius sinuous. Structure of mesopleuron strongly shagreened and wrinkled with distinct punctures. Interstices between punctures at most equal to their diameter, generally much less. Epicnemial carina, in antero-ventral view, with pleurosternal angles obviously anterior to sternal angles. Pleurosternal angles rounded, obtuse to right angled. Scutellum with lateral carinae present in basal 0.7. Anterior transverse carina of propodeum present and quite strong. Posterior transverse carina only present laterally, widely interrupted centrally. Structure of propodeum less polished than in O. kevoensis. Petiolar carina and longitudinal carina delimiting area superomedia weak. Legs normal with hind femur about 6.5 times as long as wide. Hind trochantellus shorter than wide in dorsal view. Inner spur of hind tibia about $0.3-0.4$ times as long as metatarsus. Sclerotised part of first sternite ending level to spiracle. Male unknown.

\section{Colour}

Mesosoma infuscate, probably distinctly dark brown in fresh specimens (Fig. 42). Mandibular teeth black. Head with antennae and inner and outer orbits weakly yellowish. Metasoma, antennae and legs testaceous. Ovipositor sheath testaceous, of same colour as posterior metasomal segments.

\section{Ecology}

Both of the Swedish specimens were collected in areas probably dominated by mature subalpine forests consisting of Scots pine Pinus sylvestris and spruce Picea abies (L.) H.Karst. Unfortunately, no information on flight period or habitat is recorded on the labels.

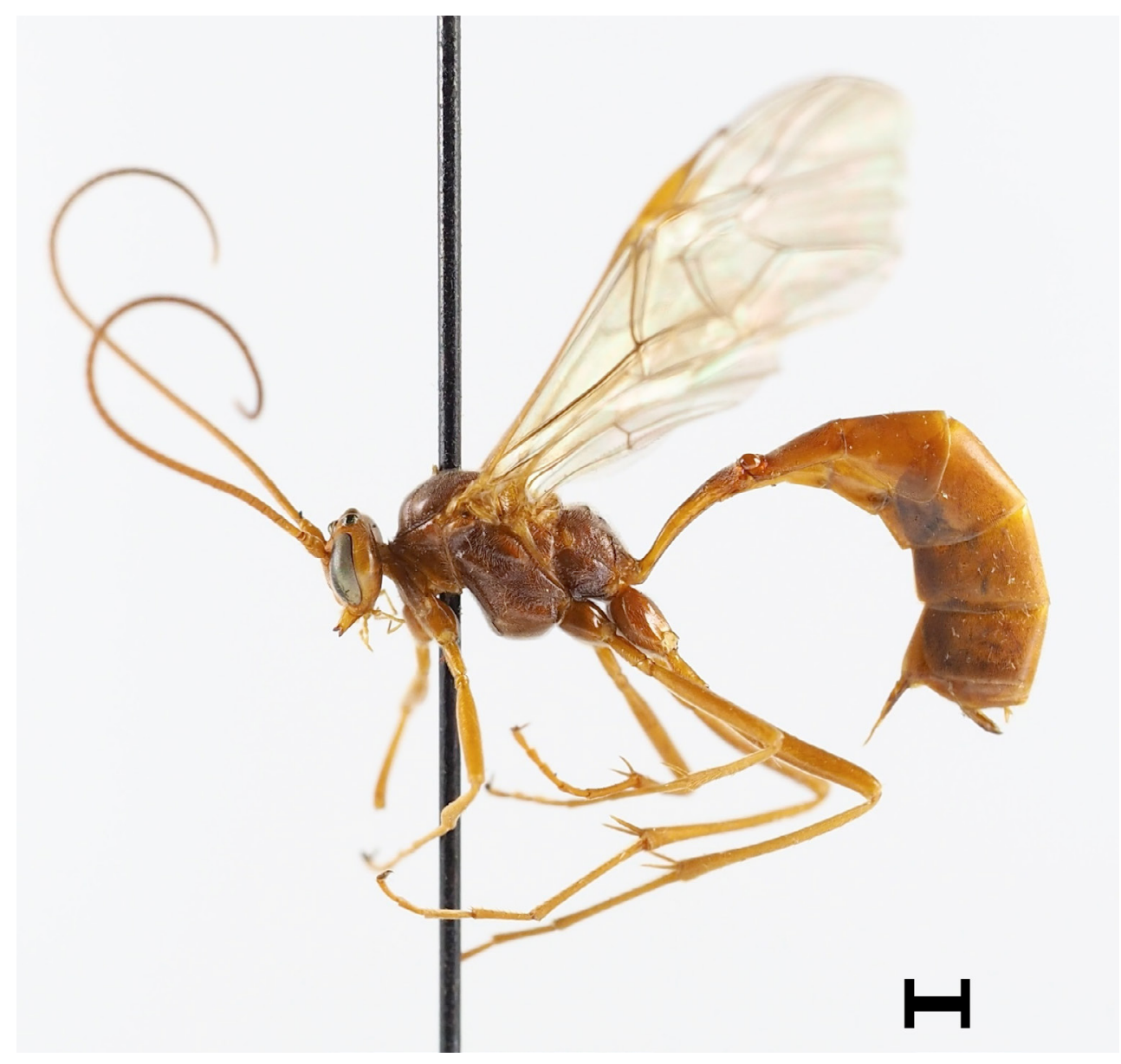

Fig. 42. Ophion subarcticus Hellén, 1926, q. Scale bar $=1 \mathrm{~mm}$. 


\section{Distribution in Sweden}

Judging from the known specimens, this is an exceedingly rare species. The only known specimens from Sweden are two females, one of which is badly damaged by dermestids, in NHRS collected at the beginning of the $20^{\text {th }}$ century at Töfsingdalen and Tandådalen in the Province of Dalarna.

\section{Remarks}

Ophion subarcticus is similar to Ophion kevoensis but, apart from the distinct colour pattern, is distinguished by the smaller size, the longer malar space, the more shagreened mesopleuron and the more buccate temples with a wider gap between the compound eye and ocellus in dorsal view. It also strongly resemble and is sometimes confused with $O$. nigricans, a species it is probably closely related to, but $O$. subarcticus has distinct lateral carinae on the scutellum, a feature absent in $O$. nigricans. Both the holotype and paratypes in MZH had been determined by Brock as Ophion brevicornis in 1997, but share none of the features defining that species, e.g., the strongly convex uncarinated scutellum, short central flagellomeres or the complete posterior transverse carina of the propodeum.

Ophion sylvestris Johansson sp. nov. urn:1sid:zoobank.org:act:0300DD41-25C8-4585-8301-D89C2C78D810

Figs 17B, 43

\section{Diagnosis}

Similar to Ophion autumnalis Johansson sp. nov., but smaller, with a narrower face in females, slightly more buccate temples and black ovipositor sheath. Also quite similar to Ophion kevoensis, but with a narrower face in both sexes and considerably narrower malar space in males. The species here described is probably a complex of two species or ecological forms, one occurring in pine forests and one connected to more rich deciduous forests.

\section{Etymology}

The species seems to occur mainly in forested areas.

\section{Material examined}

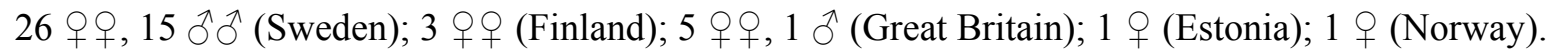

\section{Type material}

\section{Holotype}

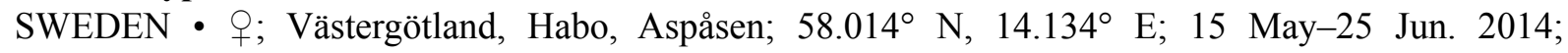
N. Johansson leg.; Malaise trap in wet deciduous forest dominated by Populus; STI-NJBC111; NHRSHEVA000008717.

\section{Paratypes}

SWEDEN • 1 †; Småland, Jönköping, Rocksjön; $57.778^{\circ}$ N, $14.195^{\circ}$ E; 10 Jun. 2016; N. Johansson leg.; MV-light; STI-NJBC109; NHRS-HEVA000008718 • 2 ㅇ; same data as for holotype; STI-NJBC106, STI-NJBC110; NHRS-HEVA000008719, NHRS-HEVA000008720 • 2 우; same data as for holotype; 20 May 2017; N. Johansson leg.; Sweepnet; NHRS-HEVA000008721, NHRS-HEVA000008722 • 1 ; ; Småland, Jönköping, Hakarp; $57.802^{\circ} \mathrm{N}, 14.282^{\circ} \mathrm{E} ; 6$ May 2017; M. Andersson leg.; MV-light in mixed forest; STI-NJBC181; NHRS-HEVA000008723 • 1 q; Småland, Alvesta, Lekarydsvägen; $56.909^{\circ} \mathrm{N}$, 14.567 E; 13-15 May 2016; M. Sjödahl leg.; MV-light; STI-NJBC215; NHRS-HEVA000008724 • 1 ऊ亍; Blekinge, Karlskrona, Tullaretorpet; $56.227^{\circ} \mathrm{N}, 15.647^{\circ}$ E; 31 May-1 Jun. 2016; C. Philipsson leg.; MV-light; STI-NJBC317; NHRS-HEVA000008725 • 1 đ̊; Skåne, Ystad, Kåseberga; 55.385 N, 
14.066 E; 11 May-22 Jun. 2017; N. Ryrholm and C. Källander leg.; MV-light trap in coastal sandslopes; STI-NJBC318; NHRS-HEVA000008726.

\section{Description}

Fore wing length $12-13 \mathrm{~mm}$. Antenna with 52-54 flagellomeres. First flagellomere about 3.0 times as long as wide. Second flagellomere 1.6-1.7 times as long as wide. Central flagellomeres about 1.3-1.5 times as long as wide. Subapical flagellomeres approximately 1.5-1.6 times as long as wide. Temples quite narrow behind eyes, more buccate in males. In lateral view temple in females about $0.4-0.5$ times as long as compound eye, 0.8 times in males. Head of female in anterior view with face narrow, distinctly narrower than 2.0 times the width of compound eye (Fig. 17B). Clypeus distinctly microsculptured with

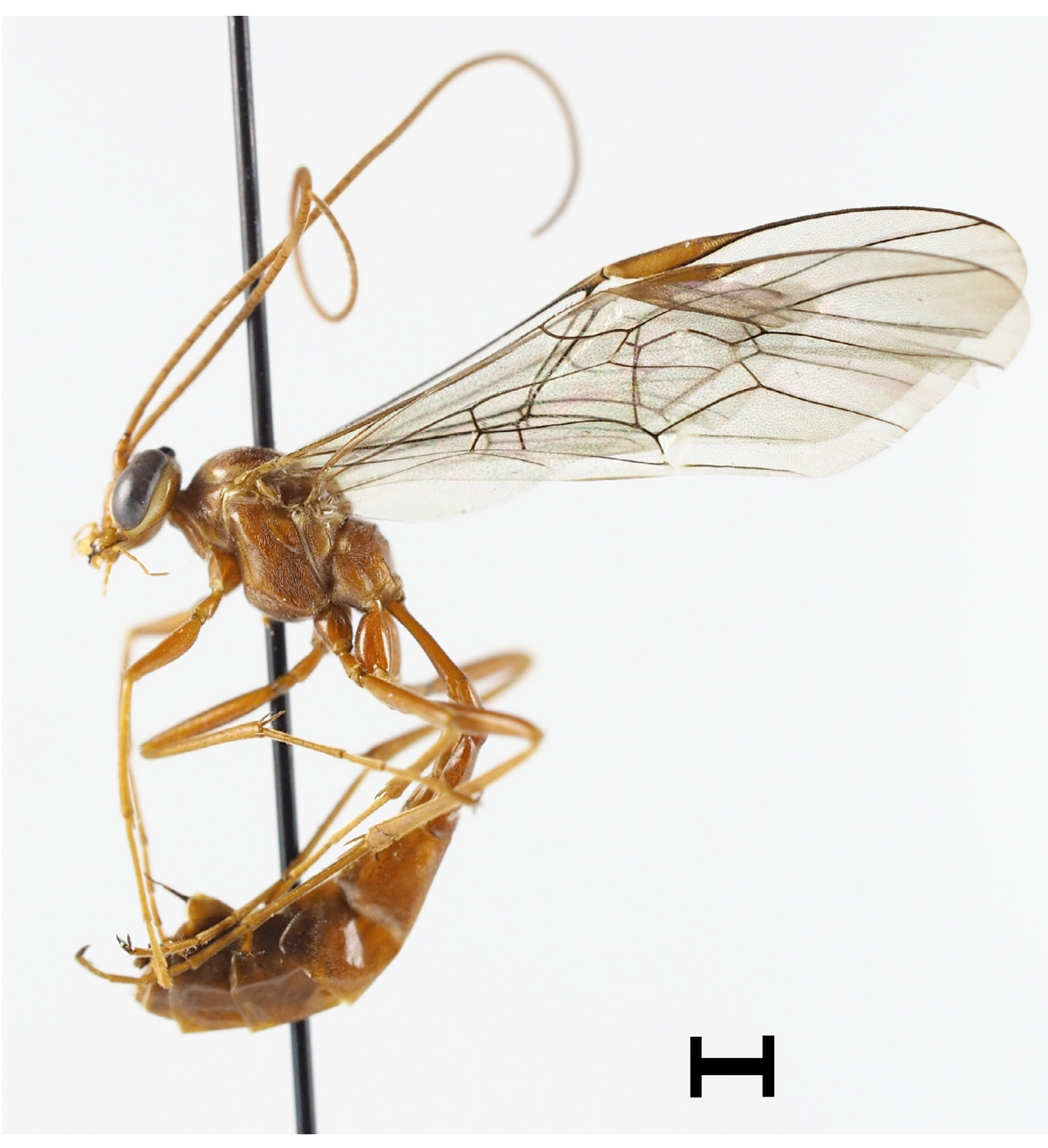

Fig. 43. Ophion sylvestris Johansson sp. nov., paratype,, (NHRS-HEVA000008721). Scale bar $=1 \mathrm{~mm}$. 
rather dense punctures with their interstices less or equal to the diameter of punctures. Head in dorsal view with gap between ocellus and compound eye in studied Swedish specimens, small but distinct, about $0.1-0.2$ times the diameter of the ocellus. Malar space about $0.1-0.2$ times as long as mandibular base in female and male. Mandibular gape right-angled, with internal angles. Wing membrane clear. Ramellus usually short, reaching $0.1-0.3$ times the width of the discosubmarginal cell, sometimes entirely absent in males. Radius sinuous. Structure of mesopleuron in males shagreened with distinct punctures. Epicnemial carina, in antero-ventral view, with pleurosternal angles obviously anterior to sternal angles. Pleurosternal angles rounded, obtuse to right angled (as in Fig. 9E). Scutellum without lateral carinae. Structure of propodeum similar to that of $O$. slaviceki and $O$. obscuratus, posterior to anterior transverse carina mostly shining. Anterior transverse carina always present centrally, anterior to area superomedia, but in a majority of the specimens studied absent or weak laterally. Posterior transverse carina usually only present laterally, widely interrupted centrally. Central longitudinal carinae only weakly present at base of the indicated area superomedia. Sclerotised part of first sternite ending level to spiracle. Legs normal with hind femur about 6.0-7.0 times as long as wide. Hind trochantellus shorter than wide in dorsal view. Inner spur of hind tibia long about $0.3-0.4$ times as long as hind metatarsus.

\section{Colour}

Body testaceous. Mandibular teeth black. Head with inner and outer orbits yellow in males and more orange in females (rarely whitish as in O. obscuratus/variegatus). Upper part of mesopleuron below the wing with pale spot. Margins of mesoscutum and usually two narrow lines centrally pale but never as extensive as in Ophion obscuratus. Ovipositor sheath black or dark brown, contrasting in colour with posterior metasomal segments.

\section{DNA barcode}

The DNA barcode sequences of 18 Swedish specimens of Ophion sylvestris Johansson sp. nov. are available at the BOLD systems database (www.boldsystems.org, BIN. BOLD: AAV4386 (AAG8327). Specimen codes: STI-NJBC: 106, 109-111, 181, 194, 198, 215, 314, 317-318, 343 (107, 196, 208, 213 , 299, 315)).

\section{Ecology}

Most of the known specimens were collected in mixed forest dominated by aspen Populus tremula L. or Scots pine Pinus sylvestris forests in the woodland areas of Central Sweden. The species has several times been sweep-netted in the daytime, indicating that it is partly diurnal. All records are from May to early June.

\section{Distribution in Sweden}

Presumably a local and quite rare species in the woodland parts of Central Sweden.

\section{Remarks}

As in the case with Ophion ocellaris, COI barcode sequeces form two distinct groups that might represent two different species, one mainly occurs in rather rich deciduous forests and one is frequently collected in dry and light Scots pine forests dominated by Calluna Salisb. and Vaccinium. There don't seem to be any reliable distinguishing characters between the two genotypes apart from a slight difference in the density of the punctures of the clypeus where the species/form occurring in pine forests has the punctures sparser with interstices between punctures about two times the diameter of punctures, while in the other species/form the interstices are more equal to or smaller than the diameter of punctures (based on a small sample). The type series focuses on the species/form occurring in deciduous forests (BIN. BOLD: AAV4386) and excludes one of the genotypes (BIN. BOLD: AAG8327). More material is needed before any detailed assessment of morphological characters can be done. Two specimens have 
an intermediate placement between the two groups (Fig. 1), but are both the result of rather poor quality samples which might explain the diverging molecular result.

Ophion tenuicornis Johansson sp. nov. urn:1sid:zoobank.org:act:C1A3799F-344E-49E3-AA66-3083A9D3FF27

Figs $8 \mathrm{C}, 10 \mathrm{~L}, 13 \mathrm{~A}, 44$

\section{Diagnosis}

Ophion tenuicornis Johansson sp. nov. is one of the species in an aggregate previously treated under the name Ophion parvulus. Ophion tenuicornis Johansson sp. nov. is easily distinguished from the other species in the aggregate currently known from Sweden by the more elongate and strongly pilose flagellomeres, and from $O$. costatus and $O$. parvulus also by the considerably narrower temple in lateral view.

\section{Etymology}

The species has very slender antennae.

\section{Material examined}

$>100$ 우우, $27 \hat{\partial} \widehat{\partial}$ (Sweden); 3 우우 (Germany); 1 우, $6 \widehat{\partial} \widehat{0}$ (Norway); 3 우우 (Lithuania).

\section{Type material}

Holotype

SWEDEN • + ; Öland, Mörbylånga, Strandskogen; $56.702^{\circ}$ N, $16.494^{\circ}$ E; 7 Sep. 2016; B. Andersson leg.; MV-light in garden on sandy soil close to deciduous forest; STI-NJBC252; NHRS-HEVA000008727.

\section{Paratypes}

SWEDEN • 2 우; Uppland, Rådmansö, Strömsborg; 59.711 ${ }^{\circ}$ N, $18.962^{\circ}$ E; 14 Aug.-7 Sep. 2016; N. Ryrholm and C. Källander leg.; MV-light trap in coastal mixed forest; STI-NJBC243, STI-NJBC248; NHRS-HEVA000008728, NHRS-HEVA000008729 • 1 \%; Uppland, Norrtälje, Väddö Skjutfält; $59.939^{\circ}$ N, $18.914^{\circ}$ E; 4 Sep. -16 Oct. 2016; N. Ryrholm and C. Källander leg.; Military shooting range, MV-light trap; STI-NJBC244; NHRS-HEVA000008730 • 1 \&; Skåne, Ystad, Spraggehusen; $55.442^{\circ}$ N, 14.246 ${ }^{\circ}$ E; 29 Jul.-28 Aug. 2016; N. Ryrholm and C. Källander leg.; MV-light trap in sanddunes; STINJBC245; NHRS-HEVA000008731 • 1 O; Gotland, Öja, Gisle; $57.049^{\circ}$ N, $18.289^{\circ}$ E; 29 Sep. -23 Oct. 2007; N. Ryrholm and C. Källander leg.; MV-light trap; STI-NJBC246; NHRS-HEVA000008732 • 1 \%; Gotland, Sundre, Suders; $56.945^{\circ}$ N, $18.303^{\circ}$ E; 29 Sep.-26 Oct. 2007; N. Ryrholm and C. Källander leg.; MV-light trap in deciduous woodland; STI-NJBC247; NHRS-HEVA000008733 • 1 क; Gotland, Sundre, Barrshage; $56.922^{\circ}$ N, $18.186^{\circ}$ E; 10 Sep.-9 Oct. 2006; N. Ryrholm and C. Källander leg.; MVlight trap in wet meadows; NHRS-HEVA000008734 - 1 \%; Öland, Borgholm, Hälludden Byxelkrok; $57.356^{\circ} \mathrm{N}, 17.058^{\circ} \mathrm{E} ; 22-24$ 2017; R. Isaksson leg.; MV-light; NHRS-HEVA000008735 • 1 \%; Norrbotten, Övertorneå, Soukolojoki; $66.472^{\circ}$ N, $23.632^{\circ}$ E; 2 Aug. -5 Oct. 2017; N. Ryrholm and

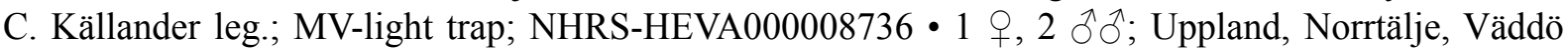
Skjutfält; $59.939^{\circ}$ N, $18.914^{\circ}$ E; 29 Jul.-18 Sep. 2017; N. Ryrholm and C. Källander leg.; MV-light trap in coastal military shooting range; NHRS-HEVA000008737 to NHRS-HEVA000008739 • 2 q ; ; Skåne, Ystad, Spraggehusen; 55.442 ${ }^{\circ}$ N, $14.246^{\circ}$ E; 28 Aug.-30 Sep. 2006; N. Ryrholm and C. Källander leg.; MV-light trap in sanddunes; NHRS-HEVA000008740, NHRS-HEVA000008741 • 1 त; same data as for holotype; 1 Aug.-28 Jul. 2016; B. Andersson leg.; MV-light in garden on sandy ground close to deciduous, oak dominated forest, NHRS-HEVA000008742 • 1 q; Gotland, Öja, Petesviken; $57.004^{\circ} \mathrm{N}, 18.295^{\circ}$ E; 5 May-13 Oct. 2013; N. Ryrholm and C. Källander leg.; MV-light trap; NHRSHEVA000008743 • 1 ठ̊; Öland, Mörbylånga, Nedra Västerstad; $56.416^{\circ} \mathrm{N}, 16.411^{\circ} \mathrm{E} ; 10$ Jul. 2018; N. Johansson leg.; MV-light in garden surrounded by deciduous forest; NHRS-HEVA000008744. 


\section{Description}

Fore wing length $15-16 \mathrm{~mm}$. Antenna with 46-53 flagellomeres. First flagellomere 4.5 times as long as wide. Second flagellomere very elongate about 3.5-4.0 times as long as wide. Central flagellomeres elongate, about 2.5-3.0 times as long as wide. Apical flagellomeres approximately 2.5 times as long as wide (Fig. 8C). Apical flagellomeres in female, less so in males, with long prominent pilosity. Length of

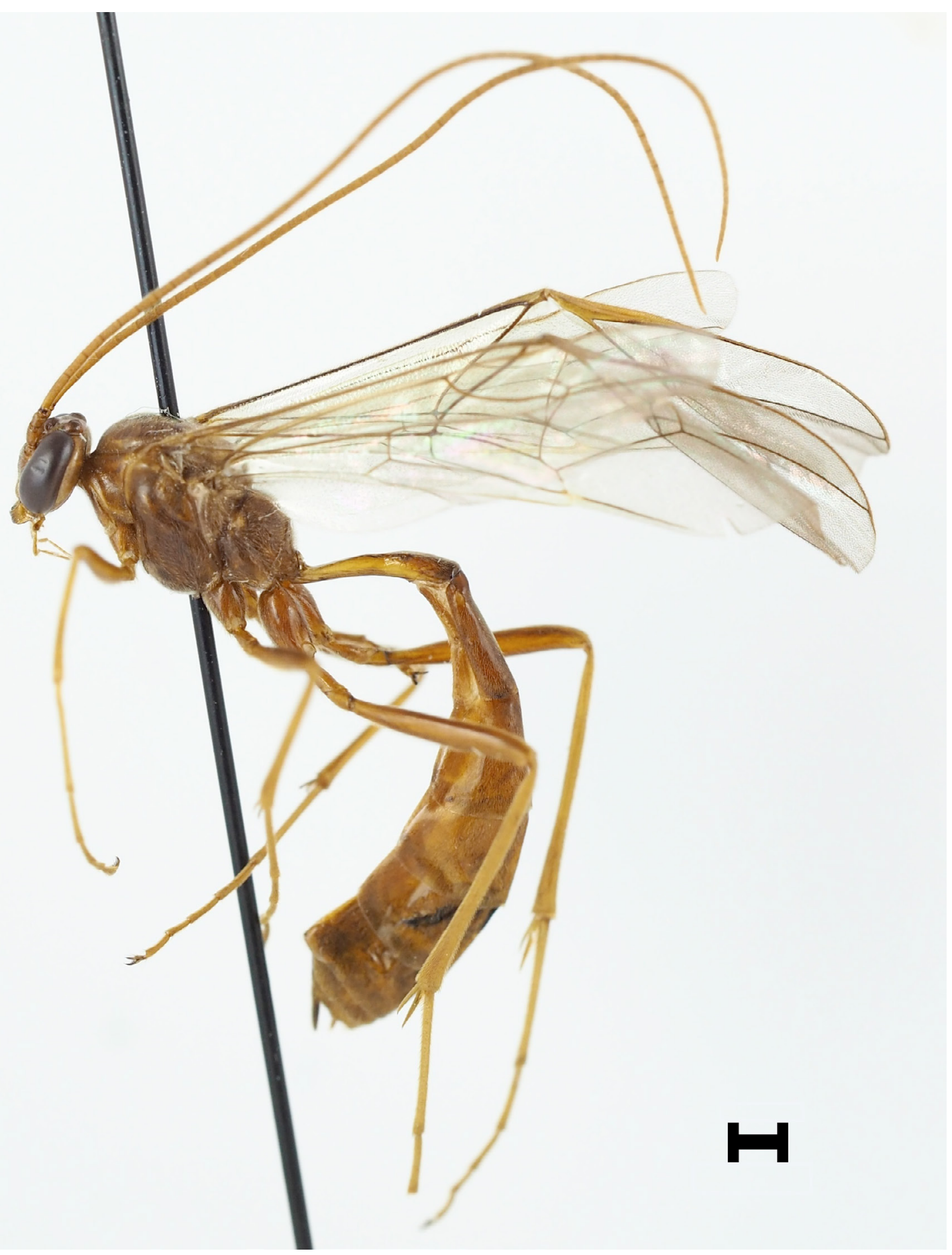

Fig. 44. Ophion tenuicornis Johansson sp. nov., paratype, $q$ (NHRS-HEVA000008743). Scale bar $=$ $1 \mathrm{~mm}$. 
pilosity in females at least 0.5 width of flagellomere (Fig. 8C). Head narrow behind eyes, in lateral view with temple $0.2-0.3$ times as long as compound eye in females, slightly longer in males, $0.4-0.5$ times the lenght of the compound eye. Ocelli in female large, partly covering the inner margin of compound eye in dorsal view, the distance between ocelli about 0.3 times the diameter of ocelli. Malar space about 0.1 times as long as mandibular base in female and about 0.3 times in male. Mandibular gape right-angled, with internal angles. Wing membrane clear. Ramellus usually distinct, reaching $0.2-0.3$ the width of discosubmarginal cell but sometimes small or absent. Radius evenly curved (Fig. 13A). Mesopleuron weakly shagreened with deep, distinct punctures. Interstices between punctures about equal to their diameter. Epicnemial carina, in antero-ventral view, with pleurosternal angles obviously anterior to sternal angles. Pleurosternal angles rounded, slightly obtuse. Scutellum with lateral carinae only indicated basally. Propodeum with very weak rugose structure, shining with anterior and posterior transverse carina strongly raised (Fig. 10L). Longitudinal carinae delimiting area superomedia and lateral longitudinal carinae sometimes weak or absent, but normally clearly indicated at the junction with the posterior transverse carina. Hind trochantellus shorter than wide in dorsal view. Legs normal with hind femur about 6.0-7.0 times as long as wide. Sclerotised part of first sternite ending level or slightly posterior to spiracle. Inner spur of hind tibia as long as 0.4 times metatarsus.

\section{Colour}

Body testaceous. If infuscate or pale markings occur, they are usually far less distinct than in other species of the aggregate. Mandibular teeth black. Ovipositor brownish, slightly contrasting with the more testaceous posterior metasomal segments.

\section{DNA barcode}

The DNA barcode sequences of nine Swedish specimens of Ophion tenuicornis Johansson sp. nov. are available at the BOLD systems database (www.boldsystems.org, BIN. BOLD: ACK3000. Specimen codes: STI-NJBC: 243-248, 250-252).

\section{Ecology}

The flight period is late summer and autumn. One female in NHRS was reared from Thyatira batis (Linnaeus, 1758) and one female was reared from the same host in HSC. This is notable since only the two species of the subgenus of Platophion are known to parasitize the subfamily Thyatirinae. Both reared specimens are rather small, which suggests the existence of additional hosts.

\section{Distribution in Sweden}

Occurs commonly all over the country, but rarer in the north.

Ophion vardali Johansson sp. nov. urn:1sid:zoobank.org:act:2395488B-9203-4CB7-BE81-62510D5989BA

Figs $19 \mathrm{~A}-\mathrm{B}, 45 \mathrm{~A}-\mathrm{B}$

\section{Diagnosis}

Similar to Ophion pteridis, but besides the obvious differences in colour, with the head more rounded in anterior view and the face wider in relation to the compound eyes. The occipital carina is centrally raised forming an acute angle, the head is more buccate with a distinct gap between the lateral ocellus and the compound eye and the central flagellomeres are stouter. Also similar to Ophion inclinans Johansson sp. nov. and $O$. arenarius Johansson sp. nov., but the head has a distinct gap between the lateral ocellus and compound eye, the head in anterior view is more rounded and the face wider in relation to the compound eyes. According to the molecular analysis the species is 
closely related to Ophion pteridis, but based on the distinct morphological characters, both species are regarded as valid.

\section{Etymology}

Named in honour of Hege Vårdal, curator at the Swedish Museum of Natural History, who has been of great help during this study.

\section{Material examined}

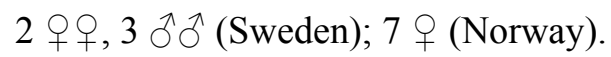

\section{Type material}

\section{Holotype}

NORWAY • O; Nordland, Bodø, Ausvika; 67.336 N, 14.496 E; 10 Aug. 2018; G. Ørsnes leg.; coastal meadow adjacent to forest; BOLD: DS-ICHNN; NHRS-HEVA000008745.

\section{Paratypes}

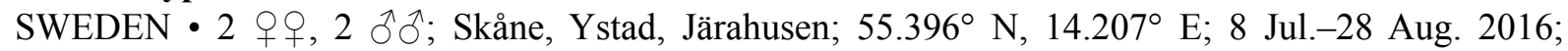
N. Ryrholm and C. Källander leg.; MV-light trap in coastal sanddunes in mixed oak and pine forest; NHRS-HEVA000008746 to NHRS-HEVA000008749 • 1 ડ̄ं Skåne, Kristianstad, Åhus; $55.944^{\circ}$ N, 14.262 ${ }^{\circ}$ E; 22-26 Jul. 1964; unknown leg.; MV-light; MZLU Type no. 6375:1.

\section{Description}

Fore wing length $16-17 \mathrm{~mm}$. Antenna in both sexes with 54-55 flagellomeres. First flagellomere 3.5-4.0 times as long as wide. Central flagellomeres about 1.5-1.7 times as long as wide. Head quite narrow behind eyes, with or without small gap between lateral ocellus and compound eye. Temple in lateral view about $0.7-0.8$ times as long as compound eye as a result of the very short compound eye in lateral view (Fig. 19B). Head in frontal view rounded (width/height measured from the apical margin of clypeus to the top of head $=1.15$ ) with face wide in relation to compound eyes (Fig. 19A). Head with occipital carina centrally raised forming an acute angle (as in Fig. 7B). Face below antennal sockets with quite scarce punctures, polished or weakly shagreened. Malar space about 0.4 times as long as mandibular base in female and about 0.4-0.5 times in male. Mandibular gape right-angled, with internal angles. Wing membrane yellowish. Ramellus distinct, reaching $0.2-0.3$ times the width of the discosubmarginal cell. Radius sinuous. Mesopleuron shagreened and distinctly punctate, spaces between punctures about equal to their diameter. Pleurosternal angles weakly obtuse to right angled, obviously anterior to sternal angles. Scutellum with distinct lateral carinae (as in Fig. 6C). Propodeum weakly shagreened, often quite polished with anterior transverse carina strong, but sometimes partly absent laterally. Posterior transverse carina often widely interrupted centrally. Area superomedia often present. Central longitudinal carinae often distinct. Sclerotised part of first sternite ending obviously posterior to spiracle. First tergite in lateral view with slight or distinct median undulation (as in Fig. 6E). Hind trochantellus shorter than wide in dorsal view. Inner spur of hind tibia as long as 0.5 times hind metatarsus.

\section{Colour}

Body testaceous, the lower part of mesopleuron, mesosternum, propleuron, coxae mostly and propodeum strongly infuscate, black or dark brown (Fig. 45A-B). Head with inner and outer orbits yellow. Mandibular teeth black. Ovipositor sheath testaceous, concolourous with posterior metasomal segments.

\section{DNA barcode}

The DNA barcode sequence of four specimens of Ophion vardali Johansson sp. nov. is available at the BOLD systems database (www.boldsystems.org, BOLD: DS-ICHNN; STI-NJBC 24-26). 


\section{Ecology}

No host records are known for this species and it is active mainly during July. The habitat seems to be open or semi-open coastal meadows.

\section{Distribution in Sweden}

Ophion vardali Johansson sp. nov. is very rare and known from only a couple of localities in the southeastern part of the country.

\section{Remarks}

On the website www.artsobservasjoner.no there are also pictures of specimens from several different coastal localities in Central and Northern Norway. One Norwegian female, kindly provided by Geir Ørsnes, is designated as holotype. The rather vague description of Ophion praecinctus Meyer, 1935 describes a species from the desert country Turkmenistan with similar colouration to $O$. vardali Johansson

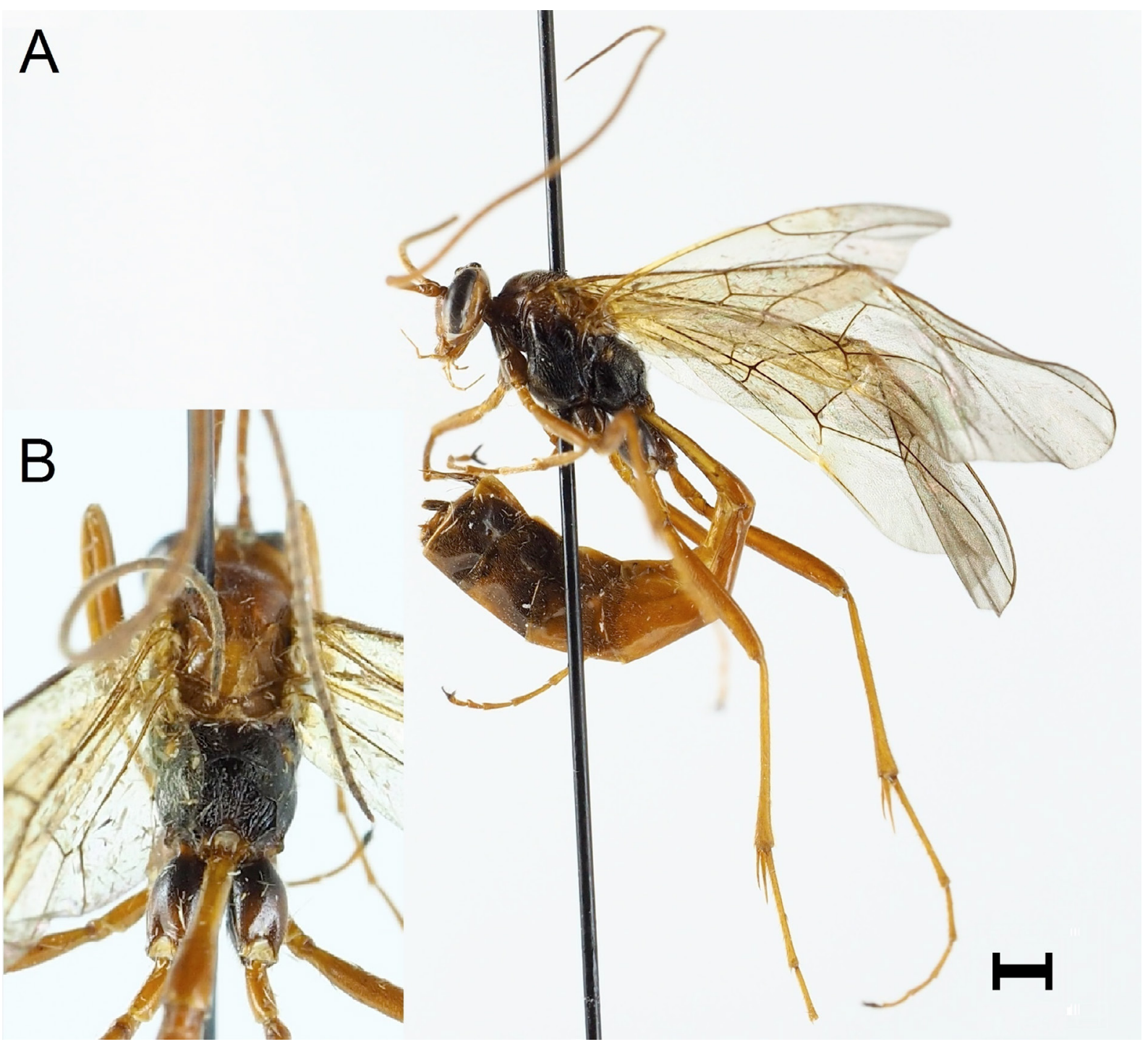

Fig. 45. Ophion vardali Johansson sp. nov., paratype, $q$ (NHRS-HEVA000008748). A. Habitus, lateral view. B. Mesosoma, postero-dorsal view. Scale bar: $A=1 \mathrm{~mm}$. 
sp. nov. The type material is lost (Townes et al. 1965; Andrey Khalaim, ZIN, pers. com.) and there seems to be no remaining additional material determined by the Meyer. The description (Meyer 1935) and a simplified translated key (Meyer 1937) refers to a very small species (body length $12 \mathrm{~mm}$ ), with transverse head, long malar space, vague notauli, deep concavities along the inner eye margin and two distinct transverse ridges on the propodeum, all of which are characters that cannot be attributed to $O$. vardali Johansson sp. nov.

Ophion variegatus Rudow, 1883 stat. rev.

Figs $7 \mathrm{M}, \mathrm{O}, 11 \mathrm{~A}-\mathrm{B}, 17 \mathrm{~A}, 50 \mathrm{~A}-\mathrm{D}$

\section{Material examined}

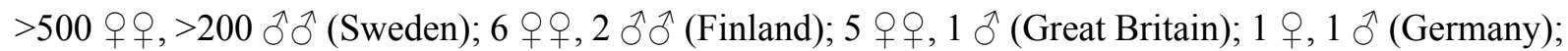

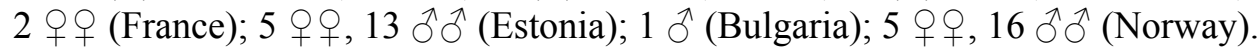

\section{Neotype}

FRANCE • Grand Est (prev. Alsace), Haut-Rhin, Mulhouse, Chalampé; 10 May 1931; A. Seyrig leg.; MNHN.

\section{Redescription}

Fore wing length 14-16 mm. Antenna with 53-62 flagellomeres. First flagellomere about 3.0-3.5 times as long as wide. Central flagellomeres in male usually longer than in $O$. obscuratus, about 1.6 times as long as wide (Fig. 7O). Subapical flagellomeres approximately 1.5-1.6 times as long as wide. Temples slightly buccate. Head in lateral view temple $0.7-0.8$ times as long as compound eye in females and 0.5-0.6 times in males. Face wide in anterior view (Fig. 17A). Gap between compound eye and lateral ocellus usually distinct, about 0.3 times the diameter of ocellus. Occipital carina usually curved before junction with hypostomal carina, junction usually with an angle of 70-90 degrees (Figs 7M, 50C). Malar space about 0.2 times as long as mandibular base in female and male. Mandibular gape right-angled, with internal angles. Wing membrane clear. Ramellus usually short, reaching $0.1-0.3$ times the width of the discosubmarginal cell. Radius sinuous. Structure of mesopleuron shining or with distinct microsculptures between punctures, with weak, very regular punctation consisting of small punctures. Interstices between punctures about equal to their diameter, up to 2.0 times their diameter. Epicnemial carina, in antero-ventral view, with pleurosternal angles obviously anterior to sternal angles. Pleurosternal angles rounded, usually right angled, rarely obtuse or slightly acute. Sternal angles usually more distinct and the epicnemal carina between the sternal and pleurosternal angles more concave than in O. obscuratus (Fig. 50B) but the overlap is considerable. Scutellum without lateral carinae. Structure of propodeum similar to that of O. luteus. Posterior to anterior transverse carina mostly shining. Anterior transverse carina always present centrally anterior to area superomedia, but often also present laterally, though rarely strongly raised. Posterior transverse carina usually only present laterally, widely interrupted centrally (as in Fig. 10A). Central longitudinal carinae weak or absent. Sclerotised part of first sternite ending level to spiracle. Legs normal with hind femur about 6.0-7.0 times as long as wide. Hind trochantellus usually longer than in other species except $O$. luteus, O. slaviceki and O. obscuratus (as in Fig. 7F). Slightly shorter than wide in dorsal view. Inner spur of hind tibia long about $0.3-0.4$ times as long as metatarsus.

\section{Colour}

Body usually more brownish than other species and with extensive whitish pattern on thorax (Fig. 11A-B), similar to that of O. obscuratus. Mandibular teeth black. Ovipositor sheath testaceous. 


\section{DNA barcode}

The DNA barcode sequences of 15 Swedish specimens of Ophion variegatus are available at the BOLD systems database (www.boldsystems.org, Specimen codes: STI-NJBC: 99, 101-103, 199-206, 210, $312,316)$.

\section{Ecology}

Ophion variegatus occurs in a variety of different habitats ranging from semi-open forests to gardens and hedgerows. Host records from Mythimna impura (Hübner, 1808) (Brock 1982) probably refers to this species. Ophion variegatus is active from May to June in Southern Sweden and flies until the beginning of August in the Northern parts of Central Sweden.

\section{Distribution in Sweden}

Southern and Central Sweden

\section{Remarks}

This species has widely been regarded as the spring or early summer brood of Ophion obscuratus but has been shown to be univoltine, at least in Norhern Europe (Mark Shaw, NMS, pers. com.). Apart from the phenological differentiation it is also smaller on average with a lower number of flagellomeres and a small but consistent difference in the shape of the occipital carina at the junction with the hypostomal carina. The taxonomic history of this species is rather complex and accounted for in the Discussion: "The Ophion obscuratus aggregate". To stabilize the name a neotype is designated (Fig. 50A-D). The molecular analysis for the presumed aggregate around this species is weak and its potential genetic delimitation towards $O$. obscuratus and $O$. autumnalis Johansson sp. nov. therefore remain uncertain. Furthermore an additional potential species in the aggregate is indicated by the molecular analysis (STI-NJBC: 199, 316). A wider revision of the Western Palaearctic Ophion obscuratus $\mathrm{s}$. lat., including molecular methods, is probably necessary to clearify the taxonomy of this problematic aggregate.

Ophion ventricosus Gravenhorst, 1829

Fig. $11 \mathrm{C}-\mathrm{D}$

Ichneumon impressus Thunberg, 1822: 262 (not Gmelin, 1790) (preoccupied).

Ophion ventricosus Gravenhorst, 1829: 702.

\section{Material examined}

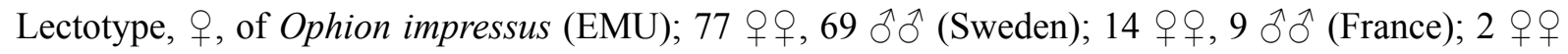
(Norway).

\section{Diagnosis}

Fore wing length $14-16 \mathrm{~mm}$. Antenna in both sexes with 44-56 flagellomeres. First flagellomere 2.5-3.5 times longer than wide. Head strongly buccate behind eyes. Malar space about 0.2 times as long as mandibular base in female and about 0.3 times in males. Mandibular gape right angeles with internal angles. Mesopleuron weakly shagreened or polished, distinctly punctate. Spaces between punctures about equal to their diameter. Pleurosternal angles strongly obtuse, weakly defined and obviously anterior to the almost absent sternal angles. Sternal part of epicnemial carina very broad an evenly curved. Scutellum with distinct lateral carinae at least in the basal half. Radius of forewing distinctly thickened and bent near junction with pterostigma. Ramellus short. Wing membrane strongly yellowish. Propodeum strongly coriaceous with distinct carination. 


\section{Colour}

Body testaceous with conspicuous black markings on mesosoma and head (Fig. 11C-D). Metasoma in both sexes with posterior segments at least partly black. Mandibular teeth black.

\section{DNA barcode}

The DNA barcode sequences of four Swedish specimens of Ophion ventricosus are available at the BOLD systems database (www.boldsystems.org, BIN. BOLD: ABV5256. Specimen codes: STI-NJBC: 94, 96-98).

\section{Ecology}

This species occurs during early summer, May-June, in oak-dominated deciduous landscapes. It has been reared from Phigalia pilosaria (Denis \& Schiffermüller, 1775) (Brock 1982).

\section{Distribution in Sweden}

Primarily a southern species occurring in areas with oak forests.

\section{Remarks}

The most distinctive of the Swedish Ophion species, with its yellowish wing membrane and black body markings.

Ophion wuestneii Kriechbaumer, 1892

Fig. 16B-C

Ophion wuestneii Kriechbaumer, 1892a:232-233.

\section{Material examined}

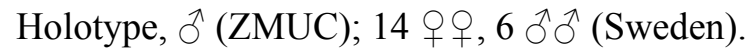

\section{Diagnosis}

Fore wing length $12-13 \mathrm{~mm}$. Antenna in both sexes with 55-60 flagellomeres. First flagellomere 4.0-4.5 times as long as wide. Central flagellomeres 1.5 times as long as wide. Head in female narrowed behind eyes, temples slightly more buccate in male. Face in anterior view relatively wide. Malar space about 0.2 times as long as mandibular base in female and about 0.3 times in male. Mandibular gape right-angled, with internal angles. Wing membrane clear. Pterostigma about 3.0 times as long as wide. Ramellus short or absent (Fig. 16B). Discocubitus evenly curved. Radius sinuous. Mesopleuron polished and weakly punctate. Interstices between punctures about 1.5-2 times their diameter. Pleurosternal angles obtuse, well defined, obviously anterior to sternal angles. Scutellum with distinct lateral carinae. Propodeum slightly coriaceous, often quite polished with anterior transverse carina partly absent laterally. Posterior transverse carina often widely interrupted centrally. Area superomedia absent, only weakly indicated posteriorly. Hind trochantellus shorter than wide in dorsal view. Hind femur strongly elongate, about 8.0-9.0 times as long as wide (Fig. 16C). Sclerotised part of first sternite ending distinctly posterior to spiracle. Inner spur of hind tibia 0.3 times as long as hind metatarsus.

\section{Colour}

Body testaceous. Head with inner and outer orbits yellow. Mandibular teeth black. Mesoscutum often with brownish areas. Ovipositor sheath testaceous. 


\section{DNA barcode}

The DNA barcode sequences of three Swedish specimens of Ophion wuestneii are available at the BOLD systems database (www.boldsystems.org, BIN. BOLD: ACS3763. Specimen codes: STI-NJBC: $17,89,90)$.

\section{Ecology}

Nothing is known about the hosts of this species. It is active during spring and early summer from late March to early June.

\section{Distribution in Sweden}

Rare in the southern parts of the country. Only known from a handful of localities but probably overlooked.

\section{Remarks}

Ophion wuestneii might be confused with smaller specimens of $O$. scutellaris, but is easily separated by the characters given in the key.

\section{Discussion}

\section{Species delimitation and definition}

In such a taxonomically difficult genus as Ophion the criteria used in delimiting and defining species is bound to be a subject of much discussion. In this study the molecular and morphological results reflects two taxonomic dimensions, each containing its own advantages or downsides when it comes to defining or verifying valid species. The relation between these two dimensions has been subject to much interest from taxonomists in recent years and this study has indeed encountered many of the challenges which occur when trying to combine molecular and morphological methods to delimit the species involved. The results are not always easy to interpret and the molecular dimension indicates that Ichneumonid wasps have some characteristics that make the relation between morphospecies and commonly used thresholds for molecular species definition more complicated than in other groups.

The molecular method in this study focus on the sequencing of a standardized 658 base pair segment of the mitochondrial cytochrome oxidase 1 gene (COI). This method has been promoted for species discovery, identification and delimitation (Hebert et al. 2003), but it has been shown that COI analysis alone is not sufficient to exclude such distorting factors as for example, hybridization and high intraspecific variation (Funk \& Omland 2003). Therefore the combination of morphometrics and barcoding has been promoted as an accurate method in species delimitation in Ophion (Schwarzfeld \& Sperling 2014). Apart from hybridization and high intraspecific variation there are several other factors that can affect the outcome of the molecular analysis.

The results of the barcoding in this study shows that at least some of the sampled material possibly is infected with Wolbachia, as indicated by the preliminary results from the Ophion obscuratus aggregate. Wolbachia infections, which are frequent in Ichneumonids, can potentially lead to failure in the barcoding or misleading results from COI-sequencing (Klopfstein et al. 2016). Because of the additional infection pathway, parasitoid wasps might even be more exposed to Wolbachia infections than other insects (Cook \& Butcher 1999). This can partly be resolved by introducing additional markers as the nuclear 28S rRNA (28S) and the internal transcribed spacer 2 (ITS2) (Klopfstein et al. 2016; Schwarzfeld et al. 2016), but still there are several reasons to treat the barcoding results cautiously, as these additional markers under certain circumstances can lead to erroneous conclusions regarding species delimitation. 
Another plausible distorting factor to be aware of when using the COI marker, is the presumed existence of pseudogenes or numts (nonfunctional copies of mitochondrial genes incorporated into the nuclear genome), also shown to be present in Ophion, which potentially contribute to misleading phylogenetic analyses by coamplifying the numts and thereby indicating 'false' molecular species (Song et al. 2008; Schwarzfeld et al. 2016).

One of the main conclusions drawn from the molecular analysis in this study is that valid species involved in several species aggregates or groups in Ophion show a small sequence divergence, often less than 1\%. This is a pattern reminiscent of that found in the genus Diplazon Nees v. Esenbeck, 1818 (Klopfstein et al. 2016) possibly indicating a similar process of speciation where the evolutionary rate of the COI-marker is too low to keep up with the often very high speciation rate (Feder \& Forbes 2010; König et al. 2015). Klopfstein et al. (2016) showed that the often advocated 2\% sequence divergence threshold (Hebert et al. 2004) was insufficient in the parasitoid genus Diplazon and only recovered six out of 16 valid species. Lowering the treshhold to $0.5 \%$ recovered 10 out of 16 species.

This means that the use of COI, with or without the support of additional markers, is an important tool when it comes to discovering potentially new species, but that careful morphological assessments and ecological observations in the form of 'classical' taxonomy is necessary to define them as valid species (Klopfstein 2014; Simonsen et al. 2019). The sample size and composition as well as the genetic markers used, can also potentially affect the results of the molecular analysis, making the process of species delimitation based on molecular methods alone quite complex (Bergsten et al. 2012; Hamilton et al. 2014; Schwarzfeld \& Sperling 2015; Philips et al. 2018).

In all, it is clear that the molecular and morphological data complemented each other quite well when it comes to identifying and delimiting species in this study, but it shall also be noted that the COI data partly failed where morphology and life history provided good evidence for the existence of valid species.

The implications for future studies of Ophion, as for other parasitoid groups, are that even small differences in the COI marker could indicate the existence of valid species that need to be defined using supplementary methods, and that a thorough study of morphology and natural history is necessary to interpret the barcoding results to obtain as accurate a perception of the species delimitation as possible. It would be interesting to study the more detailed relation between the DNA (primarily the widely used COI marker) and the morphological species conception based on this revision in a future project similar to that of Simonsen et al. (2019).

In this study 18 species out of 41 (44\%) are described as new to science from Sweden, a country which could be regarded as having a comparatively well known fauna. However the high proportion of new species should be considered in a context where three major factors interact and contribute in their own way to the poor state of knowledge in the genus Ophion. First, Ophion species are mainly nocturnal and therefore rarely collected before the introduction of electric light, especially MV-light, and rare species have therefore rarely or never been collected in such numbers that their specific morphology could be decoded. Furthermore, the morphological difference between species is smaller than in most other subfamilies of Ichneumonidae. For example, only a couple of species exhibit different colour patterns, which is often used as a diagnostic character in other subfamilies or genera, for example Klopfstein (2014) and Riedel (2012). Other morphological features useful in the distinction of species are generally subtle and understanding them and their relation to intraspecific variation takes a combination of experience, abundant material and the support of modern DNA barcoding. The third and final major factor is of a taxonomic nature. Several species aggregates have historically been regarded as highly variable single species which, in combination with the small morphological differences between species, have obscured 
the existence of several closely related but valid species and led to the misinterpretation of available types and original descriptions. A parallel can be drawn with the recently revised Ophioninae genus Enicospilus Stephens, 1829 (Johansson 2018), a genus with similar characteritics but considerably fewer species, where three out of $11(28 \%)$ species in the Swedish fauna were described as new to science. This number also shows that the estimation of putative species occurring in Great Britain made by Schwarzfeld \& Sperling (2015) is surprisingly accurate, if it is assumed that Sweden and Great Britain share many of the species defined in this study. The number of species suggested by the analysis in the study is in the order of about 25-35 species depending on the method used. When it is considered that the analysis made by Schwarzfeld \& Sperling missed the diversity within the O.pteridis and O.perkinsi aggregates due to the rarity of the species involved, the estimated number of species is very close to the figure presented in this study.

A plausible explanation for the existence of several aggregates of closely related species in Ophion is that many of these related species have split relatively recently in the history of evolution, probably by specializing on a specific group of closely related hosts or hosts with similar larval morphology and ecology. Species within Ophion that show signs of such a specialization on hosts of similar ecology or morphology are, for example Ophion costatus (hosts are hairy final instar larvae of Acronicta), $O$. parvulus (host larvae developing in a concealment spun of joined leaves), O. slaviceki (hosts are Agrotis Ochsenheimer, 1816 larvae pupating underground) and $O$. artemisiae (host larvae feeding on the poisonous plant genus Artemisia). Shaw $(1994,2004)$ gives examples of the potential radiations of parasitoids on hosts in particular niches, a mechanism which is apparent also in Ophion. Gokhman (2018) addresses the topic of species definition in relation to molecular methods and suggest that host specialization is to be regarded as a vital part of the species definition and thereby useful also in defining morphologically cryptic species which are indicated by molecular methods.

Host-related specialization also affects the phenology, geographic distribution and preferred habitat of the parasitoid, making the species definition applied in this study practically useful in conservation biology, studies of ecosystems and biodiversity. This also highlights the importance of continuing the work of acquiring reliable host records for European Ophion species, an area where lepidopterists can make an important contribution.

\section{Species groups and aggregates}

The results of this study also gives some clues on how to approach the solution of the higher phylogeny of the genus. Schwarzfeld et al. (2016) defined 13 species groups supported by molecular methods on a global scale of which seven, the Ophion minutus, O. areolaris, O. scutellaris, O. parvulus, O. pteridis, $O$. luteus and $O$. obscuratus species groups, are relevant to the present study. The phylogenetic analysis in this study (Fig. 1) largely supports the suggested species groups. The Ophion minutus group, which is represented in the Swedish fauna by $O$. minutus and $O$. ventricosus, has some special characters both regarding morphology (strongly curved and partly thickened vein $R s+2 r$ ) and ecology (parasitising Geometridae). The presumption made by Schwarzfeld et al. (2016) that this group is to be regarded as a sister to the remaining Ophion with a close relation to other Ophioninae such as Eremotylus Förster, 1869 is supported by our analysis and the group should even be considered as a separate genus. The $O$. areolaris species group (subgenus Platophion sensu Hellén) is quite straightforward with two morphologically well defined species, $O$. areolaris and $O$. ocellaris, and a potentially cryptic sister species closely related to the latter. The $O$. scutellaris group also forms a distinct branch on the tree. The second, cryptic European species in this group, indicated by Schwarzfeld et al. (2016), is most likely conspecific with Ophion wuestneii as defined in this study.

The $O$. parvulus species group includes at least five species in Sweden, presuming that $O$. kallanderi Johansson sp. nov. is included in this group, which is strongly indicated by the morphology and molecular 
analysis of the species. Ophion dispar is adjacent to the Ophion parvulus group but the very characteristic morphology of this species makes it probable that it should be assigned to its own species group. The definition of the Ophion pteridis species group and its relation to the Ophion luteus species group is more problematic. The barcoded specimens of $O$. vardali Johansson sp. nov. and O. pteridis have a position which indicates a close relation to both the $O$. luteus species group and the remaining species of the morphologically defined $O$. pteridis aggregate ( $O$. inclinans and $O$. arenarius Johansson sp. nov.) and the result could indicate that the $O$. pteridis and $O$. luteus groups may not be that well separated from one another and need to be redefined. The usually partly carinated scutellum of $O$. kevoensis, as defined in this study, also shows that species within the $O$. luteus group may exhibit morphological features partly used to define the $O$. pteridis species group. Furthermore, several members of the $O$. obscuratus species group, as defined by Schwarzfeld et al. (2016), e.g., the O. perkinsi aggregate (Fig. 4), have all the morphological defining characters of the $O$. pteridis group. This could indicate that the $O$. luteus species group would also include the $O$. pteridis group, forming a larger species group based on morphological features, which still needs to be defined.

The final species group defined by Schwarzfeld et al. (2016), the $O$. obscuratus species group, is rightfully described as an 'unresolved challenge' and its contents are probably partly obscured by the poor taxonomic state of the genus, which is partly sorted out in this paper. Based on the results of this study one solution would be to divide the $O$. obscuratus species group into at least three smaller species groups as follows. The $O$. longigena species group, including $O$. longigena, $O$. paukkuneni, O. ellenae, O. matti, O. norei, O. perkinsi and O. artemisiae, would then be defined morphologically by the partly carinate scutellum, the punctate propodeum, the rather densely punctate face, the usually buccate head and the relatively prominent pleurosternal angles. The $O$. obscuratus group, comprising $O$. obscuratus, $O$. variegatus, $O$ sylvestris Johansson sp. nov. and $O$. autumnalis, would be defined by a combination of the partly pale-marked mesosoma, the relatively long hind trochantellus and the rather typical carination of the propodeum. It shall be noted that the inclusion of $O$. sylvestris Johansson sp. nov. in this group is somewhat forced as it has some features atypical of the other members of the proposed species group, such as the narrow face and infuscate ovipositor sheath. The Ophion mocsaryi species group, comprising $O$. mocsaryi, O. splendens, O. brocki, O. confusus, $O$. crassicornis, $O$. brevicornis, $O$ borealis and $O$. angularis, has the ovipositor sheath black in the female, contrasting with the apical metasomal segments (it shall be noted that the ovipositor is frequently more brownish/ testaceous in females of $O$. brevicornis). Ophion subarcticus would possibly form a species group with the presumably closely related $O$. nigricans or might be incuded in the $O$. mocsaryi species group close to $O$. brevicornis. The molecular position of $O$. forticornis in a position intermediate between the $O$. mocsaryi and $O$. obscuratus species groups is also partly supported by the morphological features of the species as it shares some characteristics occurring in both species groups.

The new species groups presented here are merely to be seen as a suggestion on how to solve the higher phylogeny of the genus and the hypothesis must be tested on more material from a much larger geographical area, including more species. On a morphological level the subdivision into aggregates of morphologically similar species is more useful when trying to resolve and understand the species delimitations. Below some of the more challenging aggregates of morphologically similar species are discussed in detail.

\section{The Ophion luteus aggregate}

This aggregate, often treated under the name $O$. luteus, consists of three apparently ecologically and morphologically distinct, but closely related species according to the morphological analysis and the barcoding results (Fig. 3). The names Ophion slaviceki, Ophion luteus, Ophion kevoensis and Ophion distans, have been used for the forms/species involved in this aggregate. Ophion slaviceki and O. distans have widely been regarded as junior synonyms of O. luteus by recent authors (Brock 1982; Broad 2012; 
Broad et al. 2015). Study of the Linnean types shows that the male lectotype belongs to the form widely known as the distans-morph (see also Brock 1982; Broad et al. 2015).

The male holotype of $O$. slaviceki in ZSM (Fig. 46A-C) was studied and in accordance with Horstmann (2006) this study agrees that this specimen represents the species refered to in this study and Kriechbaumer's original description. The doubt presented by Brock (1982) that the original description of $O$. slaviceki was not in accordance with the holotype, was based on a misinterpretation of the terminology used (Horstmann 2006). Oosterbroek (1978) and Brock (1982) also proposed the synonymy between $O$. slaviceki and $O$. luteus followed by subsequent authors. This synonymy was based on the erroneous assumption that $O$. luteus is an extremely variable species regarding ecology, morphology and phenology. Broad et al. (2015) and Schwarzfeld \& Sperling (2015) argued that the synonymy is supported by the sequencing of British material and given the limited samples in combination with the rather small genetic differences, this interpretation is understandable when relying on COI analysis alone, showing the importance of combining morphological, ecological and molecular methods.

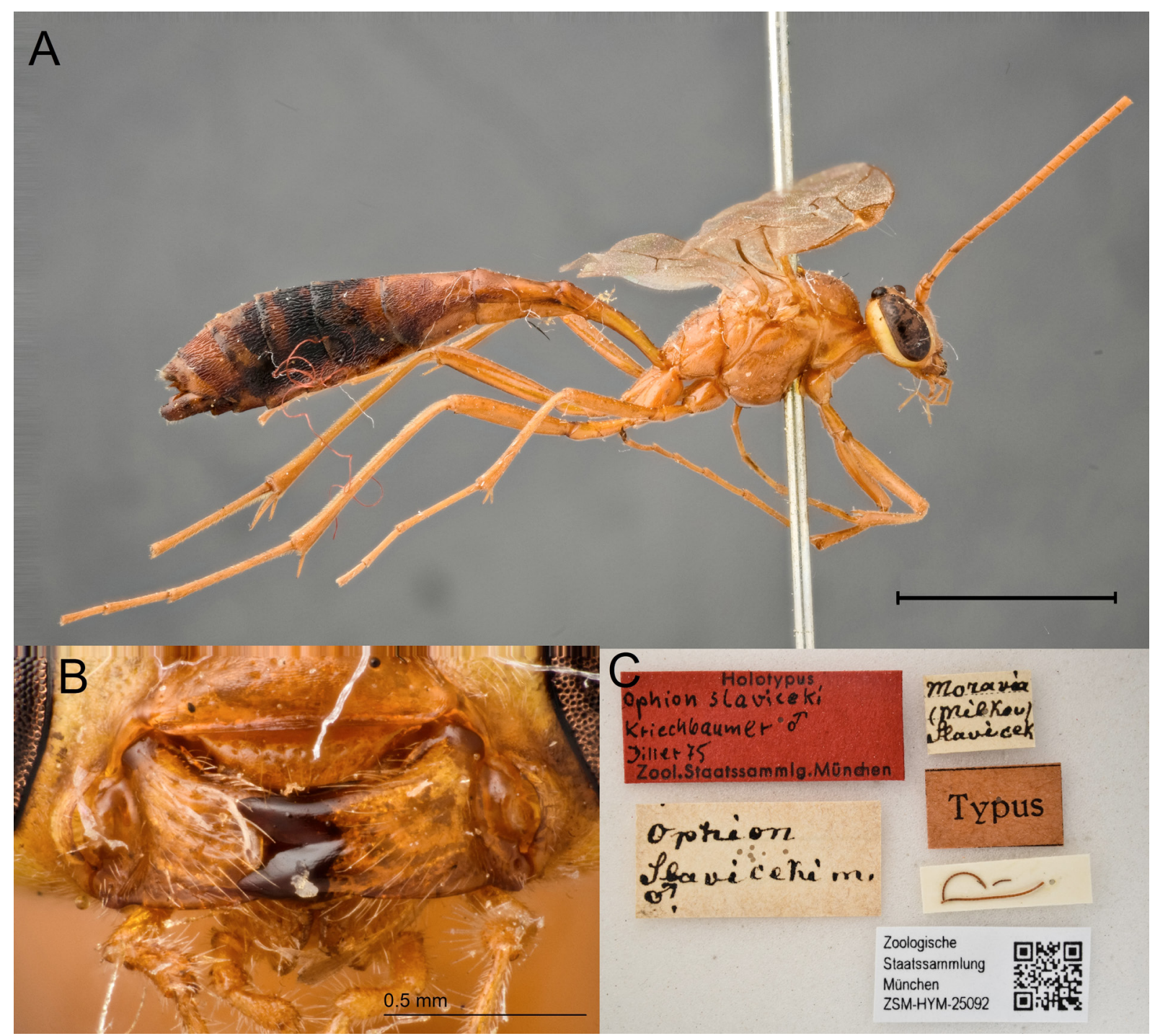

Fig. 46. Ophion slaviceki, 1892, holotype, $\widehat{O}^{\lambda}$ (ZSM). A. Habitus, lateral view. B. Mandibles, anteroventral view. C. Labels. Scale bar: $A=5 \mathrm{~mm} ; B=0.5 \mathrm{~mm}$. 
The detailed results of the barcoding in this study (Fig. 3) shows that the analysed specimens form three separate groups within the same BIN, where the spring active 'distans' morph and the southern population of the larger late summer form comprise two of the groups. Seven additional northern specimens form a vaguely defined group alongside the southern late summer form. The partly carinated scutellum, the longer ramellus, the right angled mandibular gape, the generally shorter hind trochantellus and the darker colour separates this form, here treated as conspecific with Ophion kevoensis, from $O$. slaviceki and O. luteus. Ophion kevoensis is also ecologically distinct as its main habitat seems to be subalpine boreal semi-open coniferous forests with Vaccinium. One specimen of Ophion slaviceki from Sölkäsaari in Haparanda (STI-NJBC327) in Northern Sweden genetically deviates from the southern population (Fig. 3). The locality is far beyond the northern distribution limit for any of the known hosts of $O$. slaviceki and this specimen might represent a northern ecological form of the species using an additional host.

The morphological, ecological and genetic dissimilarities displayed by the large number of studied specimens strongly supports the existence of three separate species. This motivates the reinstatement of the name O. slaviceki Kriechbaumer, 1892 stat. rev. for the larger species (Fig. 46A-C), mainly parasitizing the noctuid moths Agrotis exclamationis and Agrotis segetum. The species with a more pronounced northern distribution, which might be conspecific with the O. luteus treated by Várkonyí et al. (2002), is here treated as Ophion kevoensis, and the generally smaller spring-active species with more buccate temples (sometimes referred to as the distans-morph) is the true $O$. luteus. The holotype of Ophion calcaratus was studied and the synonymy with $O$. slaviceki is confirmed. The type of Ophion pictus is lost (Townes et al. 1965; Andrey Khalaim, ZIN, pers. com.) but the original description with the reference to the host being Agrotis (Kokujev 1906a) supports synonymy with O. slaviceki.

\section{The Ophion mocsaryi aggregate}

Another aggregate that poses a systematic challenge is found around Ophion mocsaryi. Schwarzfeld et al. (2016) treats this aggregate as a subgroup of the vaguely defined O. obscuratus group, but note that the group is particularly challenging and that the species pair $O$. mocsaryi/costatus probably hold additional undescribed species. Here we show that part of the confusion regarding this complex has been caused by the erroneous interpretation of Ophion costatus, a species for which the type is probably lost (Königsmann 1964; Brock 1982; Heinz Schnee, Markleeberg, pers. com.). The main interpretation by previous authors (Meyer 1935, 1937; Schmiedeknecht 1906, 1908; Gauld 1978; Oosterbroek 1978; Brock 1982; Aubert et al. 1984; Broad 2012) is that $O$. costatus is a species closely related and morphologically very similar to $O$. mocsaryi. Brock (1982) sums up the history of taxonomic interpretations of the species and states that part of the confusion is due to the original description being vague and applicable to several species of Ophion. The aggregate around $O$. mocsaryi, as shown in this study, consists of several species with different morphological features, creating the aggregate nature of $O$. costatus auct. that has caused further confusion.

In Ratzeburg's original description (Ratzeburg 1848) there are, however, several clues as to the true identity of $O$. costatus. The description of the strongly raised anterior and posterior carinae of the propodeum as well as the strong longitudinal carinae delimiting the area superomedia has historically led to the conclusion that this is a species closely related to Ophion mocsaryi, one of few European species to exhibit this feature. Ratzeburg also concludes that it is a large and robust species, larger than other Ophion known to him except for Enicospilus (as Ophion) undulatus (Gravenhorst, 1829), with dark testaceous colouration and very long antennae. The carinae of the propodeum are so distinct that they are referred to as: 'raised like wings'. While the colouration and antennal size are applicable to several species, the strongly raised propodeal carinae in combination with the large size reduces the number of potential candidates. Apart from $O$. brocki, Johansson sp. nov., only $O$. ellenae Johansson sp. nov., O. matti Johansson sp. nov and Ophion artemisiae, and two of the morphospecies in the 
O. parvulus aggregate could potentially fit this description. Ophion ellenae Johansson sp. nov., O.matti Johansson sp. nov. and $O$. artemisiae have rather short antennae while $O$. brocki Johansson sp. nov. and one of the members of the $O$. parvulus aggregate, O. tenuicornis Johansson sp. nov., have slender bodies that can hardly be regarded as robust. When added up, all of the morphological features listed by Ratzeburg (1848) only seem to fit with one of the autumnal morphs within the O. parvulus aggregate. This species is usually one of the largest and stoutest Ophion species (fore wing length often around $19 \mathrm{~mm}$ ), which in large specimens has the anterior and posterior carinae of propodeum, as well as the central longitudinal carina very strongly raised, the transverse carinae even more strongly raised than those found in the mocsaryi aggregate (Fig. 47A-B). It has long antennae and often displays darker colouration on the meso- and metasoma, also in accordance with the description. This species also usually exhibits one or more longitudinal wrinkles in the area superomedia, a feature frequently occuring in this species but generally missing in all other Northern European Ophion. This feature is of particular interest as Ratzeburg mentions that $O$. costatus has "einige, in der rinne selbst stehende längsrunzeln". In the context of the original description this means that there are longitudinal wrinkles in the area petiolaris that are distinct enough to be mentioned in the rather short diagnosis. Distinct wrinkles in this area frequently occur in many Ophion species but only in one species are there also one or several distinct longitudinal wrinkles emanating from the base of the area superomedia. If it is assumed that Ratzeburg slightly misdefines the placement of the wrinkles or refers to a specimen with actual wrinkles in the mentioned area, this also supports the hypothesis that the true $O$. costatus is conspecific with the morphospecies in the $O$. parvulus aggregate.

Furthermore Ratzeburg refers to a rearing from Acronicta aceris (larvae collected by the Danish entomologist Christian Drewser). This abundant host would indicate that $O$. costatus is a rather common species occuring over a wide geographical range which is contradictory to the rarely collected and geographically delimited O. costatus sensu Brock. Brock (1982) states that there are no rearing records of any Ophion from A. aceris, but overlooks the fact that there actually is one Ophion species reared from Acronicta by his own records. Brock refers to this species as part of the autumn brood of Ophion parvulus. This is also in accordance with the interpretation presented here as the morphospecies fitting the Ratzeburg description is one of the three species in the parvulus aggregate active during autumn. One male reared from Acronicta leporina (MMUE) and one male in the Brock collection (UMB) probably reared from Acronicta sp. (Brock 1982) have been studied and both specimens are conspecific with the interpretation of Ophion costatus presented in this study. It also seems plausible that a species would have to adopt some kind of specialised oviposition behavior to deal with the very hairy final instar larvae of Acronicta (especially A. leporina and A. aceris) thereby creating an ecological niche which historically has led to speciation. The original description by Ratzeburg, in combination with the rearing
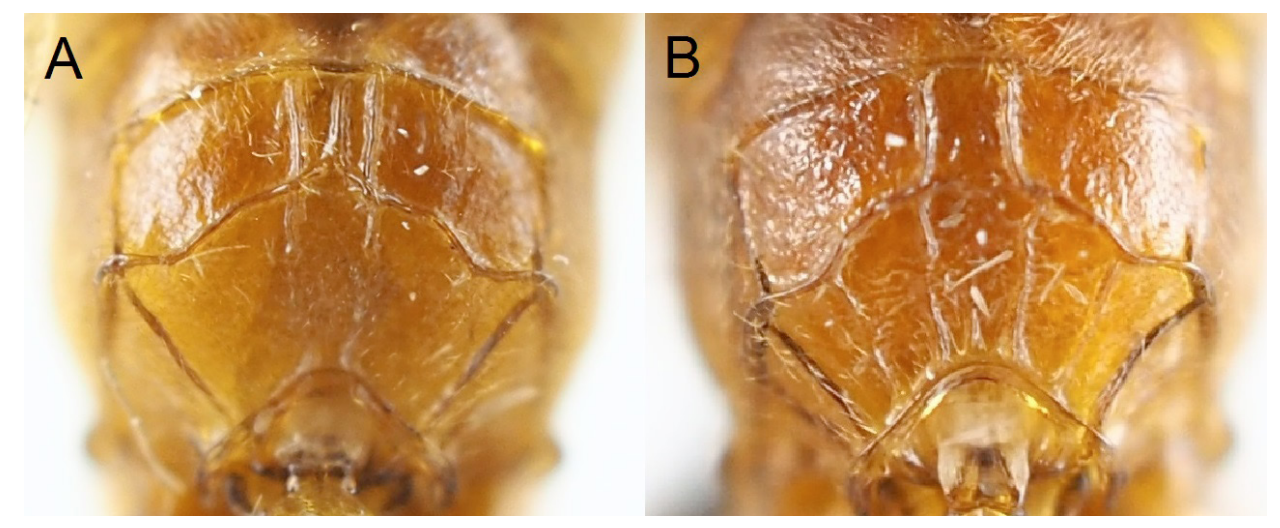

Fig. 47. Propodeum of females, posterodorsal view. A-B. Ophion costatus Ratzeburg, 1848. 
records and morphological analysis, shows that Ophion costatus is not to be regarded as a part of the $O$. mocsaryi aggregate, but belongs to the $O$. parvulus aggregate.

Brauns (1889) was the first reviser of Ophion costatus and introduced a new character that has been adopted by later authors, further adding to the confusion: the nervellus intercepted by the discoidella above the middle. Brauns, however, doubts whether his species is conspecific with Ratzeburg's species. There are no 'costatus' in the Brauns collection (Brock 1982; Zoltán Vas, HNHM, pers. com.) but the diagnosis and rearing record refered to by Brauns (1889) show that $O$. costatus sensu Brauns is conspecific with Ophion artemisiae Boie, as defined in this study (see remarks under $O$. artemisiae). Aubert et al. (1984) report Ophion costatus from Israel and according to the rather short and vague description the records might refer to $O$. costatus as defined here but the specimens have not been studied and it is possible that they represent another species.

It has not been possible within the frame of this study to check relevant collections for specimens with a potential connection to Ratzeburg's specimens and we therefore refrain from designating a neotype at this stage. If a neotype is to be designated this should be based on a specimen collected in or nearby Lolland-Falster in Denmark, which was the primary collecting ground for Christian Drewser (Lars Vilhelmsen, ZMUC, pers. com.) and therefore is to be regarded as the most probable type locality.

One of the four remaining morphospecies occurring in Sweden that comprise the O. mocsaryi aggregate shares the distinct carination of the propodeum evident in the holotype and the studied paratype of Ophion mocsaryi (Fig. 48D). This species, however, differs in the more numerous flagellomeres (59-62 flagellomeres, while O. mocsaryi has 52 flagellomeres in the holotype and 51 in the studied male paratype). It also has a slightly more transverse head in anterior view, enlarged compound eyes and more narrowed temples (Fig. 15D, G), and is here described as Ophion brocki Johansson sp. nov.

Another of the remaining species of the aggregate, which together with Ophion brocki Johansson sp. nov. has been interpreted as O. costatus in British collections (NMS and BMNH), is easily identified by its larger size, the shape of the epicnemial carina, the number of flagellomeres and the nervellus being broken at or above the middle. It is here described as Ophion splendens Johansson sp. nov.

The other two species are genetically distinct according to the barcoding, but morphologically very similar and separable by the characters given in the key and descriptions. One of the species is treated as conspecific with Ophion mocsaryi, although most specimens do not have the very distinct carination displayed by the type material and usually have more flagellomeres. The other is here described as Ophion confusus Johansson sp. nov. The discrepancies between the majority of studied specimens and the types of Ophion mocsaryi s. str. might be explained by the fact that they actually represent two different species, but no such conclusion can be supported at this stage. Furthermore there is probably another potential species of the aggregate occurring in Sweden. One female specimen from Central Sweden forms a clade with some British females in BOLD and has the temples more buccate than other $O$. mocsaryi females studied. As more material is needed before any definitive conclusions on the validity of the species can be drawn from the preliminary results, it is here treated under the provisional name Ophion mocsaryi var.

There is yet at least one additional species in the $O$. mocsaryi aggregate occurring in Central and Southern Europe, which can be expected to occur also in Southern Sweden. This species is about equal in size and has a similar number of flagellomeres (55-62) to O. brocki Johansson sp. nov. It is also similar to $O$. brocki in having a deep posterior sulcus behind the lateral ocelli and strongly narrowed temples and in the key to species it will key out as $O$. brocki. It is distinguished from $O$. brocki Johansson sp. nov. by the more transverse head in anterior view, and the anterior tranverse 


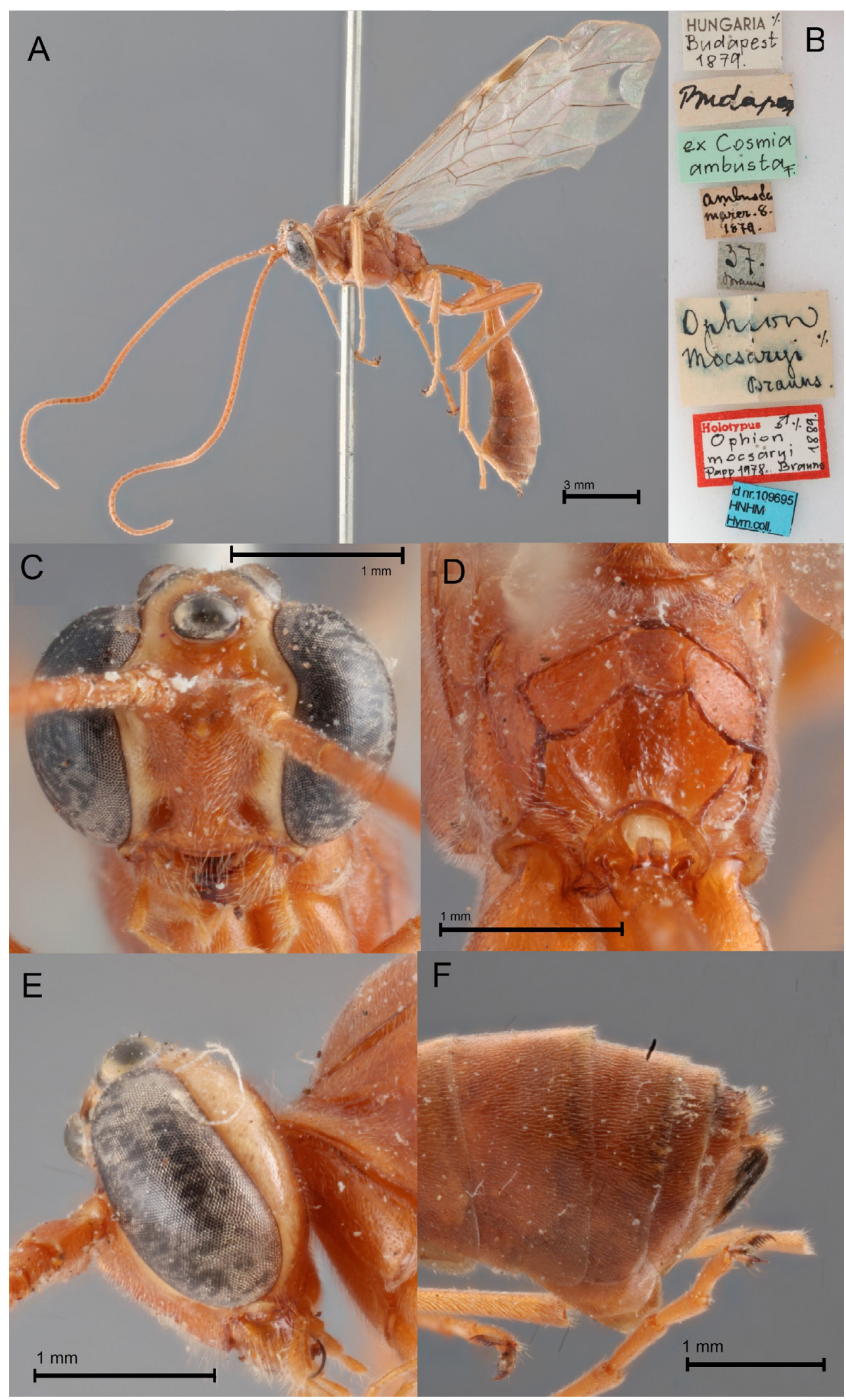

Fig. 48. Ophion mocsaryi Brauns, 1889, holotype, $q$ (HNHM). A. Habitus, lateral view. B. Labels. C. Head, anterior view. D. Propodeum, posterodorsal view. E. Head, lateral view. F. Posterior segments of metasoma, lateral view. 
carina of the propodeum always being absent laterally. The first author has studied specimens from France, Hungary, Italy and Croatia.

\section{The Ophion obscuratus aggregate}

Another presumed aggregate of historic taxonomic difficulty occurs around Ophion obscuratus. This aggregate is not to be confused with the O. obscuratus group as defined by Schwarzfeld et al. (2016). Brock (1982) suggested that there are at least three morphs discernible among the British material of Ophion obscuratus apart from the similar Ophion forticornis. In this study these morphs are treated as valid species and another species of similar morphology is described. Two of the species, among them the nominate form, have rich pale markings on the body (Fig. 11A-B) and are easily separable from other Swedish species of Ophion. The male lectotype is quite badly damaged by dermestids with the fore and mid legs and part of the head and mesosoma missing. The large pin has destroyed large parts of the scutellum. The type material of the species studied shows that the Fabricius type specimen in Copenhagen most likely belongs to the large autumnal form, referred to by Brock (1982) as "autumnal giants" based on the large size (fore wing length $18 \mathrm{~mm}$ ) and the shape of the occipital carina. This species is active during late autumn and early winter and is defined morphologically by the larger size, more numerous flagellomeres and details in the shape of the occipital carina (see key to species and diagnosis). Brock's hypothesis that the two pale marked forms represent different generations (Brock 1982) is erroneous, as the early summer generation has been shown to be univoltine (Mark Shaw, NMS, pers. com.). Applying a name for the early summer species becomes more problematic.

The situation regarding the junior synonyms is as follows. The synonym Ophion obscurus Fabricius, 1804 is straightforward as it is a new name adopted by the author himself for $O$. obscuratus and is therefore to be regarded as a synonym of $O$. obscuratus, with the same type specimen. The next name in synonymy is Ophion polyguttator Thunberg, 1824. The type is lost (Roman 1912; pers. obs. by the authors) but the original description of Ichneumon polyguttator (Thunberg, 1822) refers to a species with black thorax, scutellum and abdomen displaying three yellow stripes dorsally on the thorax and yellow spots on the abdomen; "Thoracie et scutellare nigro, abdomine nigro, fuscus abd, lateribus flavomaculatis thoracis dorso luteo trilineato". Note that the publications of new descriptions and nomenclatural acts by Thunberg (1822-1824) is to be regarded as interrupted and all new names established in these works have to be dated from 1824 (Horstmann 1999). From the original description this seems unlikely to refer to a species conspecific with $O$. obscuratus, but two years later Thunberg (1824) puts his newly described species, now spelled pollyguttator, in synonymy with $O$. obscurus. The original description of O. obscuratus (Fabricius, 1798) is similar to that of O. polyguttator and states "thoracis dorso luteo: lineis tribus abbreviates punctoque fuscis, abdominis lateribus flavo maculatis". In Thunberg's collection in Uppsala there are, however, two specimens of the spring/early summer species collected in Uppsala, probably by Thunberg himself. One male and one female are labelled Ophion sinuatus (Fig. 49), a name that was never published (Yu \& Horstmann 1997) and therefore is to be regarded as a nomen nudum. There is no label 'polyguttator' at all in the collection indicating the true identity of Thunberg's species. This shows that Thunberg most likely, after describing $O$. polyguttator, noticed the similarity between his and Fabricius' descriptions and subsequently put the species in synonymy without seeing any actual material of Fabricius' species. Otherwise the two specimens of $O$. obscuratus $\mathrm{s}$. lat. would have been placed under the now absent labels 'polyguttator' or 'obscurus' instead of 'sinuatus'. Based on this, $O$. polyguttator is excluded from synonymy with $O$. obscuratus stat. rev. and regarded as a nomen inquirendum.

Ophion flavolineatus Brullé, 1846, the next name to be described in this complex, was synonymized with O. obscuratus by Gauld \& Mitchell (1981). The type specimen in MNHN, collected in Papua New Guinea (!), is in very poor condition due to dermestid damage and most of the antennae, the apical part 


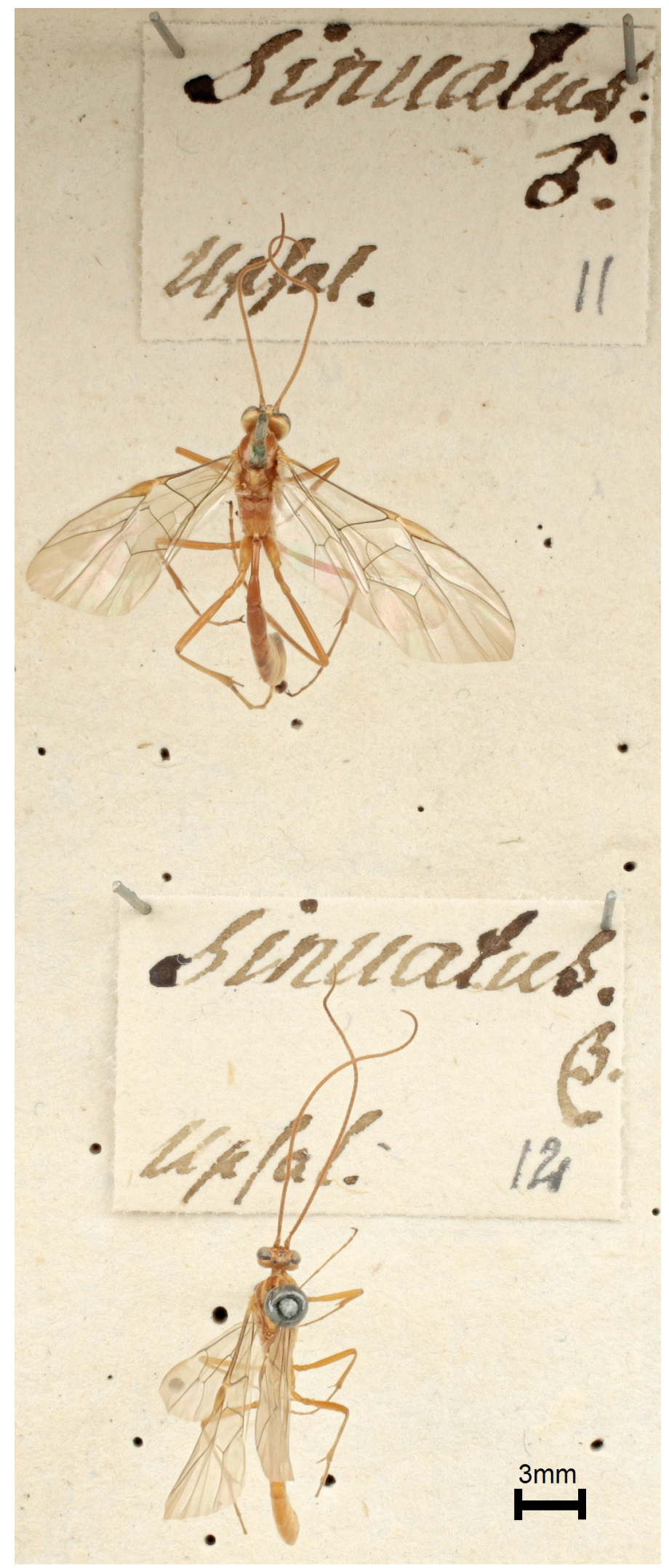

Fig. 49. The two specimens of Ophion variegatus Rudow, 1883 in coll. Thunberg in UPSZ under the label Ophion sinuatus (nomen nudum). A female (labelled as male) above and male below. 
of the metasoma, and most of the head is missing. The shape of the temple and the occipital carina and the rather weakly expressed sternal angles are in agreement with the type of Ophion obscuratus. Even though the type locality would indicate that this is a tropical species, not conspecific with O. obscuratus, there are no formal reasons to reject Ophion flavolineatus from synonymy with $O$. obscuratus based on morphology at this stage.

The final synonym is Ophion variegatus Rudow, 1883. The type, collected in Elsass (Alsace), now Grand Est in Northeastern France, is lost, but the species was interpreted and synonymised with O. obscuratus by Horstmann (1993). This study agrees with Horstmann that the species according to Rudow's description represents one of the pale marked species in the $O$. obscuratus aggregate. The only detail in Rudow's original description (Rudow 1883) that indicates a connection to either the autumnal or spring/early summer form is the body length. Rudow states that the body length of the described species is $18 \mathrm{~mm}$. This better matches the on average smaller spring/early summer species although one should be aware that measurements of the body in ichneumonids should always be regarded as approximate. Horstmann did not designate a neotype, but refers to a specimen of $O$. obscuratus in his own collection in order to stabilize the name. However, there is no label on any of the specimens of O. obscuratus in Horstmann's collection in ZSM clearly referring to this attempt to stabilize the name and the collection contains several specimens of both the spring/early summer species as well as the autumn species. One male, which belong to the spring /early summer species, has a blue determination label "Ophion obscuratus Fab. $\sigma^{\lambda}$ " in Horstmann's handwriting, which might indicate that this was the specimen referred to in the paper.

In the absence of a type specimen in combination with the fact that Rudow's description lacks any morphological characters to distinguish it from O. obscuratus with certainty, apart from the rather vague note of the size of the species, $O$. variegatus could formally be regarded as a nomen dubium which would require a new name for the early summer species. However, introducing a new name would not serve stability given the rather dynamic taxonomic situation of the $O$. obscuratus aggregate, and therefore a neotype for Ophion variegatus is designated in accordance with Horstmann's intention to stabilize the name based on the size given in the original description. The specimen in Horstmann's collection was collected in the Ostfriesischen Inseln (a band of islands off the Northern coast of Germany) which is about $400 \mathrm{~km}$ from Alsace. There are no specimens in the Horstmann collection collected closer to Rudow's type locality and therefore suitable for designating a neotype. In MNHN there are two specimens of the spring/early summer species collected in Alsace. A neotype for Ophion variegatus Rudow, 1883 (Fig. 50A-D) is designated from one of the two specimens in MNHN and the species is reinstated as a valid species, stat. rev.

The reinstatement of Ophion variegatus is not entirely straightforward. More than any other species pair in the genus, $O$. obscuratus and $O$. variegatus seem to partly overlap in all known characters. The characterization used to distinguish the species in this study seem to apply to material from Northern Europe while it is less useful on material from Central and Southern Europe. COI sequences from Ophion obscuratus s. lat. specimens from all over Europe kindly shared by Gavin Broad and material studied by the first author seem to indicate that the aggregate consists of several undescribed species in the Western Palaearctic (Broad unpublished data).

It should be noted that there are several additional pale- marked species occurring in Southern Europe. The subspecies $O$. obscuratus ceballosi Izquierdo, 1984 and the potentially closely related $O$. cortesi Ceballos, 1940, described from Spain (Ceballos 1940), are, judging from their original descriptions, also presumably valid species within this aggregate, as well as O. turcomanicus Szépligeti, 1905 and Ophion eremita Kokujev, 1906. None of these species are known from Sweden and therefore not treated in detail in this study. 
Apart from the pale marked species in the aggregate, two more similar morphs with less extensive pale markings were identified during this study, which are both described as new to science. One small autumnal form occurring in heathlands in Southern Sweden is decribed as Ophion autumnalis Johansson sp. nov. and one form occurring during early summer in mixed forest as Ophion sylvestris Johansson sp. nov. The latter, which might be a complex of two species, is according to the sequencing probably not to be included in the $O$. obscuratus aggregate. It has the ovipositor more or less black or dark brown, contrasting in colour with the more testaceous posterior metasomal segments and the face and head less transverse in anterior view.

Brock (1982) refers to the existence of an autumnal dwarf form of $O$. obscuratus occurring in British heathlands in autumn. The first author has studied several dwarf specimens of $O$. obscuratus from

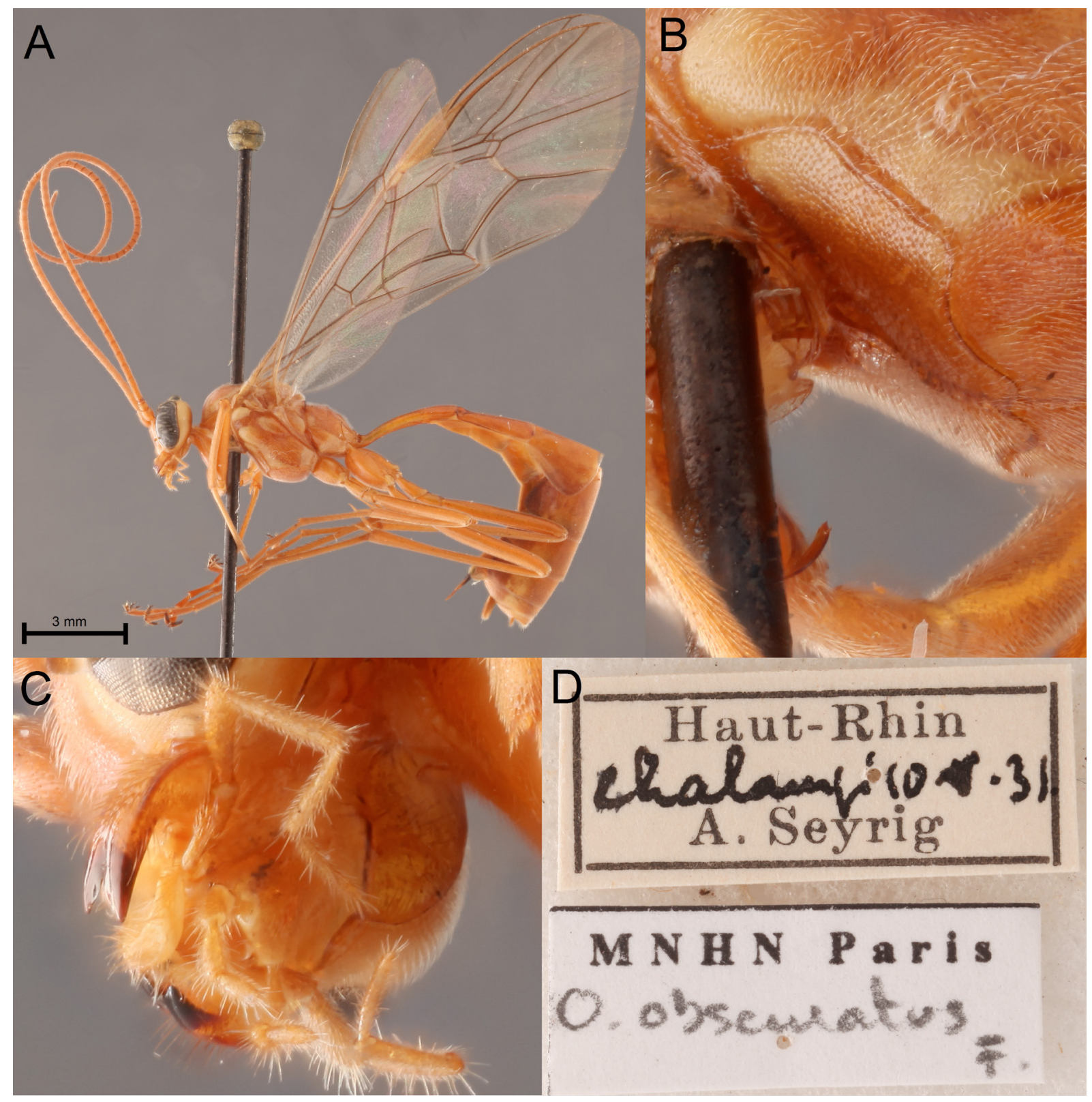

Fig. 50. Ophion variegatus Rudow, 1883, neotype, + (MNHN). A. Habitus, lateral view. B. Epicnemial carina, lateroventral view. C. Occipital carina, lateroventral view. D. Labels. 
the British Isles (BMNH) and they are conspecific with the species here described as $O$. autumnalis Johansson sp. nov. The female holotype of Ophion bipictor Aubert, 1980, a presumably Southern and Central European species with rather discrete pale markings on the mesosoma and stout flagellomeres, was also studied and it is also possible that this species is closely related to, or included in the obscuratus aggregate.

The molecular analysis of the presumed aggregate around $O$. obscuratus is weak due to some special circumstances during the barcoding (see Material and methods) and the genetic delimitation between the species therefore remains uncertain. A wider revision of the Western Palaearctic Ophion obscuratus s. lat., including molecular methods, is probably necessary to clarify the taxonomy of this problematic aggregate.

\section{The Ophion parvulus aggregate}

In this study five species (Ophion costatus, Ophion paraparvulus Johansson sp. nov., Ophion tenuicornis Johansson sp. nov., Ophion kallanderi Johansson sp. nov. and Ophion parvulus) are recognized as an aggregate previously treated under the name Ophion parvulus (Table 1). These species are readily identified by the usually evenly curved radius, the pleurosternal angles being weakly pronounced and situated distinctly anterior to the sternal angles, the short hind trochantellus, the spiracle of the sclerotised part of the first tergite being at the same level as the hind margin of the first sternite and the often distinct anterior and posterior transverse carinae of the propodeum. The five species treated are distinguished by the characters given in the key to species, the species desciptions and Table 1. The female of Ophion kallanderi Johansson sp. nov. has the radius weakly sinuate, but other morphological features, as well as the position indicated by the molecular analysis, support its position within the O. parvulus aggregate.

The lectotype of Ophion parvulus (Fig. 51A-F) is a well-preserved male, with small body size (fore wing length $11 \mathrm{~mm})$ and with quite few flagellomeres $(\mathrm{n}=45)$. In the original description by Kriechbaumer (1879b) a female reared from the same host (type lost) is mentioned. According to the description it differs from the male by having a distinct ramellus and the radius straighter in its proximal part. In males the conspicuous pilosity of the antennae displayed by the females of some species in this aggregate is less pronounced, but the relative length of the flagellomeres excludes four of the members of the aggregate. Males of Ophion costatus, which have similarly shaped flagellomeres, are generally much larger, have the temples more stongly buccate, the longitudinal carina delimiting the area superomedia often absent and almost all known specimens have a central longitudinal fold between the transverse carinae of the propodeum. The type, however, fits well with one morphospecies regarding the size and shape of the flagellomeres as well as the shape of the temples and size of the ocelli. The carination of the propodeum with the anterior transverse carina reduced laterally is a frequent feature of males in the parvulus aggregate and the strong carinae delimiting the area superomedia is also in accordance with this morphospecies, which is treated as the true Ophion parvulus. The host species from which the lectotype and one presumably lost female were reared is the noctuid Ipimorpha retusa. There seems to be no additional rearing records from that particular species, but a series of specimens in the NHRS was reared from Fissipunctia ypsillon, a species with similar ecology. Presumably the species also uses additional hosts.

The carination displayed by the holotype (Fig. 51B), which is typical of small specimens of the species, is also a feature found in males of $O$. mocsaryi and $O$. confusus Johansson sp. nov., which also occasionally have the radius evenly curved and more obtuse pleurosternal angles. However, the basal flagellomeres are stouter in those species, and the flagellomeres more numerous, excluding them as possible synonyms. 


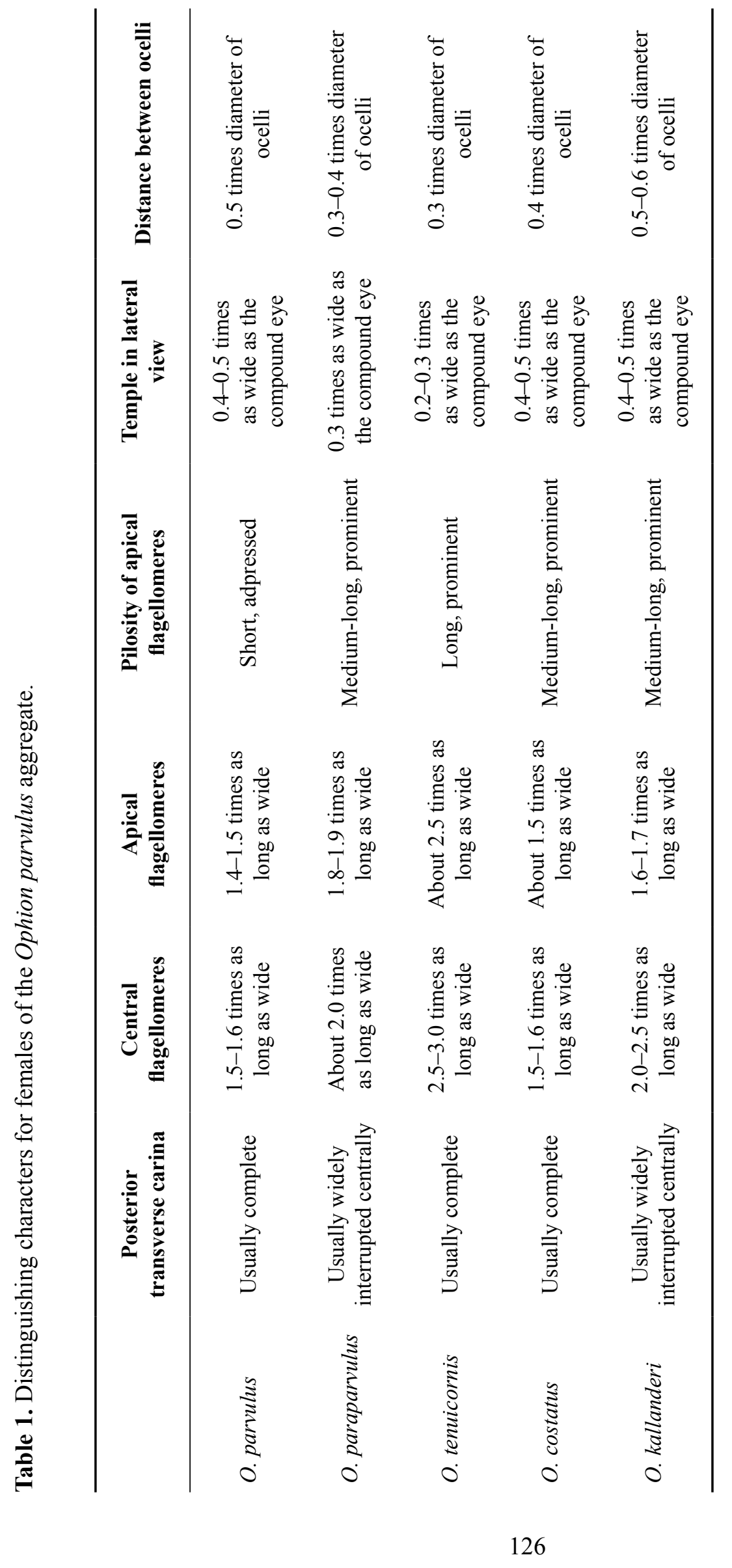




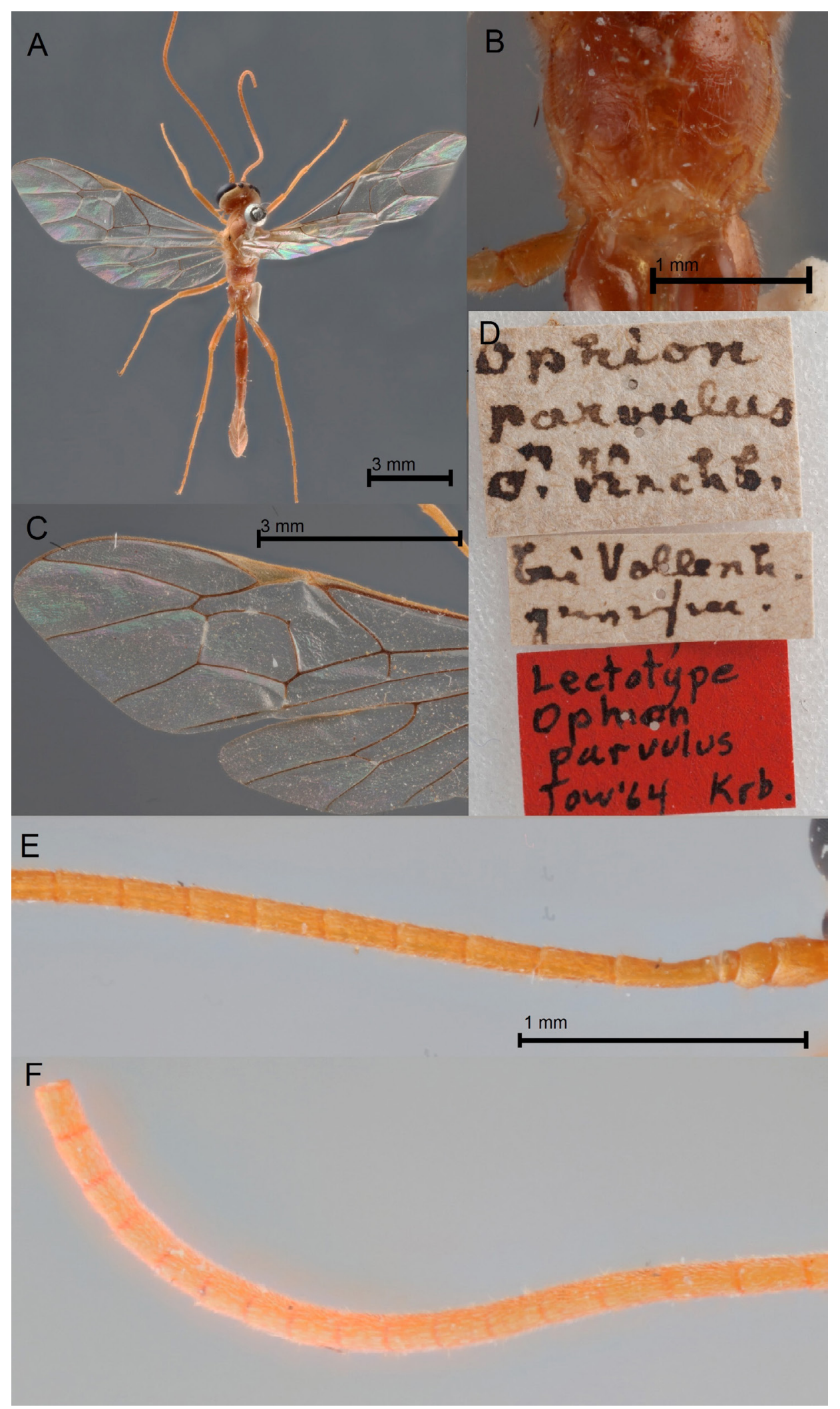

Fig. 51. Ophion parvulus Kriechbaumer, 1879, lectotype, $ð$ (ZSM). A. Habitus, dorsal view. B. Propodeum, postero-dorsal view. C. Fore wing. D. Labels. E. Basal flagellomeres. F. Subapical flagellomeres. 
The remaining three species in the aggregate that are defined by this study are here described as new to science: Ophion paraparvulus Johansson sp. nov., O. tenuicornis Johansson sp. nov. and O. kallanderi Johansson sp. nov.

The specimens so far barcoded in BOLD indicates that the European fauna holds at least one additional species in the parvulus aggregate, besides the five species occurring in Sweden.

\section{The Ophion pteridis aggregate}

This study recognizes four species, similar in appearance, that have all been treated under the name Ophion pteridis. Two of the species have the mesosoma more or less infuscate, while the other two are more evenly testaceous in colour. The aggregate is usually defined by the combination of the strongly sinuate radius, the carinated scutellum, the sclerotised part of the first sternite ending distinctly posterior to the spiracle, and the more or less obvious dorsal undulation on the first metasomal segment. The molecular results, however, indicate that the $O$. pteridis species group is polyphyletic in relation to the O. luteus species group as defined by Schwarzfeld et al. (2016) (Fig. 1). Specimens with infuscate areas on the mesosoma has been treated by some authors as aberrations, where the darker colour is explained as a result of post mortem processes (Brock 1982). This is however erroneous as the infuscation in two of the species of this aggregate is evident in living specimens. The colouration is also quite constant and therefore diagnostic. Unfortunately, the hypothesis of the unnatural origin of the infuscation has led to some misinterpretations of the type material that is hereby corrected.

Apart from the obvious colour differences, the two testaceous species have the occipital carina dorsally flattened or rounded (as in Fig. 7A) in the majority of specimens, while it is more or less angled in the darker species (as in Fig. 7B). Furthermore the head generally is more transverse in anterior view in the testaceus species (width/height measured from the ventral margin of clypeus to the top of head $=1.25-1.30$ ), while it is more rounded (width/height $=1.15-1.20)$ in the infuscate species pair. The posterior transverse carina of the propodeum is also usually more distinct in the infuscate species pair and the petiolar area has coarser structure in the form of small carinae emanating from the petiolar insertion. Studies of the type material show that Ophion pteridis (Fig. 52A-F) is the correct name for one of the two infuscate species and that Ophion albistylus is a junior synonym of that species, syn. nov. The other species with an infuscate mesosoma, easily distinguished from $O$. pteridis by the shape of the head and the face, is here described as Ophion vardali Johansson sp. nov. Because of the misinterpretation of the $O$. pteridis type and the misconception that this aggregate is one very variable species, the two species with testaceous mesosoma need to be described as new to science. Ophion arenarius Johansson sp. nov. is separated from $O$. inclinans Johansson sp. nov. by the shape of the flagellomeres and the usually slightly more transverse head in anterior view. The genetic differentiation according to the barcoding analysis is, however, small (Fig. 5). There also seems to be an ecological differentiation as $O$. arenarius Johansson sp. nov. is a rather rare species only occurring in open dry heathlands primarily in Southern Sweden, while $O$. inclinans is very common and more connected to semi-open environments and forest areas and occurs all over Sweden, with the exception of alpine areas. The barcoded specimens of Ophion inclinans partly cluster with some barcoded specimens from Finland and Norway forming two distinct groups, one of which seem almost intermediate between $O$. inclinans and $O$. arenarius (Fig. 5). These specimens, which all were collected in subalpine areas in central and northern Sweden, have the clypeus narrower and entirely shagreened, while it is wider and polished in typical specimens. Further research is needed to clearify if these forms represent different taxa or a northern variety.

\section{Additional comments on some type material}

The type of $O$. ocellaris Ulbricht, 1926, located in the collection of the Entomological Society of Krefeld was not studied despite several attempts to access it. A study of this type is however desirable in future research to confirm the presumed synonymy beween this species and Ophion fuscicollis Hellén. 


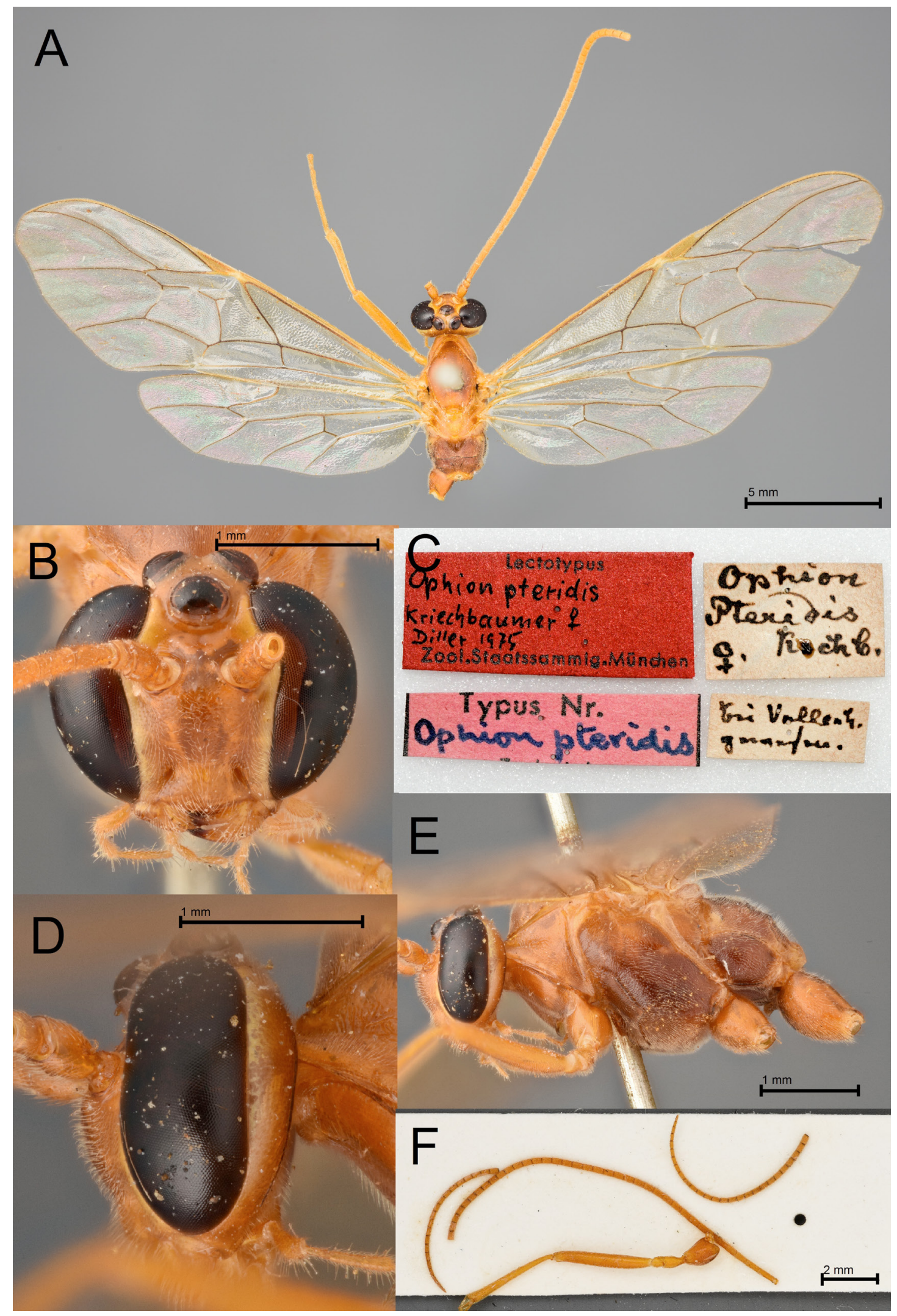

Fig. 52. Ophion pteridis Kriechbaumer, 1879, lectotype, $q$ (ZSM). A. Habitus, dorsal view. B. Head, anterior view. C. Labels. D. Head, lateral view. E. Mesosoma, lateral view. F. Parts of antennae and leg. 
During this study several unsuccessful attempts were made to access the types of Ophion kevoensis Jussila, 1965 that were on a private loan for a study of the Finnish Ophion fauna. However, the type material was studied by the second author previous to this study and at that time accurate and detailed drawings were made on which the interpretation of the species is based.

Type specimens or specimens with relation to the presumably lost types of the following species were also studied, but none of them has any relation to any of the species occurring in Sweden: Ophion asiaticus Kokujev, 1906, lectotype, ㅇ (ZIN); Ophion bipictor Aubert, 1980, holotype, ㅇ (NHML); Ophion nigricans Ruthe, 1859, lectotype, $\odot$ (NHMW); Ophion sibiricus (Szépligeti, 1905), lectotype, + (HNHM) and Ophion turcomanicus Szépligeti, 1905, lectotype, $q$ and paralectotype, $q$ (HNHM). Ophion eremita Kokujev, 1906 type lost, non type + determined by Meyer (ZIN); Ophion rostralis Meyer, 1935 type lost, non type $q$ determined by Meyer (ZIN).

\section{The estimated total number of species in Sweden and Europe}

This study shows that several Ophion species, which were previously regarded as highly variable taxa, actually comprise closely related aggregates of valid species that, although similar in appearance, are distinguishable morphologically as well as ecologically. In most cases the morphological variation within species is surprisingly small, which is contradictory to the general perception of the genus, but in line with several other recent studies of other Hymenoptera groups (Johansson \& van Achterberg 2016; Straka 2016). Apart from the known species aggregates there seem to be several previously undescribed and rarely encountered species present in the Swedish fauna, indicating that species richness in the genus has been severely underestimated.

Before this study 10 Ophion species were recognized as occurring in Sweden. This means that the number of documented taxa has increased by $400 \%$. Still it is highly probable that some undescribed species remain undiscovered. We estimate that the species richness is approximately 45 species in Sweden. For comparasion Sweden is home to approximately one quarter $(23 \%)$ of the European fauna of noctuid and geometrid moths.

The implications for the still largely unrevised European fauna are of course difficult to appreciate, but judging from the diversity of hosts and presuming a partly host correlated species richness in Ophion, the total number of species in the Western Palearctic alone might be somewhere in the region of 80 to 100 species. Schwarzfeld \& Sperling (2015) used a variety of molecular methods to estimate the total number of Ophion species occurring in the Holarctic. The authors' more conservative interpretation of the results indicates that there are between 89-121 species in the Holarctic, which is in the lower region of the estimated richness of the European fauna suggested in this study. However, Schwarzfeld \& Sperling (2015) used a very limited European material from a small geographical area (almost exclusively Great Britain) which indicates an incomplete genetic sampling. This study shows that about $25-30 \%$ of the Ophion species occurring in Sweden are rare or very rare, which makes it unlikely that they would be be sampled by chance if the barcoded specimens are selected without a thorough preliminary morphological assessment. Regardless of the methods used the conclusion is the same, that the European fauna remains largely unknown and that more taxonomic and faunistic research is needed.

\section{Acknowledgements}

Without the kind help of many people this study would have been hard to complete. First and foremost we are grateful to Nils Ryrholm \& Claes Källander for providing access to their unique sample series of MV-light trap material from three decades. Without the sheer number of specimens, this study would have been impossible. Hege Vårdal at the NHRS has been absolutely crucial to this study in arranging the receipt and shipping of specimens, photographing important type-material and for access to the NHRS collections. Gavin Broad at the BMNH has been a very valuable source of taxonomic discussions 
as well as giving access to British specimens and type-material which has increased the quality of this study. Many people have donated material for study and more important contributions have been made by the following persons: Arne Pettersson, Michael Andersson, Birgitta Andersson, Artur Larsson, Håkan Andersson, Tommy Lindberg, Johan Törnvall, Martin Oomen, Robin Isaksson, Mats Lindeborg, Kenneth Alexandersson, Nikolay Savenkov and Conny Philipsson. Thanks also to Alexander Berg for the excellent close up photos used in this publication. Juho Paukkunen at MZH was very helpful in providing access to the Hellén types and helped detecting some rare literature. Gergely Várkonyi for helping out with some of the Hellén types and discussions on Nordic Ophion. Reijo Jussila arranged for study of the type material of Ophion kevoensis decades ago, at the dawn of this study. Stefan Schmidt at ZSM has been of service beyond the ordinary, providing access to the Kriechbaumer types and the Horstmann collection. Lars Vilhelmsen at ZMUC helped sort out some of the confusion regarding the Fabricius types, provided access to the Ophion wuestneii type and assisted with information on the presumed type locality for Ophion costatus. Agnièle Touret-Alby at MNHN helped out with the study of Ophion flavolineatus and the designation of the neotype of Ophion variegatus. Anne Freitag and Marion Podolak, NHML, assisted with some of the Aubert types. Mark Shaw, NMS, kindly sorted out and returned some of the N. Ryrholm and C. Källander samples previously donated to him and shared some rearing records. Mark and Ashleigh Whiffin also assisted with some material from the NMS. Petr Heřman assisted with the Strobl collection in Stift Admont. Michael Ohl, Lukas Kirschey and Jutta Helbig at ZMHB provided access to the Brauns type material housed in their collections. Zoltán Vas and Tamás Németh at HNHM were of kind service and arranged for the study of some Brauns and Szépligeti types. Christer Hansson, Christoffer Fägerström, Rune Bygebjerg at MZLU and Pelle Magnusson contributed in various ways with the type material of C. G. Thomson and access to their collections. Hans Mejlon at the UPSZ guided us through the Thunberg collection and their main collection. Dominique Zimmermann at NHMW arranged for study of the type material of Ophion nigricans. Villu Soon at the TUZ kindly arranged for the loan of Ophioninae in their main collection. Mats Jonsell at the SLU gave access to the collections at their institution. Dave Karlsson helped with the samples from SMTP. Malin Strand at ArtDatabanken/STI and Gunnhild Marthinsen of NorBOL for assisting with the DNA barcoding. DNA barcode data in this publication was in part generated in collaboration with the Norwegian Barcode of Life Network (NorBOL) funded by the Research Council of Norway and the Norwegian Biodiversity Information Centre. Bengt-Åke Bengtsson and Mattias Forshage contributed with discussions on tricky taxonomic problems. Geir Ørsnes is thanked for kind assistance with the barcoding and donation of the holotype of $O$. vardali. Jostein Austevik kindly donated the Norwegian paratype of Ophion paukkuneni. Andrey Khalaim at ZIN helped to sort out the fate of some Meyer and Kokujev types assisted by Filippo Di Giovanni and Pier Luigi Scaramozzino. Andrey also kindly helped out with finding and translating some of the rare Russian literature. Heinz Schnee kindly lent some specimens from his private collection for study. Dmitri Logunov at MMUE and Ryan Mitchell at UMB assisted with specimens from their collections respectively. William Penigot lended some French Ophion specimens for study. Jarl Birkeland, Jostein Austevik and Alf Tore Mjøs donated some specimens from Norway and Lars Ove Hansen assisted with specimens from the NHMO. Seraina Klopfstein for discussions on the sequencing of ichneumonids and the relation between morphological and molecular characterization. Finally we'd like to thank the two anonymous reviewers and Gavin Broad, who gave valuable comments that greatly improved the quality of the manuscript.

\section{References}

Aubert J.F., Halperin J. \& Gerling D. 1984. Les ichneumonids d'Israel. Entomophaga 29 (2): 211-235.

Bergsten J., Bilton D.T., Fujisawa T., Elliott M., Monaghan M.T., Balke M., Hendrich L., Geijer J., Herrmann J., Foster G.N., Ribera I., Nilsson A.N., Barraclough T.J. \& Vogler A.P. 2012. The effect of geographical scale of sampling on DNA Barcoding. Systematic Biology 61 (5): 851-869.

https://doi.org/10.1093/sysbio/sys037 
Boie F. 1855. Beobachtungen und Bemerkungen. Entomologische Zeitung 16 (4): 97-108.

Brauns S. 1889. Die Ophioniden. Archiv des Vereins der Freunde der Naturgeschichte in Mecklenburg 43: 73-100.

Brauns S. 1895. Descriptiones specierum novarum Ichneumonidarum e fauna Hungarica. Természetrajzi Füzetek 18: 42-49.

Broad G.R. 2012. Keys for the identification of British and Irish nocturnal Ichneumonidae. Department of Entomology, Natural History Museum, London. Available from http://nocturnalichs.myspecies.info/node/38 [accessed 15 Aug. 2015].

Broad G.R., Schnee H. \& Shaw M.R. 2015. The hosts of Ophion luteus (Linnaeus) (Hymenoptera, Ichneumonidae, Ophioninae) in Europe. Journal of Hymenoptera Research 46: 115-125.

https://doi.org/10.3897/JHR.46.5347

Broad G.R., Shaw M.R. \& Fitton M.G. 2018. Ichneumonid wasps (Hymenoptera: Ichneumonidae): their classification and biology. Handbooks for the identification of British Insects 7 (12): 1-480.

Brock J.P. 1982. A systematic study of the genus Ophion in Britain (Hymenoptera, Ichneumonidae). Tijdschrift voor Entomologie 125: 57-97.

Brullé M.A. 1846. Tome Quatrième. Hyménoptères. Les Ichneumonides. In: Lepeletier de Saint-Fargeau A. (ed.) Histoire Naturelles des Insectes: 56-521. Paris. https://doi.org/10.5962/bhl.title.9005

Ceballos G. 1940. Especies españolas del genero Ophion F. (Hymenoptera; Ichnneumonidae). Eos 14 (1938): 7-22.

Ceballos G. 1962. Sobre algunas especies de la tribu Ophionini (Hymenoptera). Eos 38: 197-202.

Cook J.M., Butcher R.D.J. 1999. The transmission and effects of Wolbachia bacteria in parasitoids. Researches on Population Ecology 41: 15-28. https://doi.org/10.1007/p100011978

Çoruh S. \& Kolarov J. 2012. Description of the male of Ophion internigrans Kokujev, 1906 (Hymenoptera: Ichneumonidae: Ophioninae) with a key to the Turkish Ophion Fabricius, 1798 species. Journal of the Entomological Research Society 14 (2): 55-60.

Edgar R.C. 2004. MUSCLE: multiple sequence alignment with high accuracy and high throughput. Nucleic Acids Research 32 (5): 1792-1797. https://doi.org/10.1093\%2Fnar\%2Fgkh340

Fabricius J.C. 1798. Supplementum Entomologicae Systematicae. Proft et Storch, Kopenhagen [Hafniae]. https://doi.org/10.5962/bhl.title.122153

Fabricius J.C. 1804. Systema Piezatorum: secundum ordines, genera, species, adjectis synonymis, locis, observationibus, descriptionibus. Carolum Reichard, Braunschweig [Brunsvigae].

https://doi.org/10.5962/bhl.title.10490

Feder J.L. \& Forbes A.A. 2010. Sequential speciation and the diversity of parasitic insects. Ecological Entomology 35: 67-76. https://doi.org/10.1111/j.1365-2311.2009.01144.x

Funk D.J. \& Omland K.E. 2003. Species-level paraphyly and polyphyly: frequency, causes, and consequences, with insights from animal mitochondrial DNA. Annual Review of Ecology, Evolution and Systematics 34: 397-423. https://doi.org/10.1146/annurev.ecolsys.34.011802.132421

Gauld I.D. 1973. Notes on the British Ophionini (Hym., Ichneumonidae) including a provisional key to species. Entomologist's Gazette 24: 55-65.

Gauld I.D. 1976. Notes on the British Ophioninae (Hym., Ichneumonidae). Part 3. The identity of the species described by Morley, 1915 and Thomson, 1888 and a checklist of British species. Entomologist's Gazette 27: 113-117. 
Gauld I.D. 1978. Notes on the British Ophioninae (Hym., Ichneumonidae). Part 4. A revised key to the species of the genus Ophion Fabricius. Entomologist's Gazette 29: 145-149.

Gauld I.D. 1985. The phylogeny, classification and evolution of parasitic wasps of the subfamily Ophioninae (Ichneumonidae). Bulletin of the British Museum of Natural History, Entomology Series 51: 61-185.

Gauld I.D. 1988. A survey of the Ophioninae (Hymenoptera: Ichneumonidae) of tropical Mesoamerica with special reference to the fauna of Costa Rica. Bulletin of the British Museum of National History, Entomology Series 57: 1-309.

Gauld I.D. \& Mitchell P.A. 1981. The taxonomy, distribution and host preferences of Indo-Papuan parasitic wasps of the subfamiliy Ophioninae. CAB:Slough, Commonwealth Institute of Entomology, London.

Gokhman V.E. 2018. Dimensions and borderlines of parasitoid Hymenoptera species: A paradigm shift? Biology Bulletin Reviews 8: 227-233. https://doi.org/10.1134/S2079086418030052

Gravenhorst J.L.C. 1829. Ichneumonologia Europaea. Pars III. Sumtibus auctoris, Breslau [Vratislaviae]. https://doi.org/10.5962/bhl.title.11531

Habermehl H. 1930. Neue und wenig bekannte palaarktische Ichneumoniden (Hym.). V. Nachtrag. Konowia 9: 109-117.

Hamilton C.A., Hendrixson B.E., Brewer M.S. \& Bond, J.E. 2014. An evaluation of sampling effects on multiple DNA barcoding methods leads to an integrative approach for delimiting species: a case study of the North American tarantula genus Aphonopelma (Araneae, Mygalomorphae, Theraphosidae). Molecular Phylogenetic and Evolution 71: 79-93. https://doi.org/10.1016/j.ympev.2013.11.007

Hebert P.D.N., Cywinska A., Ball S.L. \& deWaard J.R. 2003. Biological identifications through DNA barcodes. Proceedings of the Royal Society of London B: Biological Sciences 270: S96-S99. https://doi.org/10.1098/rspb.2002.2218

Hebert P.D.N., Stoeckle M.Y., Zemlak T.S. \& Francis C.M. 2004. Identification of birds through DNA barcodes. PLoS Biology 2: 1657-1663. https://doi.org/10.1371/journal.pbio.0020312

Hellén W. 1926. Beiträge zur Kenntnis der Ichneumoniden Finlands II. Subfam. Ophioninae und Anomaloninae. Acta Societatis pro Fauna et Flora Fennica 56 (6): 1-27.

Horstmann K. 1993. Revision der von Ferdinand Rudow beschriebenen Ichneumonidae I. (Hymenoptera). Beiträge zur Entomologie 43 (1): 3-38.

Horstmann K. 1999. Zur Interpretation der von Thunberg in der Gattung Ichneumon Linnaeus beschriebenen oderbenannten Arten(Hymenoptera).Zeitschrift der Arbeitsgemeinschaft Österreichischer Entomologen 51: 65-74.

Horstmann K. 2006. Revisions of the species of Ichneumonidae (Insecta, Hymenoptera) described by Kriechbaumer from the western Palearctic Region and central Asia. Spixiana 29 (1): 1-30.

Ivanova N.V., deWaard J.R. \& Hebert P.D.N. 2006. An inexpensive, automation-friendly protocol for recovering high-quality DNA. Molecular Ecology Notes 6: 998-1002.

https://doi.org/10.1111/j.1471-8286.2006.01428.x

Izquierdo I. 1984. Los Ophioninae españoles (Hym., Ichn.). Eos 59: 45-65.

Johansson N. 2018. Review of the Swedish Enicospilus (Hymenoptera; Ichneumonidae; Ophioninae) with description of three new species and an illustrated key to species. European Journal of Taxonomy 483: 1-21. https://doi.org/10.5852/ejt.2018.483 
Johansson N. \& Achterberg C. van 2016. Revision of the Palaearctic Gasteruption assectator aggregate, with special reference to Sweden (Hymenoptera, Gasteruptiidae). ZooKeys 615: 73-94.

https://doi.org/10.3897/zookeys.615.8857

Jussila R. 1965. The Ichneumonidae of the Kevojoki area in Inari Lapland (Finland) (Rep. Kevo Subarct. Res. Stat. 2). Annales Universitatis Turkuensis. Series A.II 34: 1-186.

Jussila R. 1966. The female of the ichneumonid species Ophion kevoënsis Jussila (Hymenoptera, Ichneumonidae). Annales Entomologici Fennici 32: 315-317.

Klopfstein S. 2014. Revision of the Western Palaearctic Diplazontinae (Hymenoptera, Ichneumonidae). Zootaxa 3801 (1): 1-143. https://doi.org/10.11646/zootaxa.3801.1.1

Klopfstein S., Kropf C. \& Baur H. 2016. Wolbachia endosymbionts distort DNA barcoding in the parasitoid wasp genus Diplazon (Hymenoptera: Ichneumonidae). Zoological Journal of the Linnean Society 177 (3): 541-557. https://doi.org/10.1111/zoj.12380

Kokujev N.R. 1906a. Duae novae Ichneumonidarum species e Rossia australi (Hymenoptera). Revue Russe d'Entomologie 6: 159-160.

Kokujev N.R. 1906b. Hymenoptera asiatica nova VIII. Revue Russe d'Entomologie 6: 164-169.

Kriechbaumer J. 1879a. Ophion pteridis n. sp. Entomologische Nachrichten 5: 89-90.

Kriechbaumer J. 1879b. Ophion parvulus n. sp. Entomologische Nachrichten 5: 104-105.

Kriechbaumer J. 1879c. Ophion minutus n. sp. Entomologische Nachrichten 5: 105-106.

Kriechbaumer J. 1892a. Ophioniden-Studien. Ophion Wüstneii. Entomologische Nachrichten 15: 232233.

Kriechbaumer J. 1892b. Ophioniden-Studien. Ophion Slaviceki. Entomologische Nachrichten 15: 233234.

Kumar S., Stecher G., Li M., Knyaz C. \& Tamura K. 2018. MEGA X: Molecular Evolutionary Genetics Analysis across computing platforms. Molecular Biology and Evolution 35: 1547-1549.

https://doi.org/10.1093/molbev/msy096

König K., Krimmer E., Brose S., Ganter C., Buschlüter I., König C., Klopfstein S., Wendt I., Baur H., Krogmann L. \& Steidle J.L.M. 2015. Does early learning drive ecological divergence during speciation processes in parasitoid wasps? Proceedings of the Royal Society of London B: Biological Sciences 282: 20141850. https://doi.org/10.1098/rspb.2014.1850

Königsmann E. 1964. Braconidae aus den Resten der Ratzeburg-Sammlung (Hymenoptera). Beiträge zur Entomologie 14: 631-661.

Linnaeus C. von 1758. Systema naturae per regna tria naturae, secundum classes, ordines, genera, species cum characteribus, differentiis, synonymis locis. Tomus I. Editio decima, reformata. Laurentii Salvii, Stockholm [Holmiae]. https://doi.org/10.5962/bhl.title.542

Meyer N.F. 1935. Parasitica of the family Ichneumonidae of the USSR and adjacent countries. Part 4. Ophioninae. Akademia Nauk SSSR Press 16 (4): 1-535.

Meyer N.F. 1937. Revision der Tribus Ophionini (Hymenoptera Ichneumonidae). Konowia 16: 15-24.

Morley C. 1915. Ichneumonologia Britannica. The ichneumons of Great Britain; a descriptive account of the families, genera and species indigenous to the British islands, together with notes as to classification, localitites, habitats, host, etc. vol. 5. H. \& W. Brown, London.

Oosterbroek P. 1978. Dutch Ophionini (Hym., Ichneumonidae, Ophionidae). Entomologische Berichten 38: 103-112. 
Phillips J., Gillis D.J. \& Hanner R.H. 2018. Incomplete estimates of genetic diversity within species: Implications for DNA barcoding. Ecology and Evolution 9 (5): 2996-3010.

https://doi.org/10.1002/ece3.4757

Ratzeburg J.T.C. 1848. Die Ichneumonen der Forstinsecten in forstlicher und entomologischer Beziehung. Zweiter Band. Berlin. https://doi.org/10.5962/bhl.title.11094

Riedel M. 2012. Revision der westpaläarktischen Arten der Gattung Coelichneumon Thomson (Hymenoptera: Ichneumonidae: Ichneumoninae). Linzer Biologische Beiträge 44 (2): 1477-1611.

Roman A. 1912. Die Ichneumonidentypen C. P. Thunbergs. Zoologiska Bidrag från Uppsala 1: 229-293.

Rudow F. 1883. Einige neue Hymenoptera. Entomologische Nachrichten 9 (5): 57-64.

Schmidt K., Zmudzinski F. \& Riedel M. 2012. Beiträge zur Kenntnis der badischen Schlupwespenfauna (Hymenoptera, Ichneumonidae) 10. Unterfamilien Cyllocerinae, Mesochorinae, Ophioninae, Orthocentrinae. Carolinea 70: 43-63.

Schmiedeknecht O. 1906. Gen. Ophion F. In: Schmiedeknecht O. (ed.) Opuscula Ichneumonologica Fasc. 18: 1434-1440. Blankenburg in Thüringen.

Schmiedeknecht O. 1908. Gen. Ophion F. In: Schmiedeknecht O. (ed.) Opuscula Ichneumonologica Fasc. 19: 1441-1448. Blankenburg in Thüringen.

Schwarzfeld M.D. \& Sperling F.A.H. 2014. Species delimitation using morphology, morphometrics, and molecules: definition of the Ophion scutellaris Thomson species group, with descriptions of six new species (Hymenoptera, Ichneumonidae). ZooKeys 462: 59-114. https://doi.org/10.3897/zookeys.462.8229

Schwarzfeld M.D. \& Sperling F.A.H. 2015. Comparison of five methods for delimitating species in Ophion Fabricius, a diverse genus of parasitoid wasps (Hymenoptera, Ichneumonidae). Molecular Phylogenetics and Evolution 93: 234-248. https://doi.org/10.1016/j.ympev.2015.08.003

Schwarzfeld M.D., Broad G.R. \& Sperling F.A.H. 2016. Molecular phylogeny of the diverse parasitoid wasp genus Ophion Fabricius (Hymenoptera: Ichneumonidae: Ophioninae). Systematic Entomology 41: 191-206. https://doi.org/10.1111/syen.12152

Shaw M.R. 1994. Parasitoid host ranges. In: Hawkins B.A. \& Sheehan W. (eds) Parasitoid Community Ecology: 111-144. Oxford University Press, Oxford.

Shaw M.R. 2004. Notes on the biology of Lycorina triangulifera Holmgren (Hymenoptera; Ichneumonidae; Lycorininae). Journal of Hymenoptera Research 13: 302-308.

Simonsen T.J., Moore M.D., Dupont S.T. \& Stevens M.I. 2019. Testing DNA barcodes against morphology for the 'tripectinate Abantiades' (Lepidoptera: Hepialidae) reveals a complex relationship between COI sequence data and morphology. Austral Entomology early view 03 April 2019.

https://doi.org/10.1111/aen.12395

Song H., Buhay J.E., Whiting M.F. \& Crandall K.A. 2008. Many species in one: DNA barcoding overestimates the number of species when nuclear mitochondrial pseudogenes are coamplified. Proceedings of the National Academy of Sciences 105 (36): 13486-13491.

https://doi.org/10.1073/pnas.0803076105

Straka J. 2016. Tachysphex austriacus Kohl, 1892 and T. pompiliformis (Panzer, 1804) (Hymenoptera, Crabronidae) are a complex of fourteen species in Europe and Turkey. ZooKeys 577: 63-123. https://doi.org/10.3897/zookeys.577.7301

Strobl G. 1904. Ichneumoniden Steiermarks (und der Nachbarlander). V. Fam. Ophionidae. Mitteilungen des Naturwissenschaftlichen Vereines für Steiermark 40 (1903): 43-160. 
Szépligeti G. 1905. Ubersicht der palaarktischen Ichneumoniden. I. Theil. Annales Musei Nationalis Hungarici 3: 508-540.

Thomson C.G. 1888. Öfversigt af de i Sverige funna arter af Ophion och Paniscus. Opuscula Entomologica 12: 1185-1201. https://doi.org/10.5962/bhl.title.8248

Thunberg C.P. 1822. Ichneumonidea, Insecta Hymenoptera illustrata. Mémoires de l'Academie Impériale des Sciences de Saint Petersbourg 8: 249-281.

Thunberg C.P. 1824. Ichneumonidea, Insecta Hymenoptera illustrata. Mémoires de l'Academie Impériale des Sciences de Saint Petersbourg 9: 285-368.

Townes H.K. 1969. The genera of Ichneumonidae, Part 1. Memoirs of the American Entomological Institute 11: 1-300.

Townes H.K., Momoi S. \& Townes M. 1965. A catalogue and reclassification of the eastern Palearctic Ichneumonidae. Memoirs of the American Entomological Institute 5: 1-661.

Ulbricht 1926. Niederrheinische Ichneumoniden. 4 Nachtrag. Mitteilungen der Naturwissenschaftliches Museum Crefeld 1926: 1-30

Várkonyi G., Hanski I., Rost M. \& Itämies J. 2002. Host-parasitoid dynamics in periodic boreal moths. Oikos 98: 421-430. https://doi.org/10.1034/j.1600-0706.2002.980306.x

Yu D.S. \& Horstmann K. 1997. A catalogue of world Ichneumonidae (Hymenoptera). Parts I-II. Memoirs of the American Entomological Institute 58: 1-1558.

Yu D.S.K., van Achterberg C. \& Horstmann K. 2012. Taxapad 2012, Ichneumonoidea 2011. Database on flash-drive.

Manuscript received: 21 December 2018

Manuscript accepted: 16 July 2019

Published on: 12 September 2019

Topic editor: Gavin Broad

Desk editor: Pepe Fernández

Printed versions of all papers are also deposited in the libraries of the institutes that are members of the EJT consortium: Muséum national d'Histoire naturelle, Paris, France; Meise Botanic Garden, Belgium; Royal Museum for Central Africa, Tervuren, Belgium; Royal Belgian Institute of Natural Sciences, Brussels, Belgium; Natural History Museum of Denmark, Copenhagen, Denmark; Naturalis Biodiversity Center, Leiden, the Netherlands; Museo Nacional de Ciencias Naturales-CSIC, Madrid, Spain; Real Jardín Botánico de Madrid CSIC, Spain; Zoological Research Museum Alexander Koenig, Bonn, Germany; National Museum, Prague, Czech Republic. 